\title{
Skeletocutins A-L: Antibacterial Agents from the Kenyan Wood-inhabiting Basidiomycete, Skeletocutis sp.
}

Clara Chepkirui, ${ }^{\dagger, \#}$ Tian Cheng, ${ }^{\dagger, \#}$ Winnie Chemutai Sum, ${ }^{\ddagger}$ Josphat Clement Matasyoh,${ }^{\S}$ Cony Decock, ${ }^{\perp}$ Dimas F. Praditya, ${ }^{\|, \nabla}$ Kathrin Wittstein, ${ }^{\dagger}$ Eike Steinmann, ${ }^{\|}$Marc Stadler ${ }^{*}, \dagger$

${ }^{\dagger}$ Department of Microbial Drugs, Helmholtz Centre for Infection Research (HZI); German Centre for Infection Research (DZIF), Partner Site Hannover/Braunschweig, Inhoffenstrasse 7, 38124 Braunschweig, Germany

$\$$ Department of Biochemistry, Egerton University, P.O. BOX 536, 20115, Njoro, Kenya

${ }^{\S}$ Department of Chemistry, Faculty of Sciences, Egerton University, P.O. Box 536, 20115, Njoro, Kenya

$\perp$ Mycothéque de l' Universite Catholique de Louvain (BCCM/MUCL), Place Croix du Sud 3, B-1348 Louvain-la-Neuve, Belgium

" Department of Molecular and Medical Virology, Ruhr-University Bochum, 44801 Bochum, Germany; TWINCORE - Centre for Experimental and Clinical Infection Research (Institute of Experimental Virology) Hanover. Feodor-Lynen-Str. 7-9, 30625 Hannover, Germany

$\nabla$ Research Center for Biotechnology, Indonesian Institute of Science, J1. Raya Bogor KM 46, Cibinong 16911, Indonesia

*Corresponding author

Tel: $+49-53161814240$.

Fax: $+49-53161819499$

E-mail: marc.stadler@helmholtz-hzi.de

Author Note: ${ }^{\#}$ these authors contributed equally to this work. 
TABLE OF CONTENTS

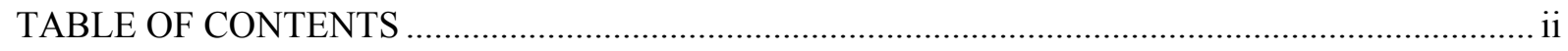

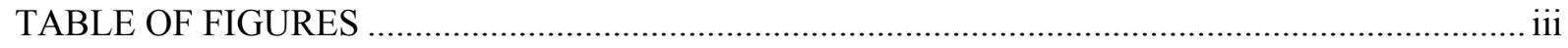

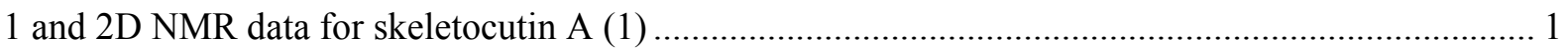

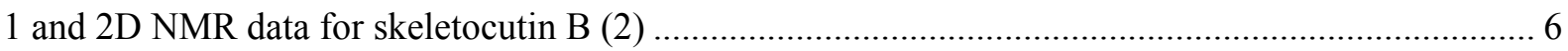

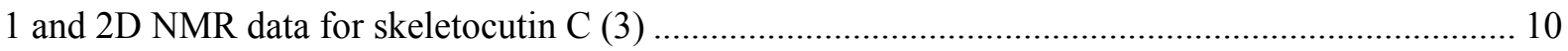

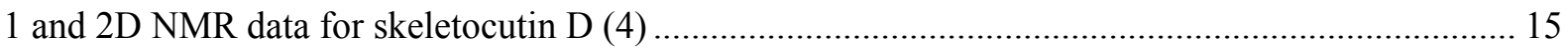

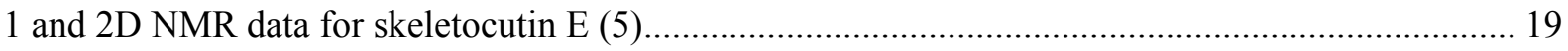

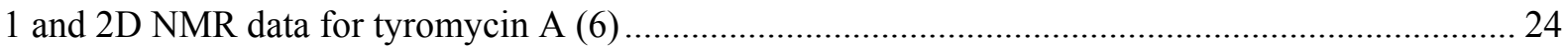

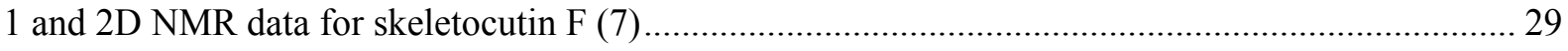

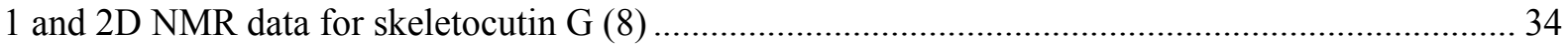

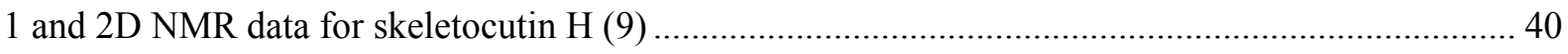

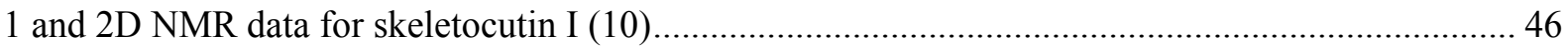

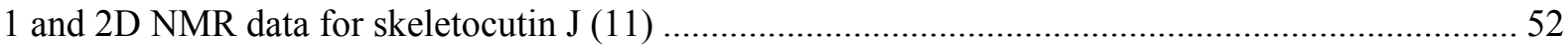

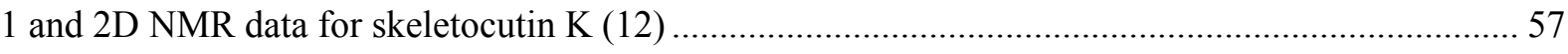

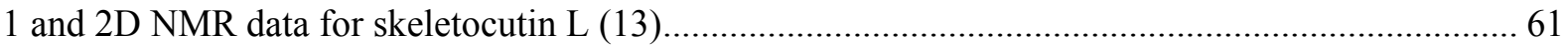

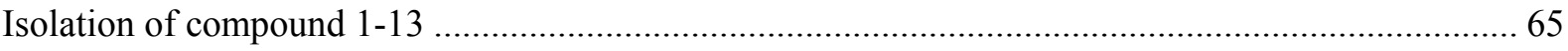

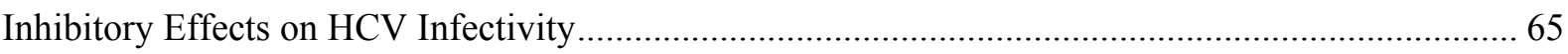

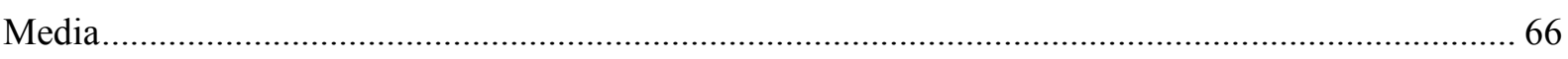

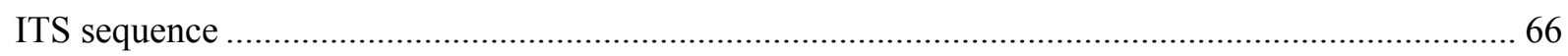




\section{TABLE OF FIGURES}

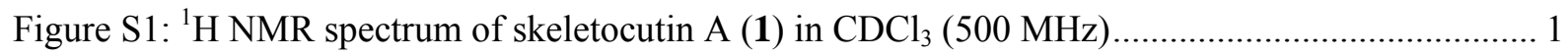

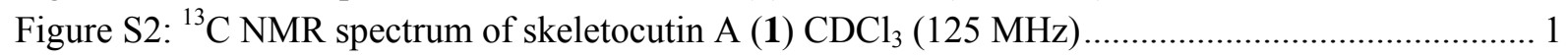

Figure S3: DEPT NMR spectrum of skeletocutin A (1) in $\mathrm{CDCl}_{3}(125 \mathrm{MHz})$.................................. 2

Figure S4: ${ }^{1} \mathrm{H},{ }^{13} \mathrm{C}$ HSQC NMR spectrum of skeletocutin $\mathrm{A}(\mathbf{1})$ in $\mathrm{CDCl}_{3}(500 \mathrm{MHz}, 125 \mathrm{MHz}) \ldots \ldots . .2$

Figure S5: ${ }^{1} \mathrm{H},{ }^{13} \mathrm{C}$ HMBC NMR spectrum of skeletocutin $\mathrm{A}(\mathbf{1})$ in $\mathrm{CDCl}_{3}(500 \mathrm{MHz}, 125 \mathrm{MHz}) \ldots \ldots . .3$

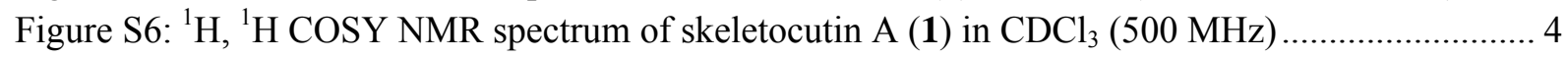

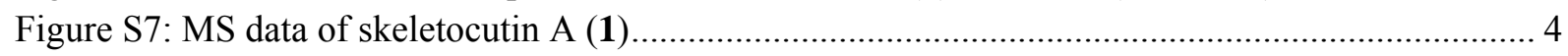

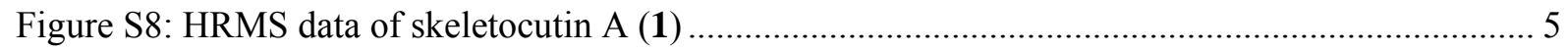

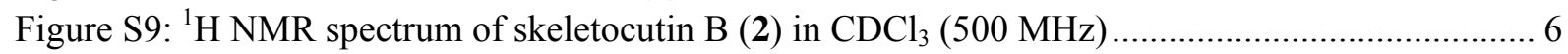

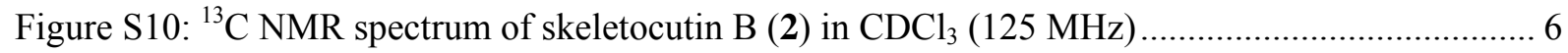

Figure S11: DEPT NMR spectrum of skeletocutin $\mathrm{B}(2)$ in $\mathrm{CDCl}_{3}(125 \mathrm{MHz})$................................. 7

Figure S12: ${ }^{1} \mathrm{H},{ }^{13} \mathrm{C}$ HSQC NMR spectrum of skeletocutin $\mathrm{B}(2)$ in $\mathrm{CDCl}_{3}(500 \mathrm{MHz}, 125 \mathrm{MHz})$...... 7

Figure S13: ${ }^{1} \mathrm{H},{ }^{13} \mathrm{C}$ HMBC NMR spectrum of skeletocutin $\mathrm{B}(2)$ in $\mathrm{CDCl}_{3}(500 \mathrm{MHz}, 125 \mathrm{MHz}) \ldots . .8$

Figure S14: ${ }^{1} \mathrm{H},{ }^{1} \mathrm{H}$ COSY NMR spectrum of skeletocutin $\mathrm{B}(2)$ in $\mathrm{CDCl}_{3}(500 \mathrm{MHz})$....................... 9

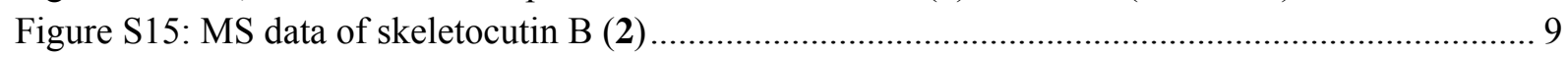

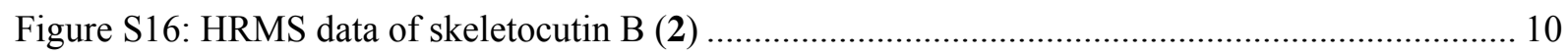

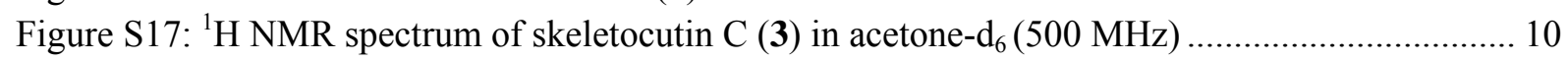

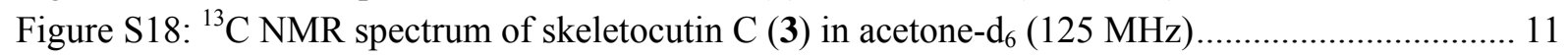

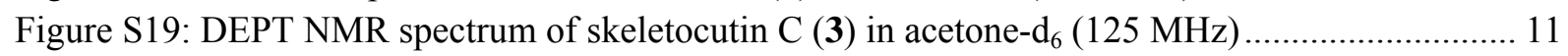

Figure S20: ${ }^{1} \mathrm{H},{ }^{13} \mathrm{C}$ HSQC NMR spectrum of skeletocutin $\mathrm{C}(3)$ in acetone-d $\mathrm{d}_{6}(500 \mathrm{MHz}, 125 \mathrm{MHz}) 12$

Figure S21: ${ }^{1} \mathrm{H},{ }^{13} \mathrm{C}$ HMBC NMR spectrum of skeletocutin $\mathrm{C}(3)$ in acetone- $\mathrm{d}_{6}(500 \mathrm{MHz}, 125 \mathrm{MHz})$

Figure S22: ${ }^{1} \mathrm{H},{ }^{1} \mathrm{H}$ COSY NMR spectrum of skeletocutin $\mathrm{C}(3)$ in acetone- $\mathrm{d}_{6}(500 \mathrm{MHz}) \ldots \ldots \ldots \ldots \ldots . . . . .13$

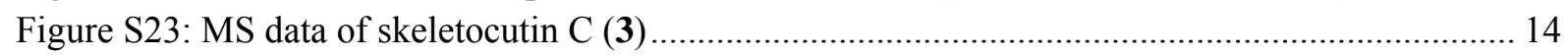

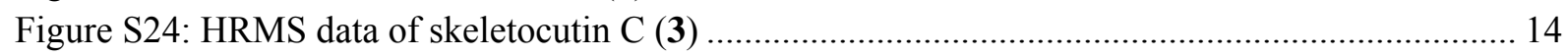

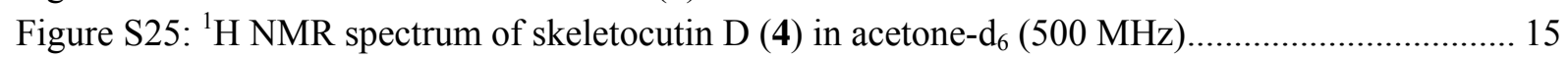

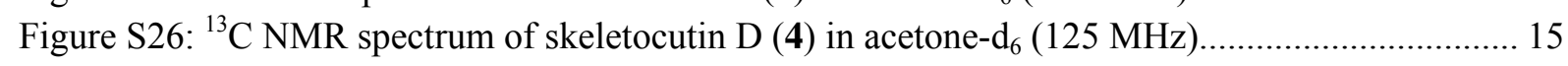

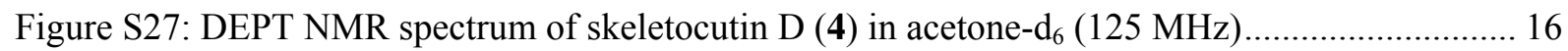

Figure S28: ${ }^{1} \mathrm{H},{ }^{13} \mathrm{C}$ HSQC NMR spectrum of skeletocutin D (4) in acetone- $\mathrm{d}_{6}(500 \mathrm{MHz}, 125 \mathrm{MHz}) 17$

Figure S29: ${ }^{1} \mathrm{H},{ }^{13} \mathrm{C}$ HSQC NMR spectrum of skeletocutin D (4) in acetone-d $\mathrm{d}_{6}(500 \mathrm{MHz}, 125 \mathrm{MHz}) 17$

Figure S30: ${ }^{1} \mathrm{H},{ }^{1} \mathrm{H}$ COSY NMR spectrum of skeletocutin D (4) in acetone- $\mathrm{d}_{6}(500 \mathrm{MHz}) \ldots \ldots \ldots \ldots \ldots . . . . .18$

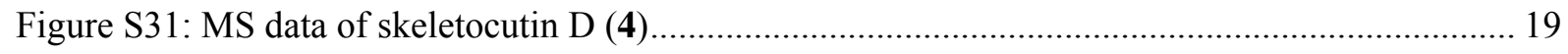

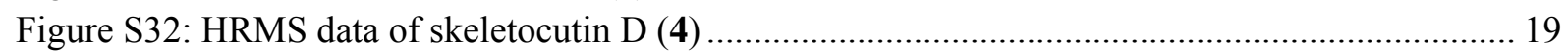

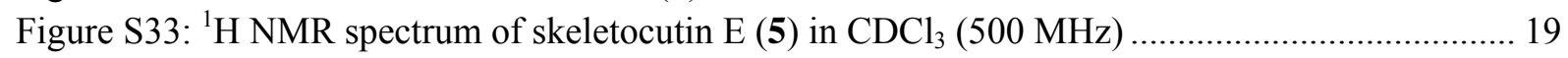

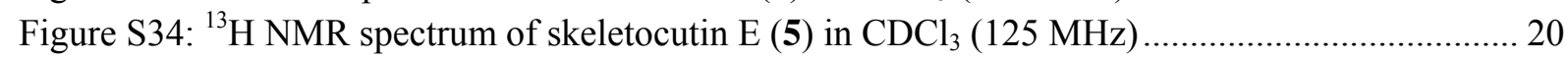

Figure S35: DEPT NMR spectrum of skeletocutin $\mathrm{E}(5)$ in $\mathrm{CDCl}_{3}(125 \mathrm{MHz})$................................. 20

Figure S36: ${ }^{1} \mathrm{H},{ }^{13} \mathrm{C}$ HSQC NMR spectrum of skeletocutin $\mathrm{E}(5)$ in in $\mathrm{CDCl}_{3}(500 \mathrm{MHz}, 125 \mathrm{MHz}) 21$

Figure S37: ${ }^{1} \mathrm{H},{ }^{13} \mathrm{C}$ HMBC NMR spectrum of skeletocutin $\mathrm{E}(5)$ in $\mathrm{CDCl}_{3}(500 \mathrm{MHz}, 125 \mathrm{MHz}) \ldots .21$

Figure S38: ${ }^{1} \mathrm{H},{ }^{1} \mathrm{H}$ COSY NMR spectrum of skeletocutin $\mathrm{E}(5)$ in $\mathrm{CDCl}_{3}(500 \mathrm{MHz})$...................... 22

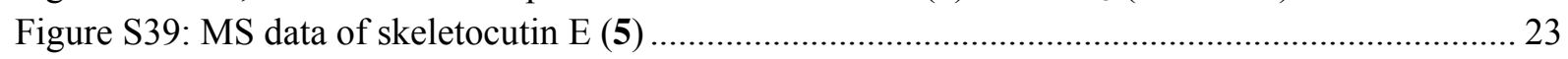

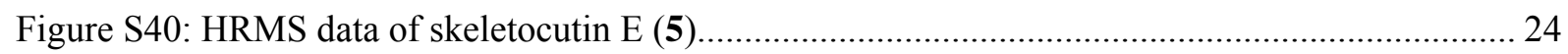

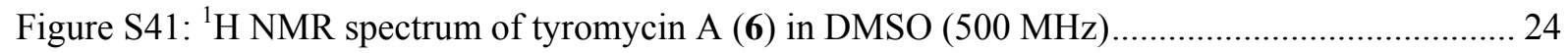

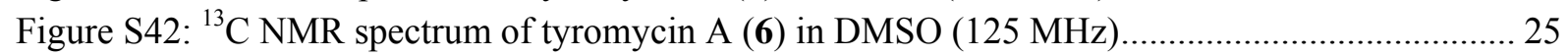

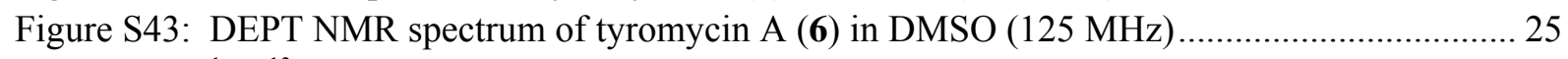

Figure S44: ${ }^{1} \mathrm{H},{ }^{13} \mathrm{C}$ HSQC NMR spectrum of tyromcin A (6) in DMSO $(500 \mathrm{MHz}, 125 \mathrm{MHz}) \ldots \ldots . .26$ 
Figure S45: ${ }^{1} \mathrm{H},{ }^{13} \mathrm{C}$ HMBC NMR spectrum of tyromycin A (6) in DMSO (500 MHz, $\left.125 \mathrm{MHz}\right) \ldots \ldots .27$

Figure S46: ${ }^{1} \mathrm{H},{ }^{1} \mathrm{H}$ COSY NMR spectrum of tyromcin A (6) in DMSO (500 MHz) ........................... 27

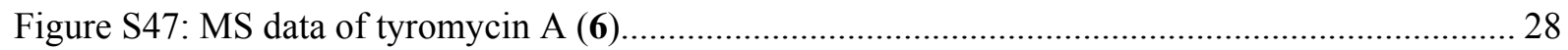

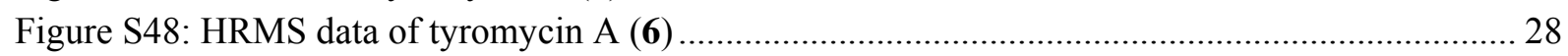

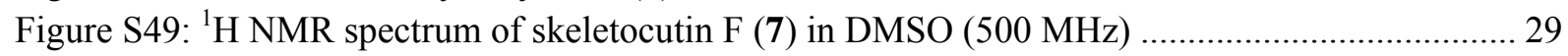

Figure S50: ${ }^{13} \mathrm{C}$ NMR spectrum of skeletocutin F (7) in DMSO (500 MHz) ..................................... 29

Figure S51: DEPT NMR spectrum of skeletocutin F (7) in DMSO (500 MHz) ............................... 30

Figure S52: ${ }^{1} \mathrm{H},{ }^{13} \mathrm{C}$ HSQC NMR spectrum of skeletocutin $\mathrm{F}(7)$ in DMSO $(500 \mathrm{MHz}, 125 \mathrm{MHz})$.... 31

Figure S53: ${ }^{1} \mathrm{H},{ }^{13} \mathrm{C}$ HMBC NMR spectrum of skeletocutin F (7) in DMSO (500 MHz, $\left.125 \mathrm{MHz}\right) \ldots 31$

Figure S54: ${ }^{1} \mathrm{H},{ }^{1} \mathrm{H}$ COSY NMR spectrum of skeletocutin F (7) in DMSO $(500 \mathrm{MHz})$..................... 32

Figure S55: ${ }^{1} \mathrm{H},{ }^{1} \mathrm{H}$ ROESY NMR spectrum of skeletocutin F (7) in DMSO (500 MHz) ..................... 32

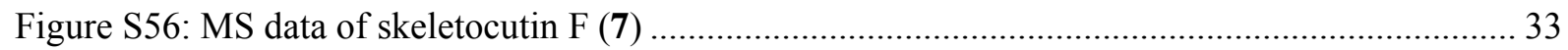

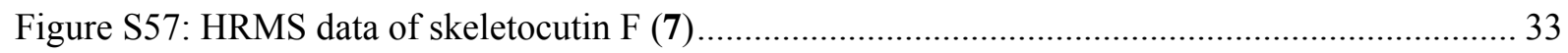

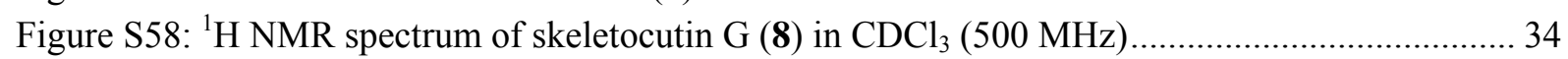

Figure S59: ${ }^{1} \mathrm{H}$ NMR spectrum of skeletocutin $\mathrm{G}(\mathbf{8})$ in $\mathrm{CDCl}_{3}(125 \mathrm{MHz})$...................................... 34

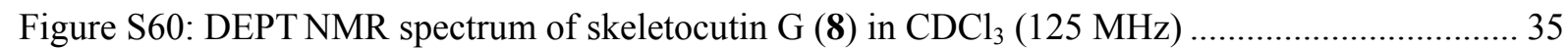

Figure S61: ${ }^{1} \mathrm{H},{ }^{13} \mathrm{C}$ HSQC NMR spectrum of skeletocutin $\mathrm{G}(\boldsymbol{8})$ in $\mathrm{CDCl}_{3}(500 \mathrm{MHz}, 125 \mathrm{MHz}) \ldots . .36$

Figure S62: ${ }^{1} \mathrm{H},{ }^{13} \mathrm{C}$ HMBC NMR spectrum of skeletocutin $\mathrm{G}(\mathbf{8})$ in $\mathrm{CDCl}_{3}(500 \mathrm{MHz}, 125 \mathrm{MHz}) \ldots 36$

Figure S63: ${ }^{1} \mathrm{H},{ }^{1} \mathrm{H}$ COSY NMR spectrum of skeletocutin $\mathrm{G}(\mathbf{8})$ in $\mathrm{CDCl}_{3}(500 \mathrm{MHz}) \ldots \ldots \ldots \ldots \ldots \ldots \ldots . . . . . . . . . . .37$

Figure S64: ${ }^{1} \mathrm{H},{ }^{1} \mathrm{H}$ ROESY NMR spectrum of skeletocutin $\mathrm{G}(\mathbf{8})$ in $\mathrm{CDCl}_{3}(500 \mathrm{MHz})$.................... 37

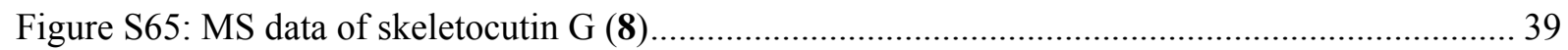

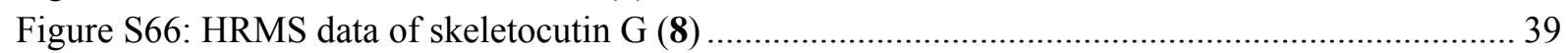

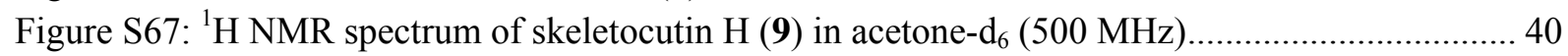

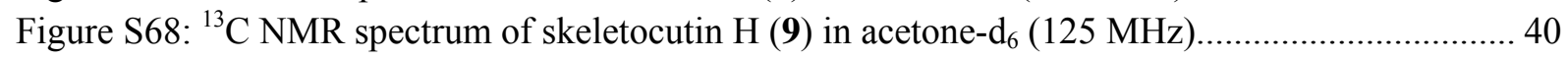

Figure S69: DEPT NMR spectrum of skeletocutin $\mathrm{H}(\mathbf{9})$ in acetone- $\mathrm{d}_{6}(125 \mathrm{MHz}) \ldots \ldots \ldots \ldots \ldots \ldots \ldots \ldots \ldots . . . . . . . . . . . .11$

Figure S70: ${ }^{1} \mathrm{H},{ }^{13} \mathrm{C}$ HSQC NMR spectrum of skeletocutin $\mathrm{H}(\mathbf{9})$ in acetone-d $\mathrm{d}_{6}(500 \mathrm{MHz}, 125 \mathrm{MHz}) 42$

Figure $\mathrm{S} 71:{ }^{1} \mathrm{H},{ }^{13} \mathrm{C}$ HMBC NMR spectrum of skeletocutin $\mathrm{H}(\mathbf{9})$ in acetone- $\mathrm{d}_{6}(500 \mathrm{MHz}, 125 \mathrm{MHz})$

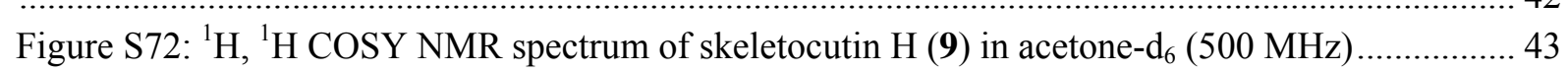

Figure S73: ${ }^{1} \mathrm{H},{ }^{1} \mathrm{H}$ ROESY NMR spectrum of skeletocutin $\mathrm{H}(\mathbf{9})$ in acetone- $\mathrm{d}_{6}(500 \mathrm{MHz}) \ldots \ldots \ldots \ldots . . . . . .43$

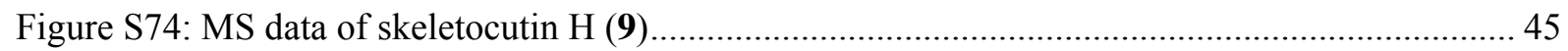

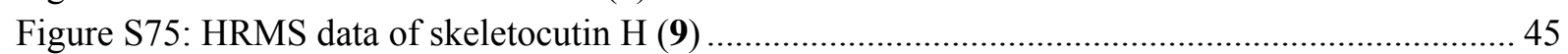

Figure S76: ${ }^{1} \mathrm{H}$ NMR spectrum of skeletocutin I (10) in $\mathrm{CDCl}_{3}(500 \mathrm{MHz})$...................................... 46

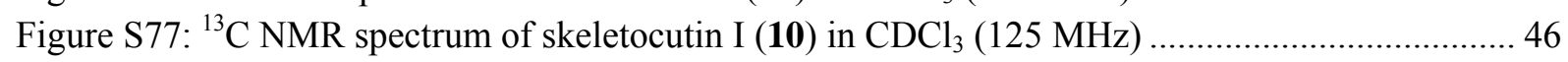

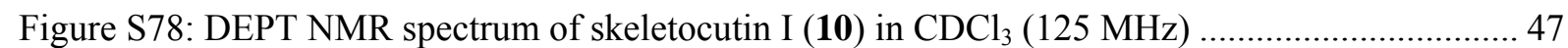

Figure S79: ${ }^{1} \mathrm{H},{ }^{13} \mathrm{C}$ HSQC NMR spectrum of skeletocutin I (10) in $\mathrm{CDCl}_{3}(500 \mathrm{MHz}, 125 \mathrm{MHz})$.... 48

Figure S80: ${ }^{1} \mathrm{H},{ }^{13} \mathrm{C}$ HMBC NMR spectrum of skeletocutin I (10) in $\mathrm{CDCl}_{3}(500 \mathrm{MHz}, 125 \mathrm{MHz}) \ldots 48$

Figure S81: ${ }^{1} \mathrm{H},{ }^{1} \mathrm{H}$ COSY NMR spectrum of skeletocutin I (10) in $\mathrm{CDCl}_{3}(500 \mathrm{MHz}) \ldots \ldots \ldots \ldots \ldots \ldots \ldots . . . . . . . . . .49$

Figure S82: ${ }^{1} \mathrm{H},{ }^{1} \mathrm{H}$ ROESY NMR spectrum of skeletocutin I (10) in $\mathrm{CDCl}_{3}(500 \mathrm{MHz})$.................... 50

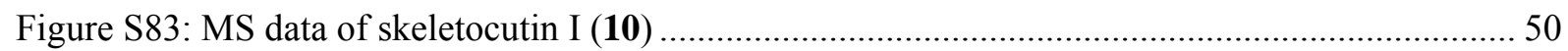

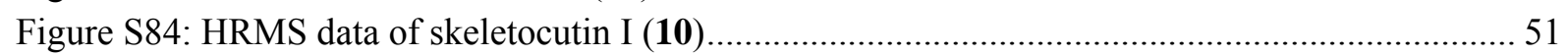

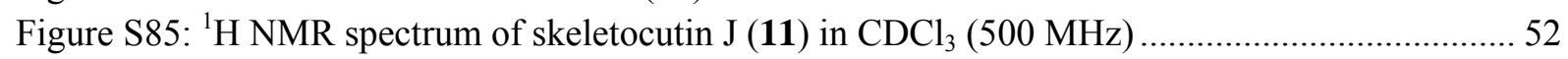

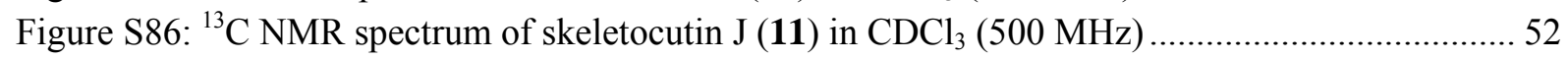

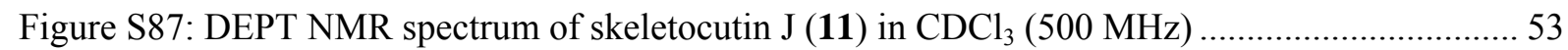

Figure S88: ${ }^{1} \mathrm{H},{ }^{13} \mathrm{C}$ HSQC NMR spectrum of skeletocutin $\mathrm{J}(\mathbf{1 1})$ in $\mathrm{CDCl}_{3}(500 \mathrm{MHz}, 125 \mathrm{MHz})$.... 53

Figure S89: ${ }^{1} \mathrm{H},{ }^{13} \mathrm{C}$ HMBC NMR spectrum of skeletocutin J (11) in $\mathrm{CDCl}_{3}(500 \mathrm{MHz}, 125 \mathrm{MHz}) \ldots 54$

Figure S90: ${ }^{1} \mathrm{H},{ }^{1} \mathrm{H}$ COSY NMR spectrum of skeletocutin $\mathrm{J}(\mathbf{1 1})$ in $\mathrm{CDCl}_{3}(500 \mathrm{MHz})$...................... 55

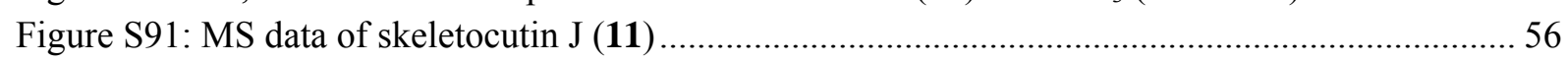


Figure S92: HRMS data of skeletocutin J (11)

Figure S93: ${ }^{1} \mathrm{H}$ NMR spectrum of skeletocutin $\mathrm{K}(\mathbf{1 2})$ in $\mathrm{CDCl}_{3}(500 \mathrm{MHz})$...................................... 57

Figure S94: ${ }^{13} \mathrm{C}$ NMR spectrum of skeletocutin $\mathrm{K}(\mathbf{1 2})$ in $\mathrm{CDCl}_{3}(500 \mathrm{MHz})$.................................... 57

Figure S95: ${ }^{1} \mathrm{H},{ }^{13} \mathrm{C}$ HSQC NMR spectrum of skeletocutin $\mathrm{K}(12)$ in $\mathrm{CDCl}_{3}(500 \mathrm{MHz}, 125 \mathrm{MHz}) \ldots 58$

Figure S96: ${ }^{1} \mathrm{H},{ }^{13} \mathrm{C}$ HMBC NMR spectrum of skeletocutin $\mathrm{K}(\mathbf{1 2})$ in $\mathrm{CDCl}_{3}(500 \mathrm{MHz}, 125 \mathrm{MHz}) . .58$

Figure S97: ${ }^{1} \mathrm{H},{ }^{1} \mathrm{H}$ COSY NMR spectrum of skeletocutin $\mathrm{K}(\mathbf{1 2})$ in $\mathrm{CDCl}_{3}(500 \mathrm{MHz})$..................... 59

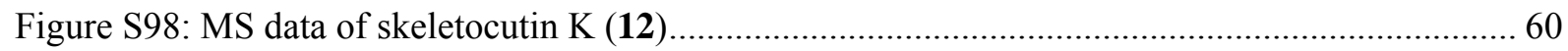

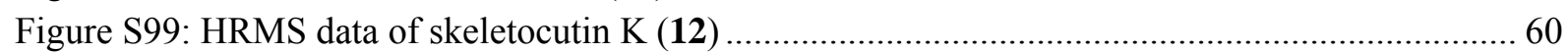

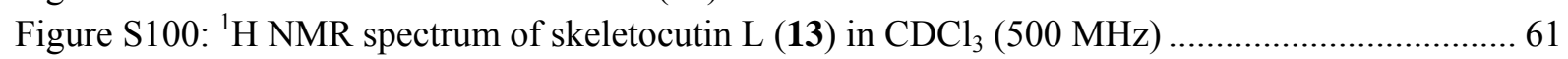

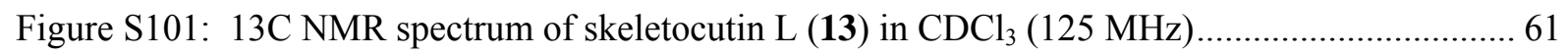

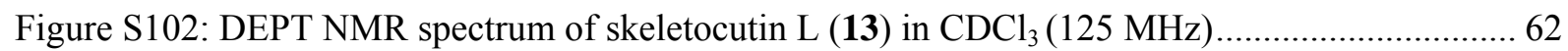

Figure S103: ${ }^{1} \mathrm{H},{ }^{13} \mathrm{C}$ HSQC NMR spectrum of skeletocutin $\mathrm{L}(13)$ in $\mathrm{CDCl}_{3}(500 \mathrm{MHz}, 125 \mathrm{MHz}) .62$

Figure S104: ${ }^{1} \mathrm{H},{ }^{13} \mathrm{C}$ HMBC NMR spectrum of skeletocutin L (13) in $\mathrm{CDCl}_{3}(500 \mathrm{MHz}, 125 \mathrm{MHz}) 63$

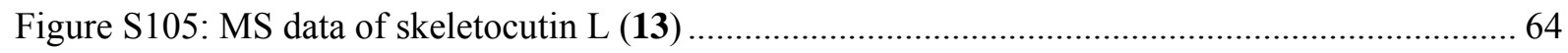

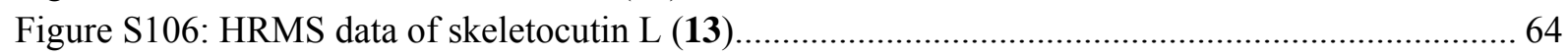

Figure S107: Phylogeny tree of Skeletocutis sp. and closely related species ..................................... 67 


\section{1 and 2D NMR data for skeletocutin A (1)}

Figure S1: ${ }^{1} \mathrm{H}$ NMR spectrum of skeletocutin A (1) in $\mathrm{CDCl}_{3}(500 \mathrm{MHz})$

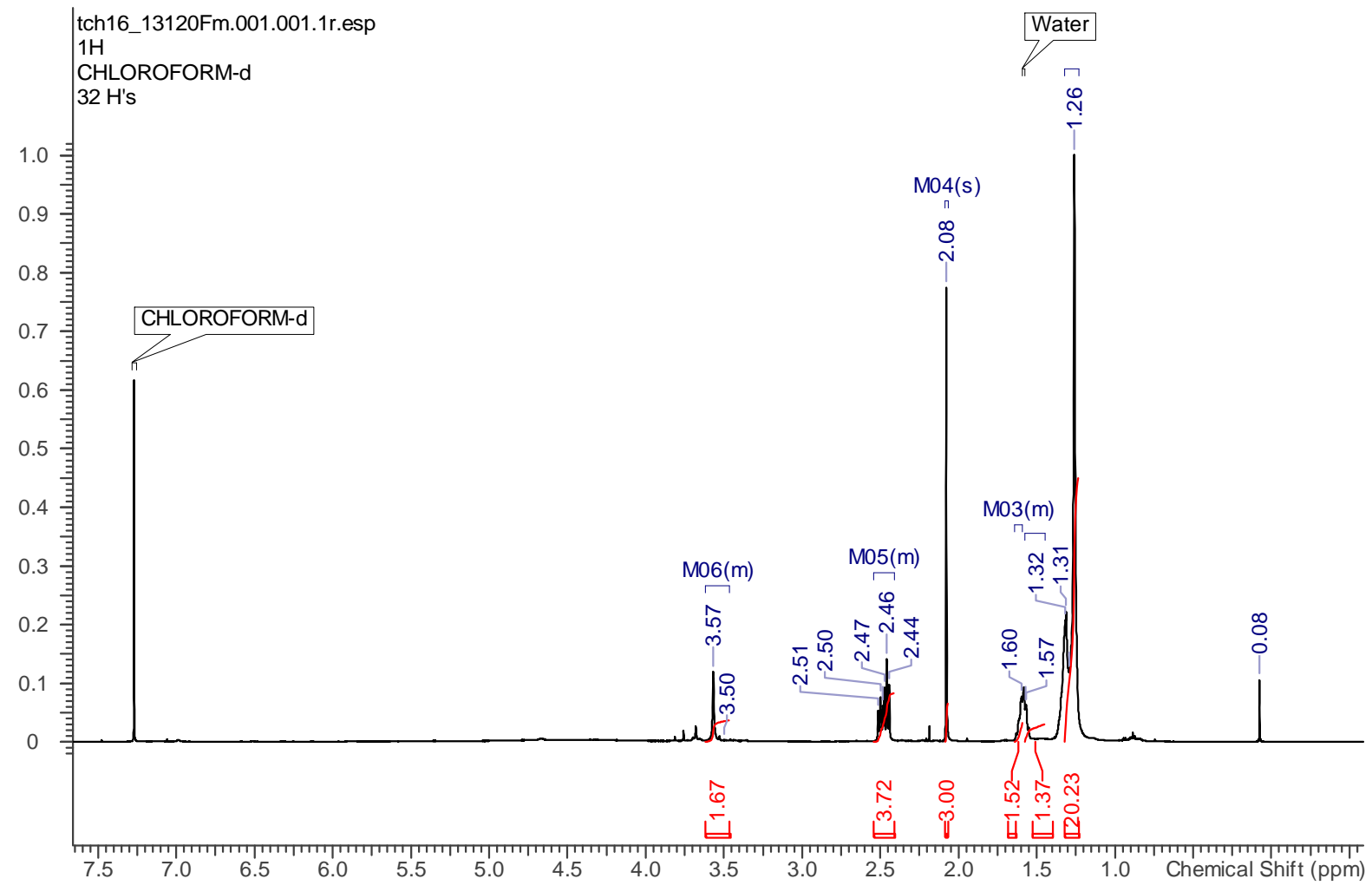

Figure S2: ${ }^{13} \mathrm{C}$ NMR spectrum of skeletocutin $\mathrm{A}(\mathbf{1}) \mathrm{CDCl}_{3}(125 \mathrm{MHz})$ 


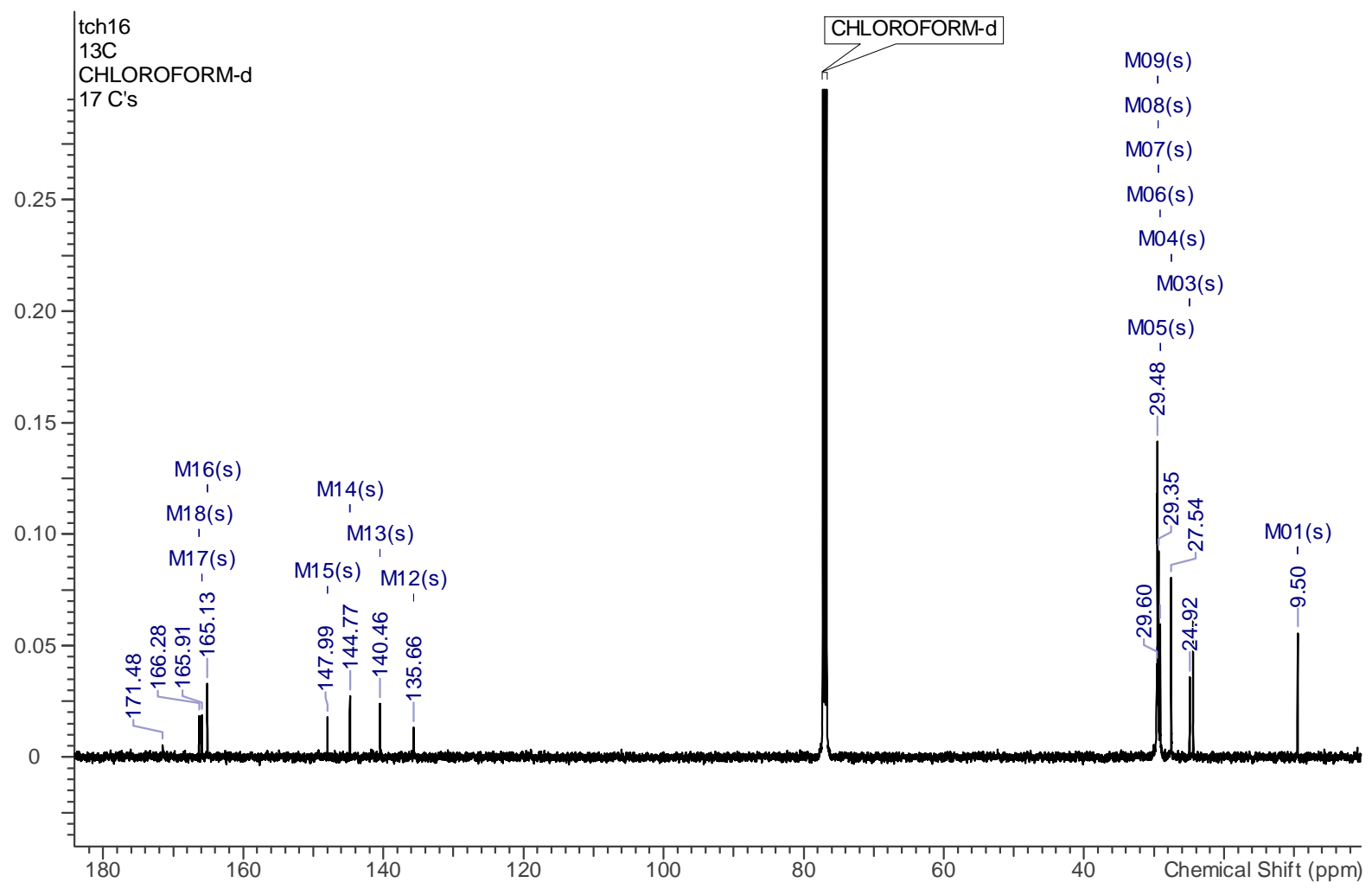

Figure S3: DEPT NMR spectrum of skeletocutin $\mathrm{A}(\mathbf{1})$ in $\mathrm{CDCl}_{3}(125 \mathrm{MHz})$

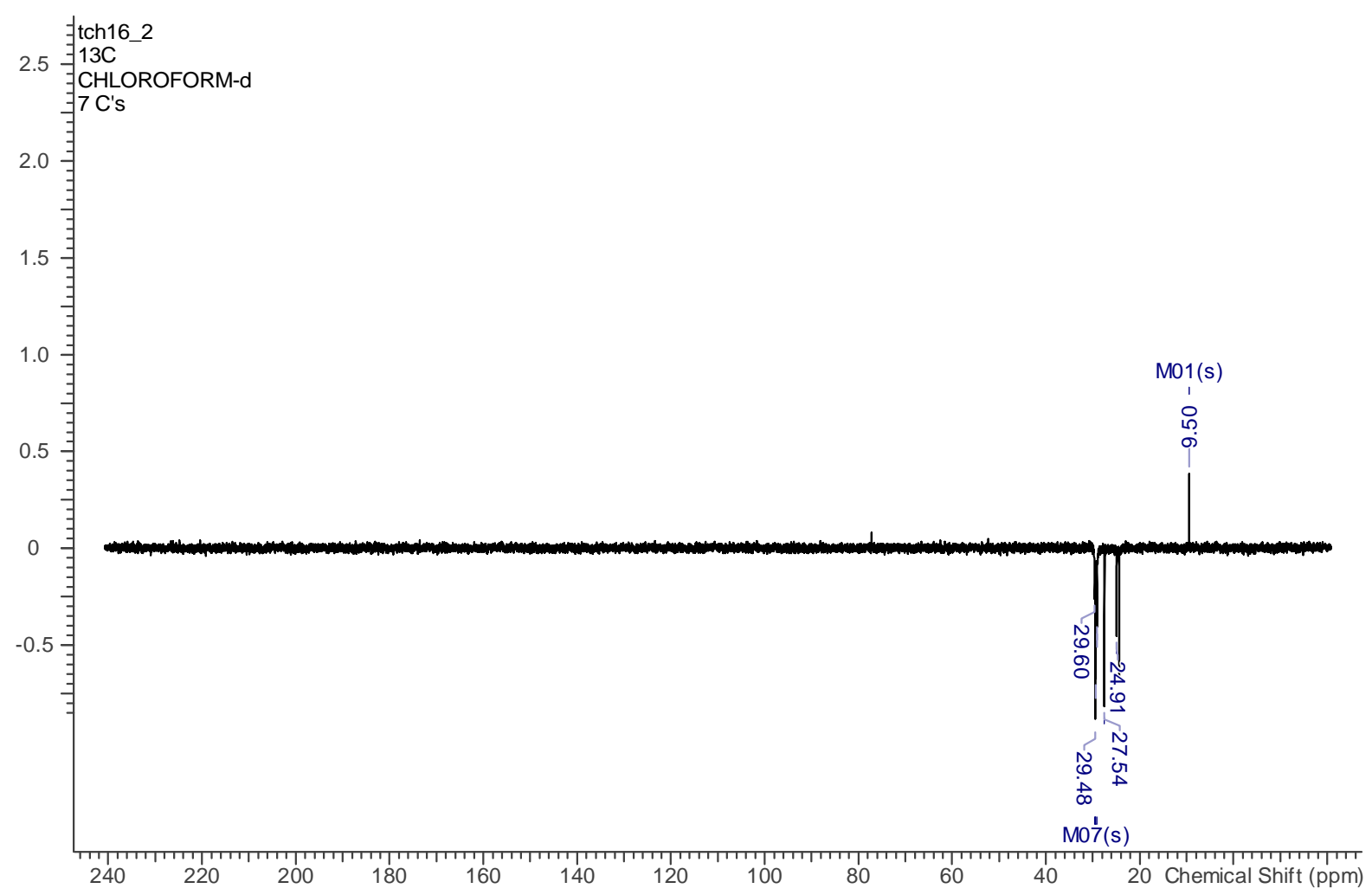

Figure S4: ${ }^{1} \mathrm{H},{ }^{13} \mathrm{C}$ HSQC NMR spectrum of skeletocutin $\mathrm{A}(\mathbf{1})$ in $\mathrm{CDCl}_{3}(500 \mathrm{MHz}, 125$ $\mathrm{MHz})$ 


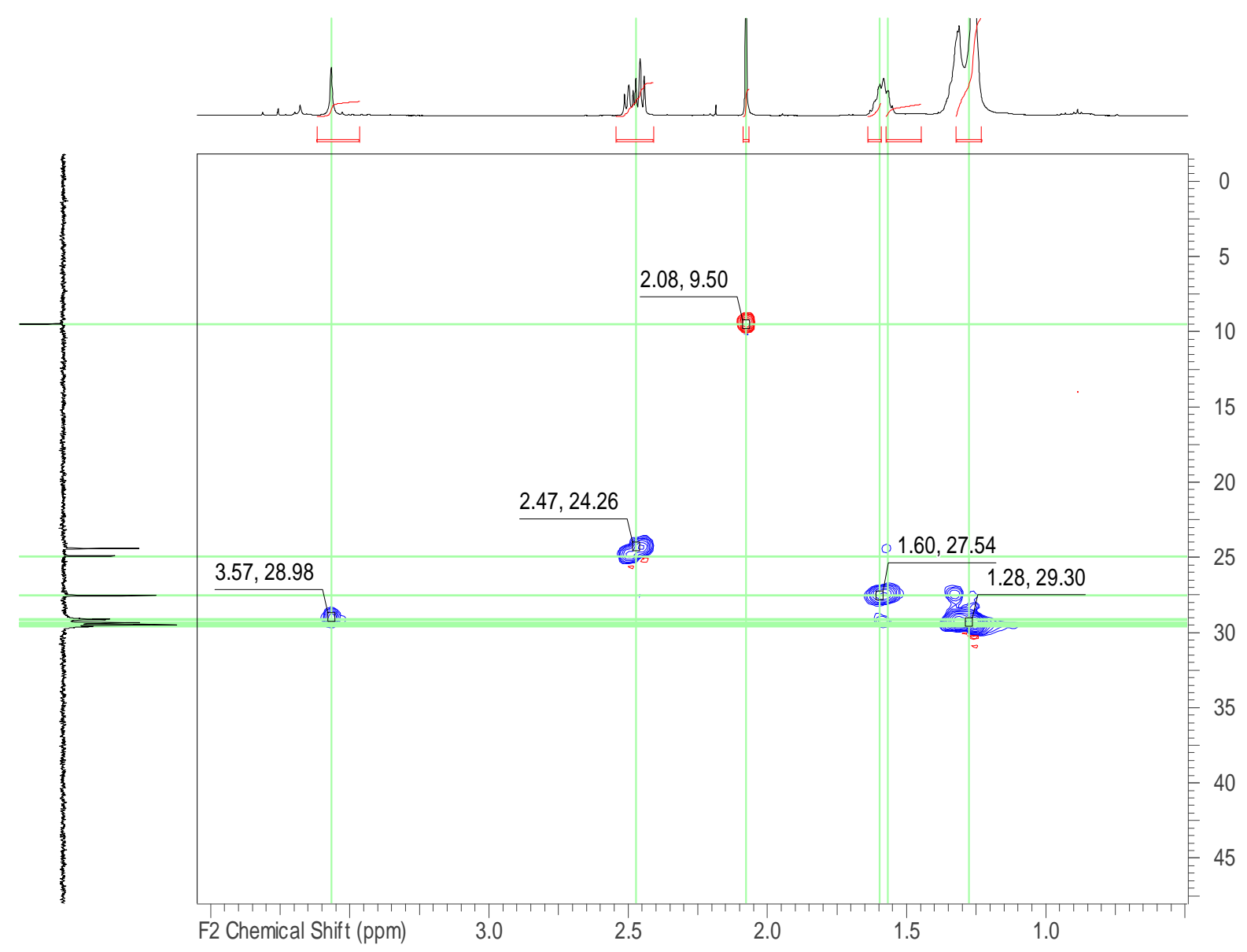

Figure S5: ${ }^{1} \mathrm{H},{ }^{13} \mathrm{C}$ HMBC NMR spectrum of skeletocutin A (1) in $\mathrm{CDCl}_{3}(500 \mathrm{MHz}, 125$ $\mathrm{MHz})$

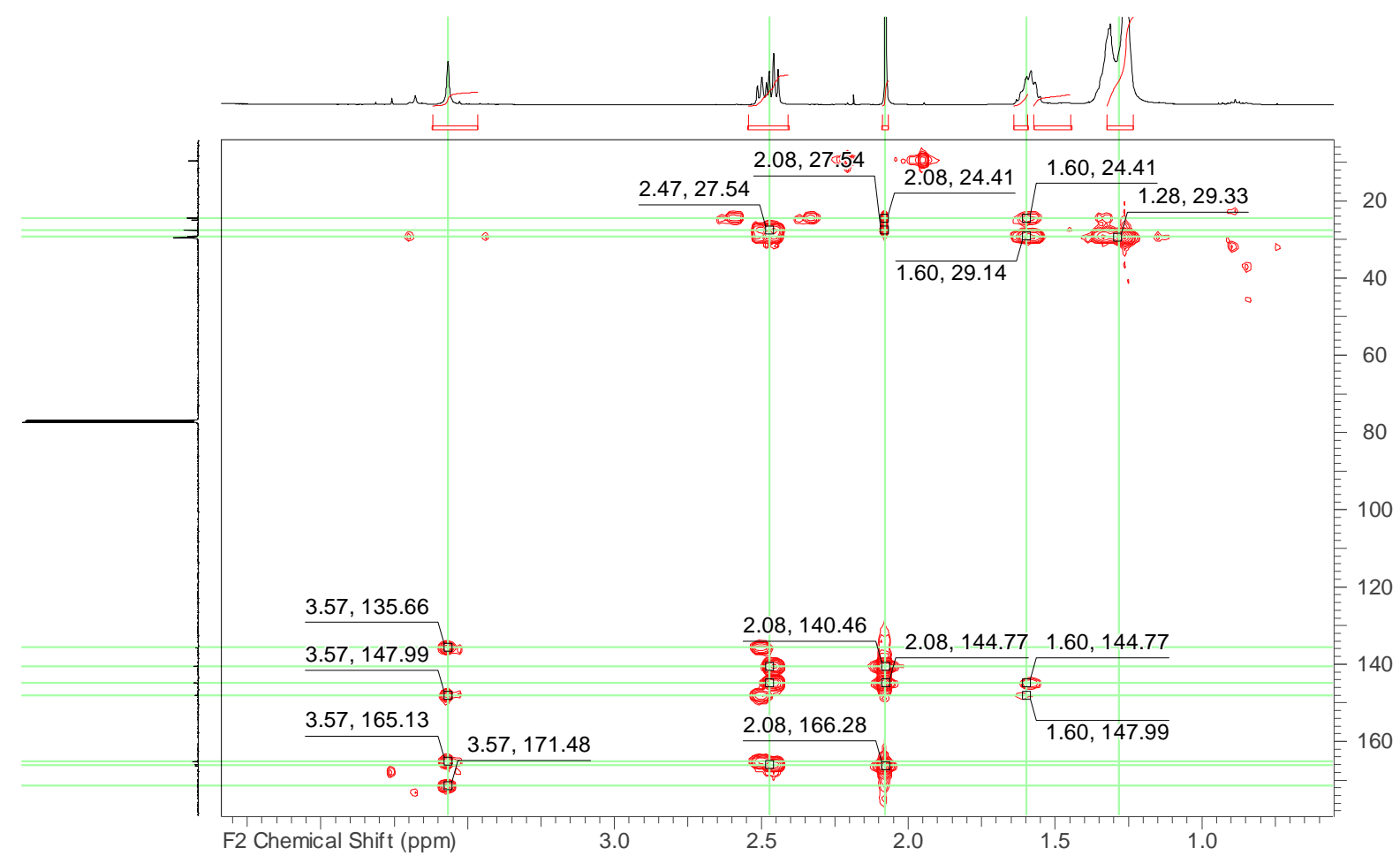


Figure S6: ${ }^{1} \mathrm{H},{ }^{1} \mathrm{H}$ COSY NMR spectrum of skeletocutin A (1) in $\mathrm{CDCl}_{3}(500 \mathrm{MHz})$

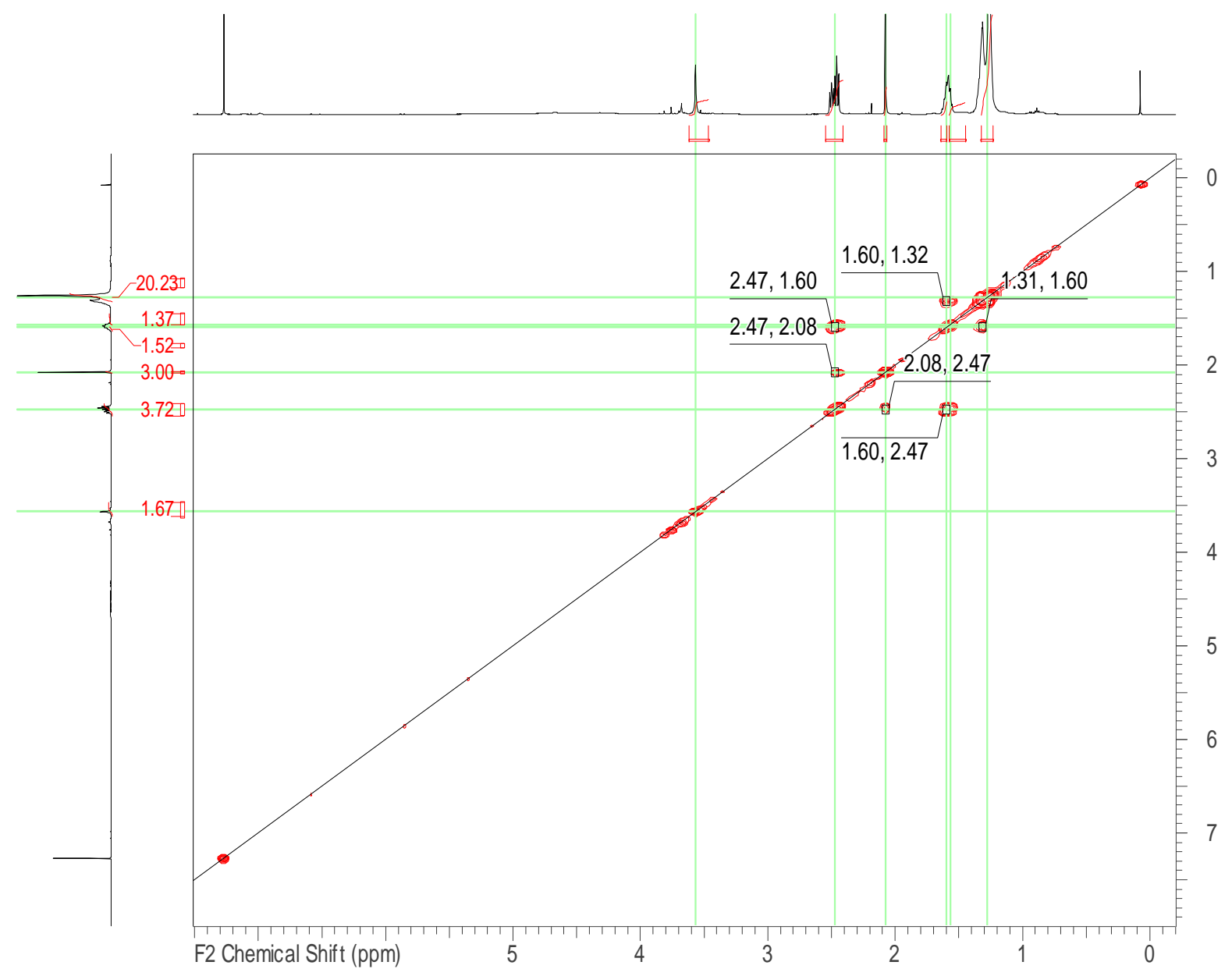

Figure S7: MS data of skeletocutin A (1) 


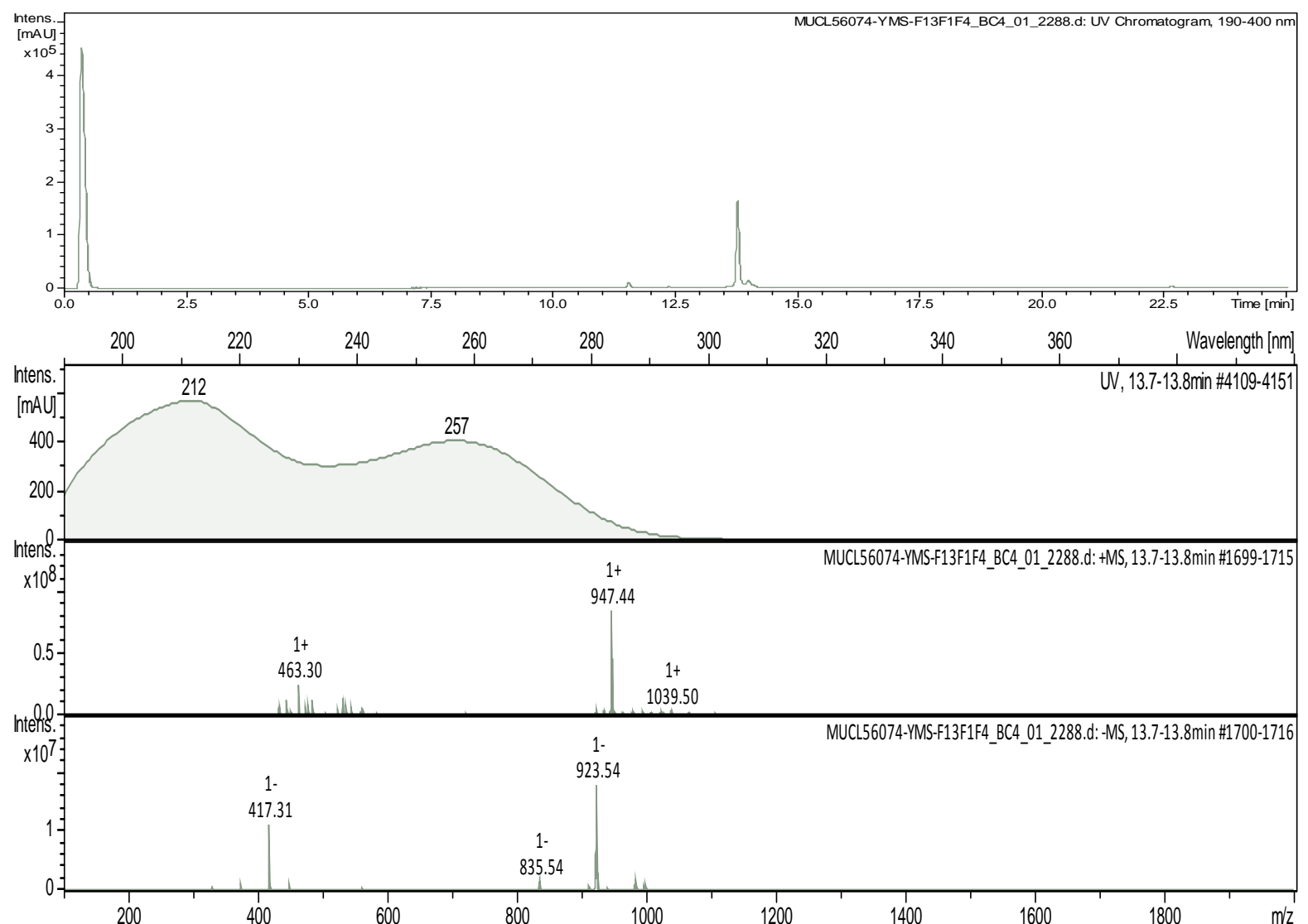

Figure S8: HRMS data of skeletocutin A (1)
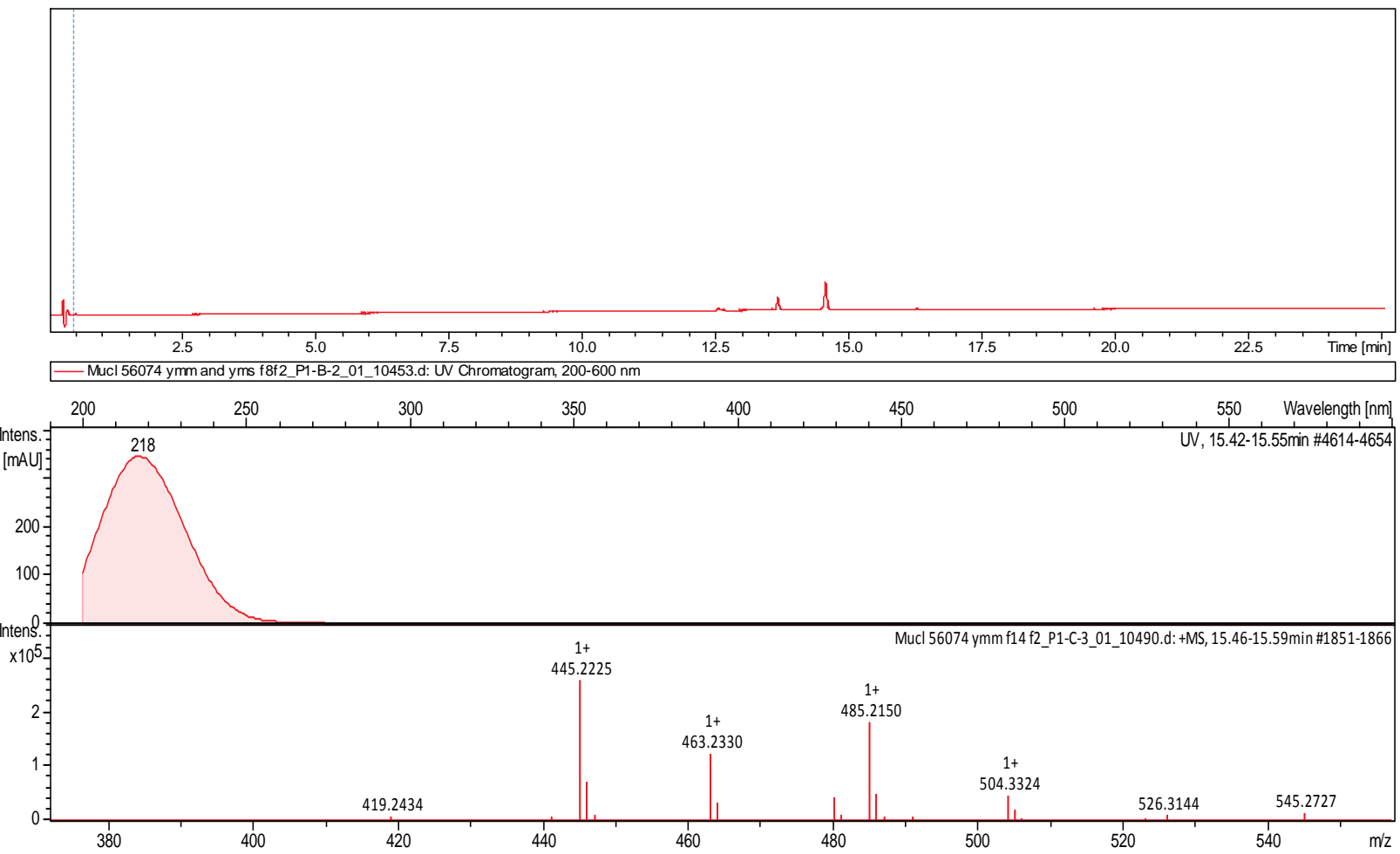


\section{1 and 2D NMR data for skeletocutin B (2)}

Figure S9: ${ }^{1} \mathrm{H}$ NMR spectrum of skeletocutin $\mathrm{B}(2)$ in $\mathrm{CDCl}_{3}(500 \mathrm{MHz})$

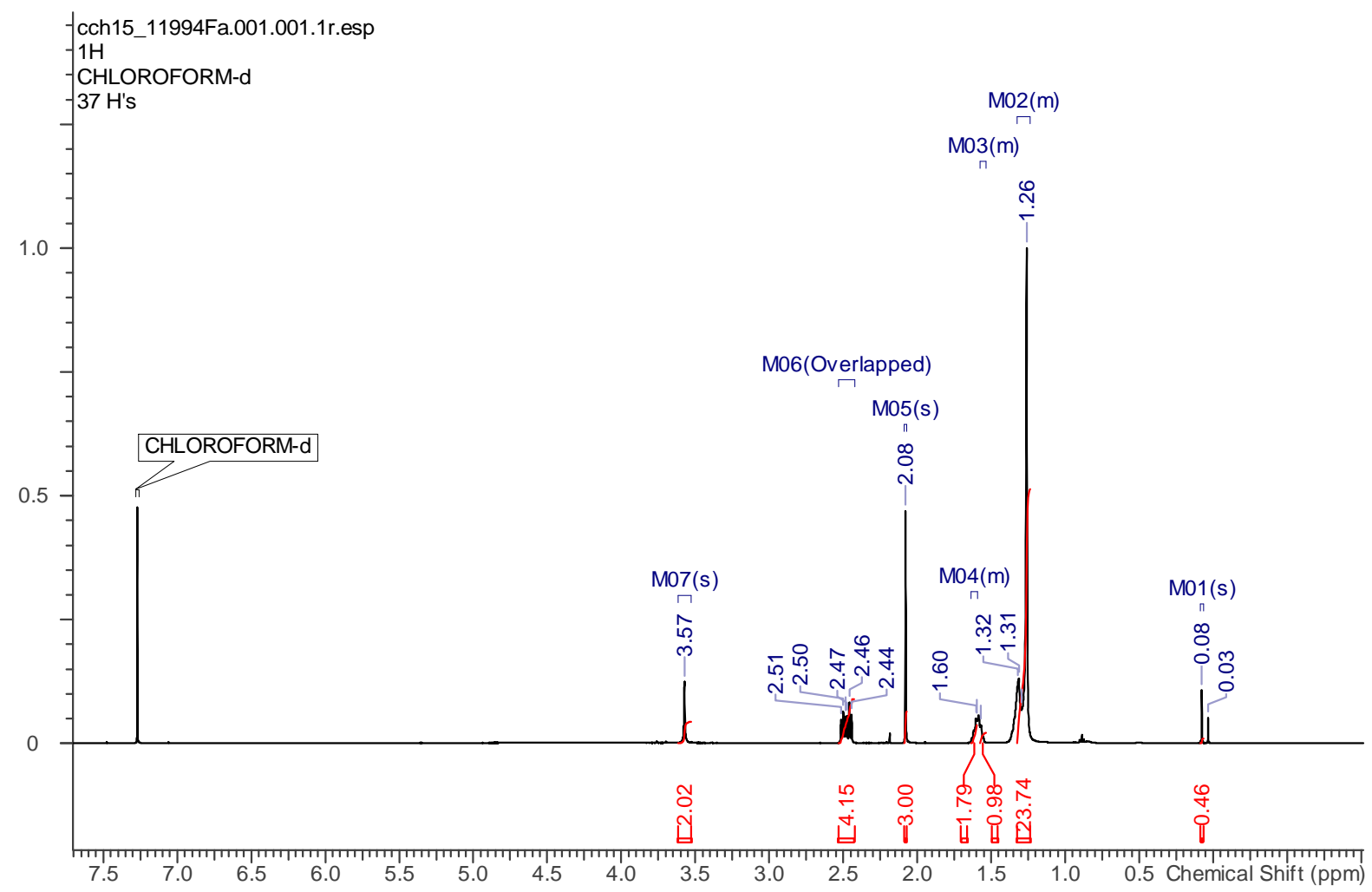

Figure S10: ${ }^{13} \mathrm{C}$ NMR spectrum of skeletocutin $\mathrm{B}(2)$ in $\mathrm{CDCl}_{3}(125 \mathrm{MHz})$

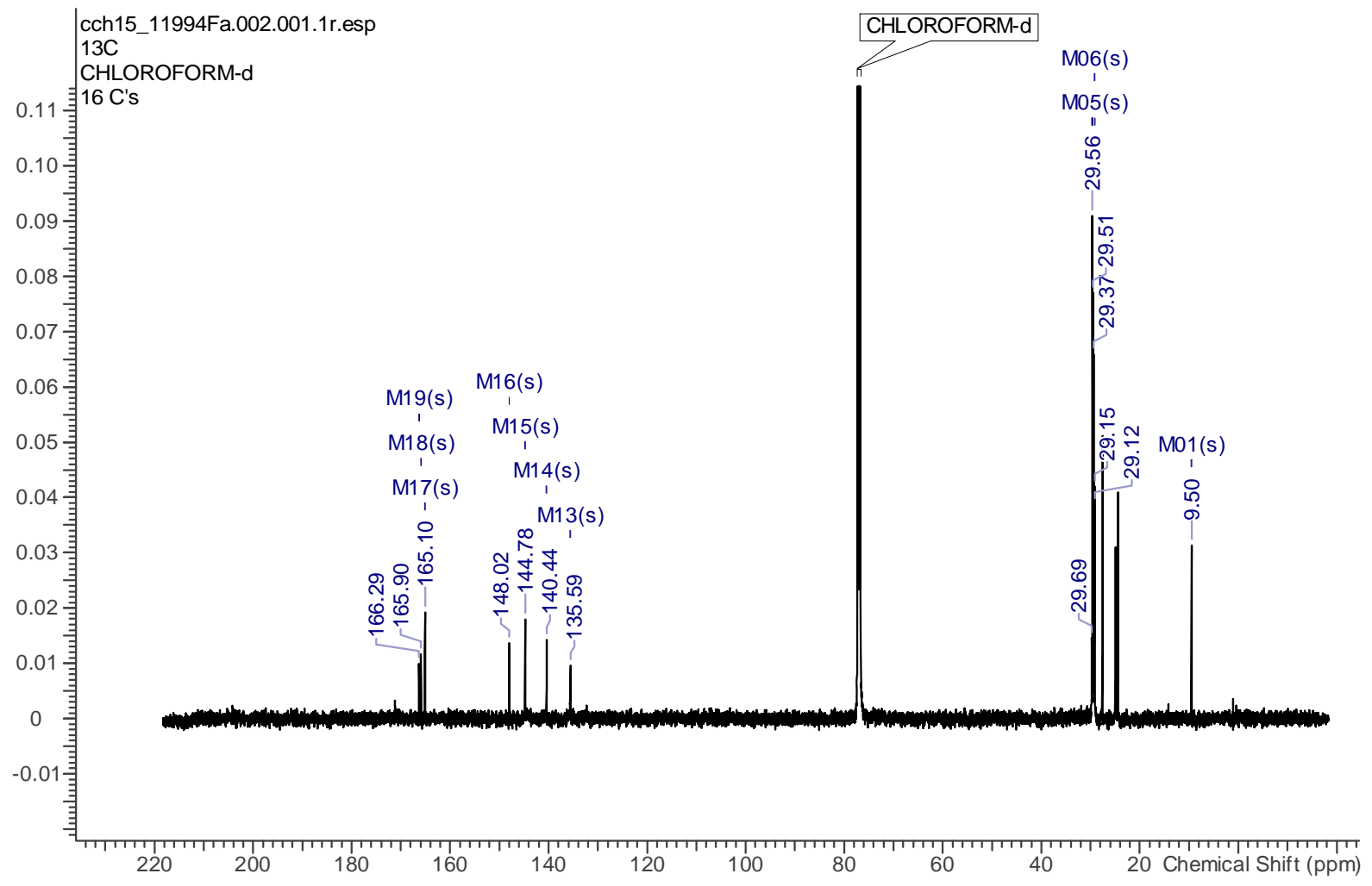


Figure S11: DEPT NMR spectrum of skeletocutin $\mathrm{B}(2)$ in $\mathrm{CDCl}_{3}(125 \mathrm{MHz})$

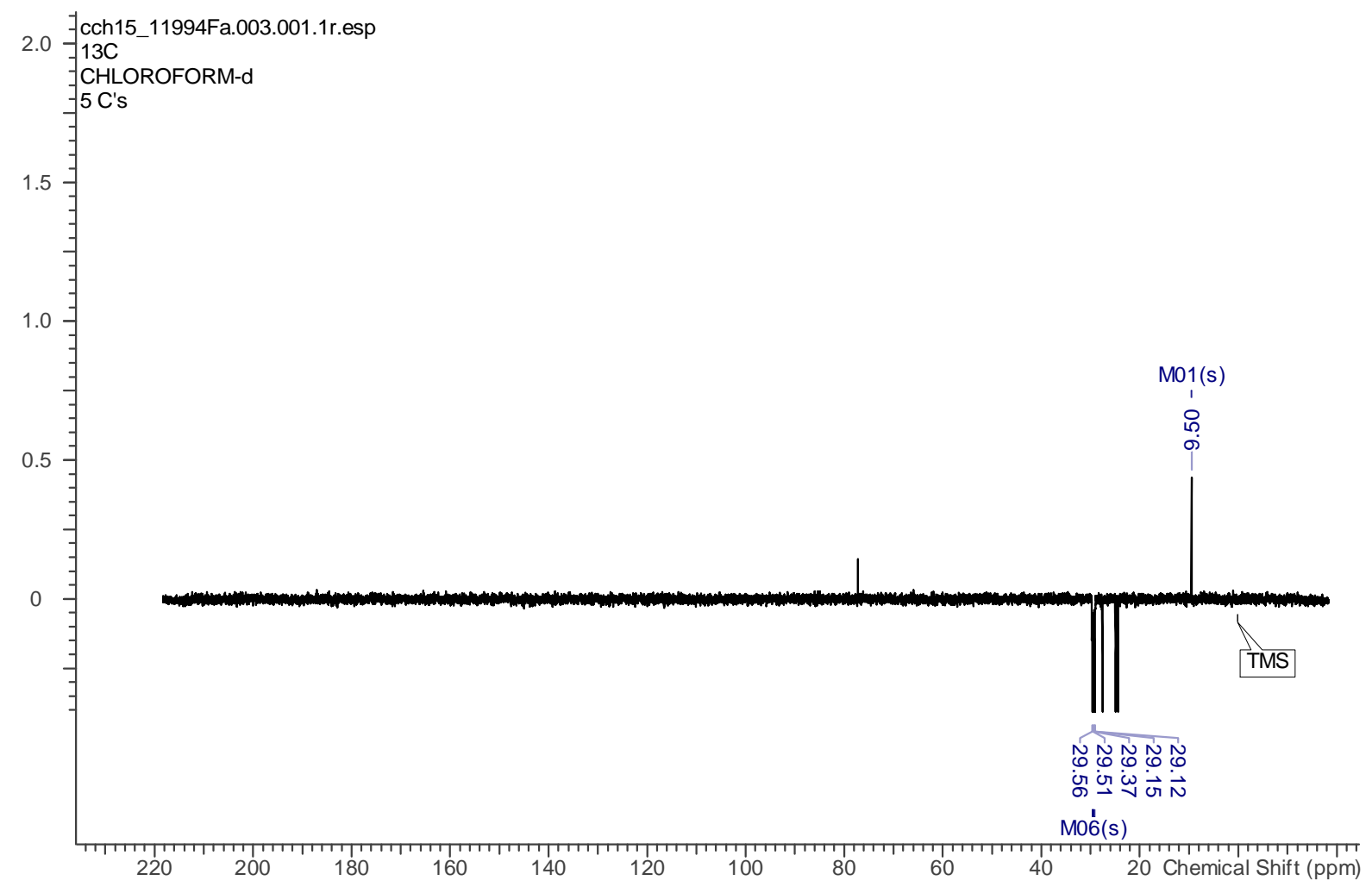

Figure S12: ${ }^{1} \mathrm{H},{ }^{13} \mathrm{C}$ HSQC NMR spectrum of skeletocutin B (2) in $\mathrm{CDCl}_{3}(500 \mathrm{MHz}, 125$ $\mathrm{MHz})$ 


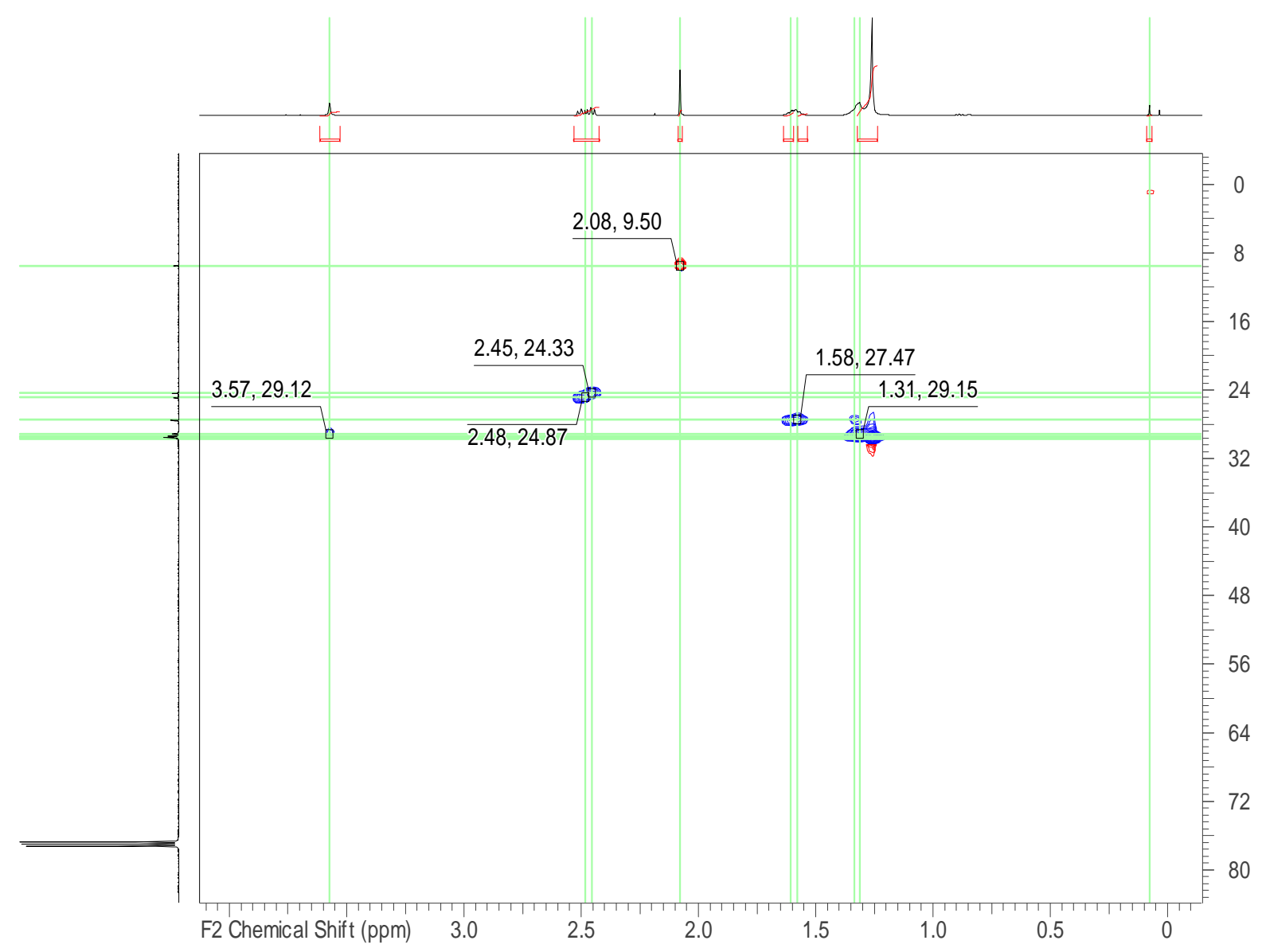

Figure $\mathrm{S} 13:{ }^{1} \mathrm{H},{ }^{13} \mathrm{C}$ HMBC NMR spectrum of skeletocutin B (2) in $\mathrm{CDCl}_{3}(500 \mathrm{MHz}, 125$ $\mathrm{MHz})$ 


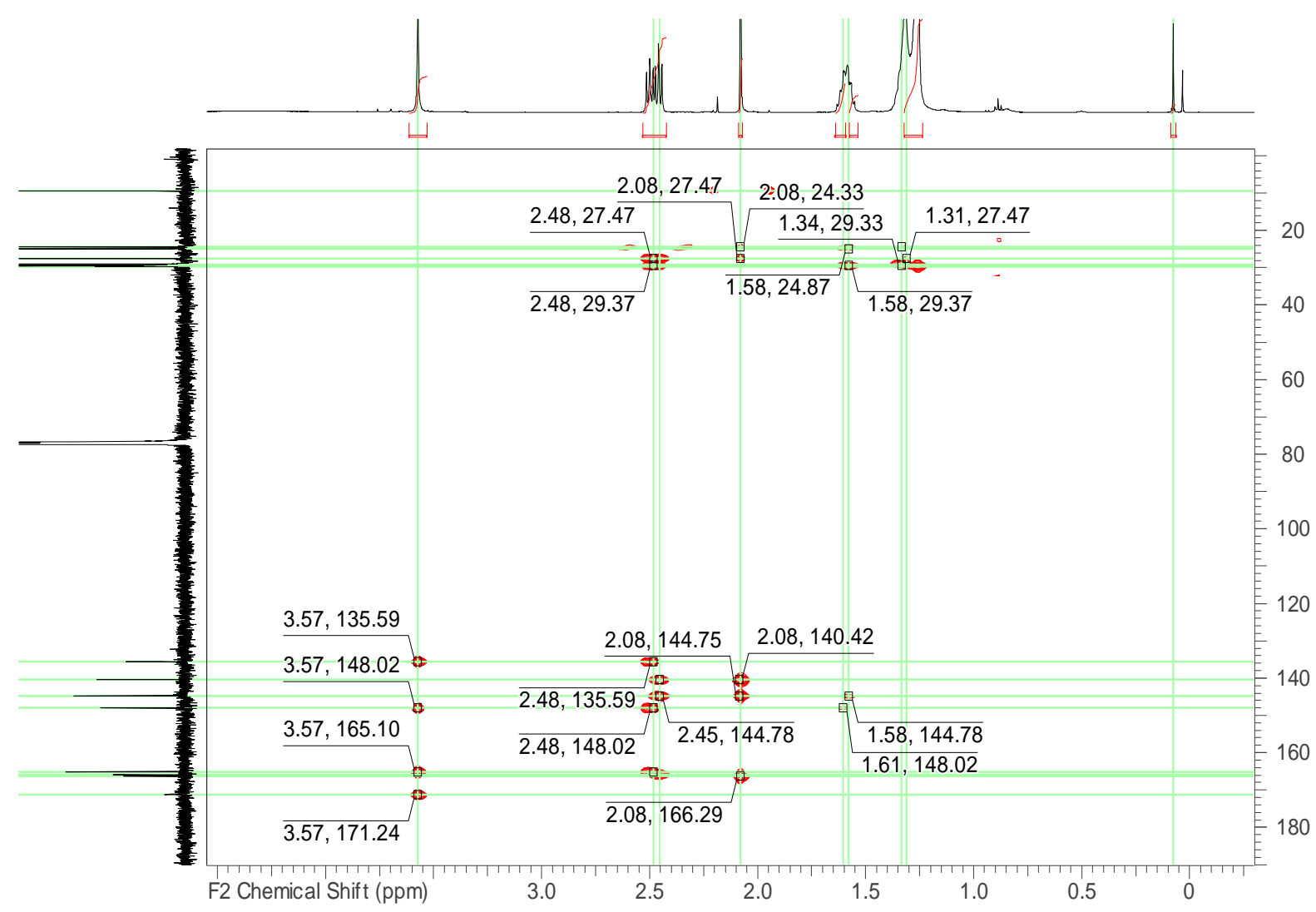

Figure S14: ${ }^{1} \mathrm{H},{ }^{1} \mathrm{H}$ COSY NMR spectrum of skeletocutin B (2) in $\mathrm{CDCl}_{3}(500 \mathrm{MHz})$

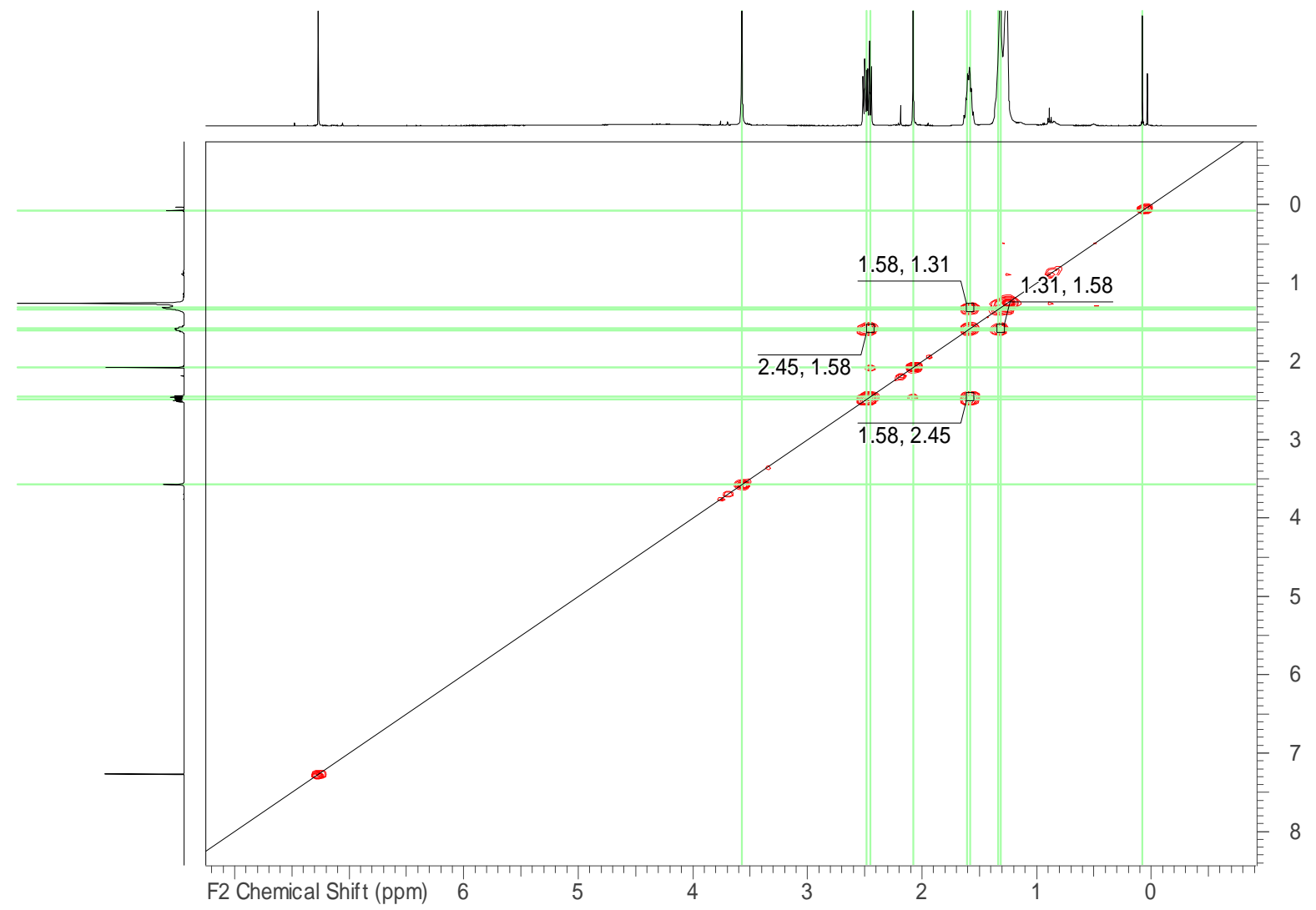

Figure S15: MS data of skeletocutin B (2) 


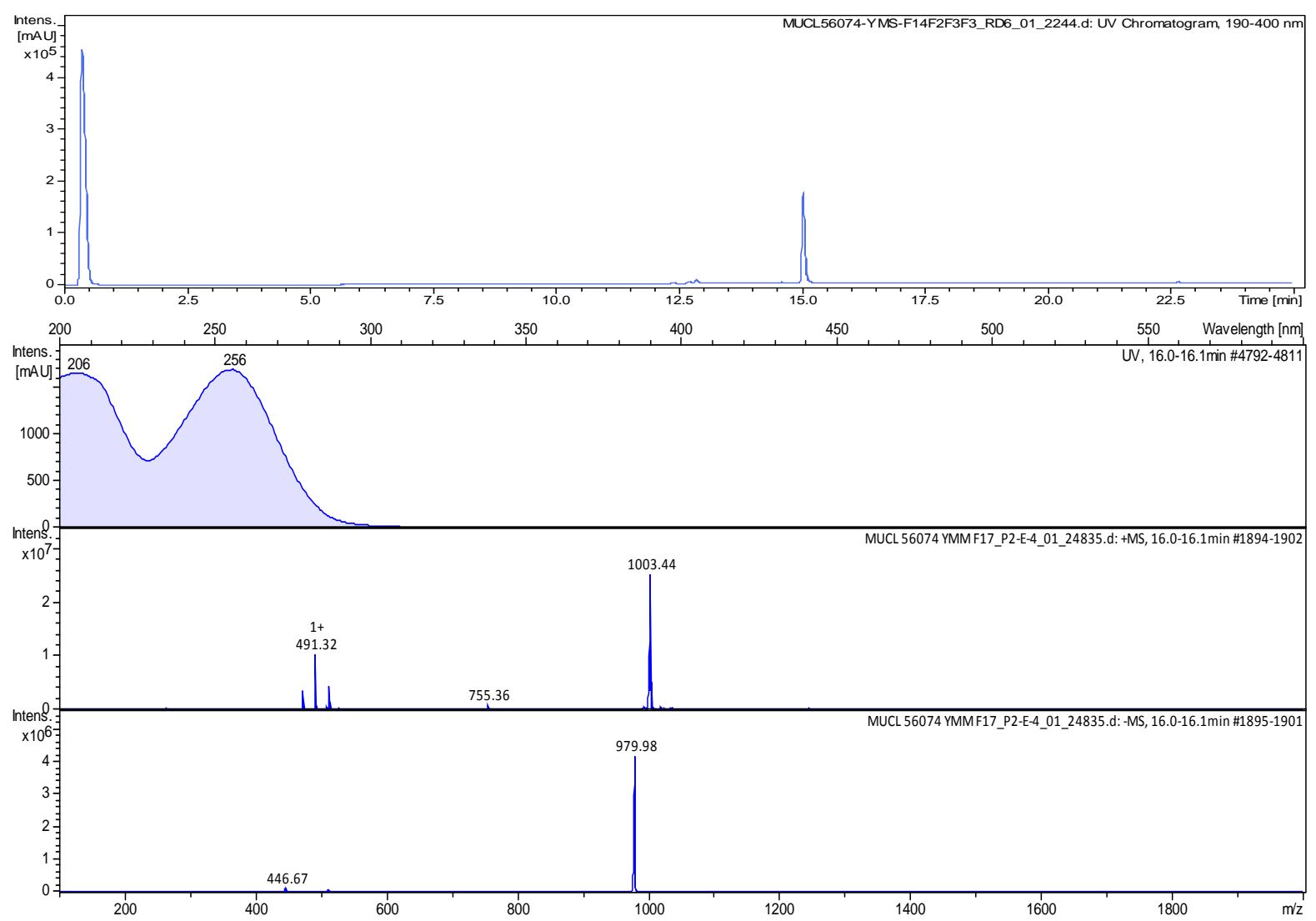

Figure S16: HRMS data of skeletocutin B (2)
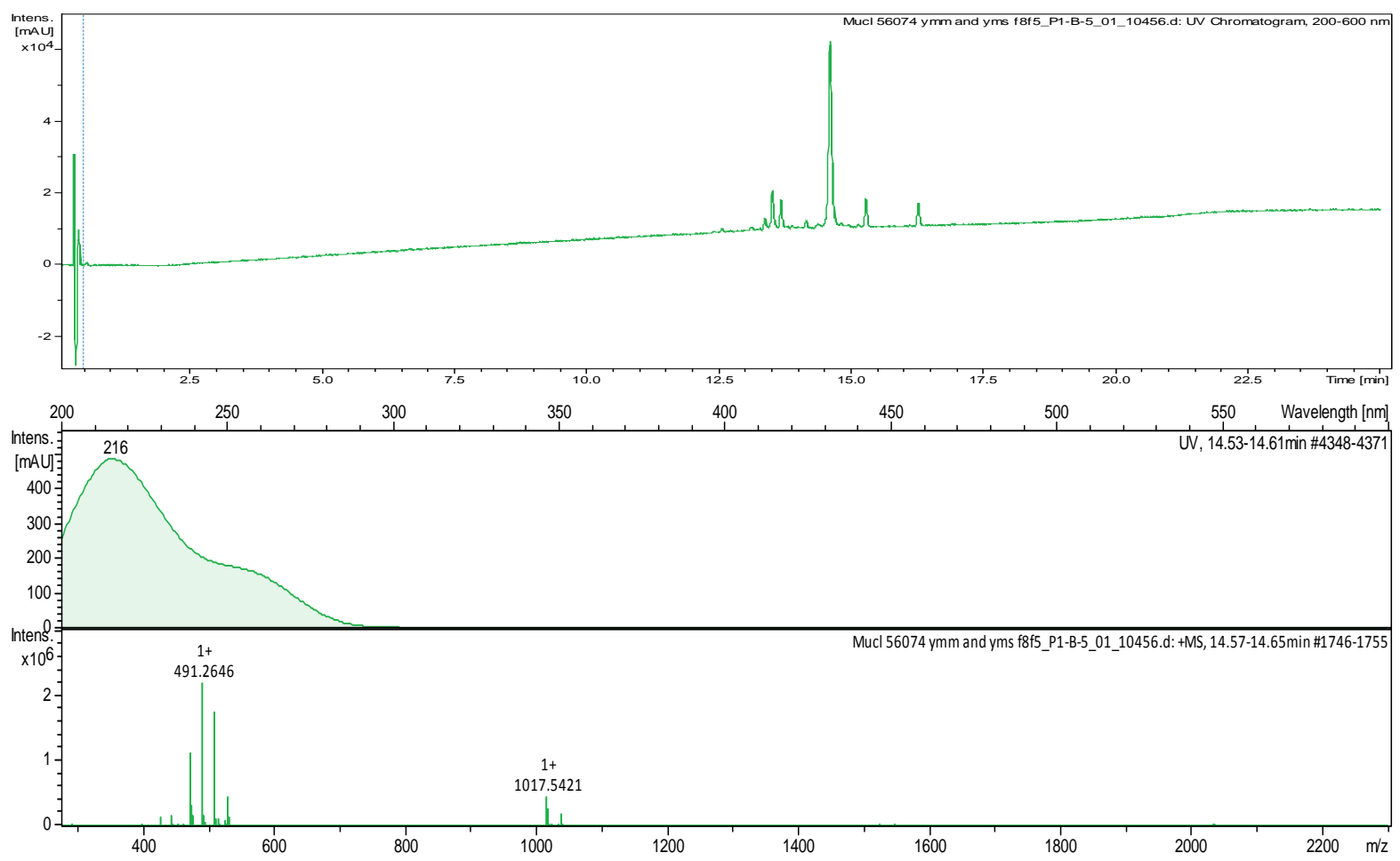

1 and 2D NMR data for skeletocutin C (3)

Figure S17: ${ }^{1} \mathrm{H}$ NMR spectrum of skeletocutin C (3) in acetone- $\mathrm{d}_{6}(500 \mathrm{MHz})$ 


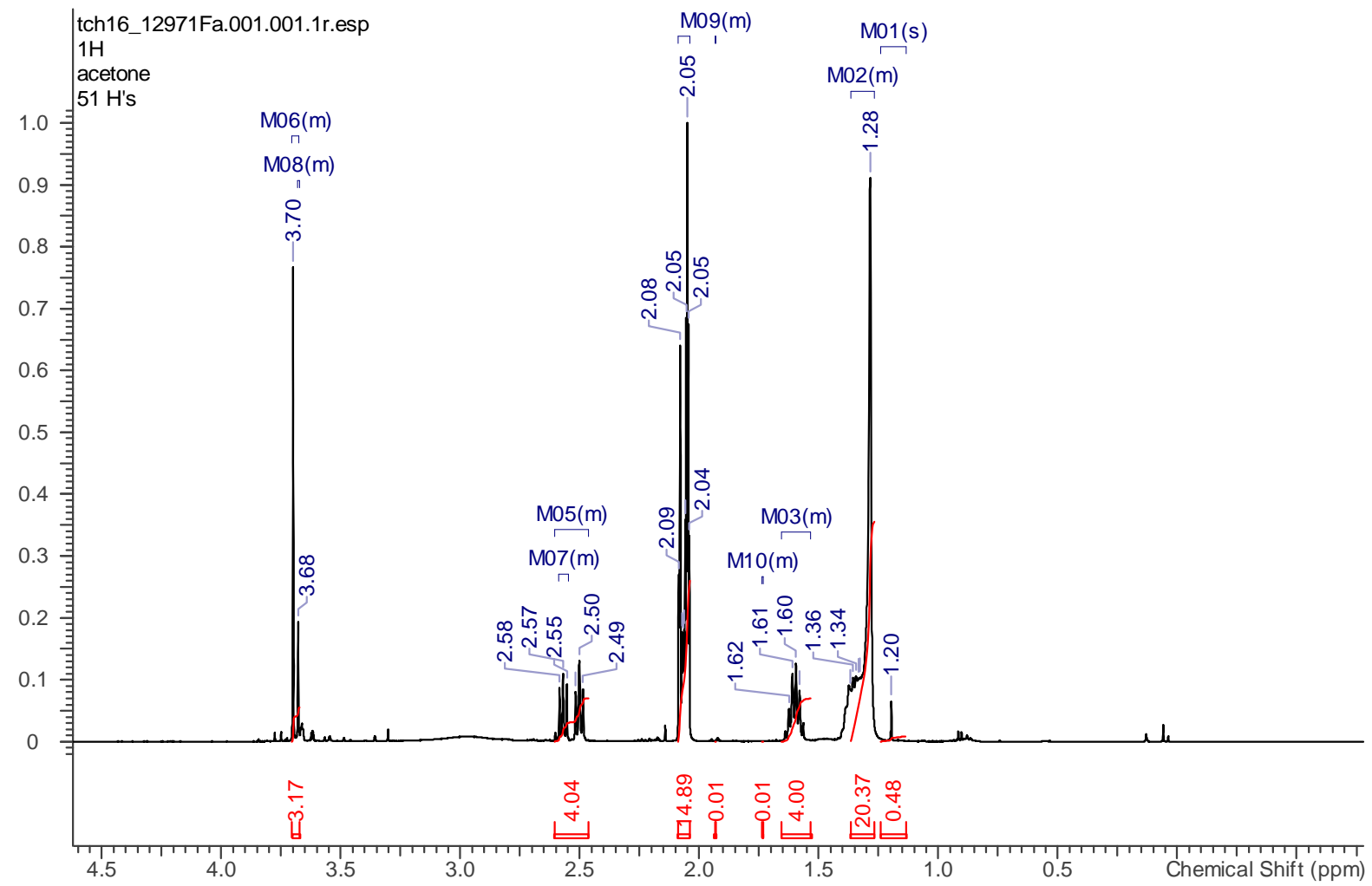

Figure S18: ${ }^{13} \mathrm{C}$ NMR spectrum of skeletocutin C (3) in acetone- $\mathrm{d}_{6}(125 \mathrm{MHz})$

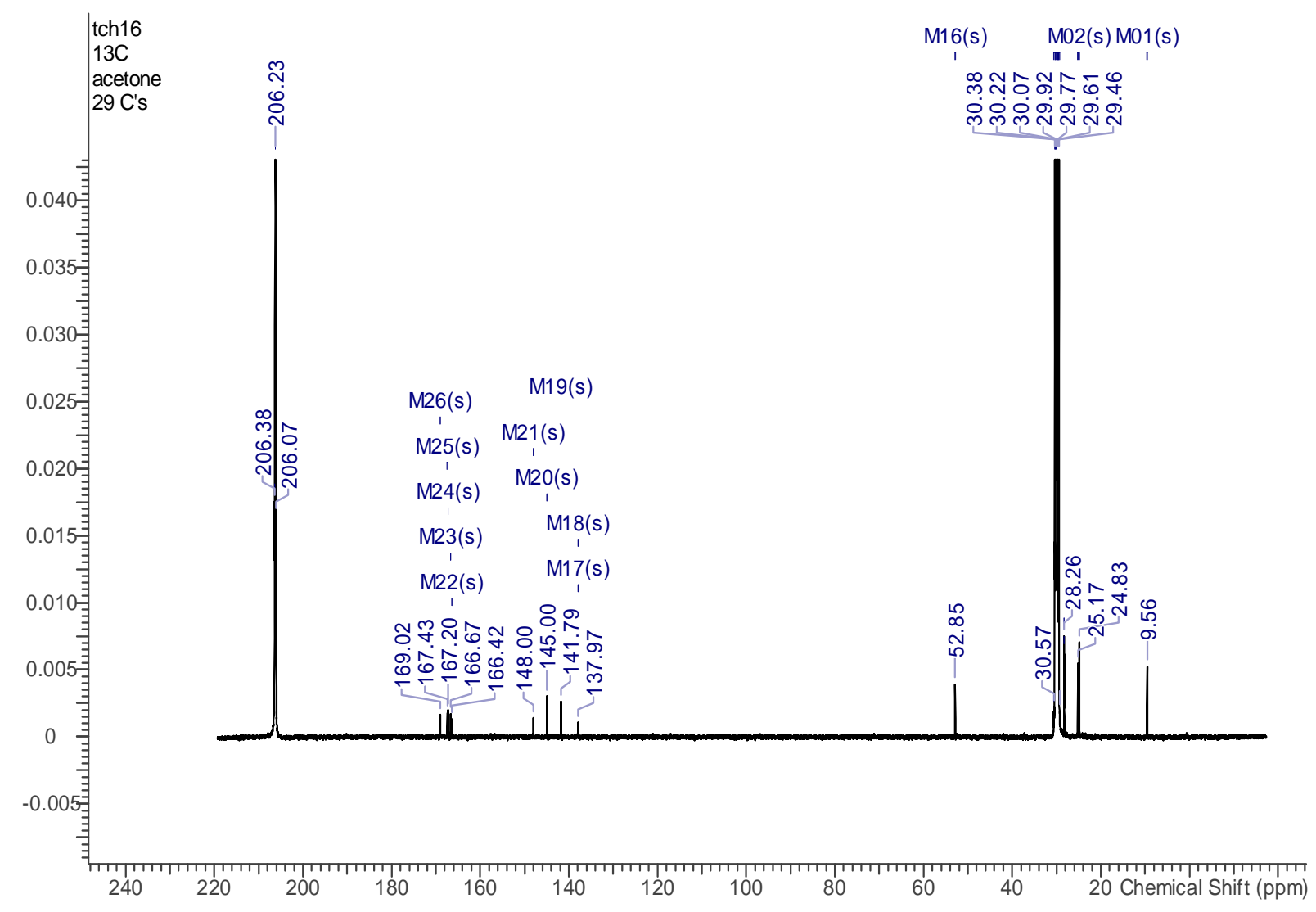

Figure S19: DEPT NMR spectrum of skeletocutin C (3) in acetone-d ${ }_{6}(125 \mathrm{MHz})$ 


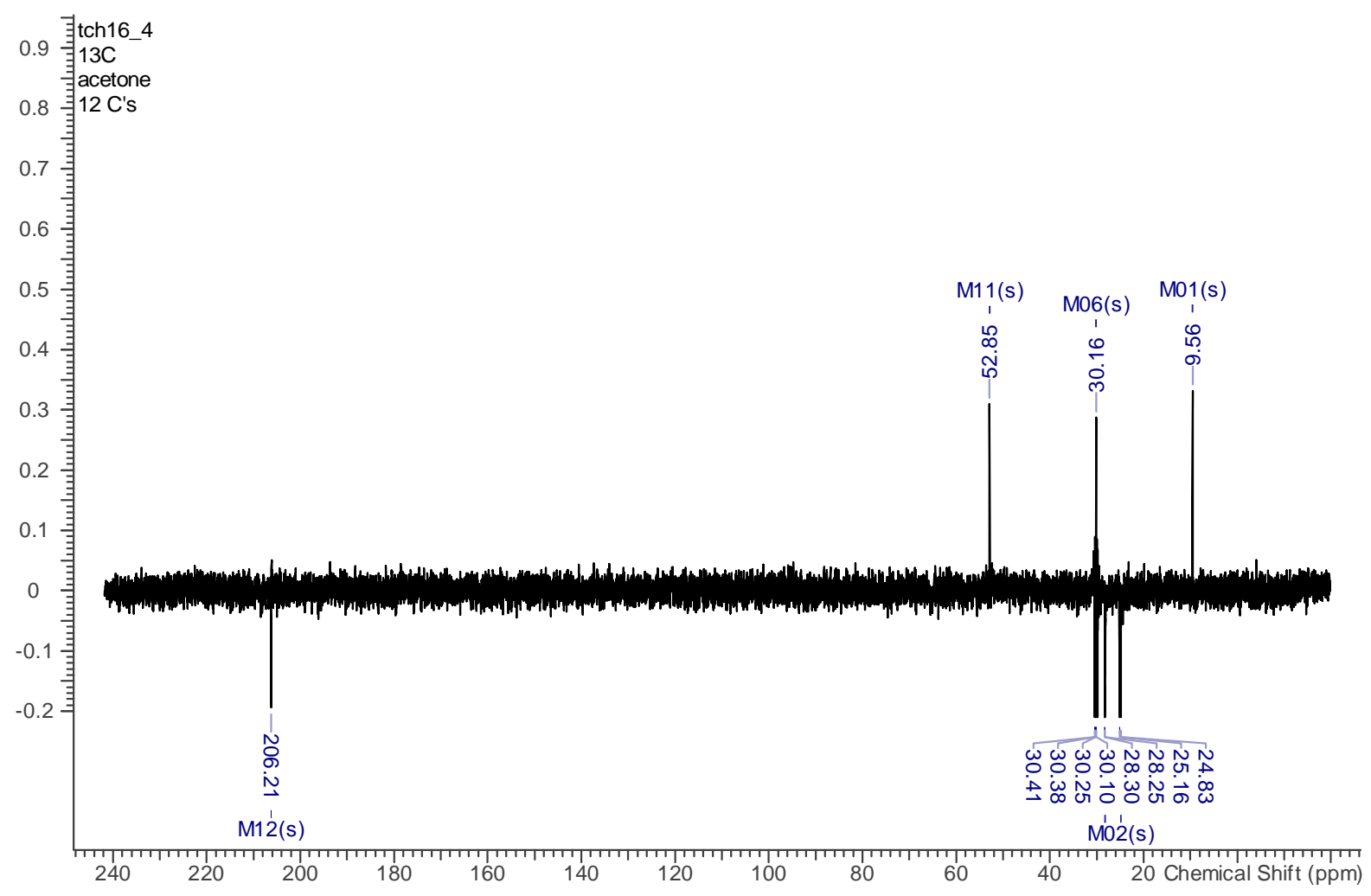

Figure S20: ${ }^{1} \mathrm{H},{ }^{13} \mathrm{C}$ HSQC NMR spectrum of skeletocutin $\mathrm{C}(3)$ in acetone- $\mathrm{d}_{6}(500 \mathrm{MHz}, 125$ $\mathrm{MHz}$ )

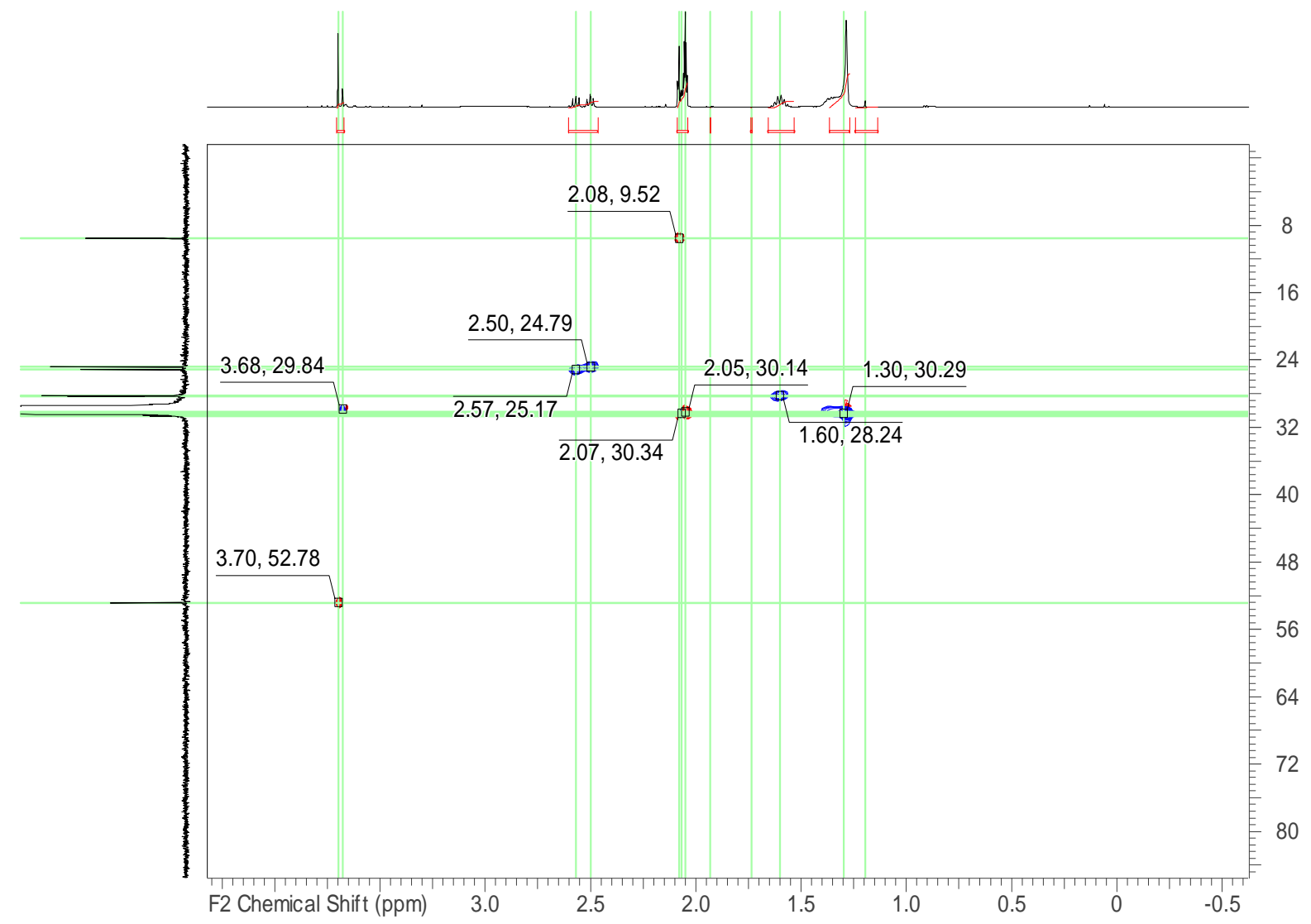


Figure S21: ${ }^{1} \mathrm{H},{ }^{13} \mathrm{C}$ HMBC NMR spectrum of skeletocutin $\mathrm{C}(3)$ in acetone- $\mathrm{d}_{6}(500 \mathrm{MHz}$, $125 \mathrm{MHz}$ )

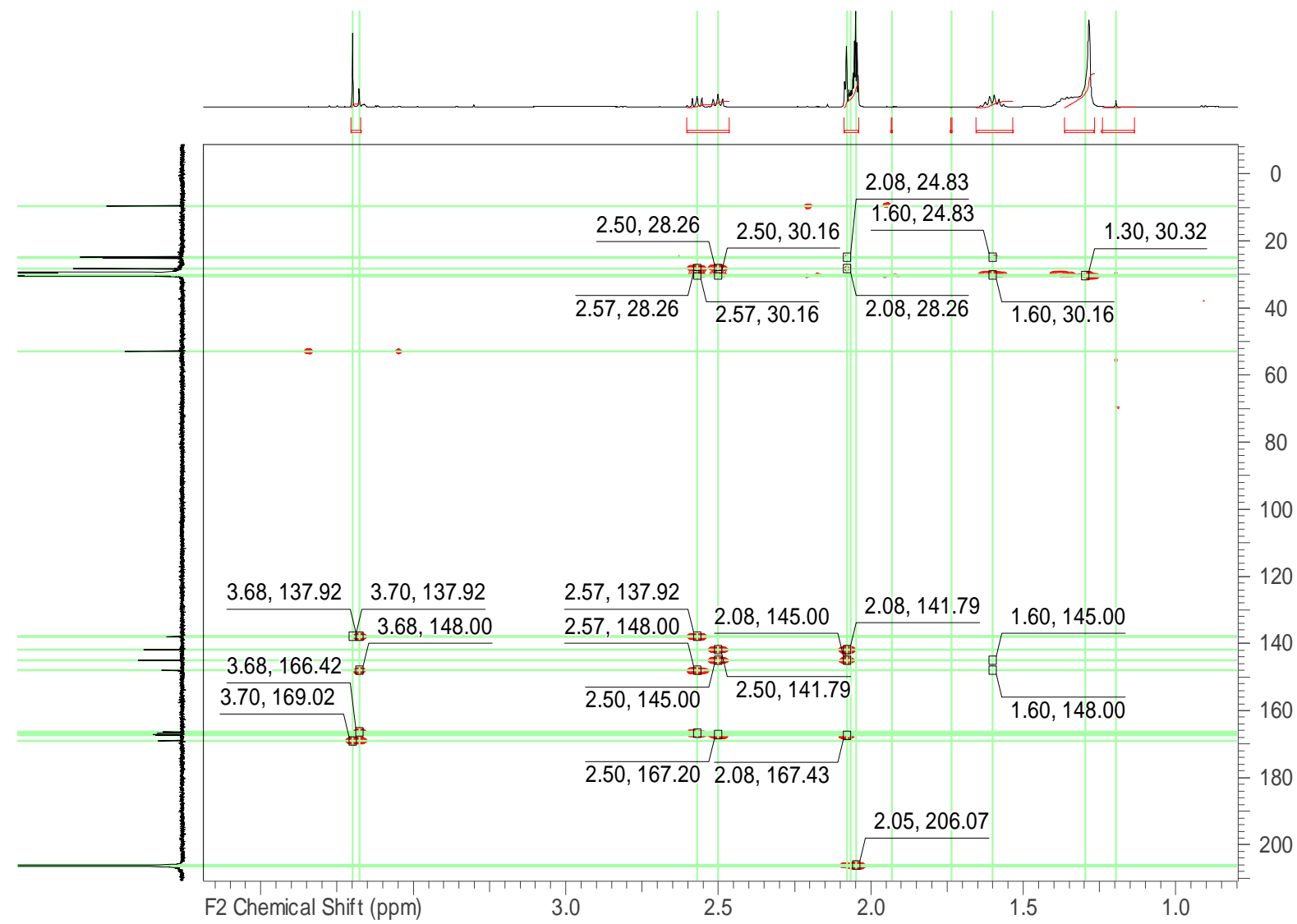

Figure S22: ${ }^{1} \mathrm{H},{ }^{1} \mathrm{H}$ COSY NMR spectrum of skeletocutin C (3) in acetone-d $\mathrm{d}_{6}(500 \mathrm{MHz})$

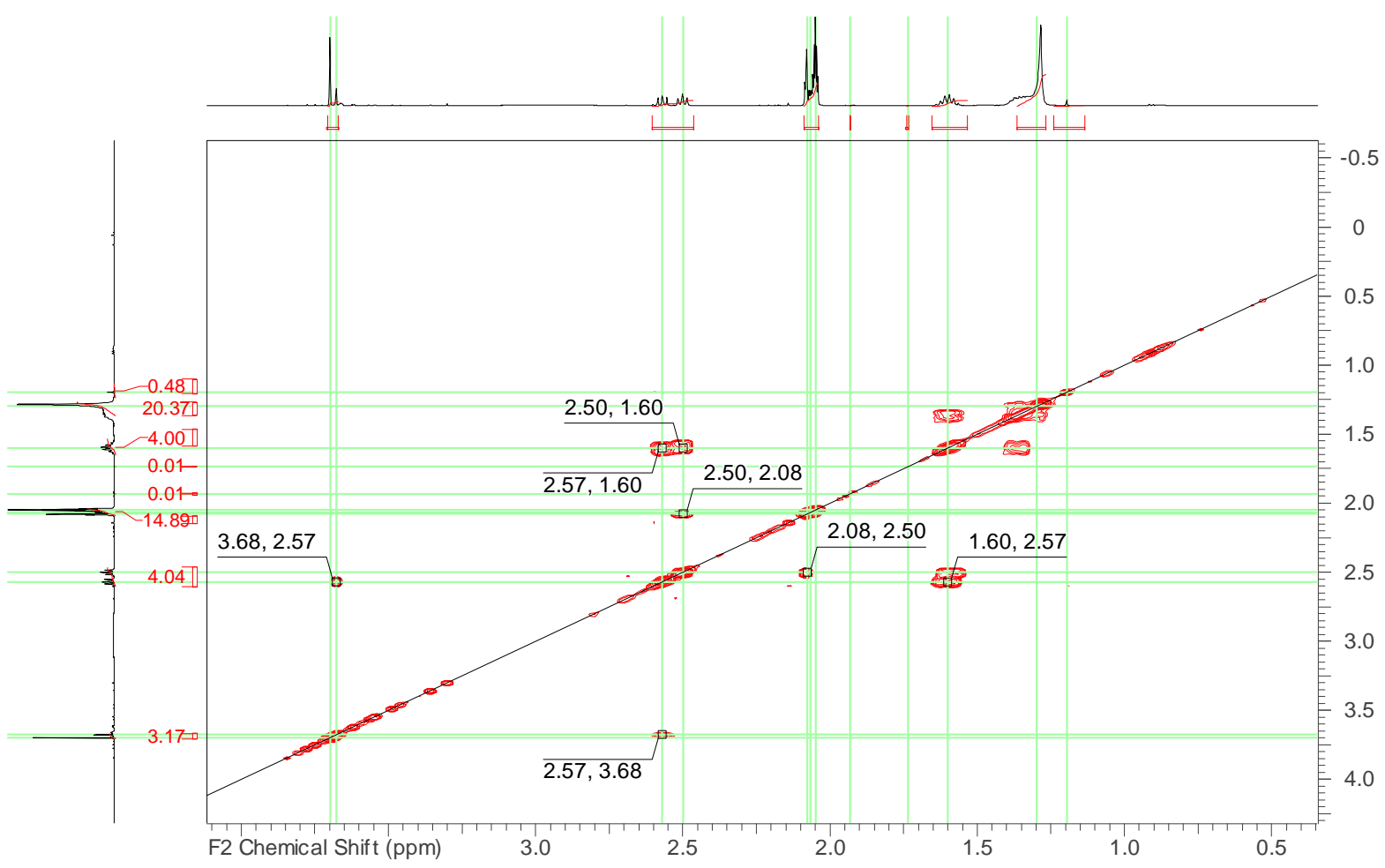


Figure S23: MS data of skeletocutin C (3)
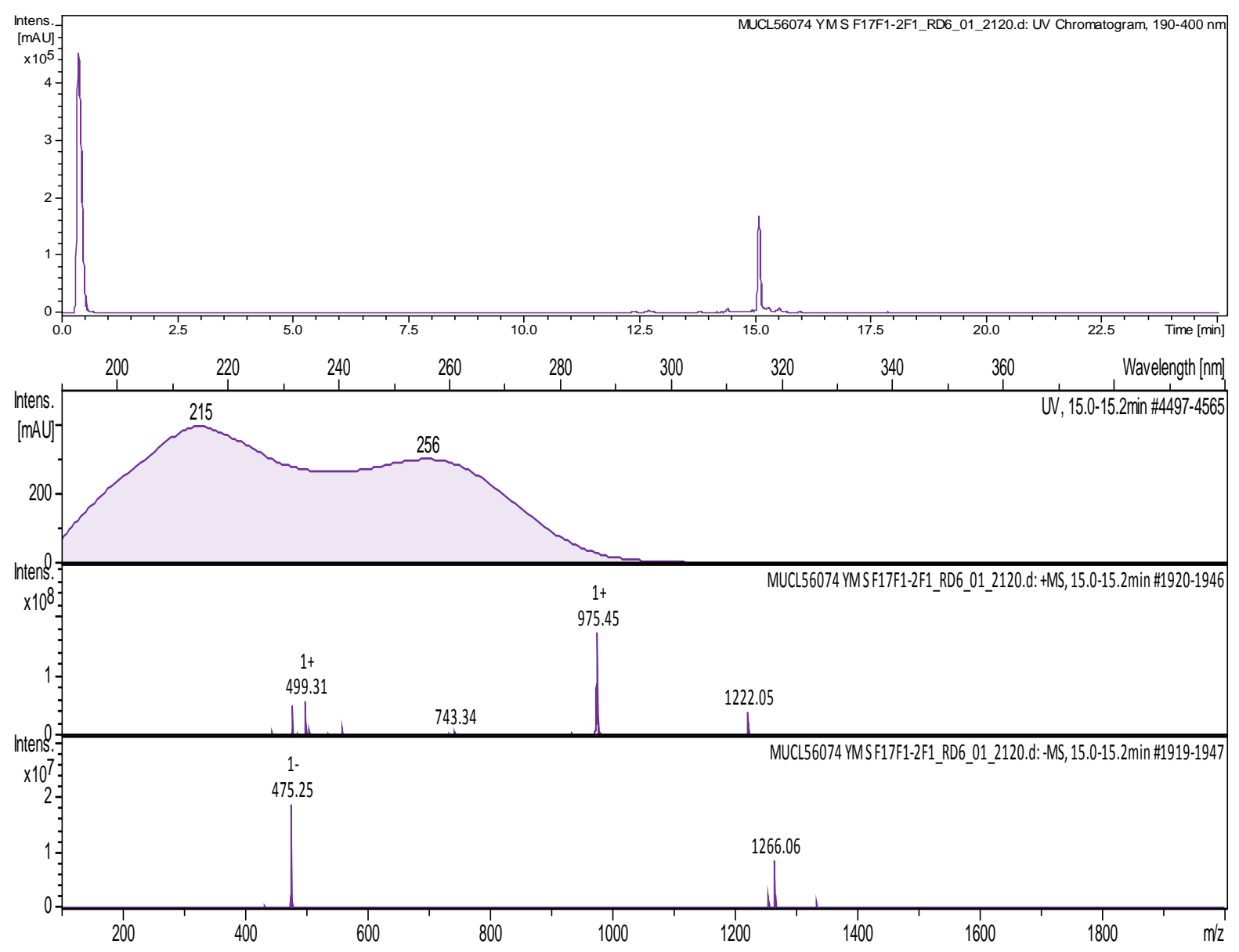

Figure S24: HRMS data of skeletocutin C (3)

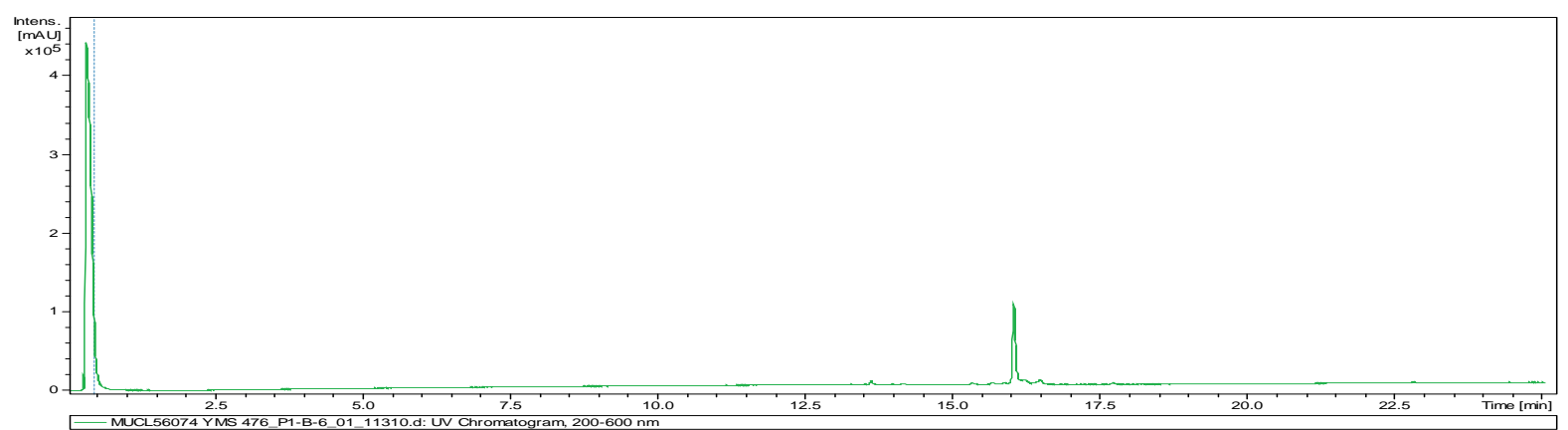




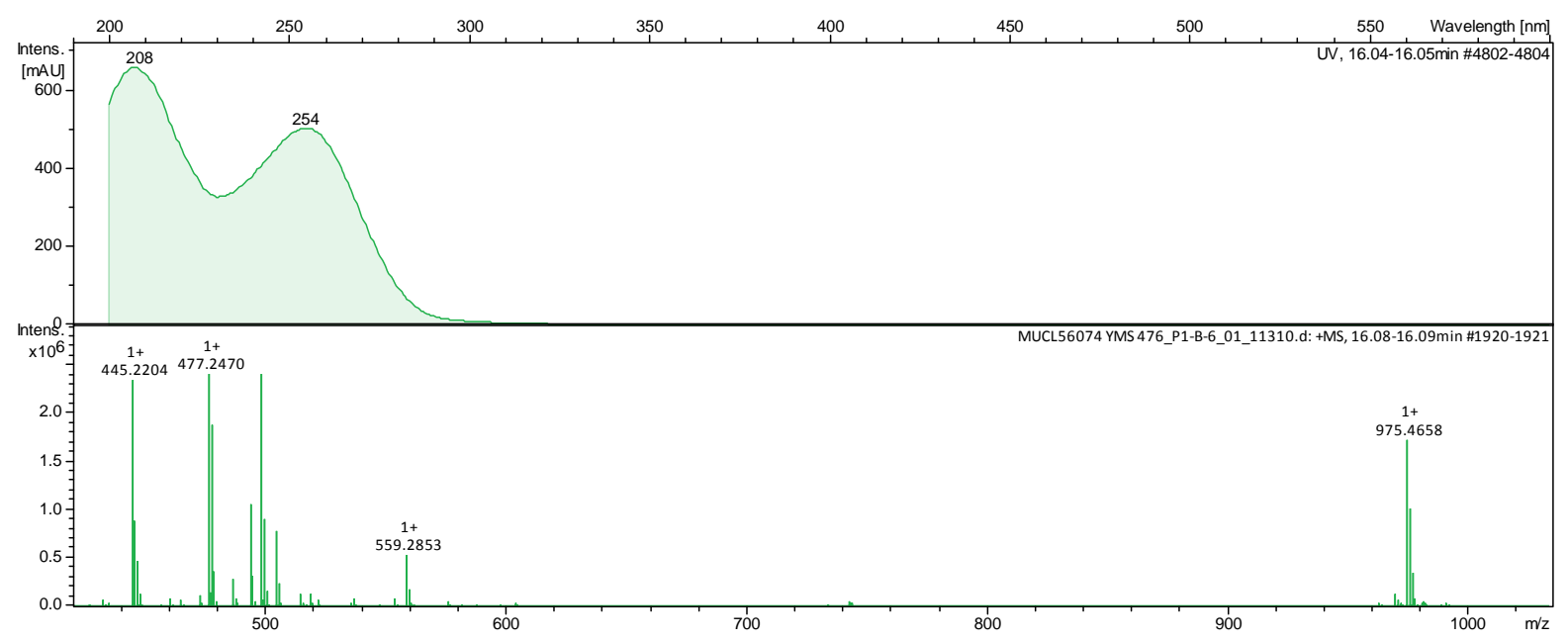

\section{1 and 2D NMR data for skeletocutin D (4)}

Figure S25: ${ }^{1} \mathrm{H}$ NMR spectrum of skeletocutin D (4) in acetone- $\mathrm{d}_{6}(500 \mathrm{MHz})$

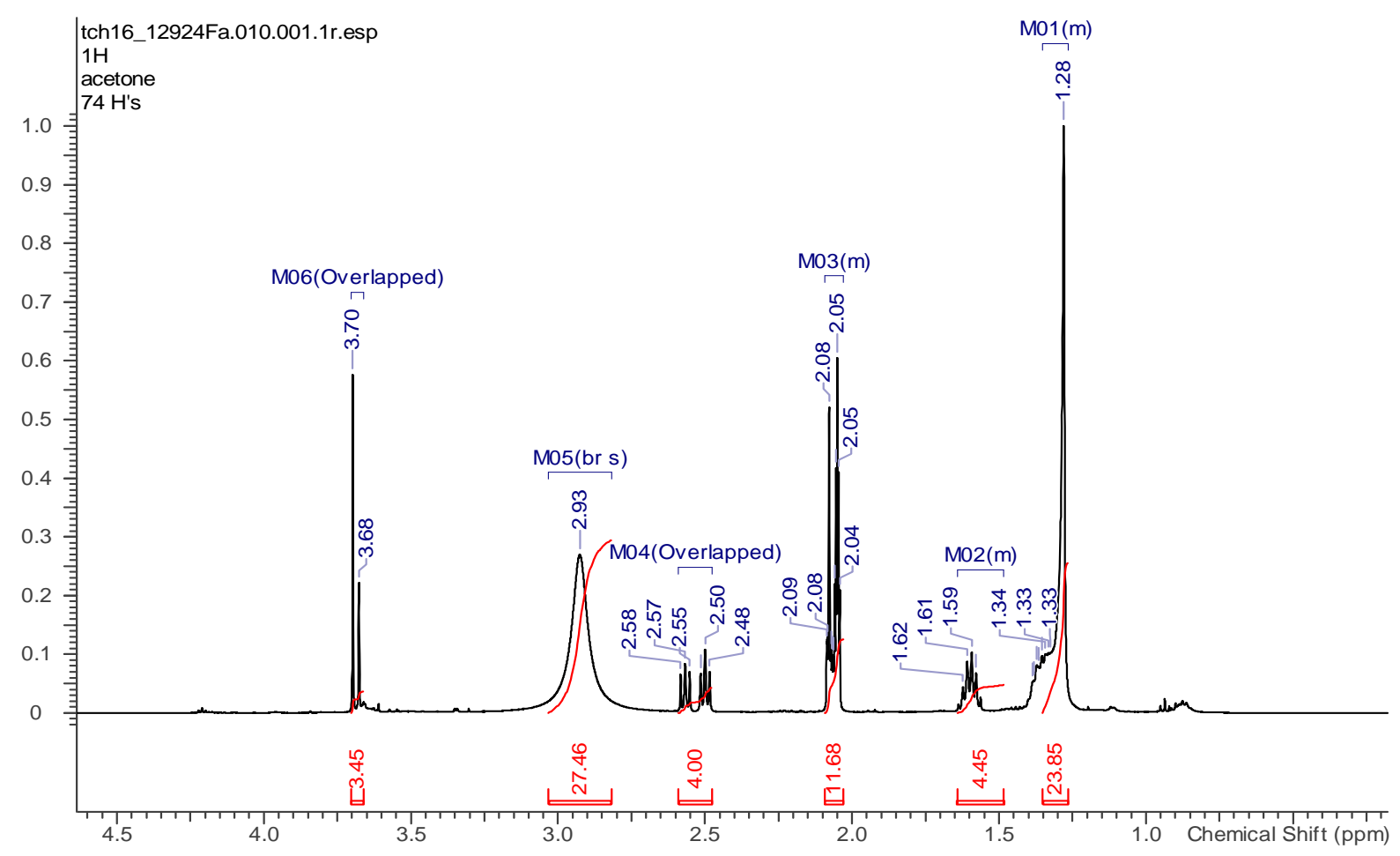

Figure S26: ${ }^{13} \mathrm{C}$ NMR spectrum of skeletocutin D (4) in acetone- $\mathrm{d}_{6}(125 \mathrm{MHz})$ 


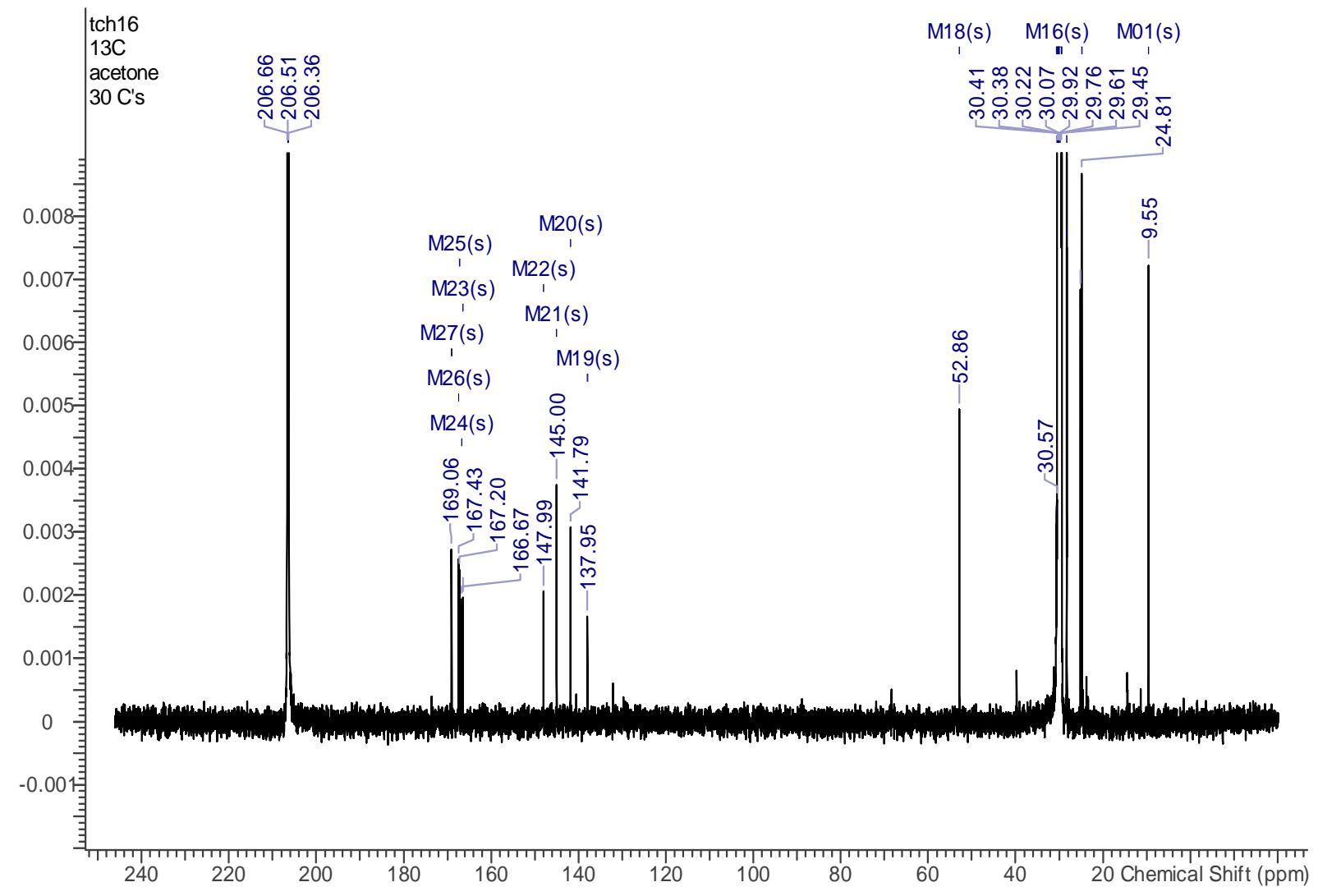

Figure S27: DEPT NMR spectrum of skeletocutin D (4) in acetone- $\mathrm{d}_{6}(125 \mathrm{MHz})$

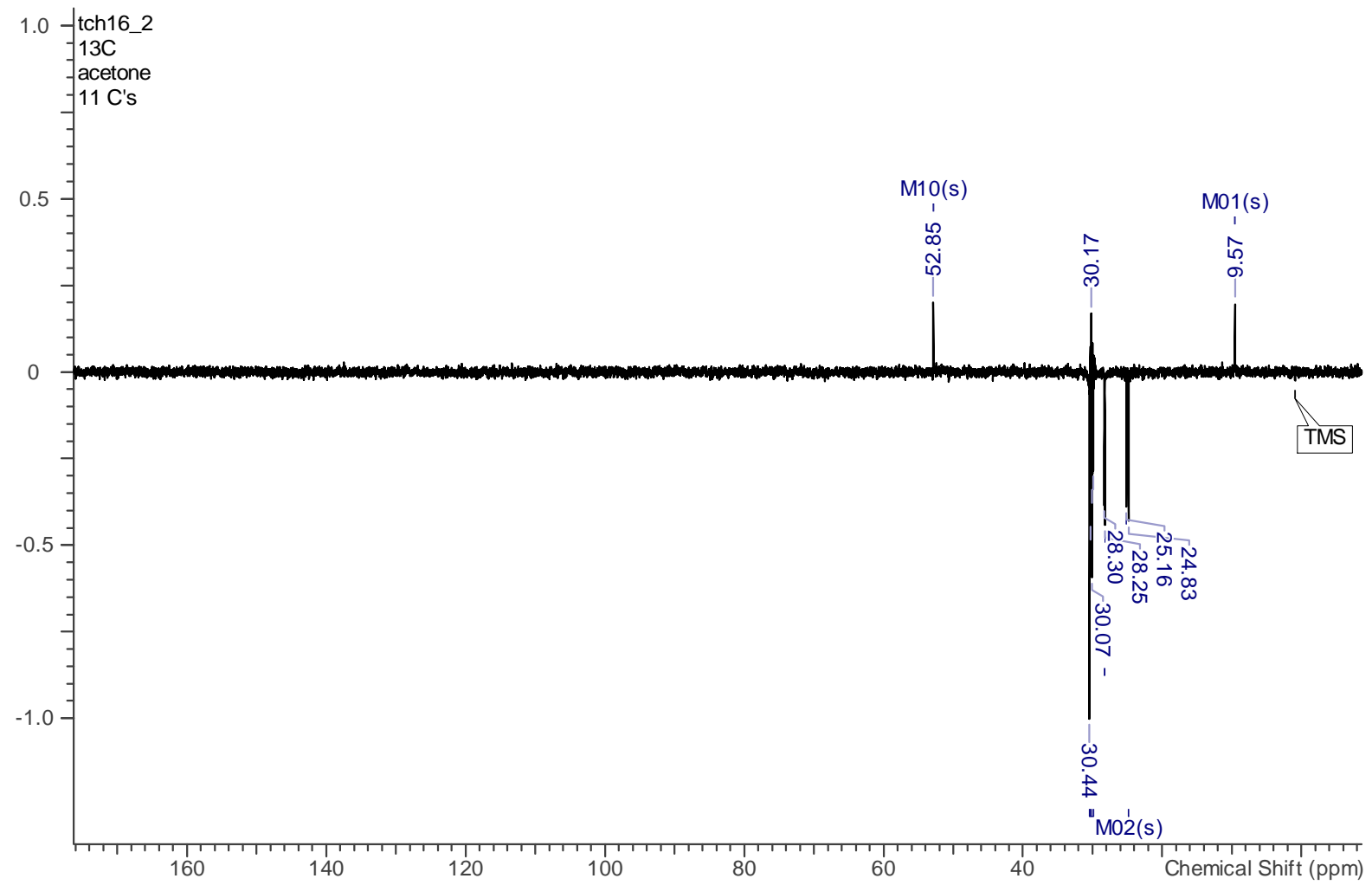


Figure S28: ${ }^{1} \mathrm{H},{ }^{13} \mathrm{C}$ HSQC NMR spectrum of skeletocutin D (4) in acetone- $\mathrm{d}_{6}(500 \mathrm{MHz}, 125$ $\mathrm{MHz}$ )

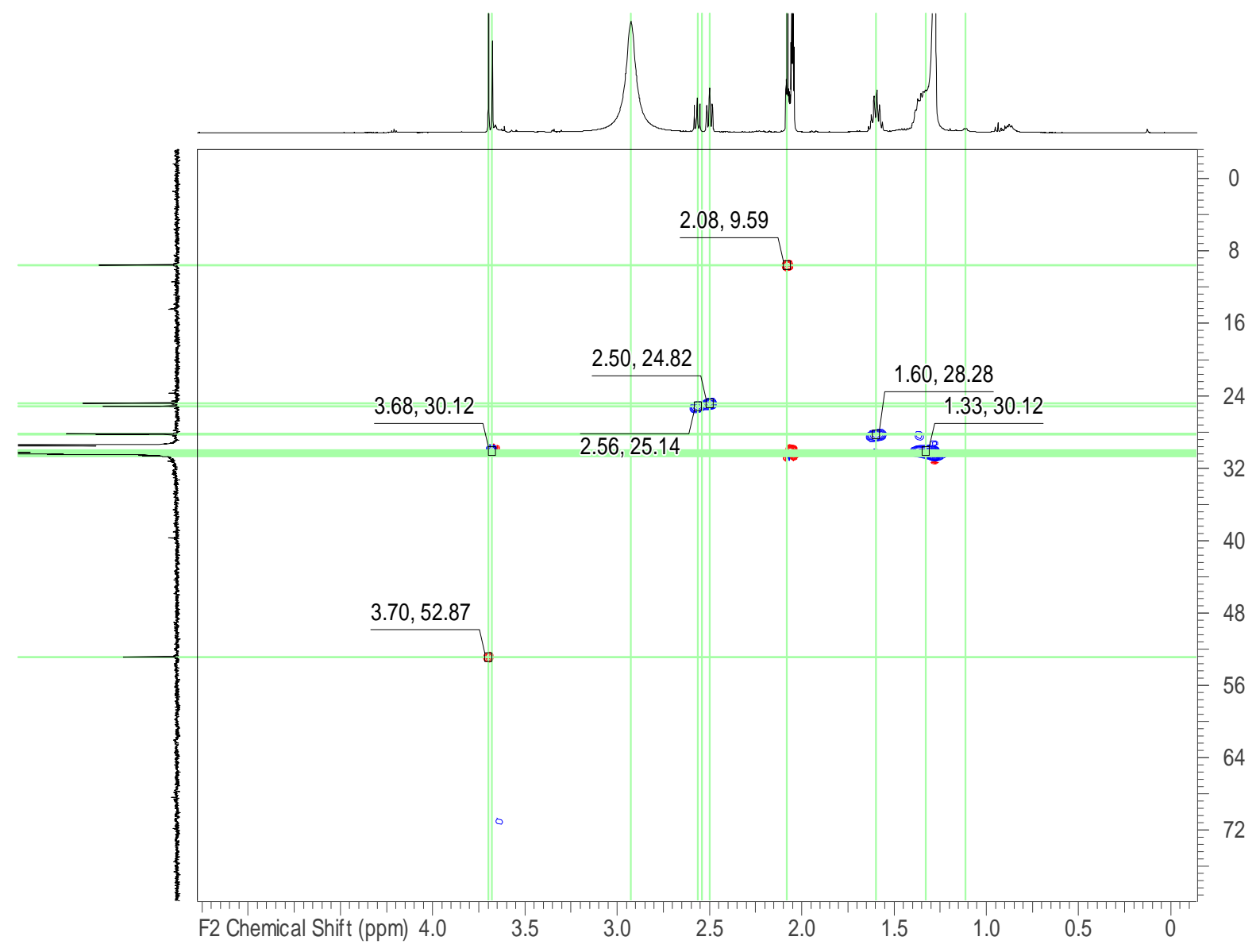

Figure S29: ${ }^{1} \mathrm{H},{ }^{13} \mathrm{C}$ HSQC NMR spectrum of skeletocutin D (4) in acetone-d $\mathrm{d}_{6}(500 \mathrm{MHz}, 125$ $\mathrm{MHz}$ ) 


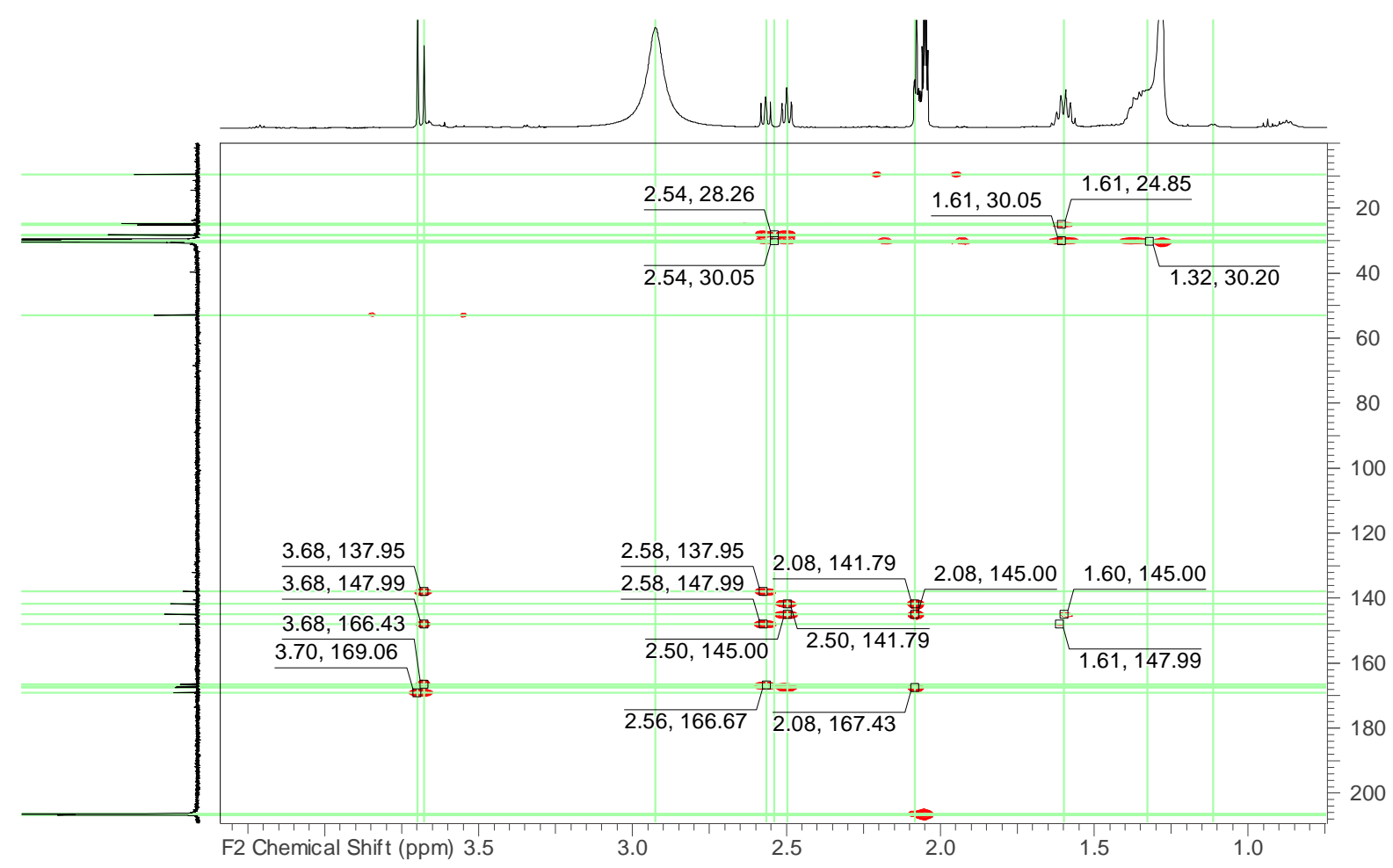

Figure S30: ${ }^{1} \mathrm{H},{ }^{1} \mathrm{H}$ COSY NMR spectrum of skeletocutin D (4) in acetone- $\mathrm{d}_{6}(500 \mathrm{MHz})$

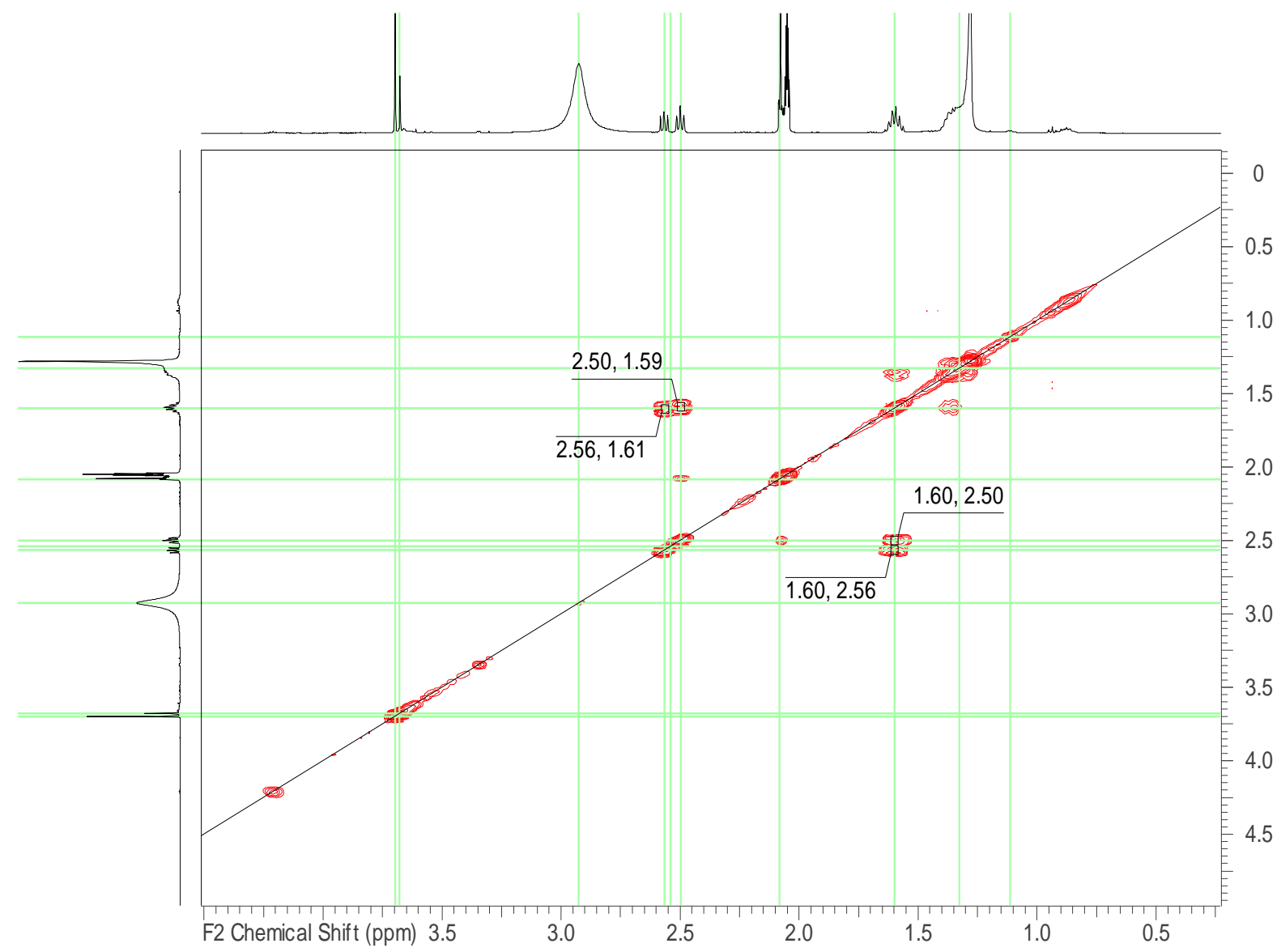


Figure S31: MS data of skeletocutin D (4)

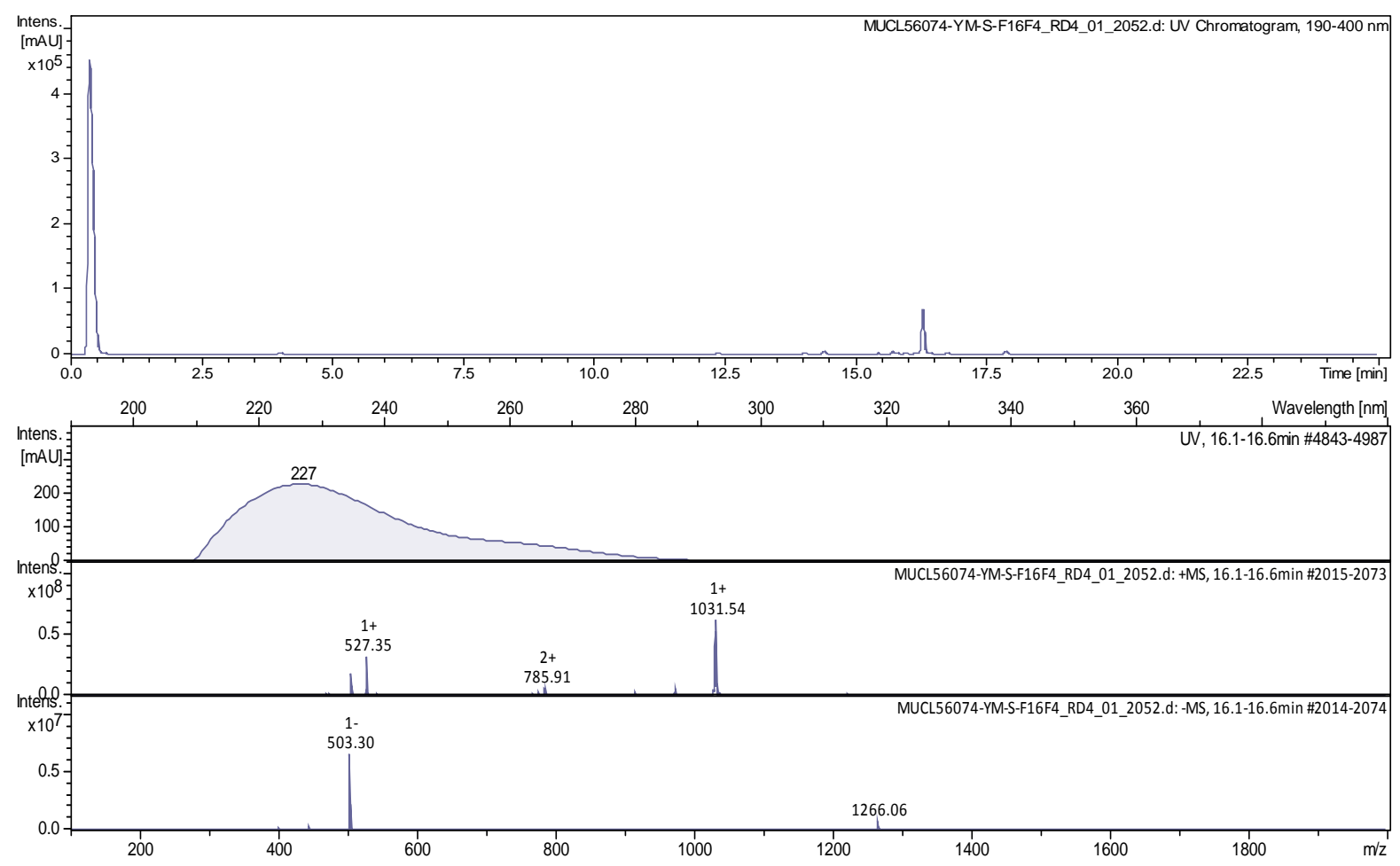

Figure S32: HRMS data of skeletocutin D (4)

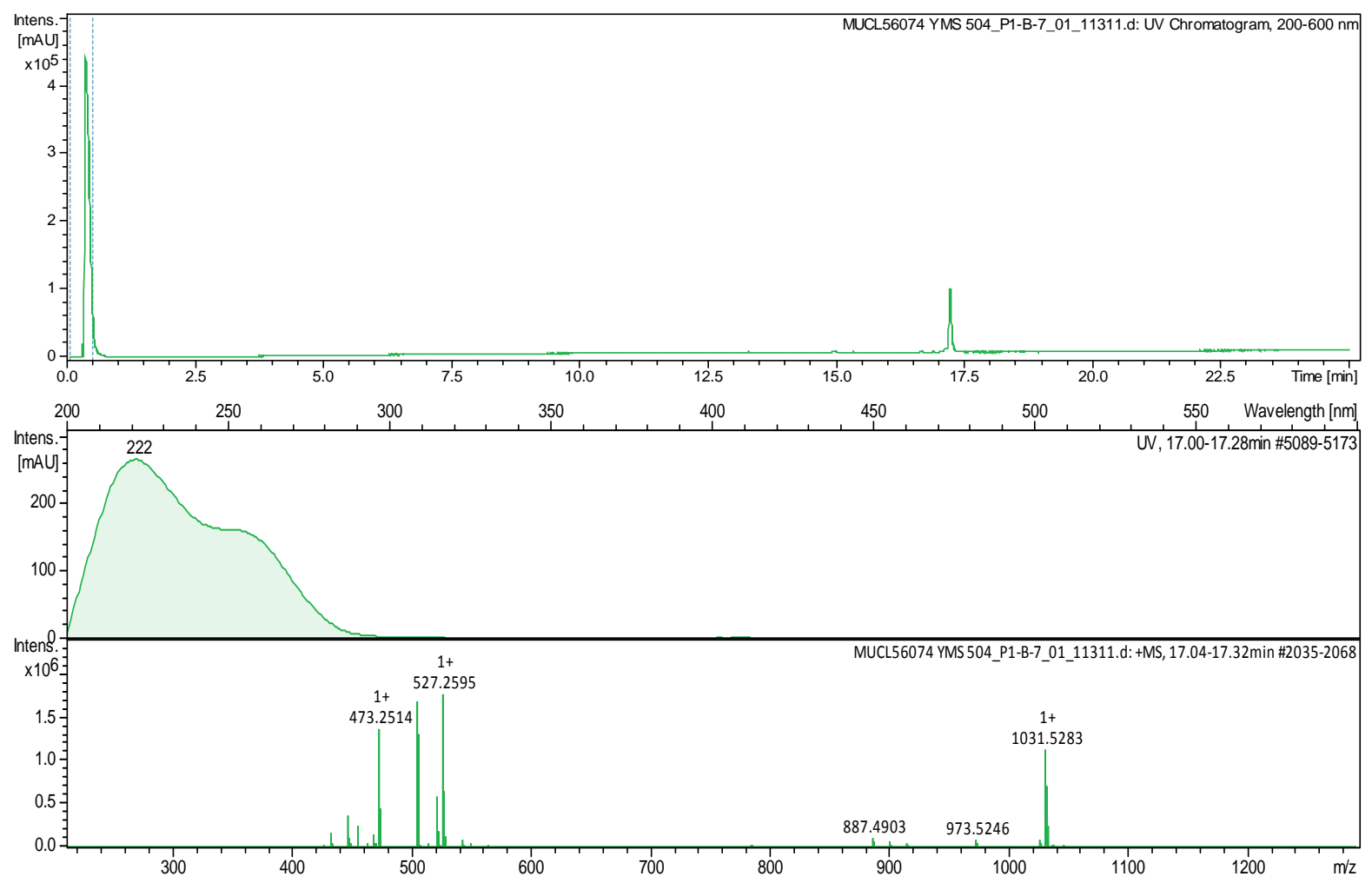

1 and 2D NMR data for skeletocutin E (5)

Figure S33: ${ }^{1} \mathrm{H}$ NMR spectrum of skeletocutin $\mathrm{E}(5)$ in $\mathrm{CDCl}_{3}(500 \mathrm{MHz})$ 


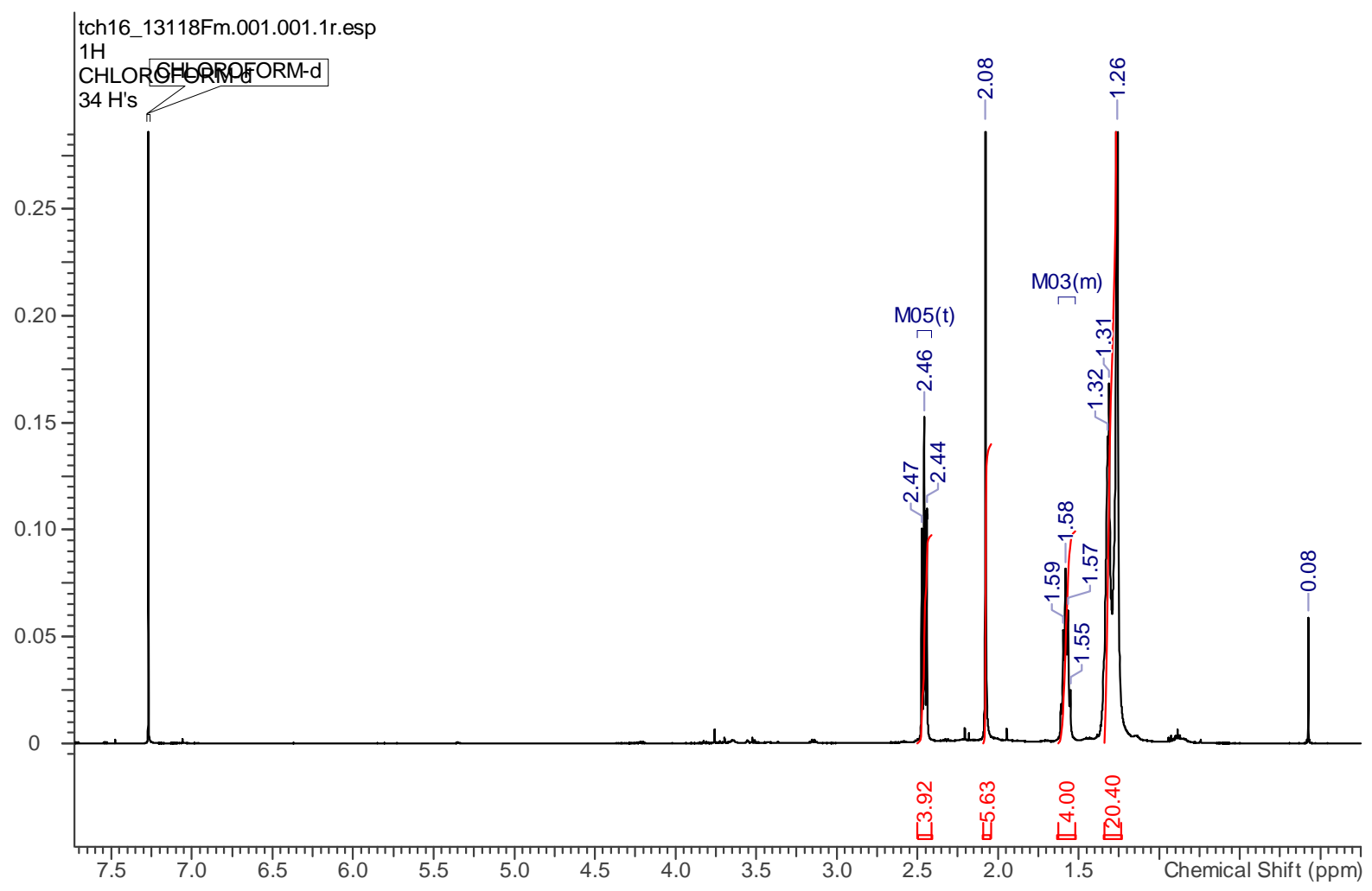

Figure S34: ${ }^{13} \mathrm{H}$ NMR spectrum of skeletocutin $\mathrm{E}(5)$ in $\mathrm{CDCl}_{3}(125 \mathrm{MHz})$

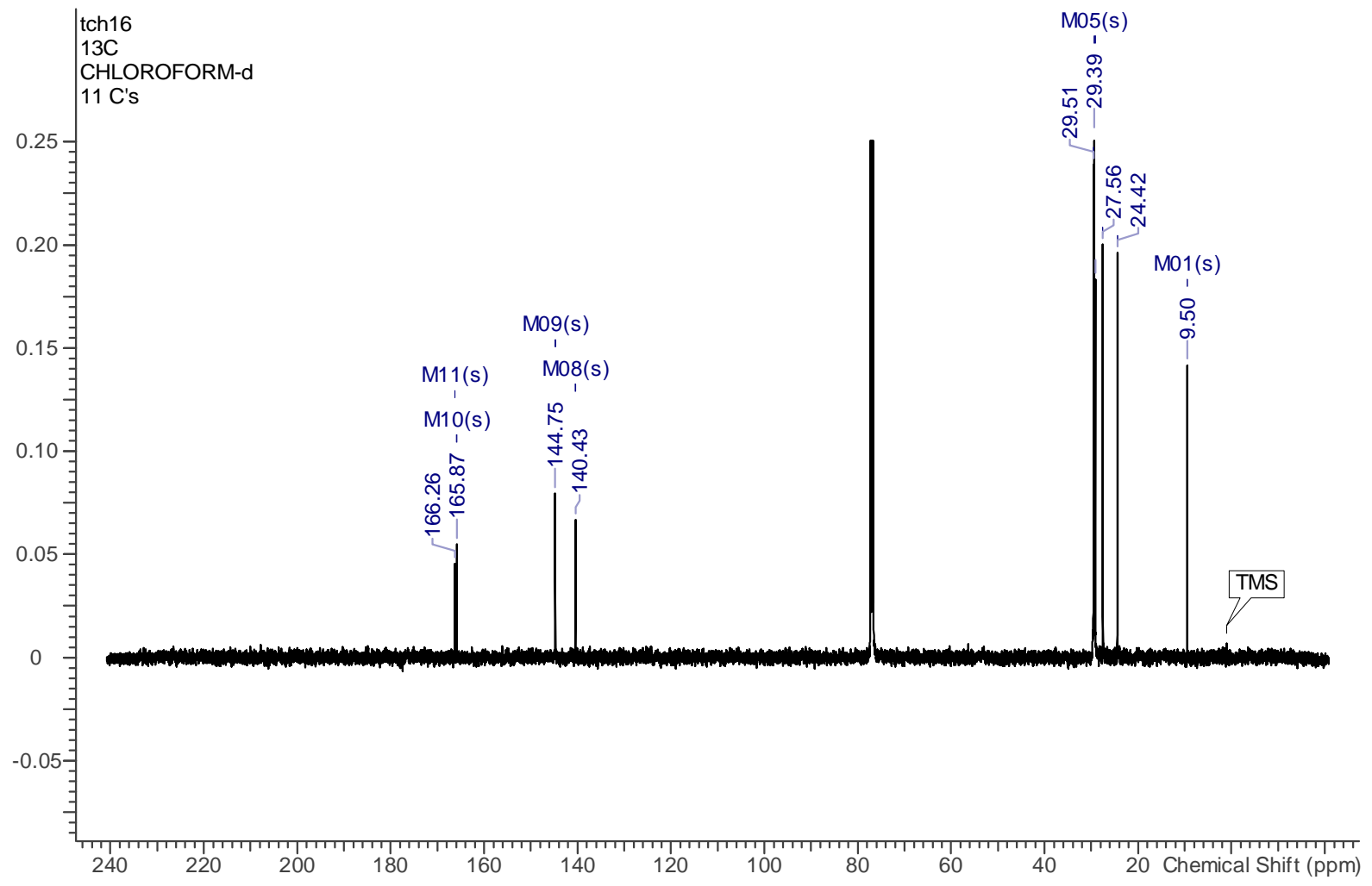

Figure S35: DEPT NMR spectrum of skeletocutin E (5) in $\mathrm{CDCl}_{3}(125 \mathrm{MHz})$ 


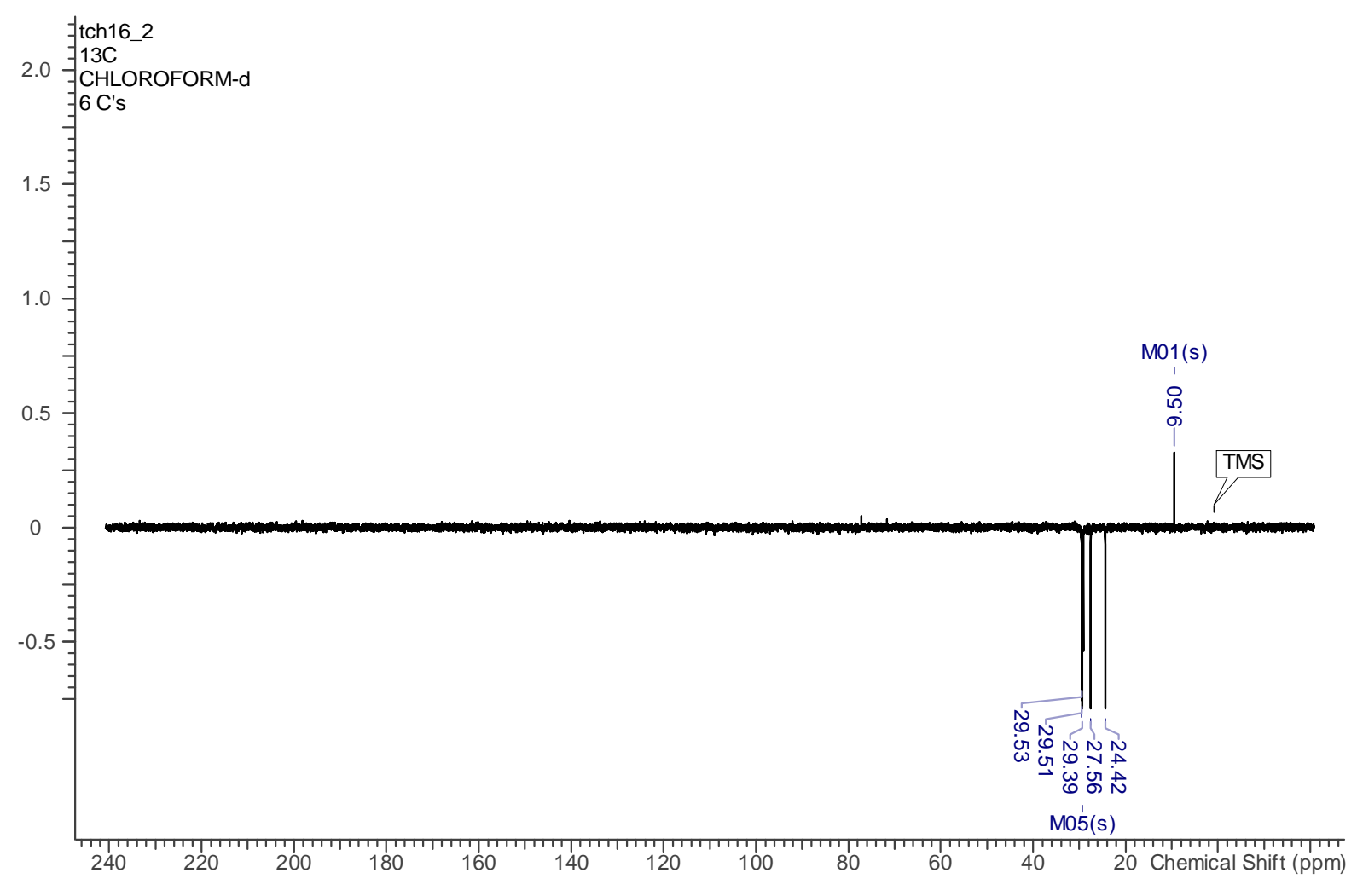

Figure S36: ${ }^{1} \mathrm{H},{ }^{13} \mathrm{C}$ HSQC NMR spectrum of skeletocutin $\mathrm{E}(5)$ in in $\mathrm{CDCl}_{3}(500 \mathrm{MHz}, 125$ $\mathrm{MHz}$ )

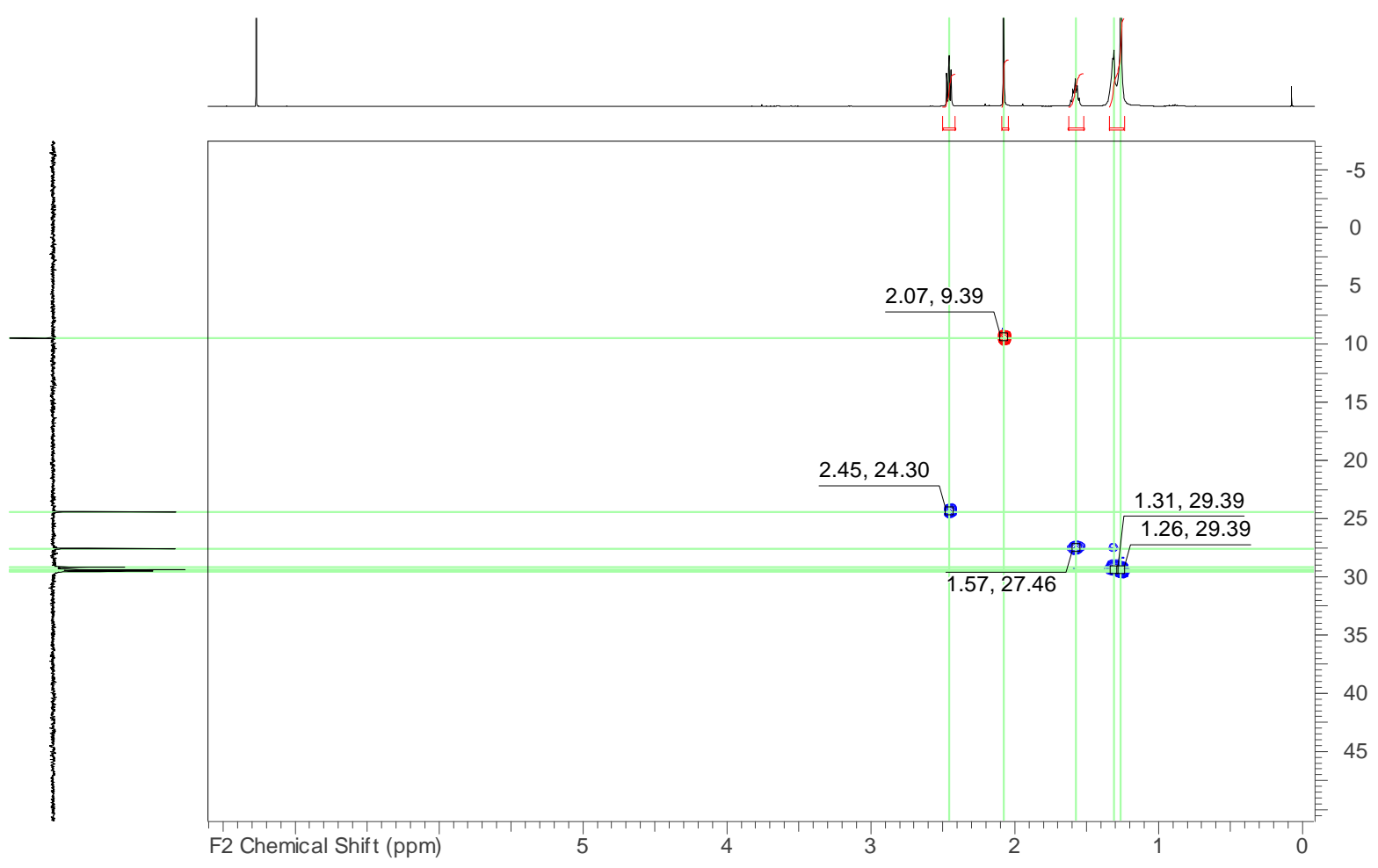

Figure S37: ${ }^{1} \mathrm{H},{ }^{13} \mathrm{C} \mathrm{HMBC}$ NMR spectrum of skeletocutin $\mathrm{E}(5)$ in $\mathrm{CDCl}_{3}(500 \mathrm{MHz}, 125$ $\mathrm{MHz}$ ) 


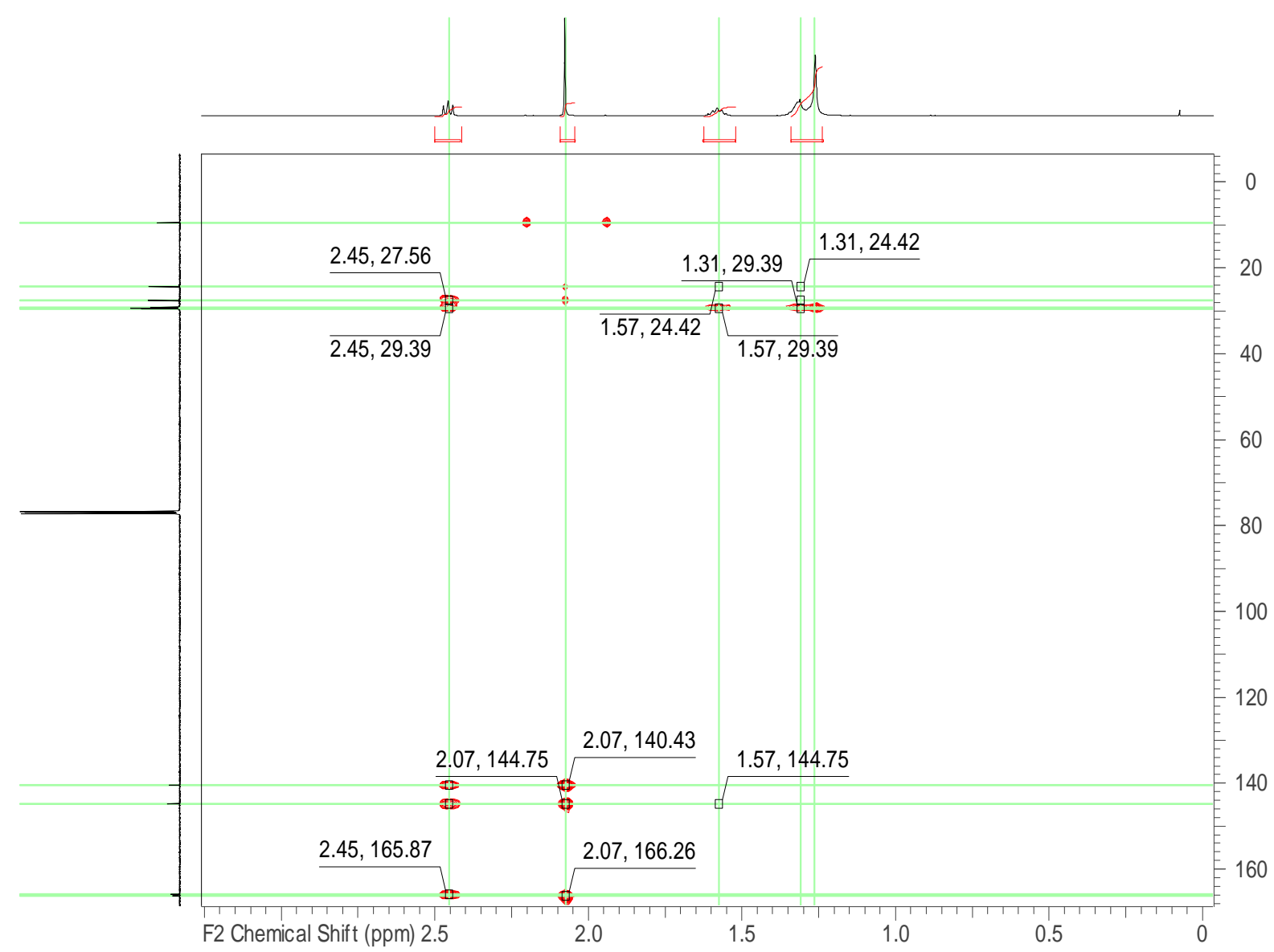

Figure S38: ${ }^{1} \mathrm{H},{ }^{1} \mathrm{H}$ COSY NMR spectrum of skeletocutin $\mathrm{E}(5)$ in $\mathrm{CDCl}_{3}(500 \mathrm{MHz})$ 


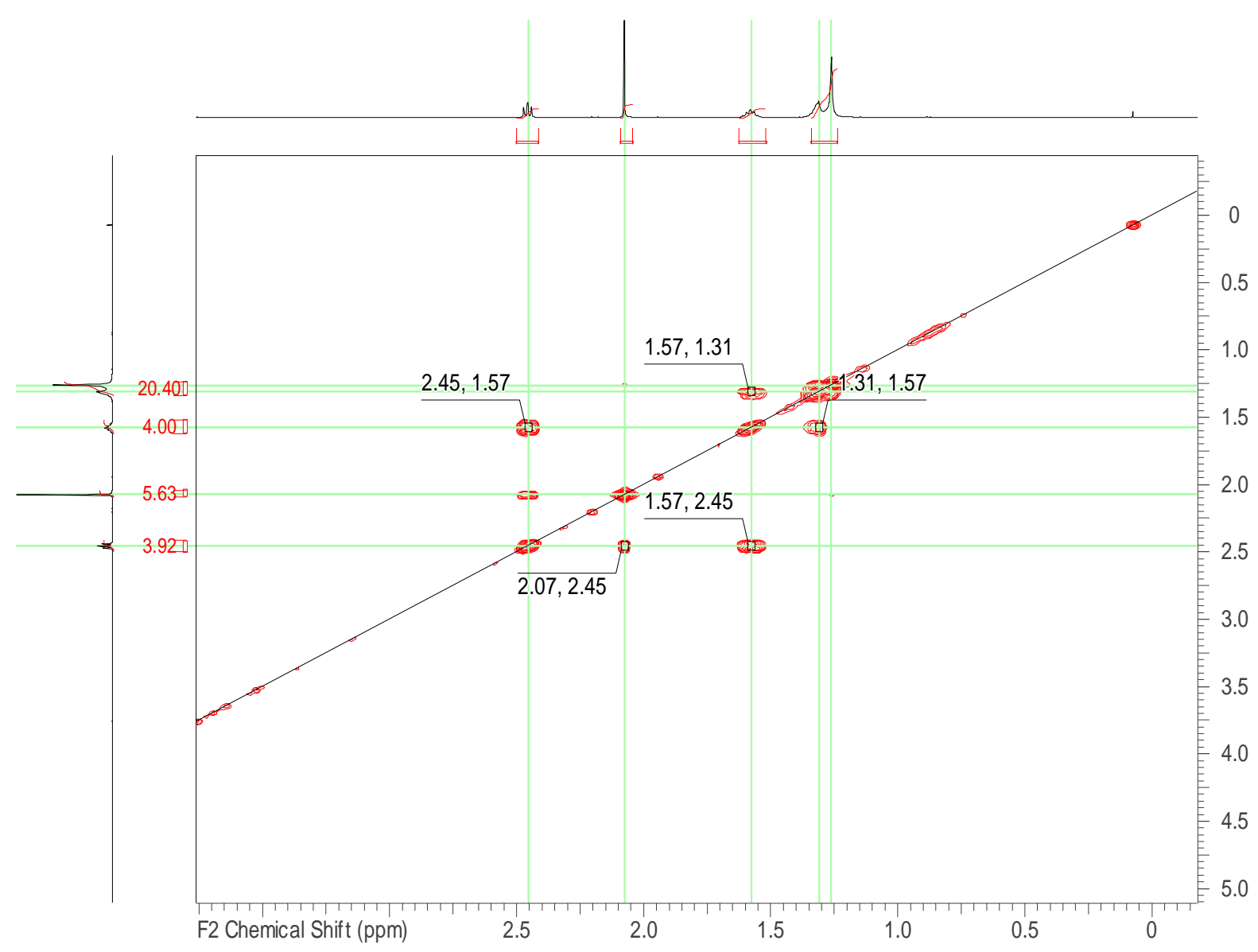

Figure S39: MS data of skeletocutin E (5)

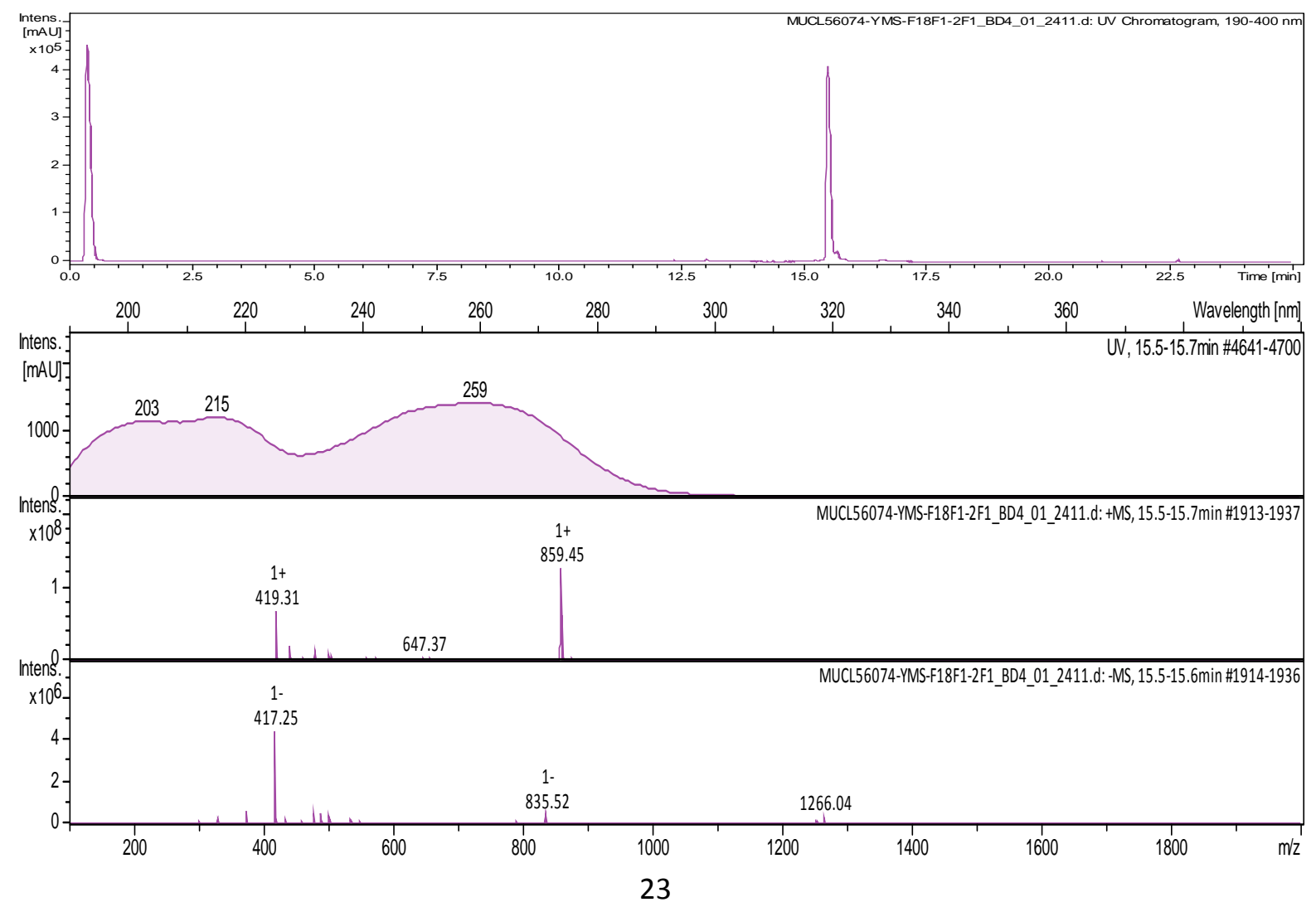


Figure S40: HRMS data of skeletocutin E (5)
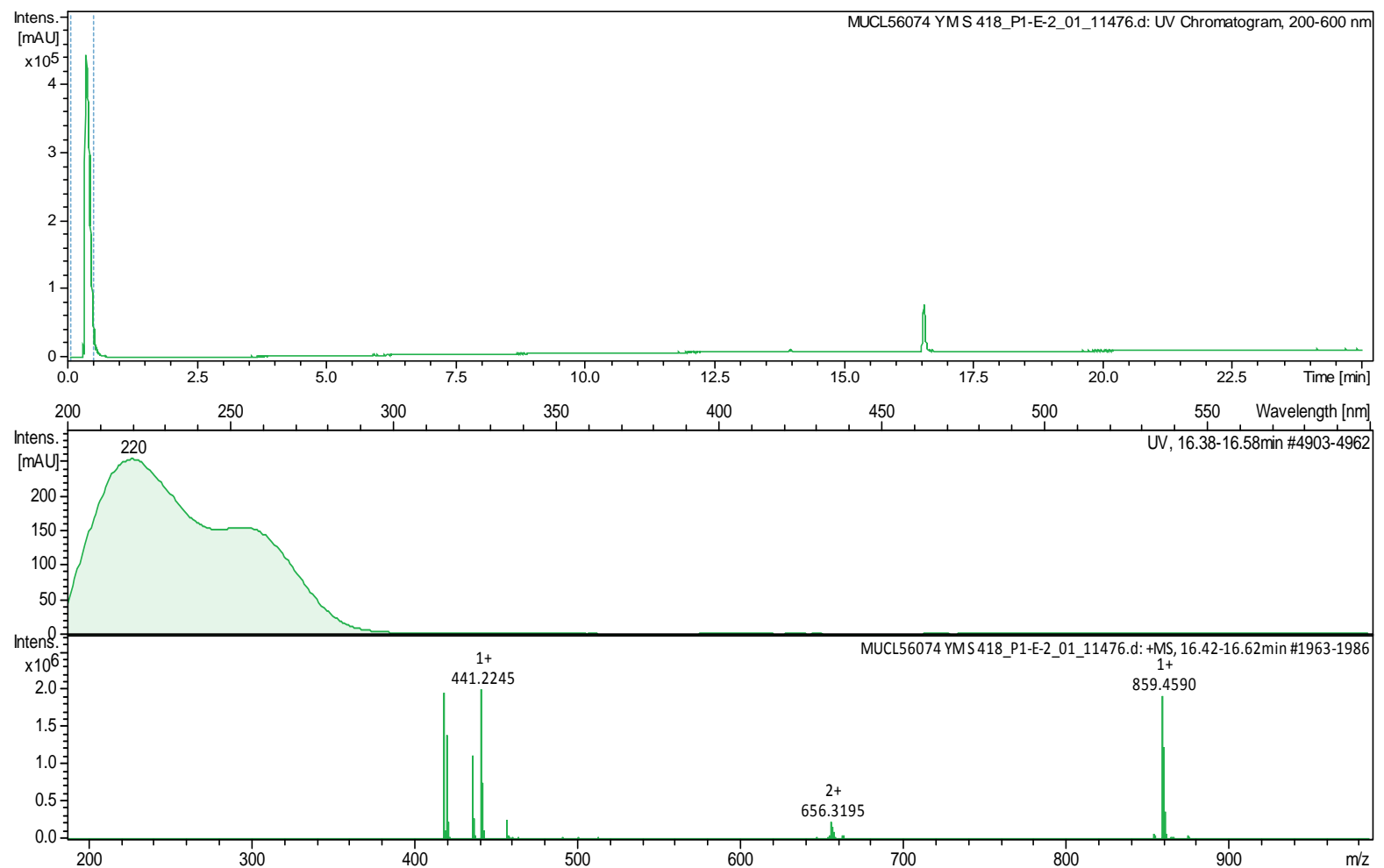

1 and 2D NMR data for tyromycin A (6)

Figure S41: ${ }^{1} \mathrm{H}$ NMR spectrum of tyromycin A (6) in DMSO (500 MHz)

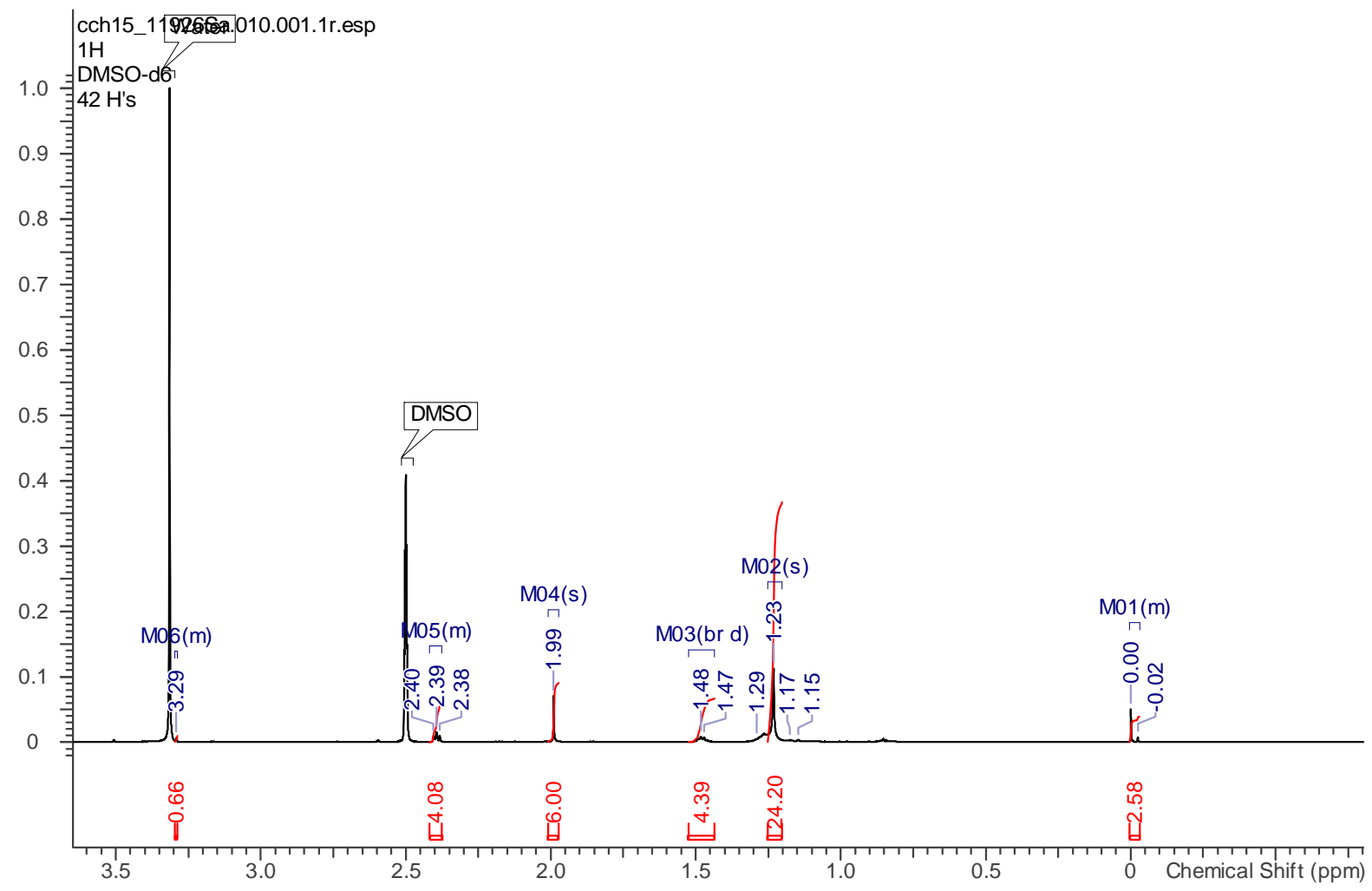


Figure S42: ${ }^{13} \mathrm{C}$ NMR spectrum of tyromycin A (6) in DMSO (125 MHz)

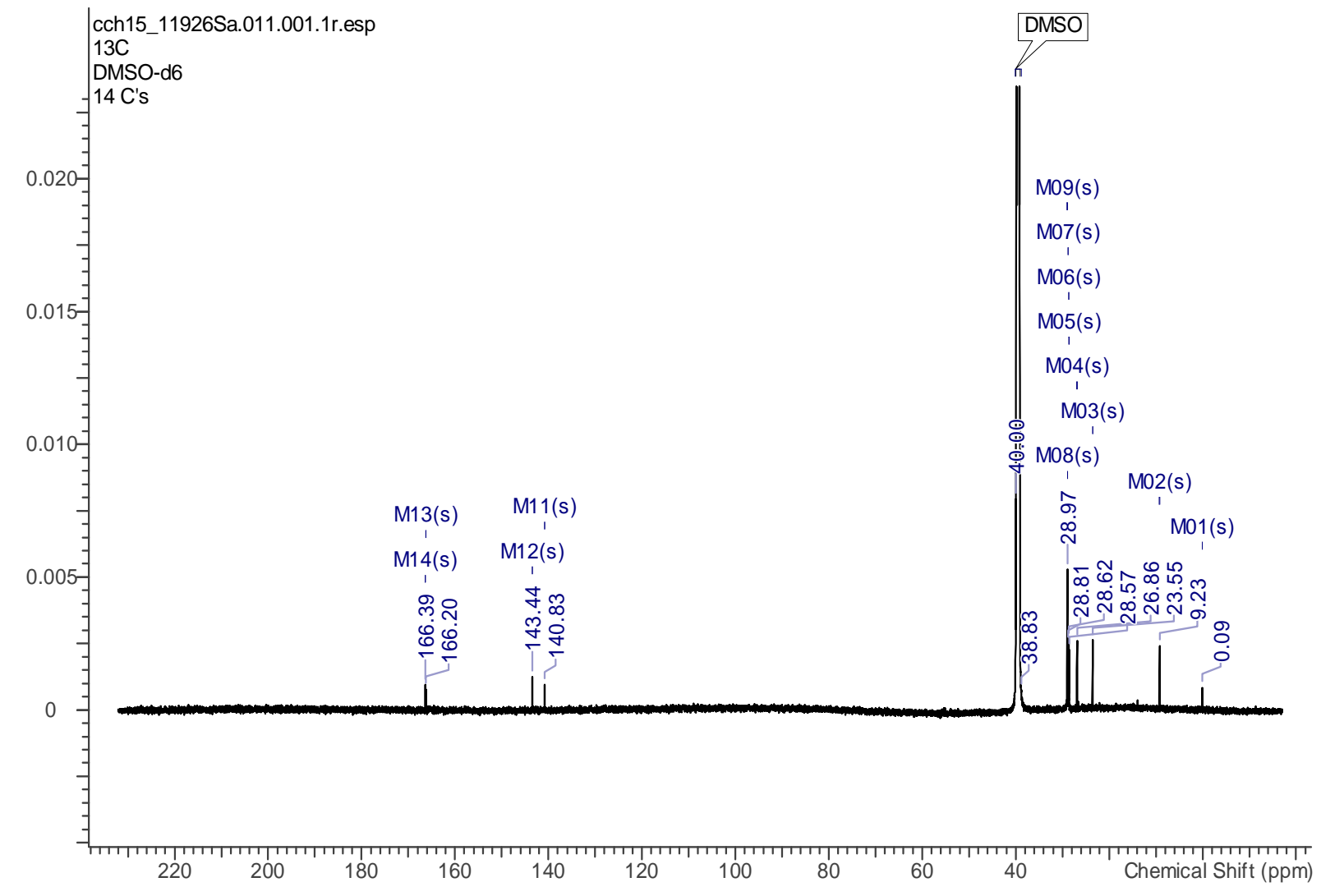

Figure S43: DEPT NMR spectrum of tyromycin A (6) in DMSO (125 MHz) 


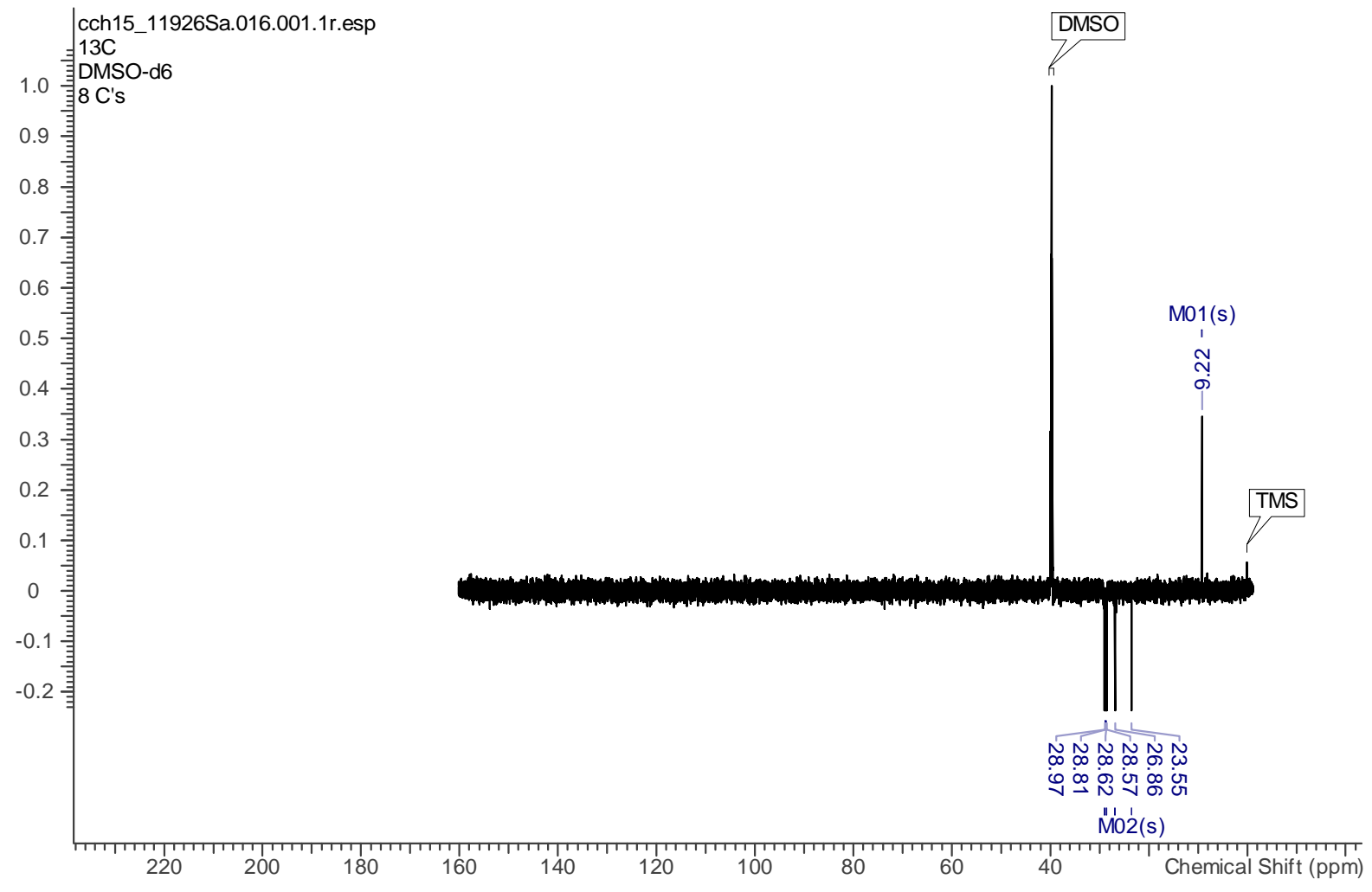

Figure S44: ${ }^{1} \mathrm{H},{ }^{13} \mathrm{C}$ HSQC NMR spectrum of tyromcin A (6) in DMSO (500 MHz, $\left.125 \mathrm{MHz}\right)$

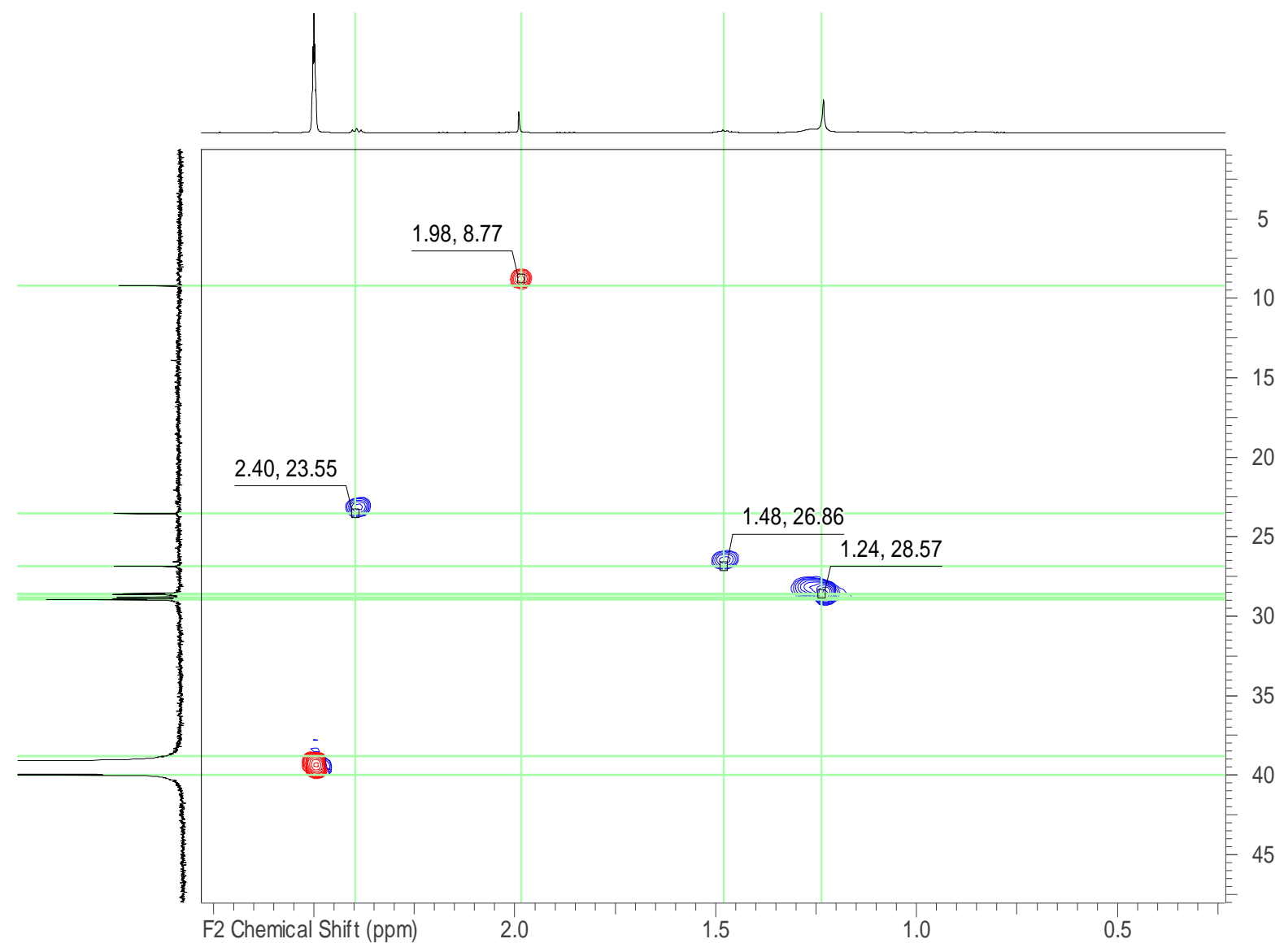


Figure S45: ${ }^{1} \mathrm{H},{ }^{13} \mathrm{C}$ HMBC NMR spectrum of tyromycin A (6) in DMSO (500 MHz, 125 $\mathrm{MHz}$ )

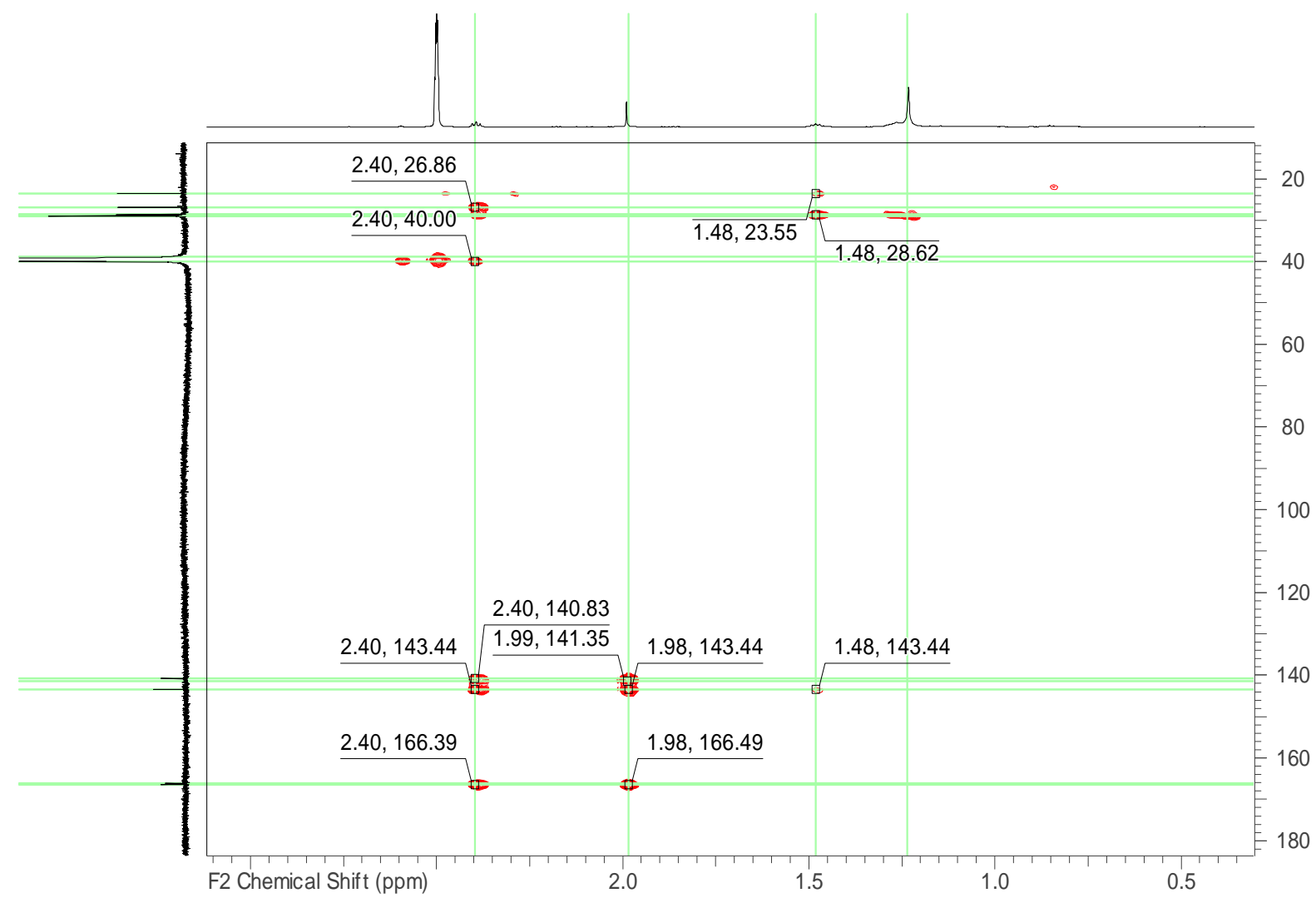

Figure S46: ${ }^{1} \mathrm{H},{ }^{1} \mathrm{H}$ COSY NMR spectrum of tyromcin A (6) in DMSO (500 MHz) 


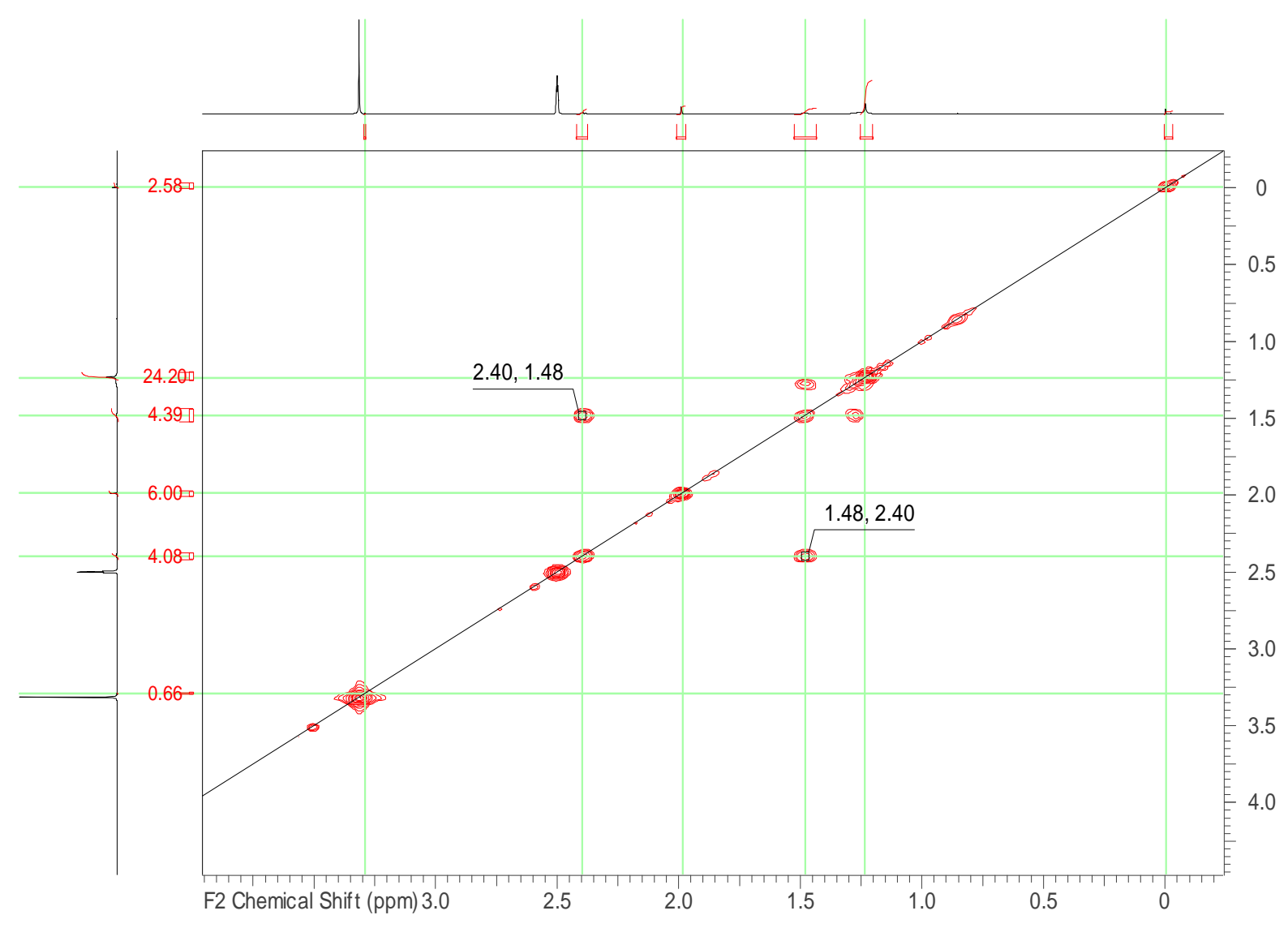

Figure S47: MS data of tyromycin A (6)
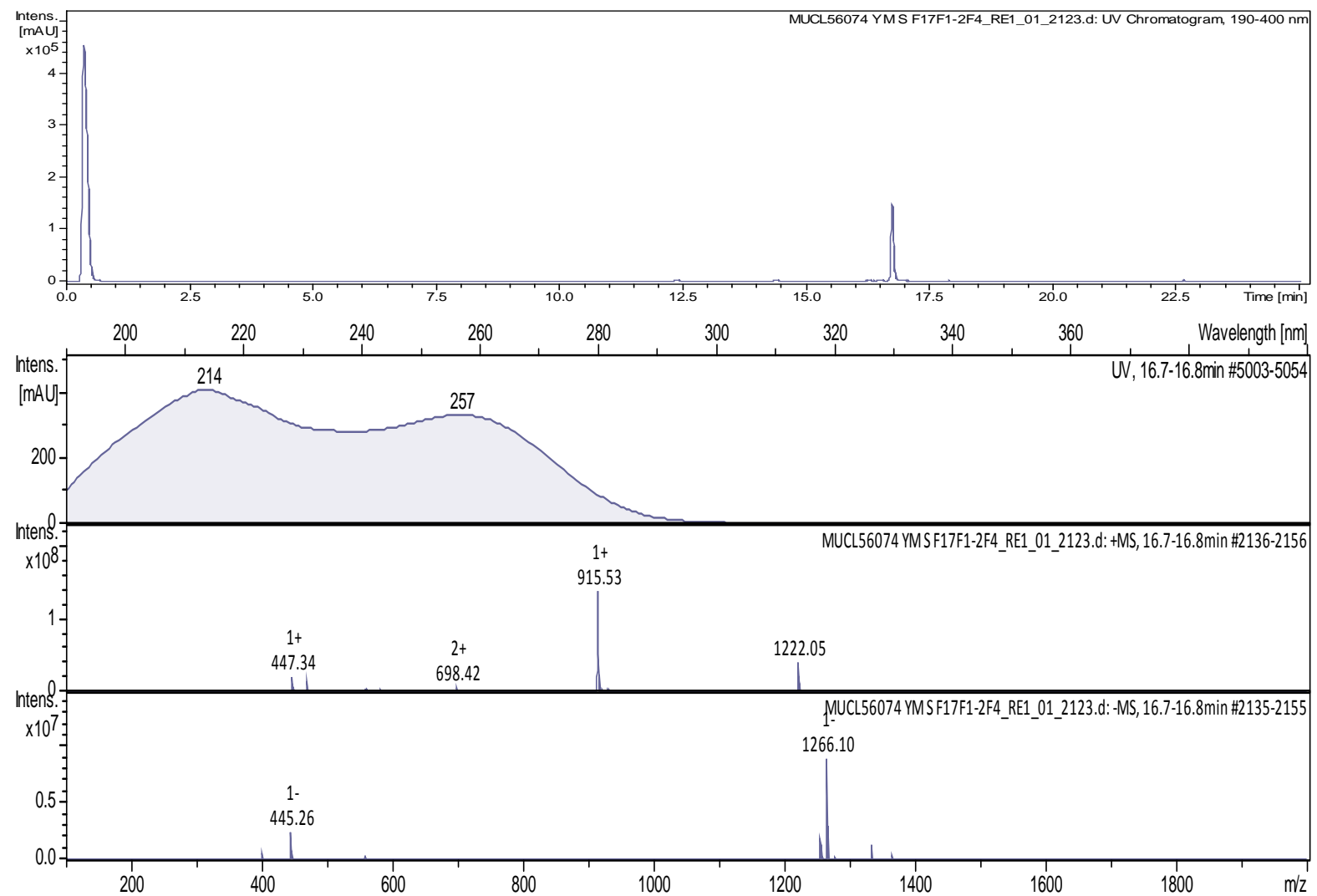

Figure S48: HRMS data of tyromycin A (6) 


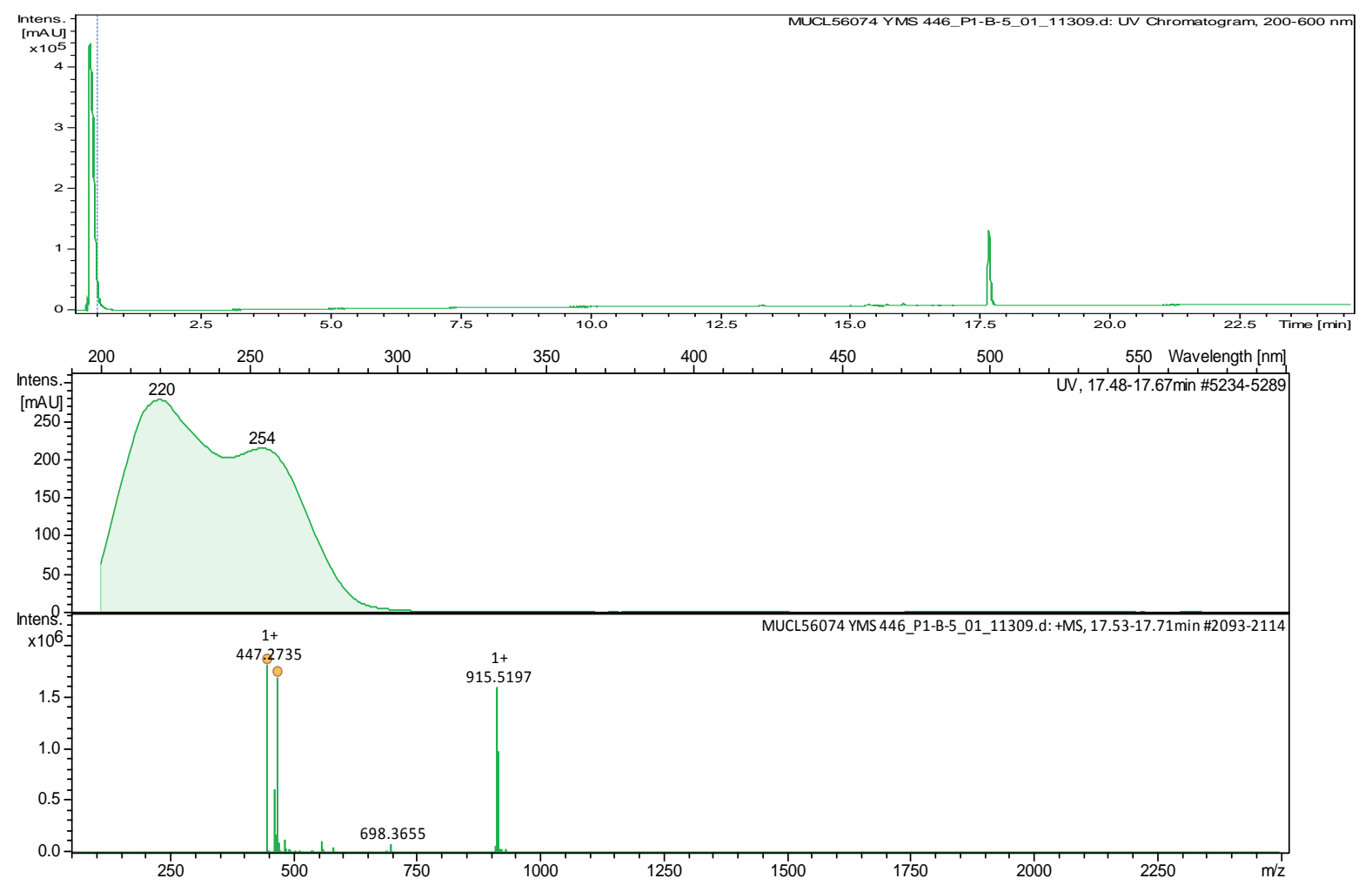

\section{1 and 2D NMR data for skeletocutin F (7)}

Figure S49: ${ }^{1} \mathrm{H}$ NMR spectrum of skeletocutin F (7) in DMSO (500 MHz)

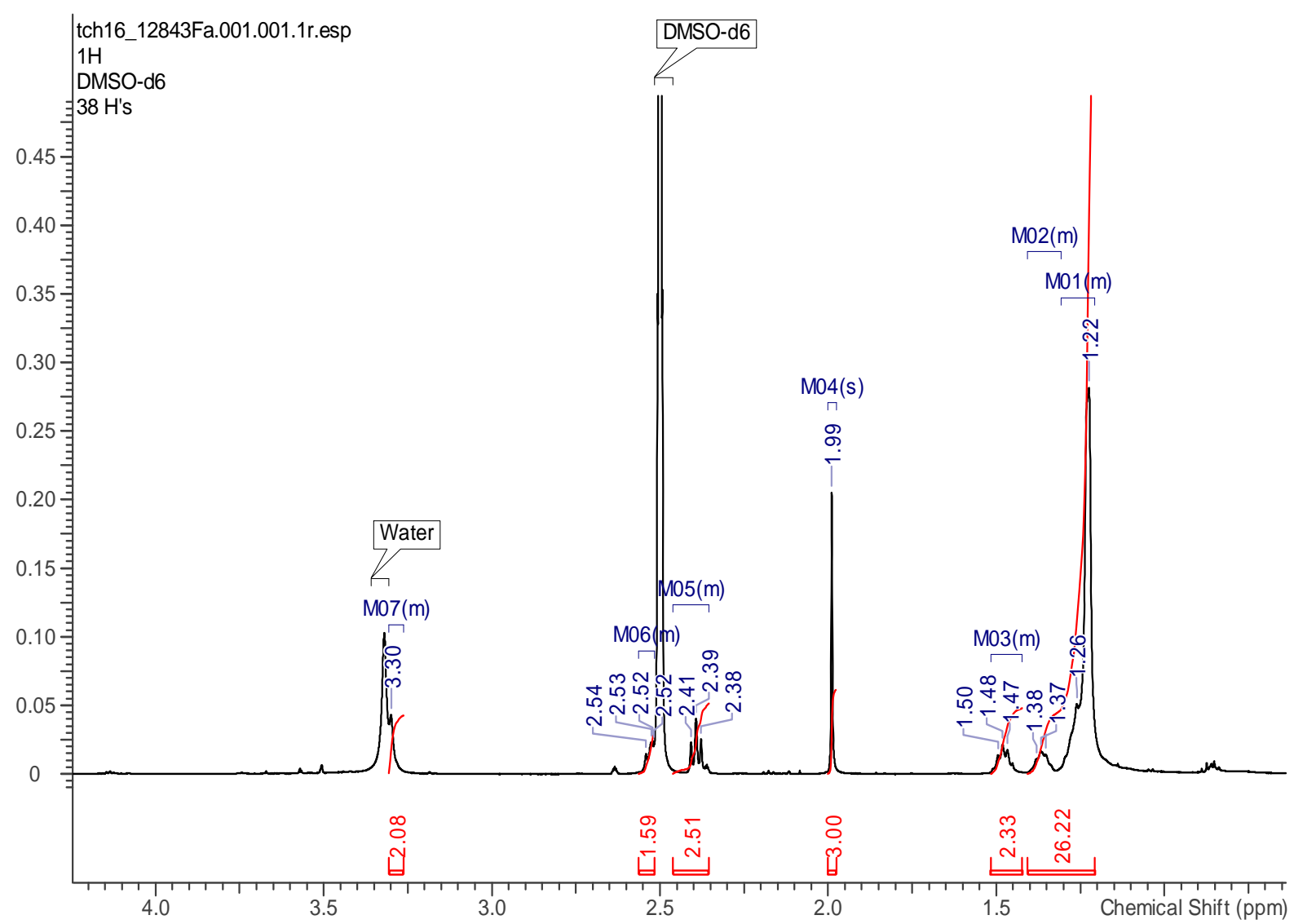

Figure S50: ${ }^{13} \mathrm{C}$ NMR spectrum of skeletocutin F (7) in DMSO (500 MHz) 


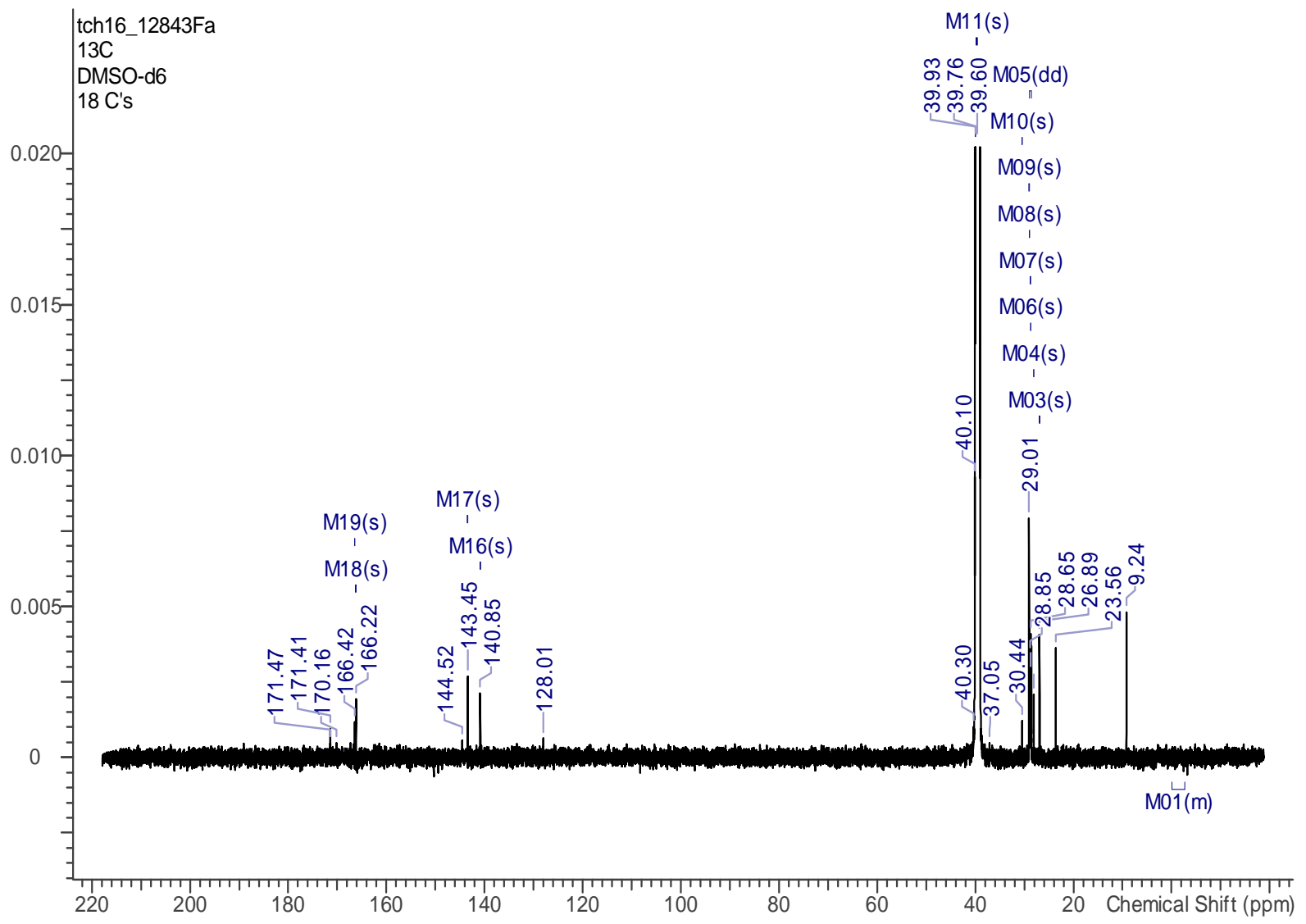

Figure S51: DEPT NMR spectrum of skeletocutin F (7) in DMSO (500 MHz)

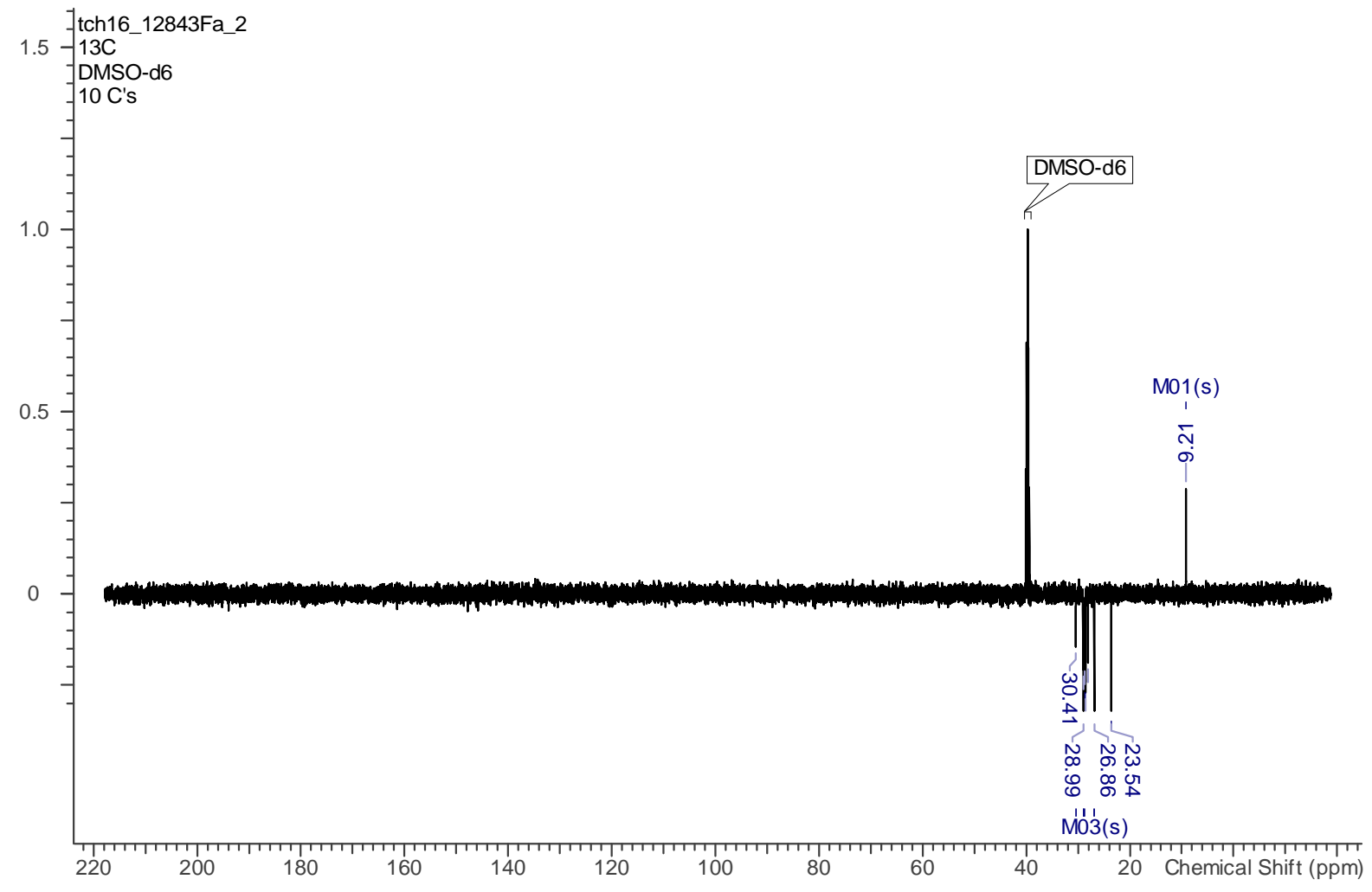


Figure S52: ${ }^{1} \mathrm{H},{ }^{13} \mathrm{C}$ HSQC NMR spectrum of skeletocutin F (7) in DMSO $(500 \mathrm{MHz}, 125$ $\mathrm{MHz})$

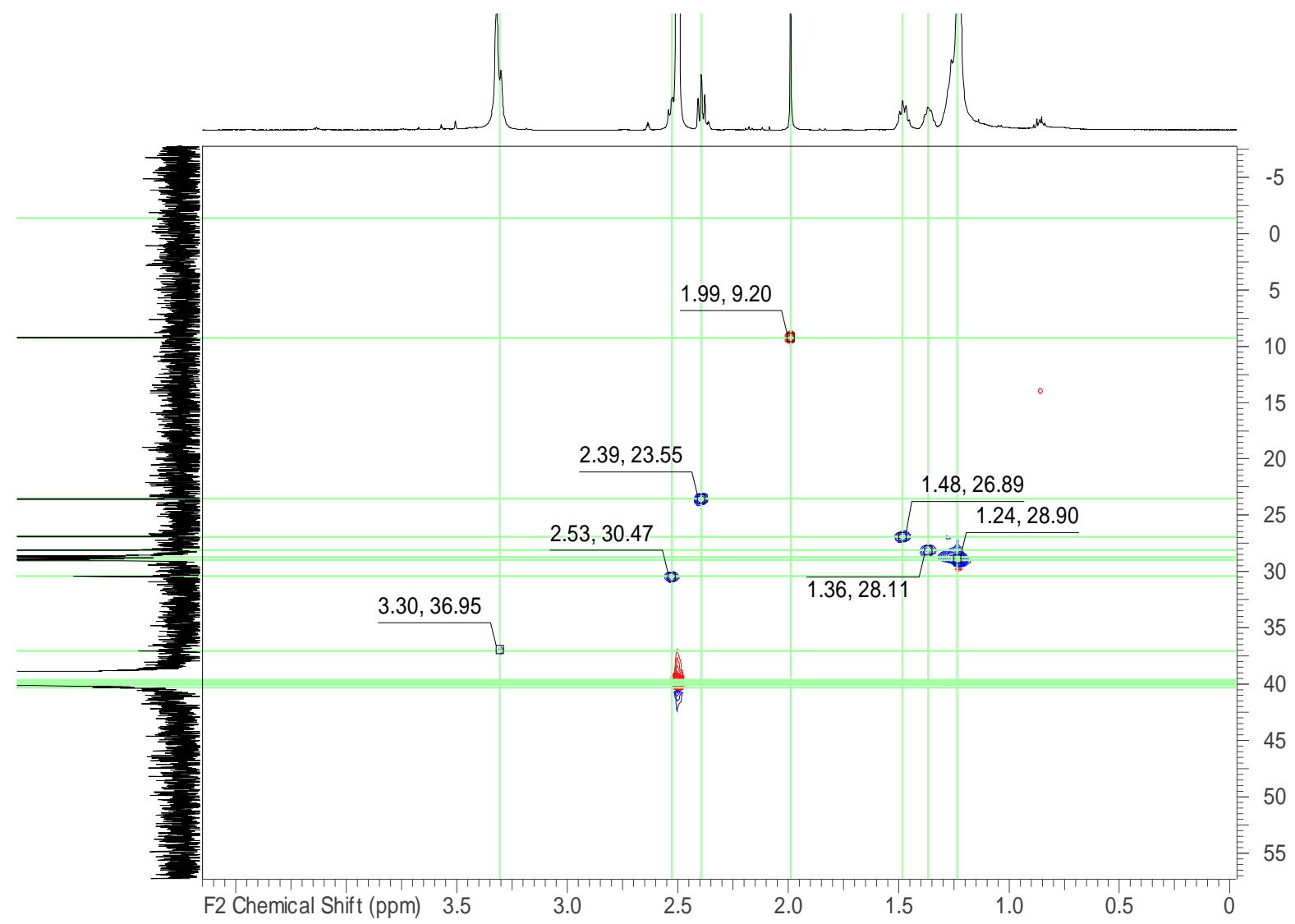

Figure S53: ${ }^{1} \mathrm{H},{ }^{13} \mathrm{C}$ HMBC NMR spectrum of skeletocutin F (7) in DMSO $(500 \mathrm{MHz}, 125$ $\mathrm{MHz}$

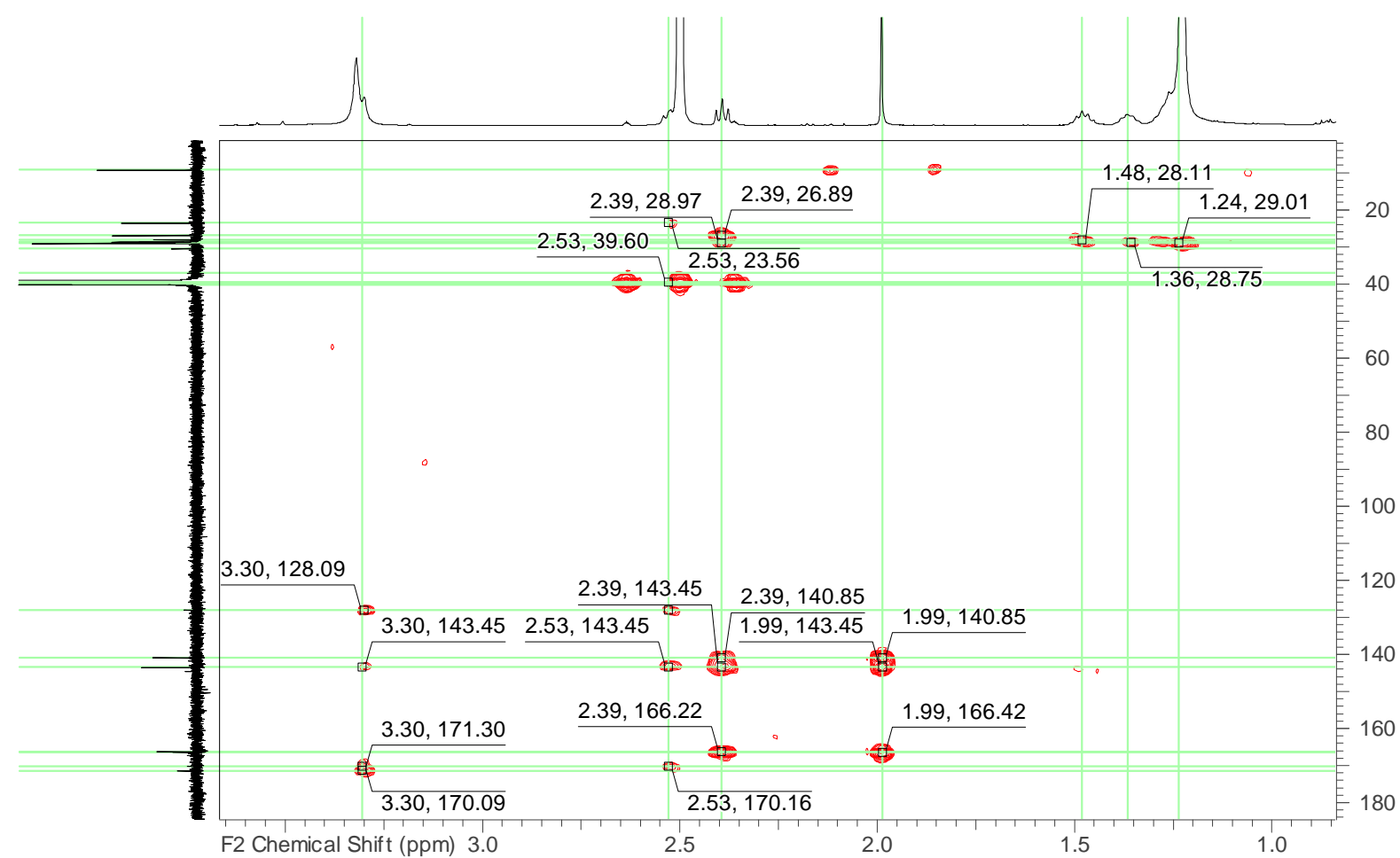


Figure S54: ${ }^{1} \mathrm{H},{ }^{1} \mathrm{H}$ COSY NMR spectrum of skeletocutin F (7) in DMSO $(500 \mathrm{MHz})$

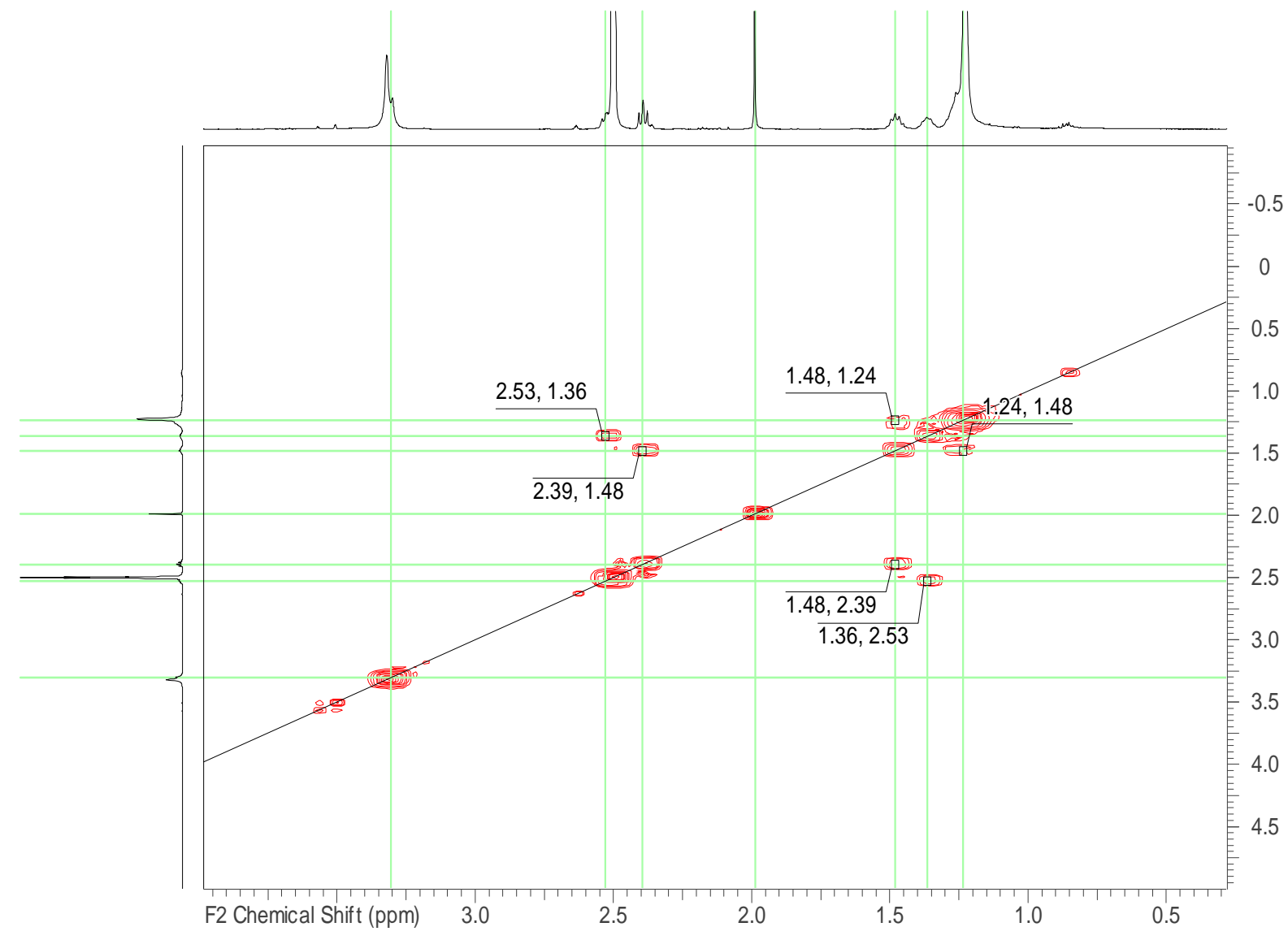

Figure S55: ${ }^{1} \mathrm{H},{ }^{1} \mathrm{H}$ ROESY NMR spectrum of skeletocutin F (7) in DMSO (500 MHz)

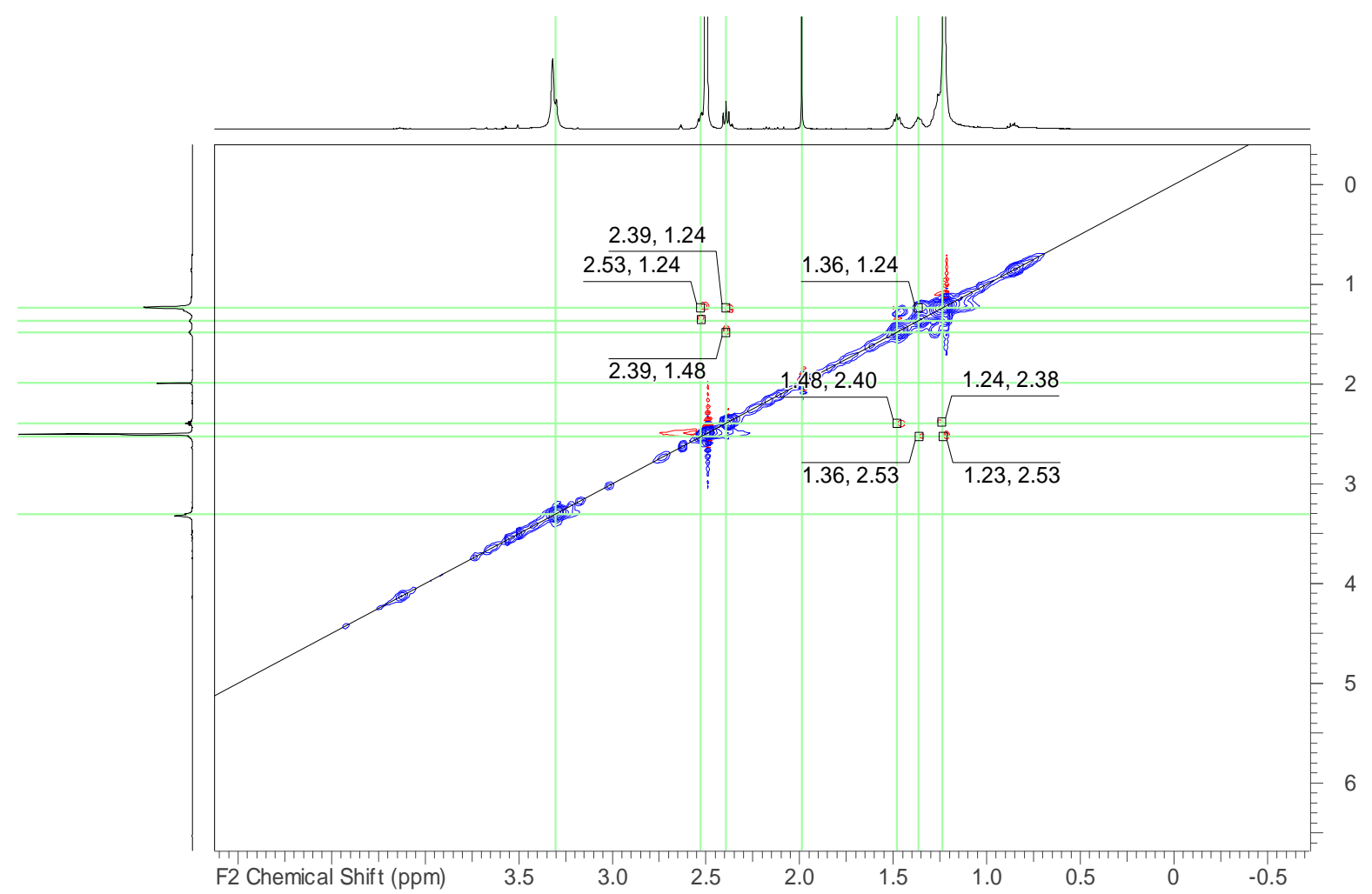


Figure S56: MS data of skeletocutin F (7)
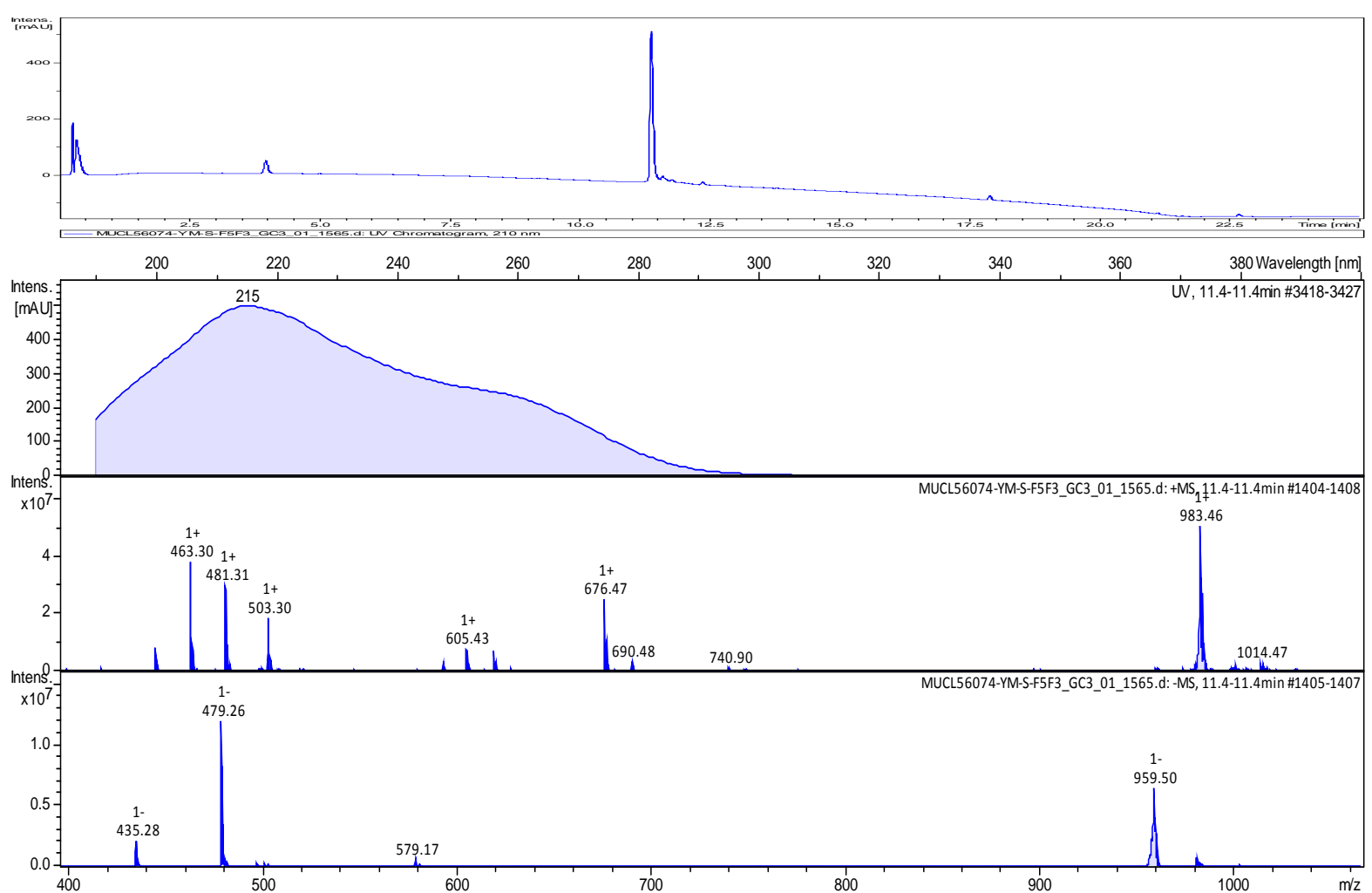

Figure S57: HRMS data of skeletocutin F (7)
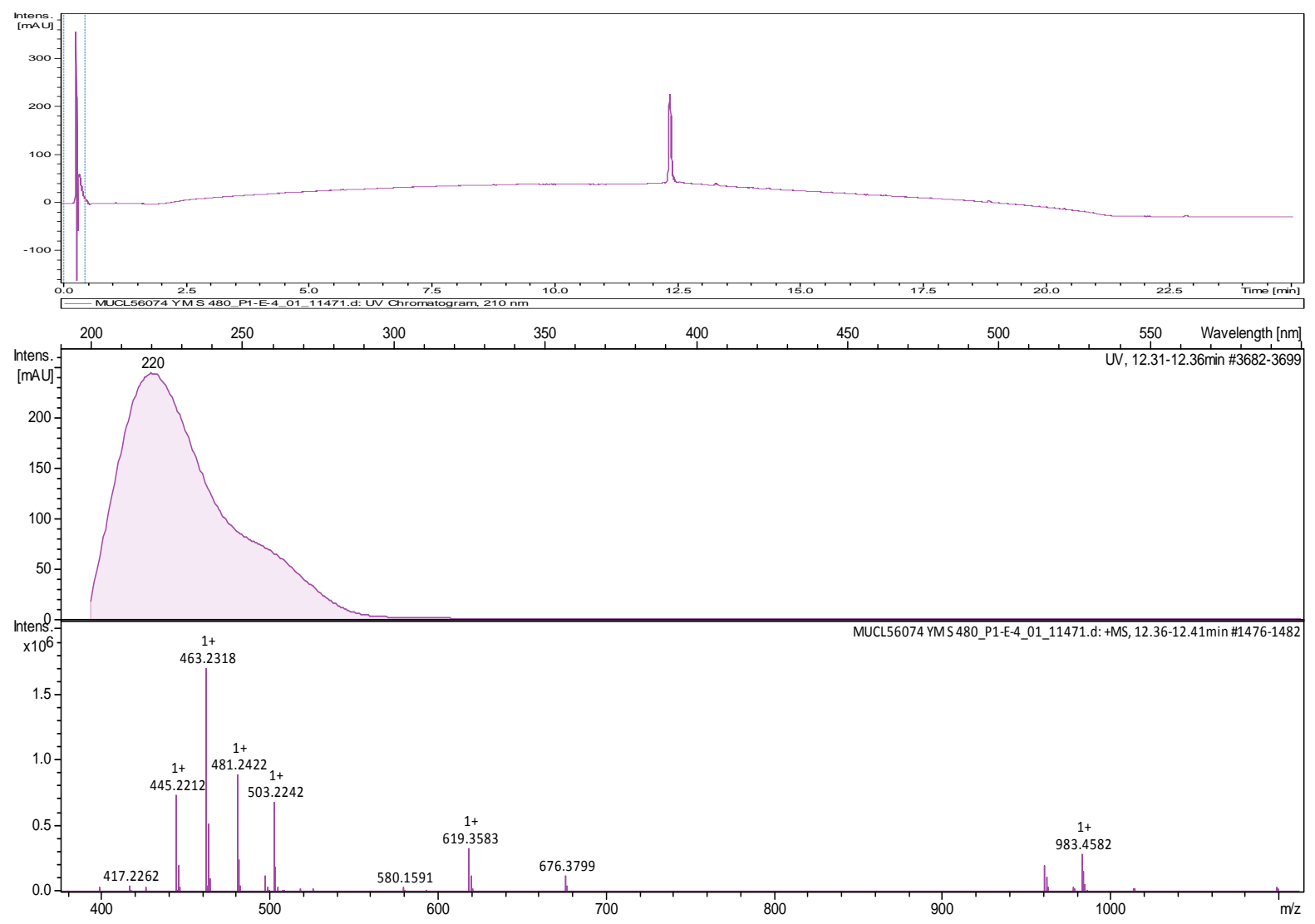


\section{1 and 2D NMR data for skeletocutin G (8)}

Figure S58: ${ }^{1} \mathrm{H}$ NMR spectrum of skeletocutin $\mathrm{G}(\mathbf{8})$ in $\mathrm{CDCl}_{3}(500 \mathrm{MHz})$

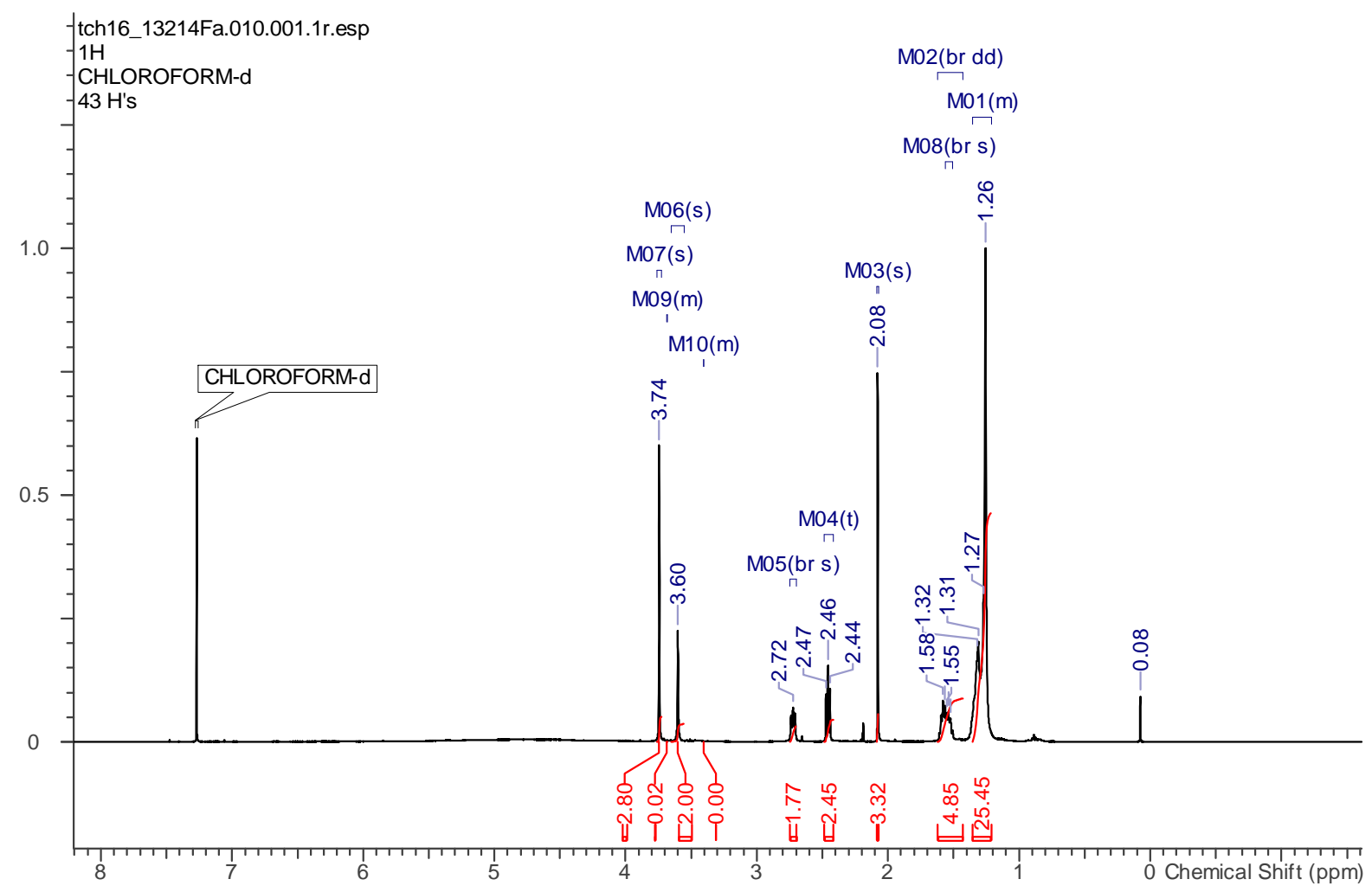

Figure S59: ${ }^{1} \mathrm{H}$ NMR spectrum of skeletocutin $\mathrm{G}(\mathbf{8})$ in $\mathrm{CDCl}_{3}(125 \mathrm{MHz})$ 


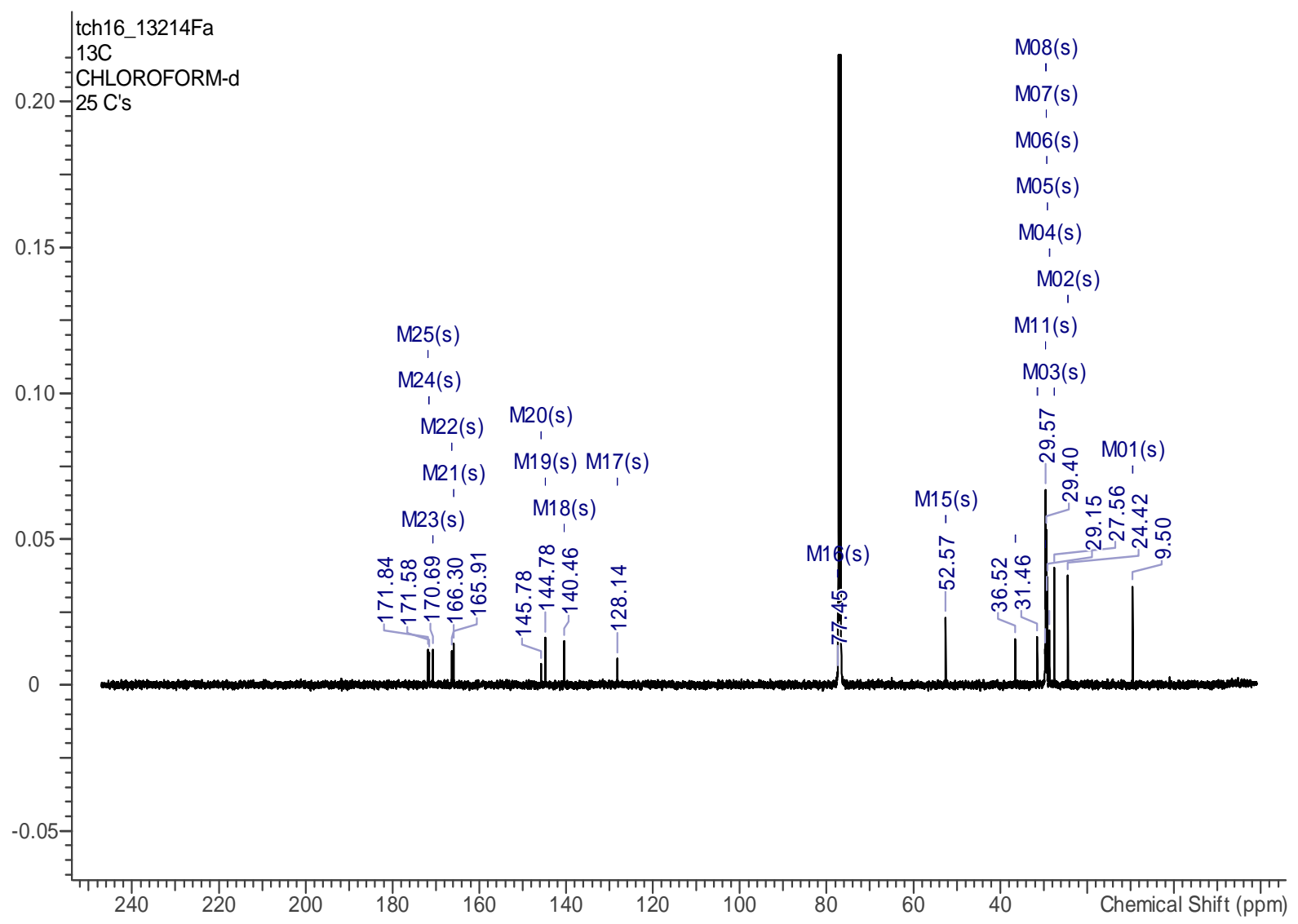

Figure S60: DEPT NMR spectrum of skeletocutin $\mathrm{G}(\mathbf{8})$ in $\mathrm{CDCl}_{3}(125 \mathrm{MHz})$

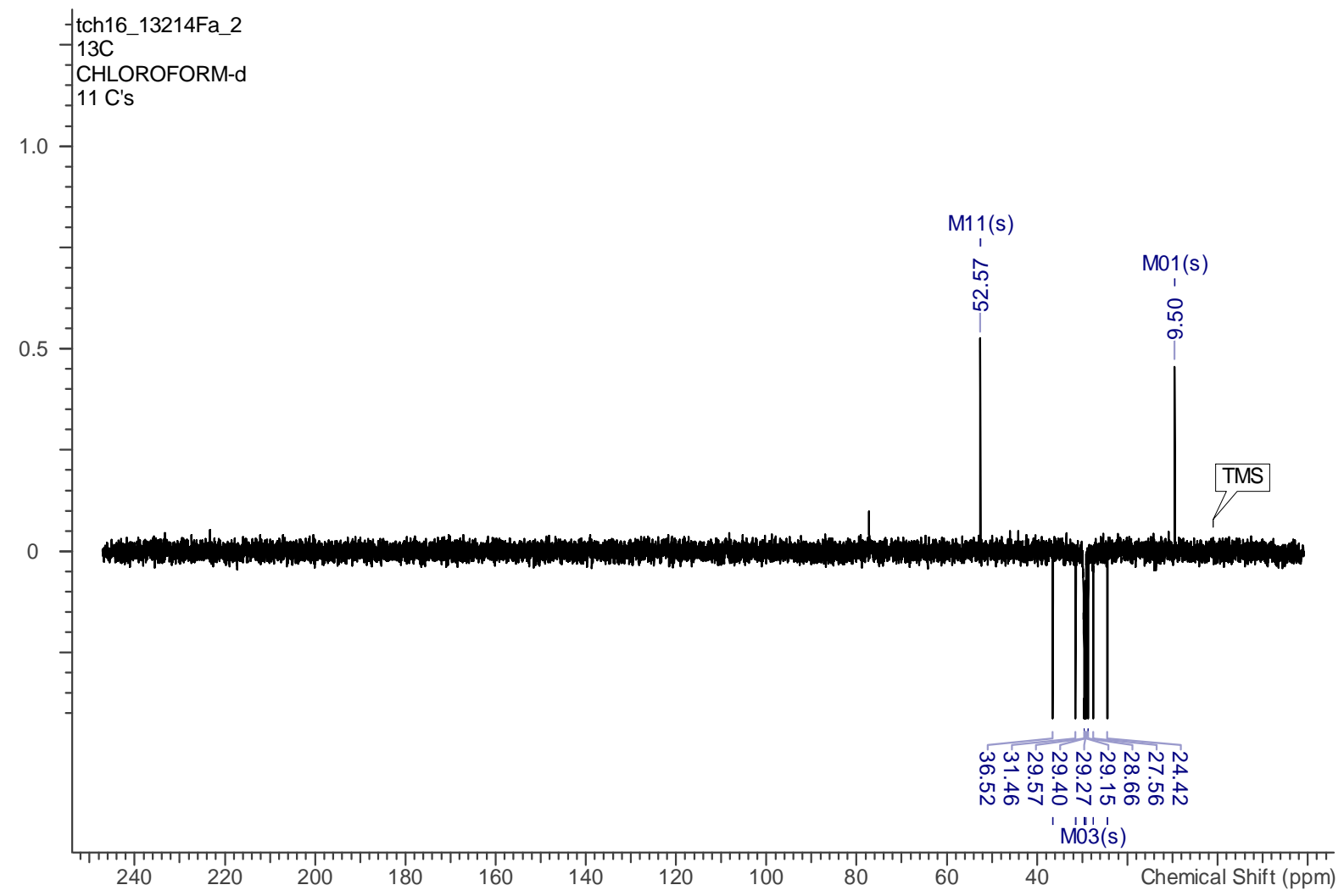


Figure S61: ${ }^{1} \mathrm{H},{ }^{13} \mathrm{C}$ HSQC NMR spectrum of skeletocutin $\mathrm{G}(\mathbf{8})$ in $\mathrm{CDCl}_{3}(500 \mathrm{MHz}, 125$ $\mathrm{MHz})$

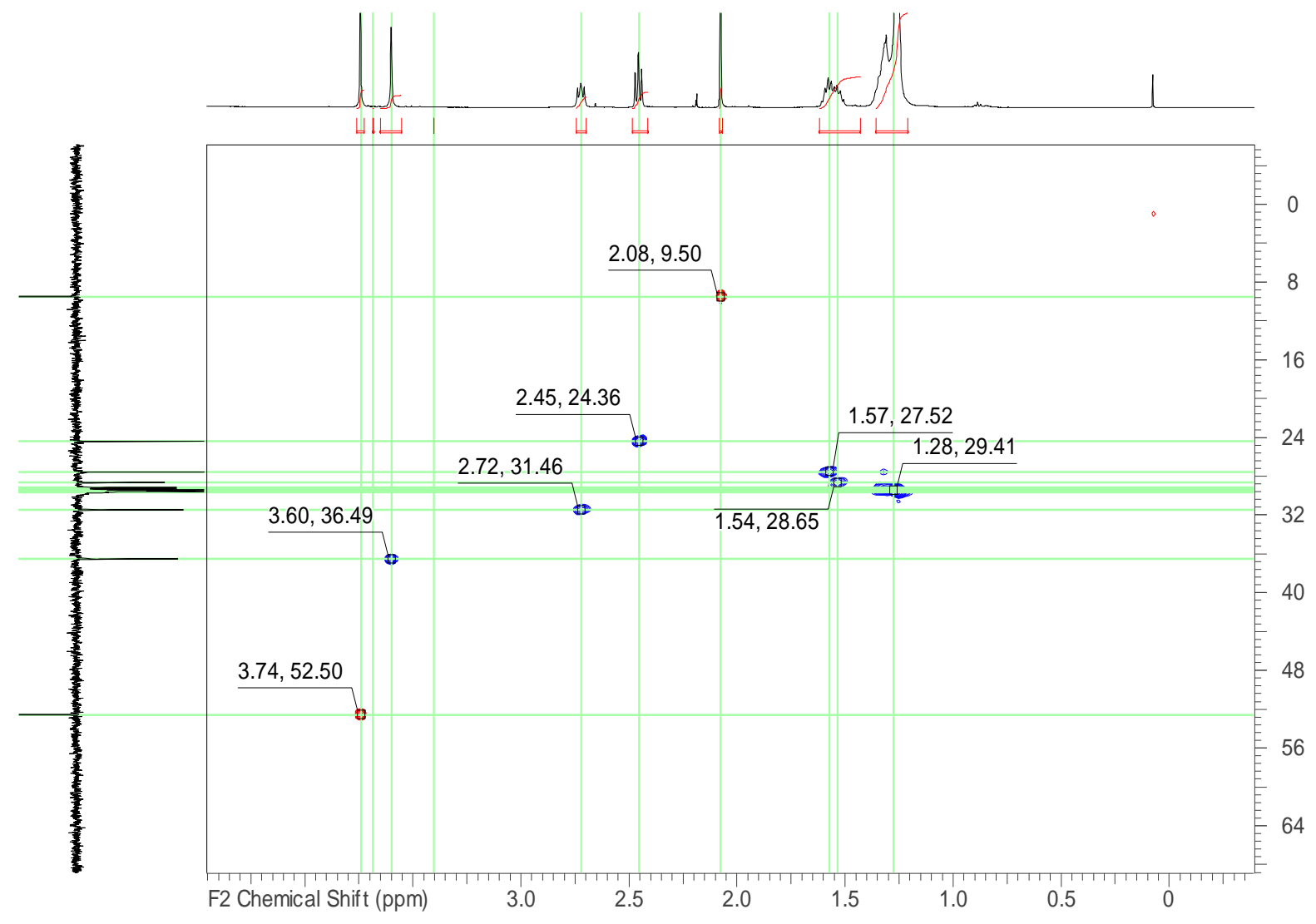

Figure S62: ${ }^{1} \mathrm{H},{ }^{13} \mathrm{C}$ HMBC NMR spectrum of skeletocutin $\mathrm{G}(\mathbf{8})$ in $\mathrm{CDCl}_{3}(500 \mathrm{MHz}, 125$ $\mathrm{MHz})$ 


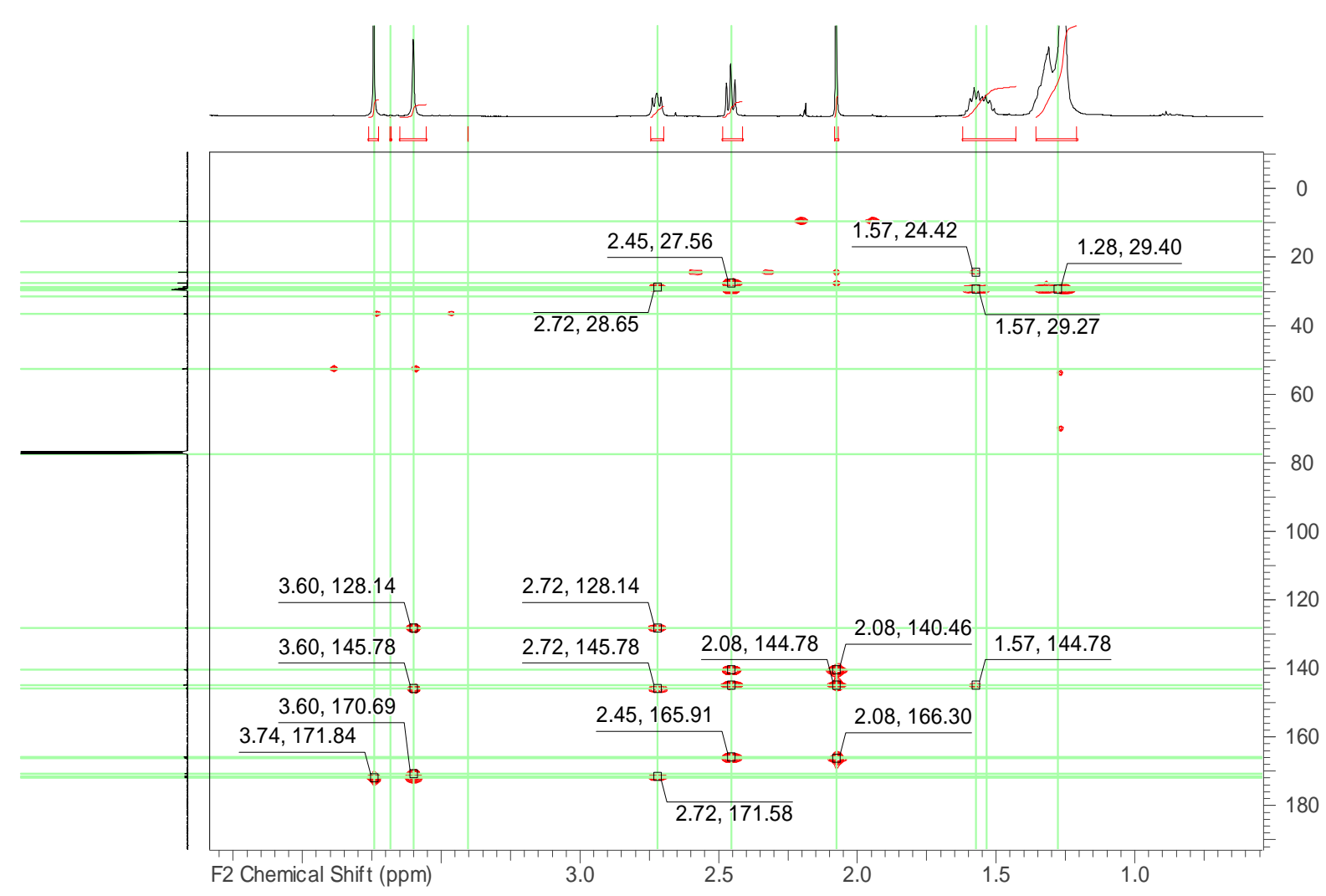

Figure S63: ${ }^{1} \mathrm{H},{ }^{1} \mathrm{H}$ COSY NMR spectrum of skeletocutin $\mathrm{G}(\mathbf{8})$ in $\mathrm{CDCl}_{3}(500 \mathrm{MHz})$

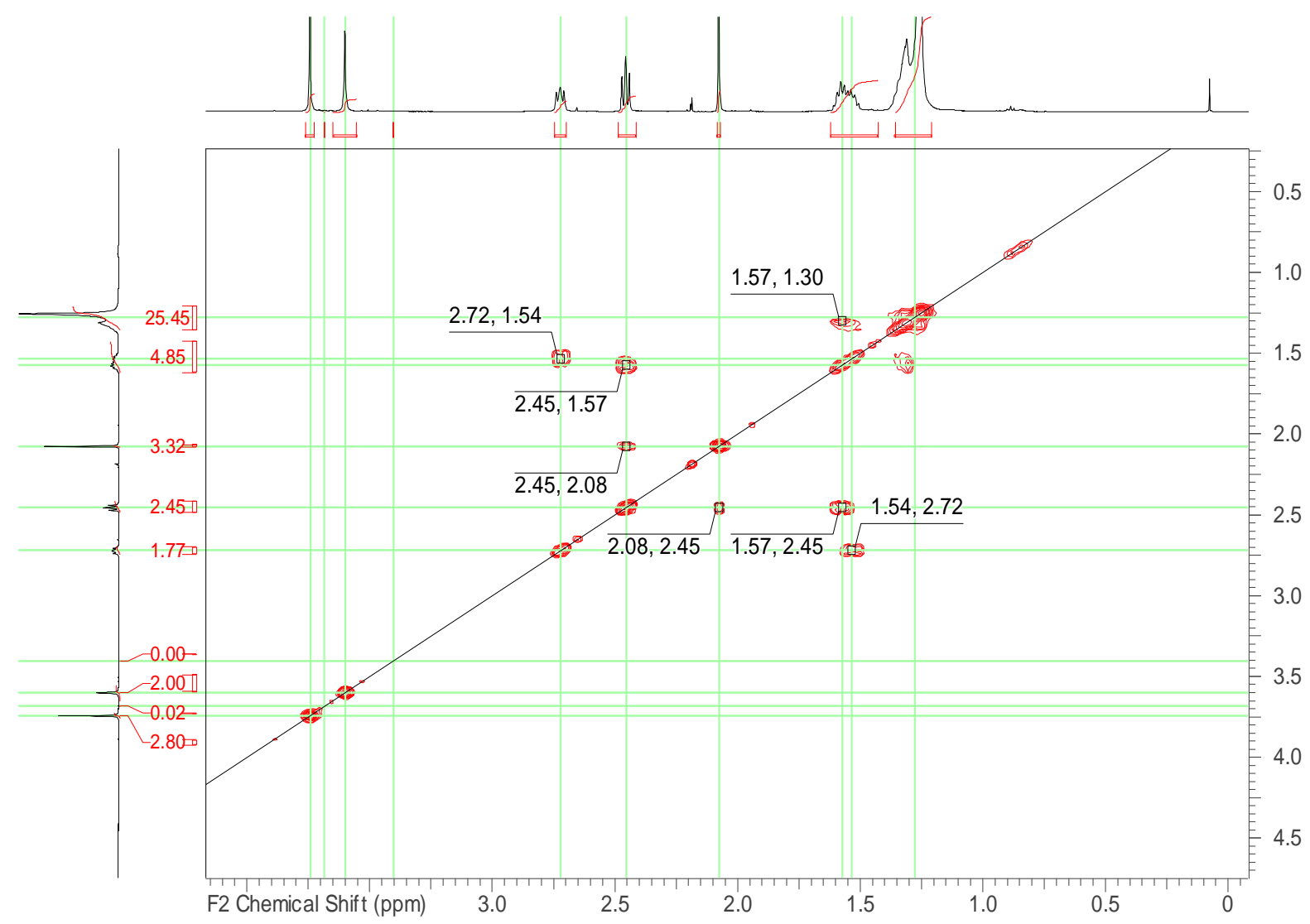

Figure S64: ${ }^{1} \mathrm{H},{ }^{1} \mathrm{H}$ ROESY NMR spectrum of skeletocutin $\mathrm{G}(\mathbf{8})$ in $\mathrm{CDCl}_{3}(500 \mathrm{MHz})$ 


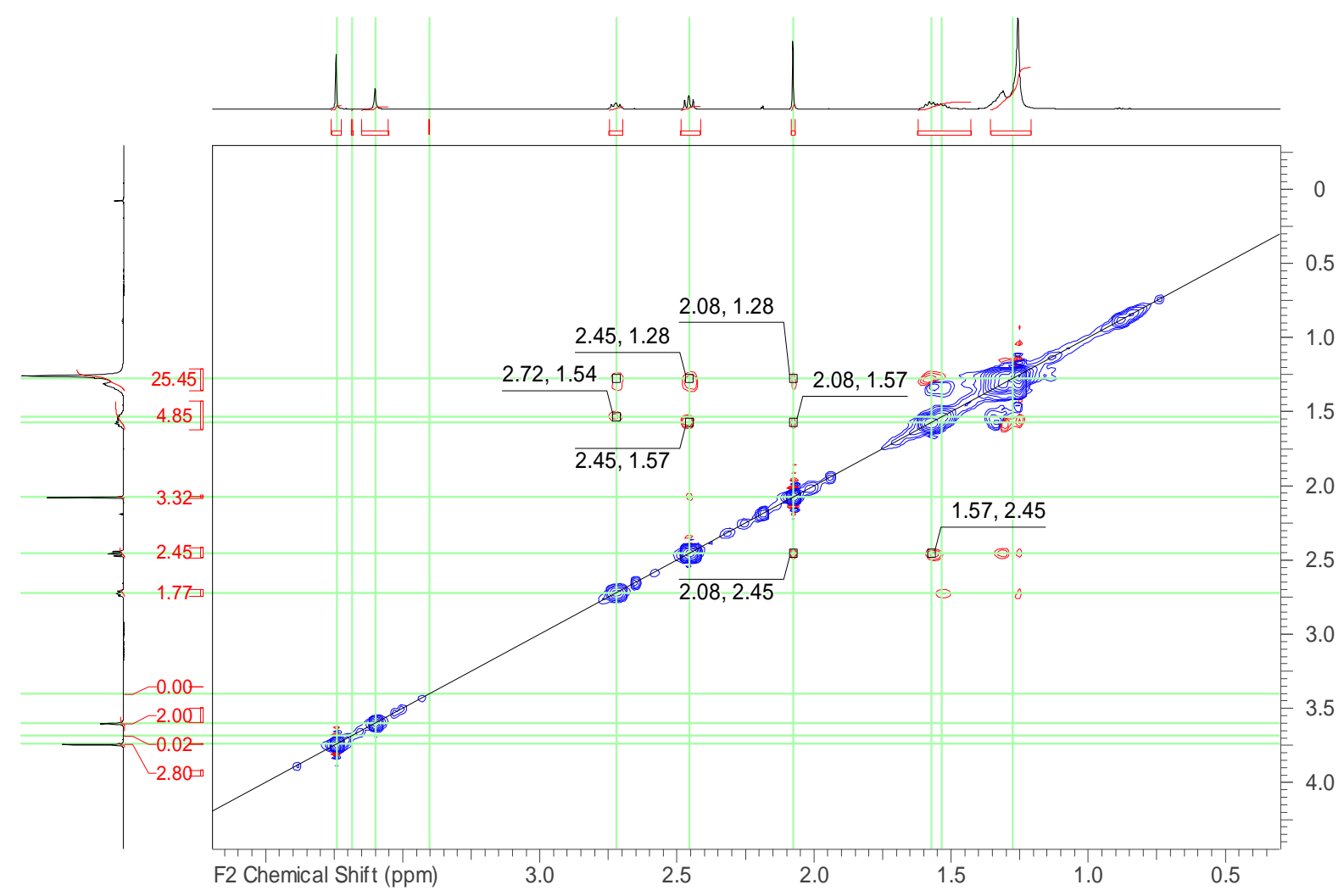


Figure S65: MS data of skeletocutin G (8)
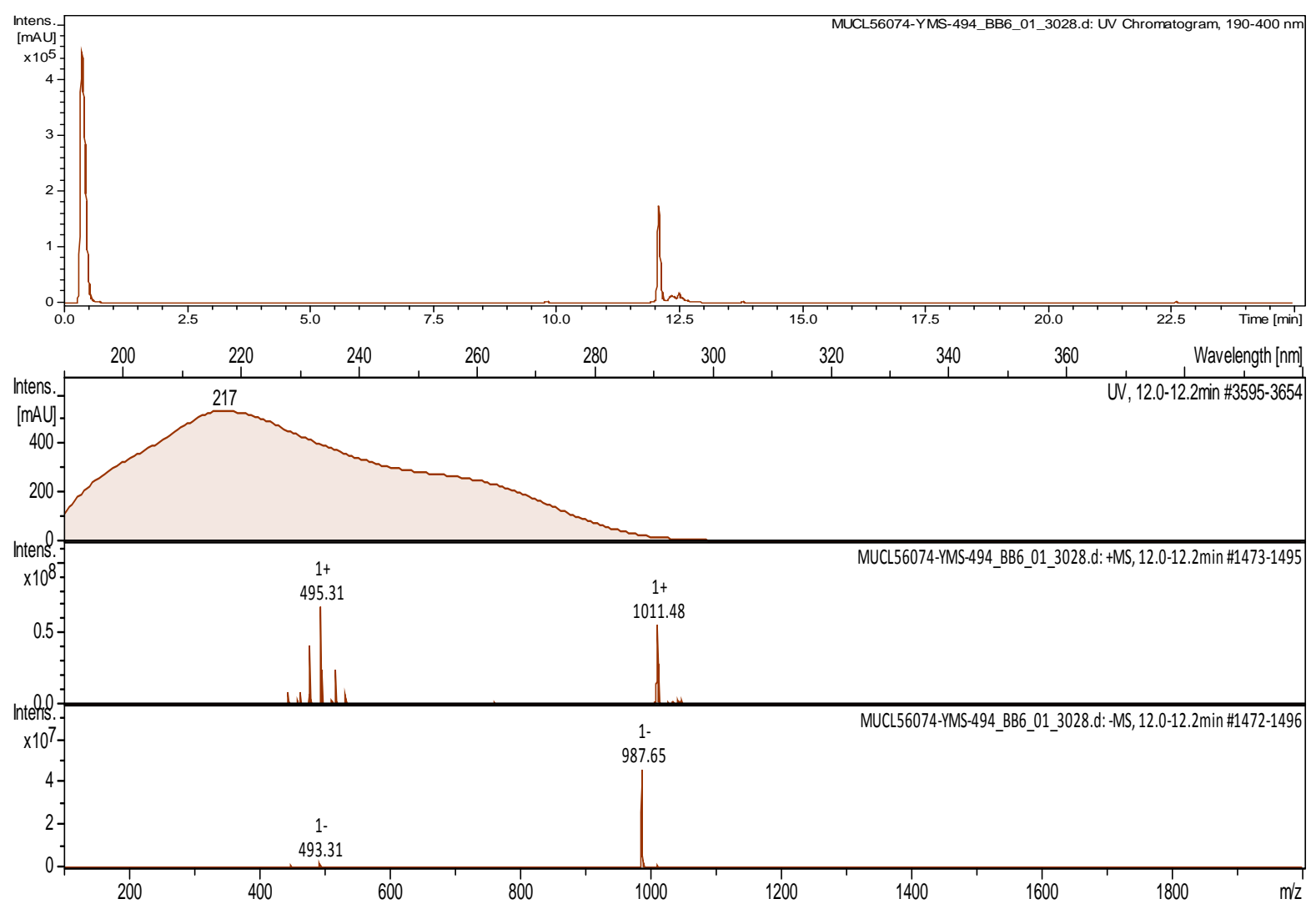

Figure S66: HRMS data of skeletocutin G (8)
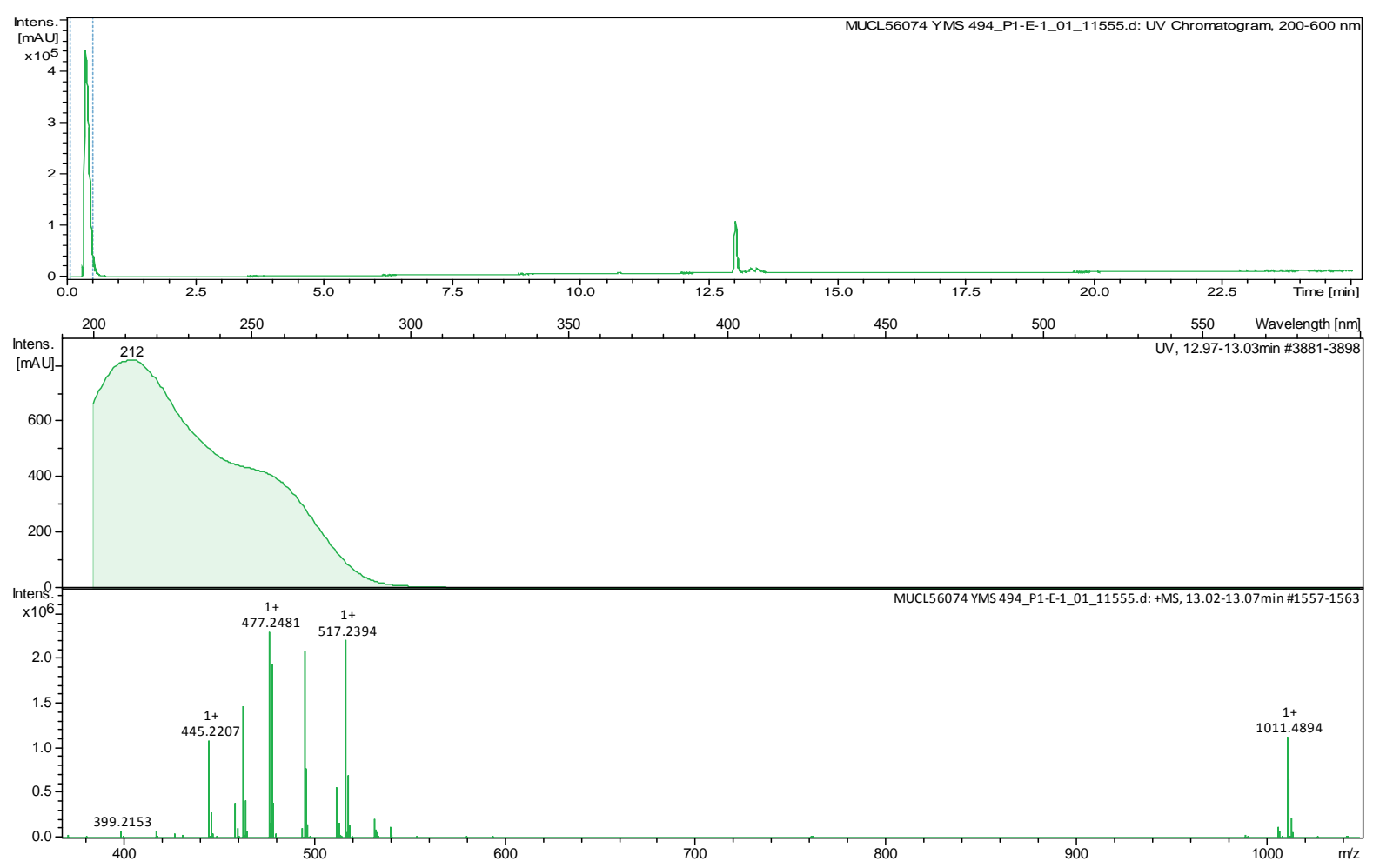


\section{1 and 2D NMR data for skeletocutin $H$ (9)}

Figure S67: ${ }^{1} \mathrm{H}$ NMR spectrum of skeletocutin $\mathrm{H}(\mathbf{9})$ in acetone- $\mathrm{d}_{6}(500 \mathrm{MHz})$

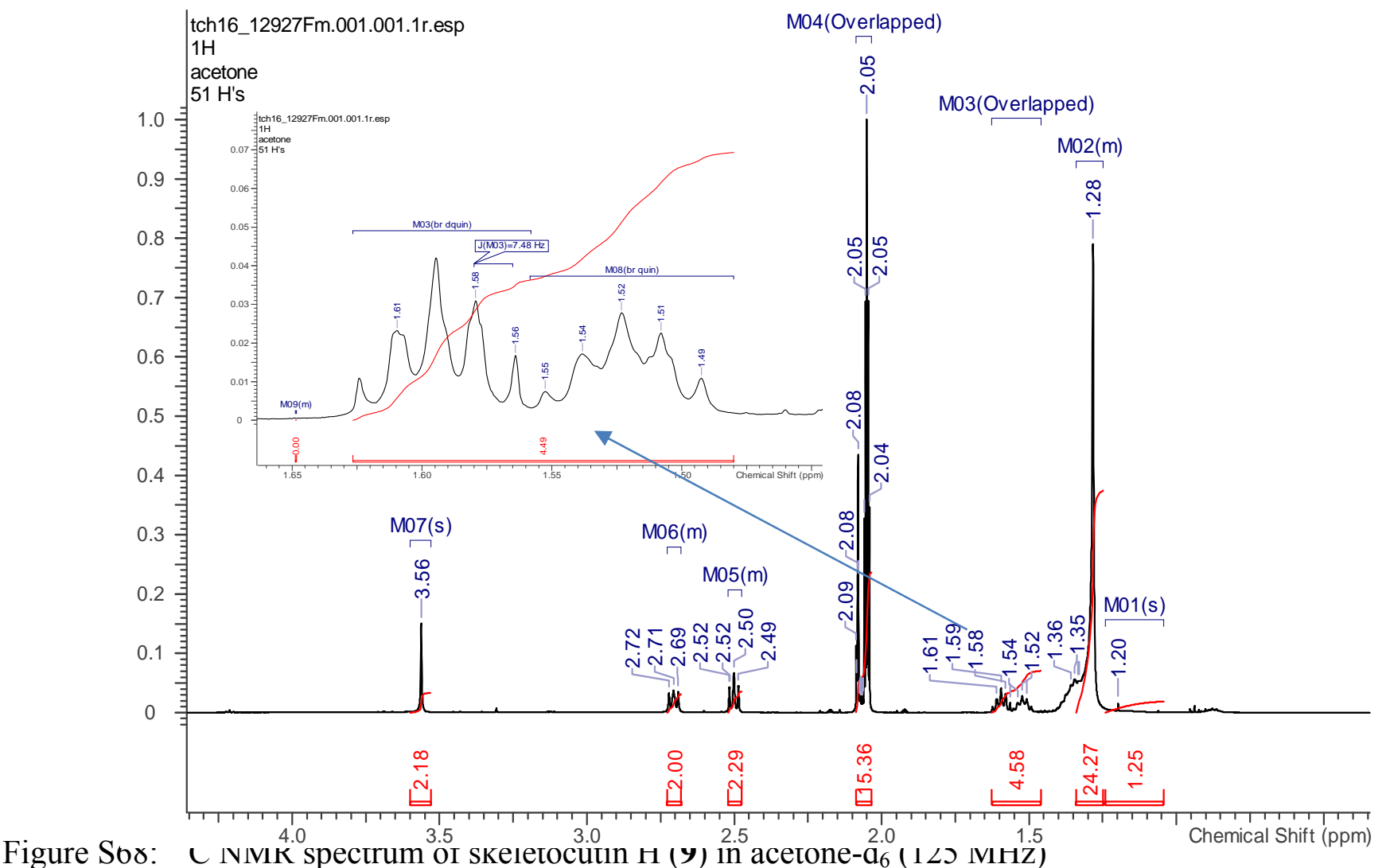

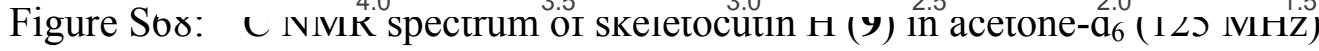




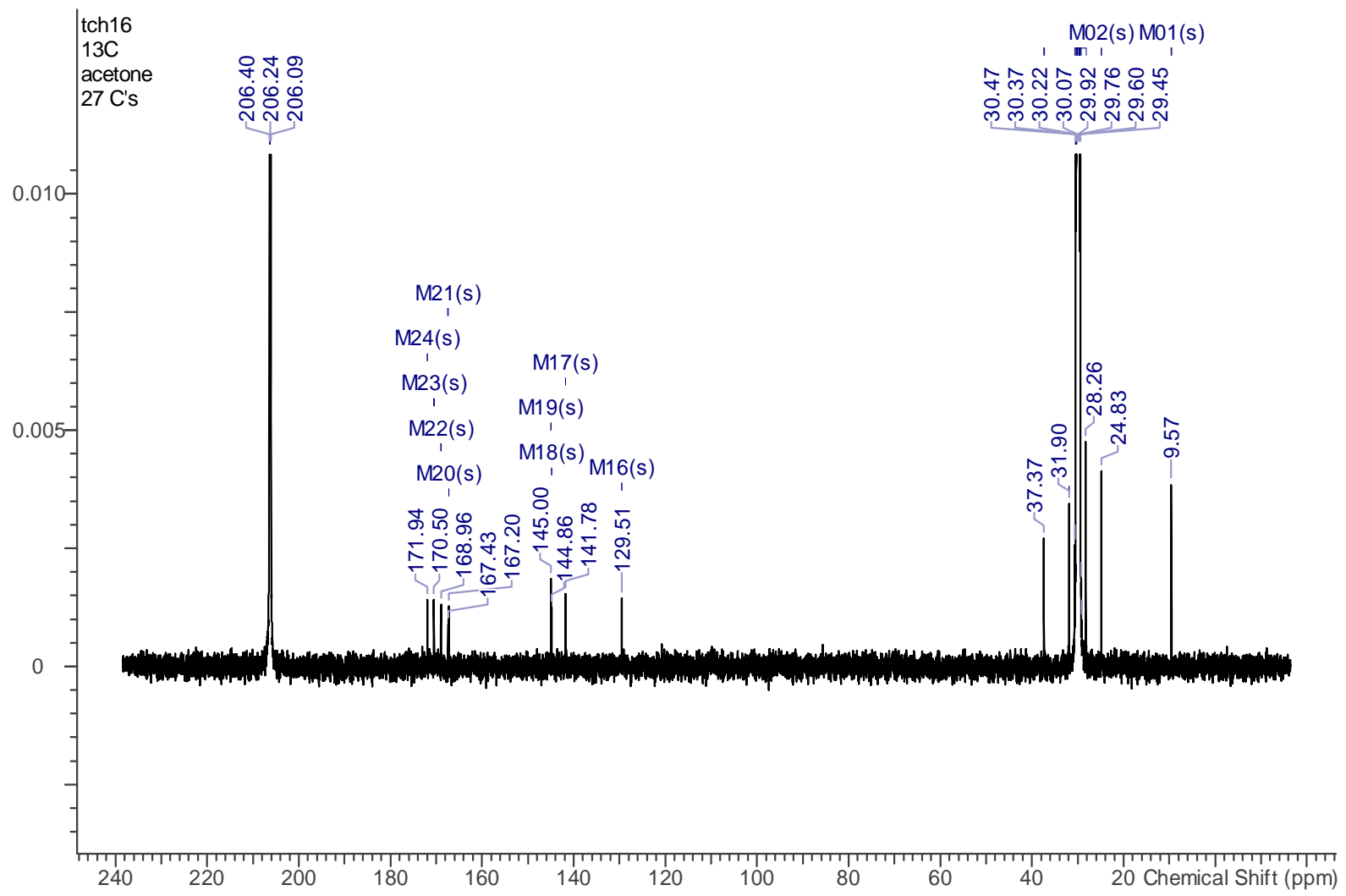

Figure S69: DEPT NMR spectrum of skeletocutin H (9) in acetone- $\mathrm{d}_{6}(125 \mathrm{MHz})$

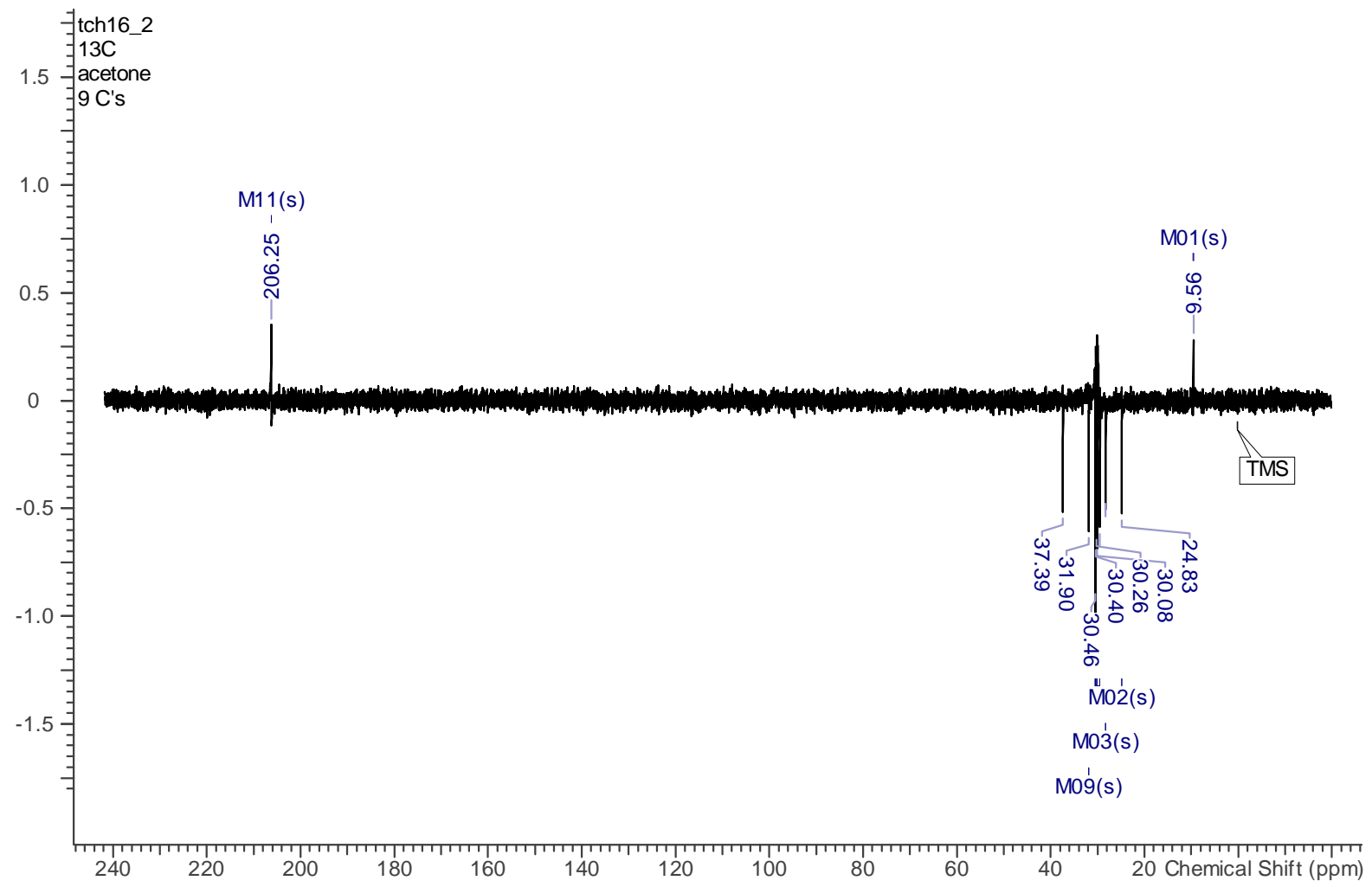


Figure S70: ${ }^{1} \mathrm{H},{ }^{13} \mathrm{C}$ HSQC NMR spectrum of skeletocutin $\mathrm{H}(\mathbf{9})$ in acetone- $\mathrm{d}_{6}(500 \mathrm{MHz}, 125$ $\mathrm{MHz})$

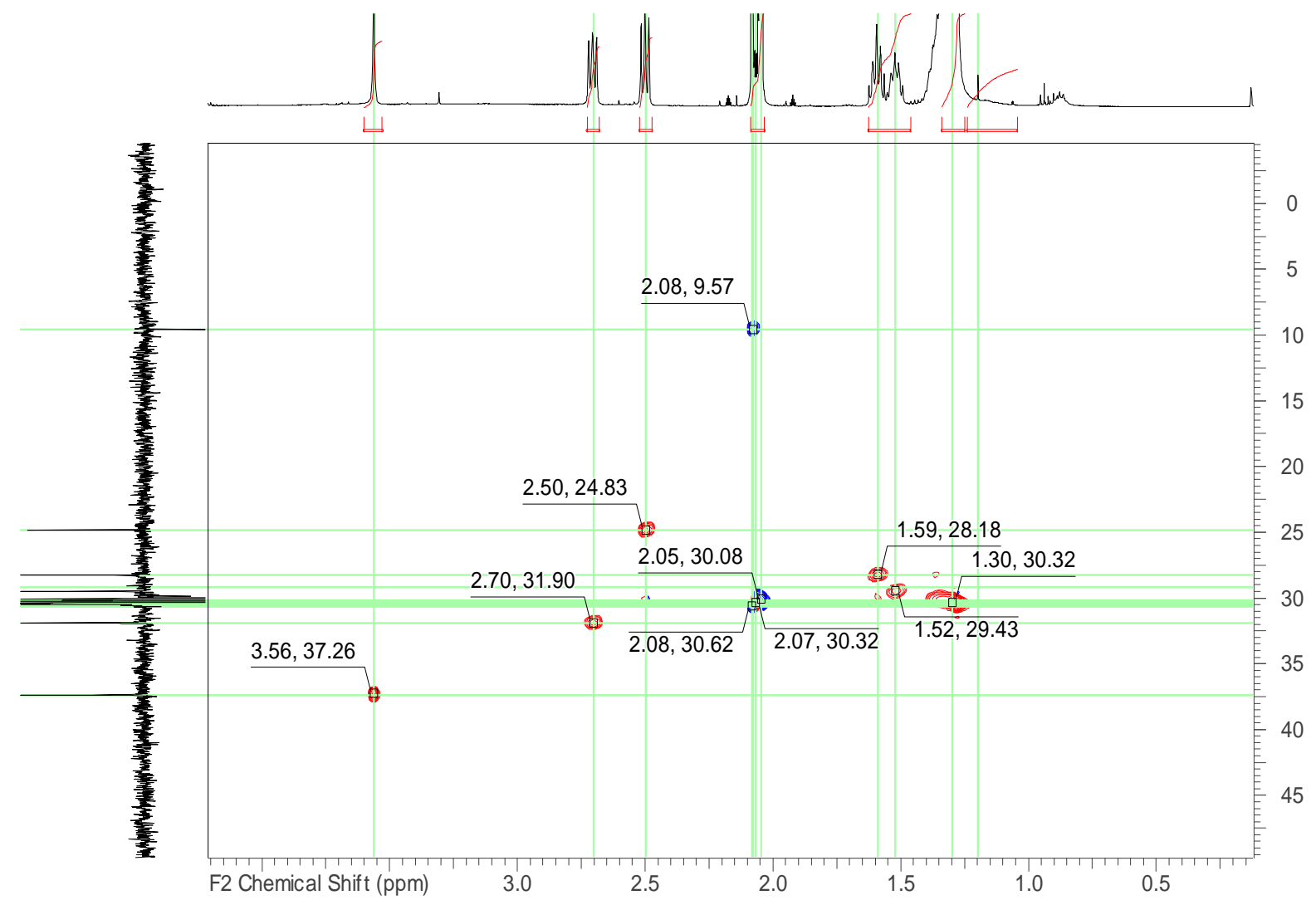

Figure S71: ${ }^{1} \mathrm{H},{ }^{13} \mathrm{C}$ HMBC NMR spectrum of skeletocutin $\mathrm{H}(\mathbf{9})$ in acetone- $\mathrm{d}_{6}(500 \mathrm{MHz}$, $125 \mathrm{MHz})$ 


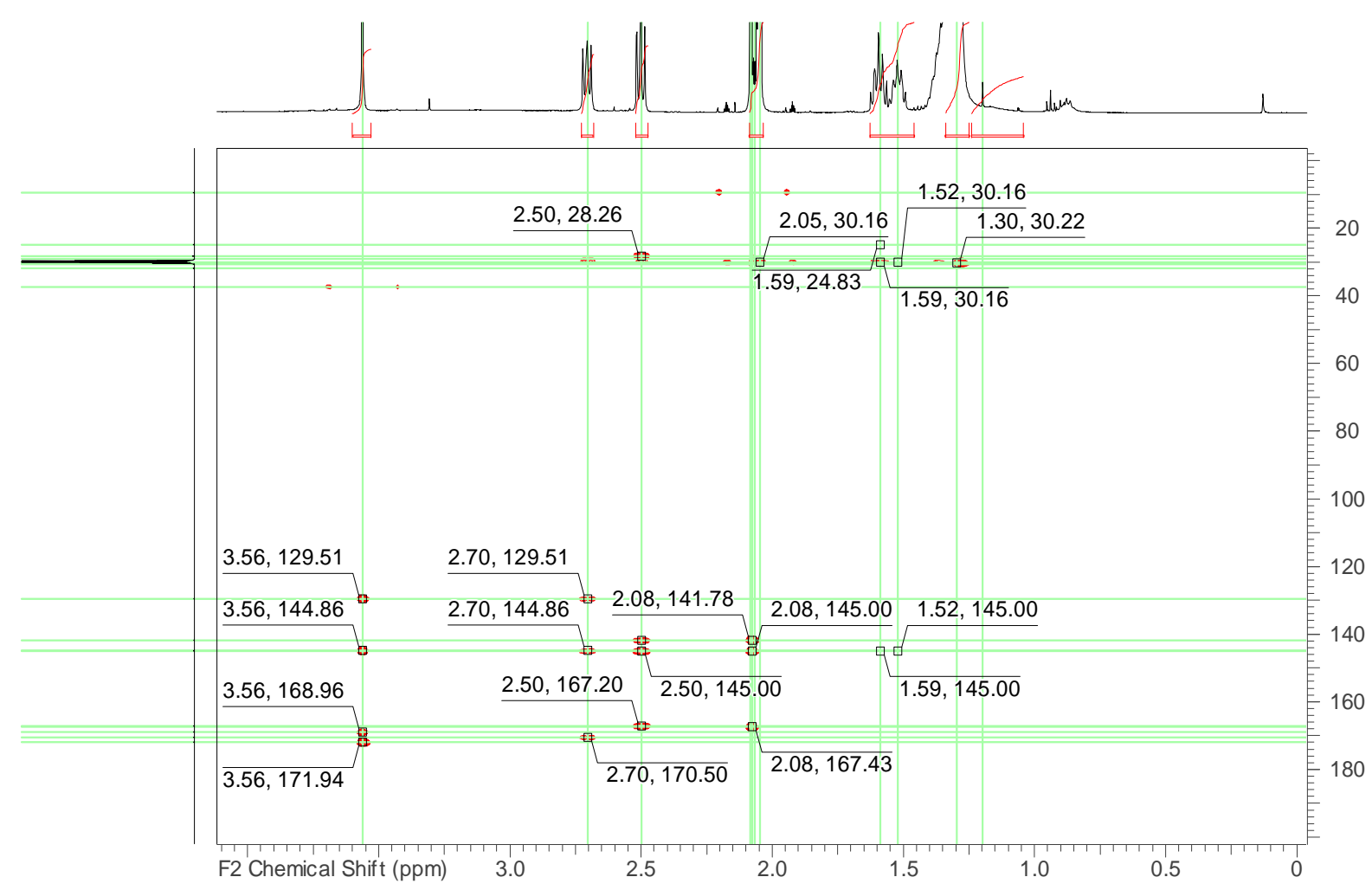

Figure S72: ${ }^{1} \mathrm{H},{ }^{1} \mathrm{H}$ COSY NMR spectrum of skeletocutin $\mathrm{H}(\mathbf{9})$ in acetone-d ${ }_{6}(500 \mathrm{MHz})$

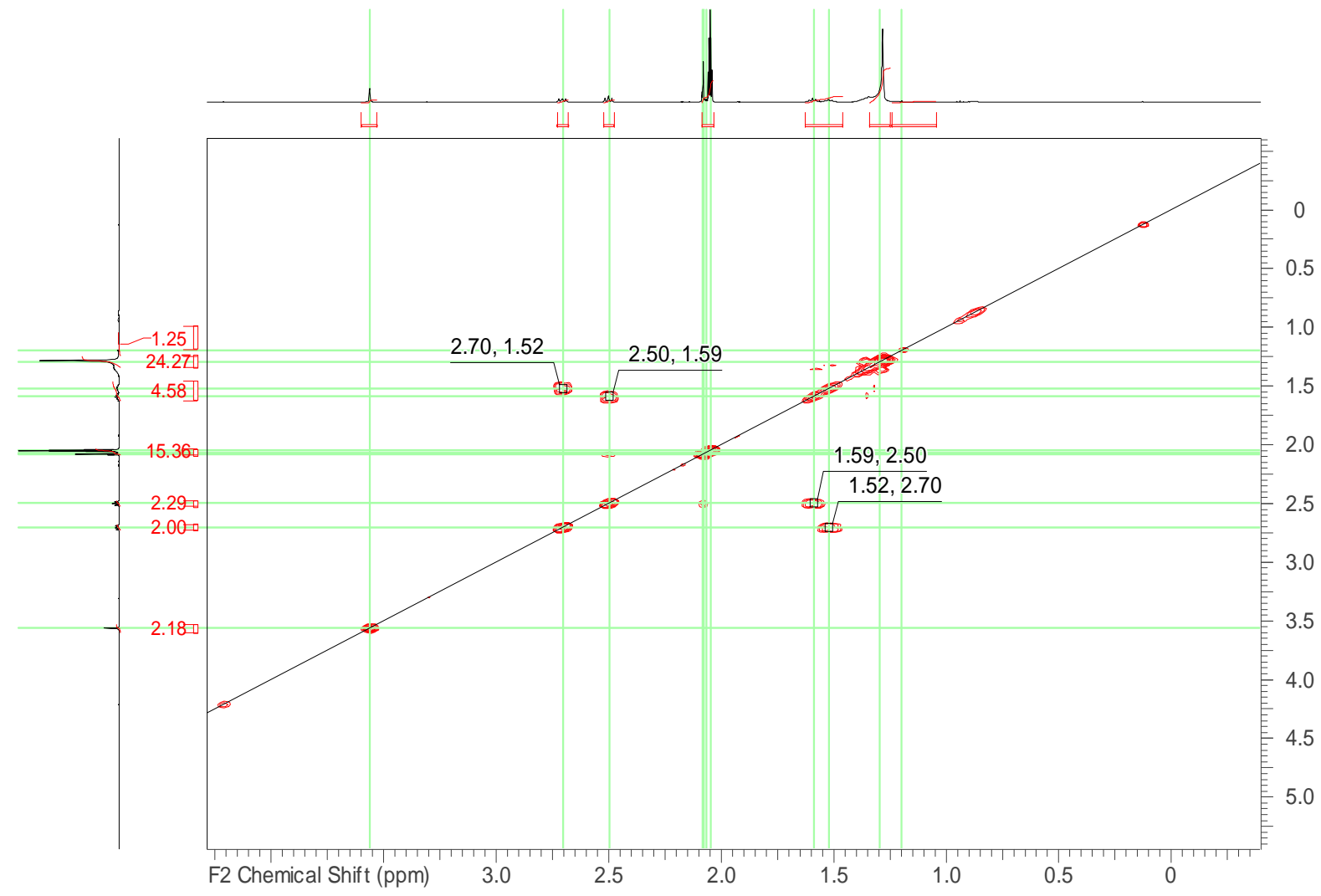

Figure S73: ${ }^{1} \mathrm{H},{ }^{1} \mathrm{H}$ ROESY NMR spectrum of skeletocutin $\mathrm{H}(\mathbf{9})$ in acetone-d $\mathrm{d}_{6}(500 \mathrm{MHz})$ 


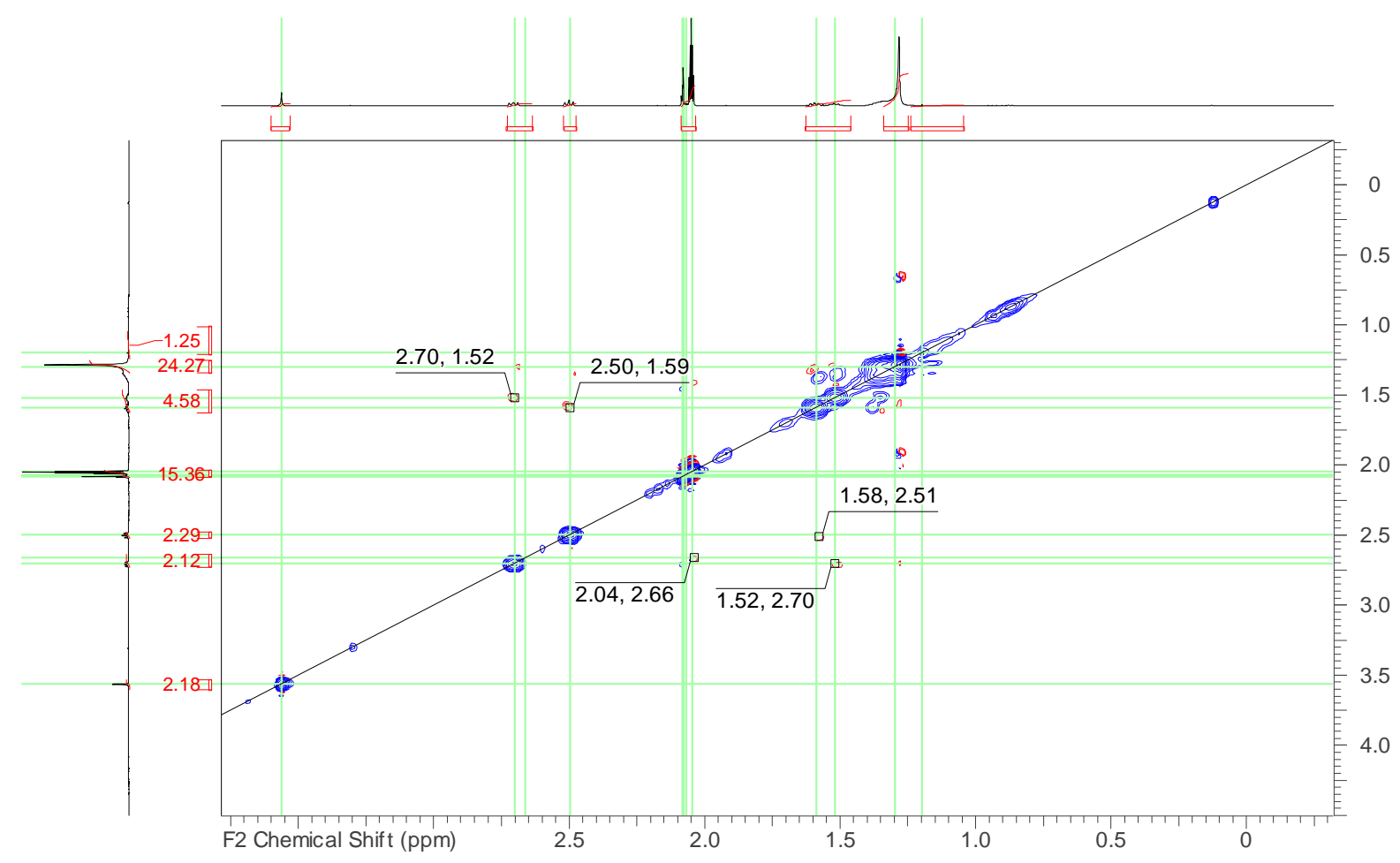


Figure S74: MS data of skeletocutin H (9)

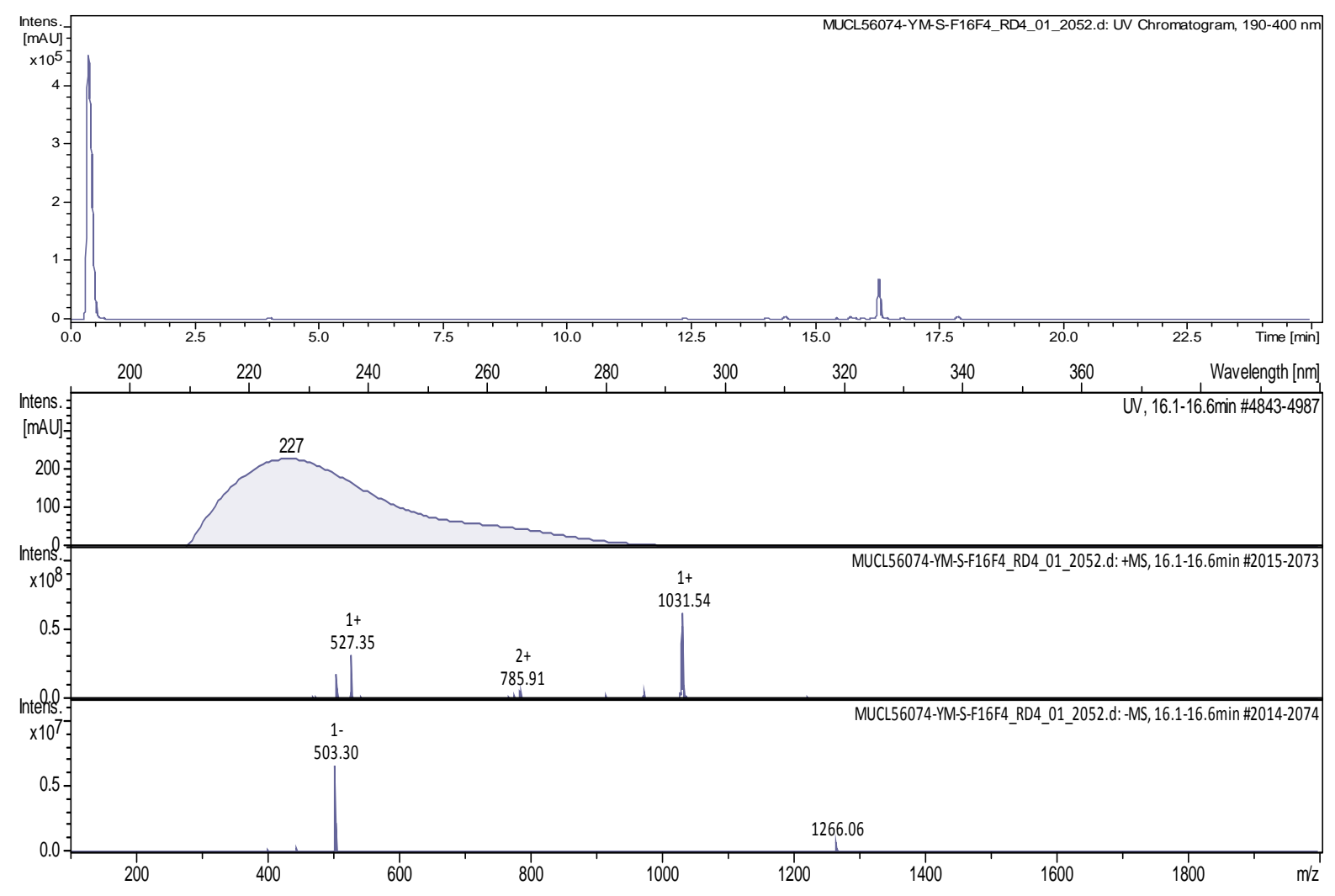

Figure S75: HRMS data of skeletocutin H (9)

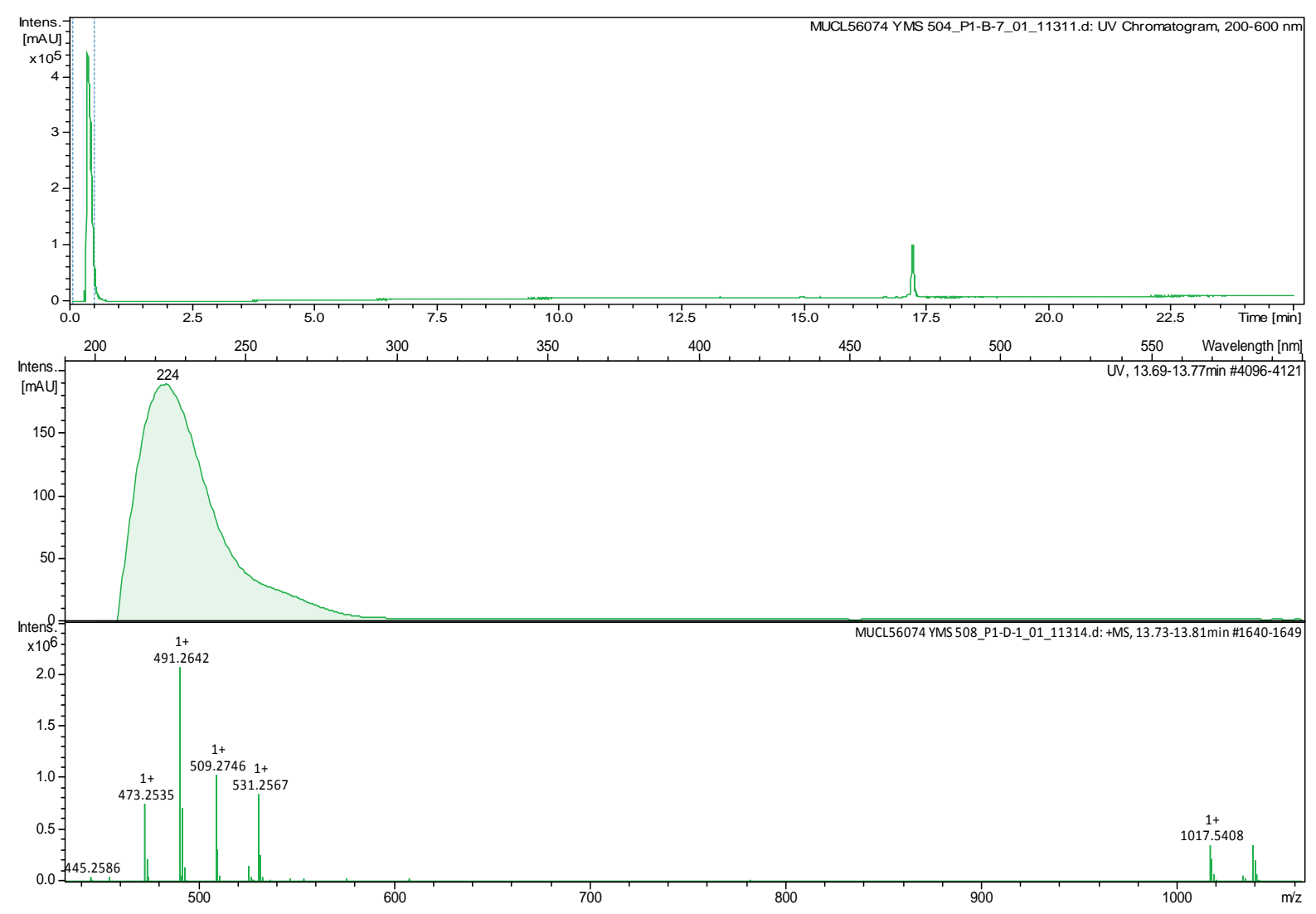




\section{1 and 2D NMR data for skeletocutin I (10)}

Figure S76: ${ }^{1} \mathrm{H}$ NMR spectrum of skeletocutin I (10) in $\mathrm{CDCl}_{3}(500 \mathrm{MHz})$

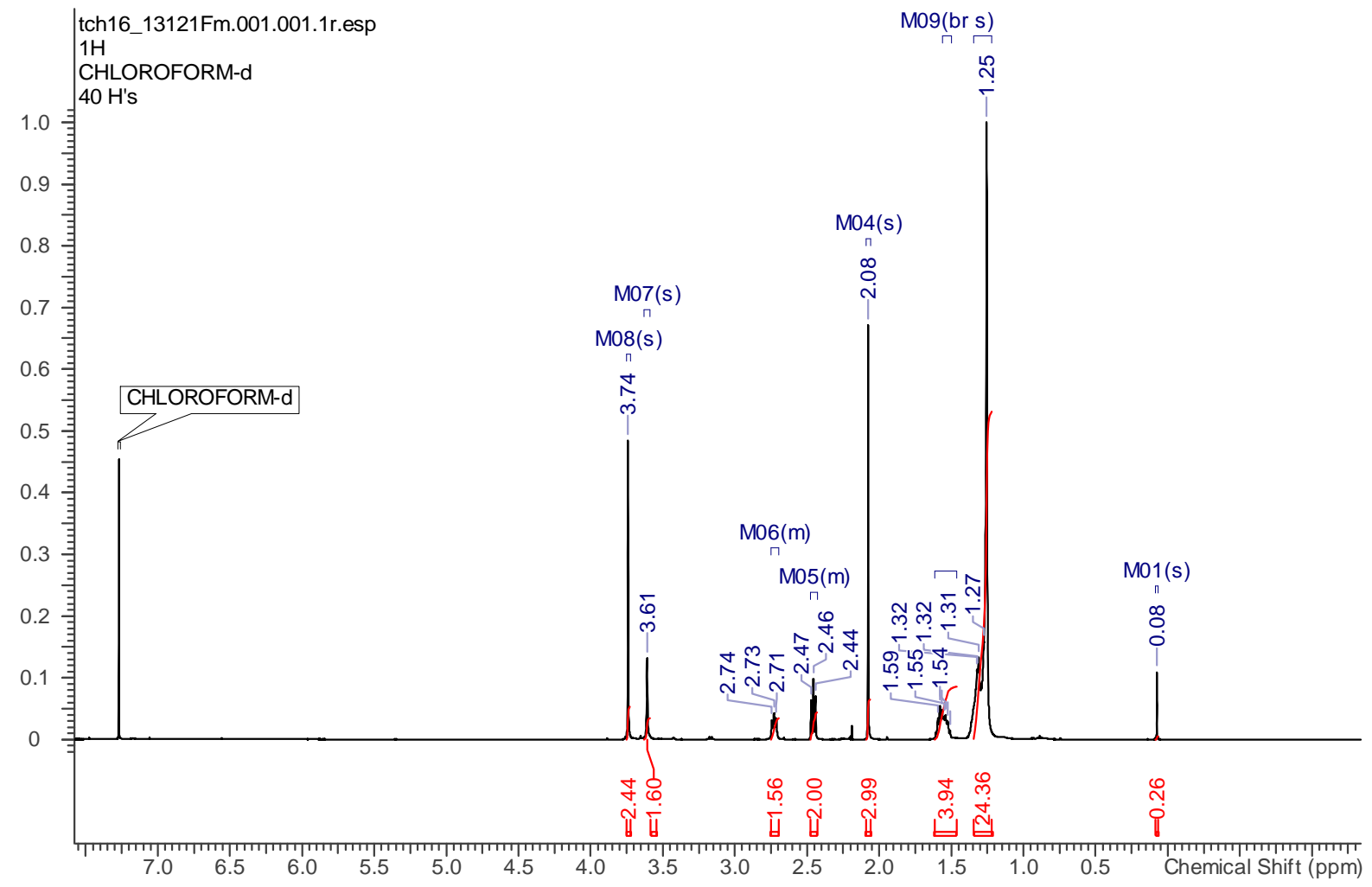

Figure S77: ${ }^{13} \mathrm{C}$ NMR spectrum of skeletocutin I (10) in $\mathrm{CDCl}_{3}(125 \mathrm{MHz})$ 


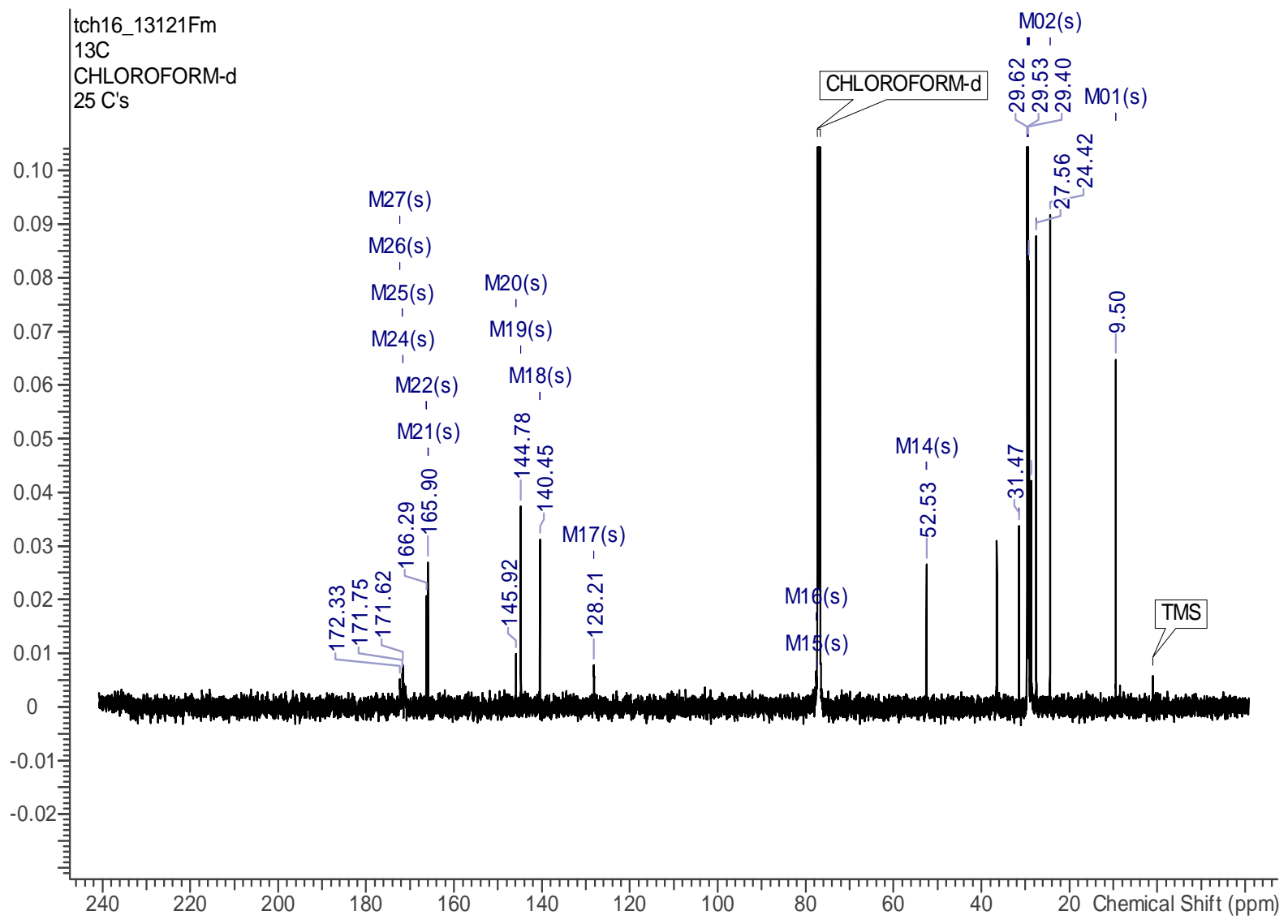

Figure S78: DEPT NMR spectrum of skeletocutin I (10) in $\mathrm{CDCl}_{3}(125 \mathrm{MHz})$

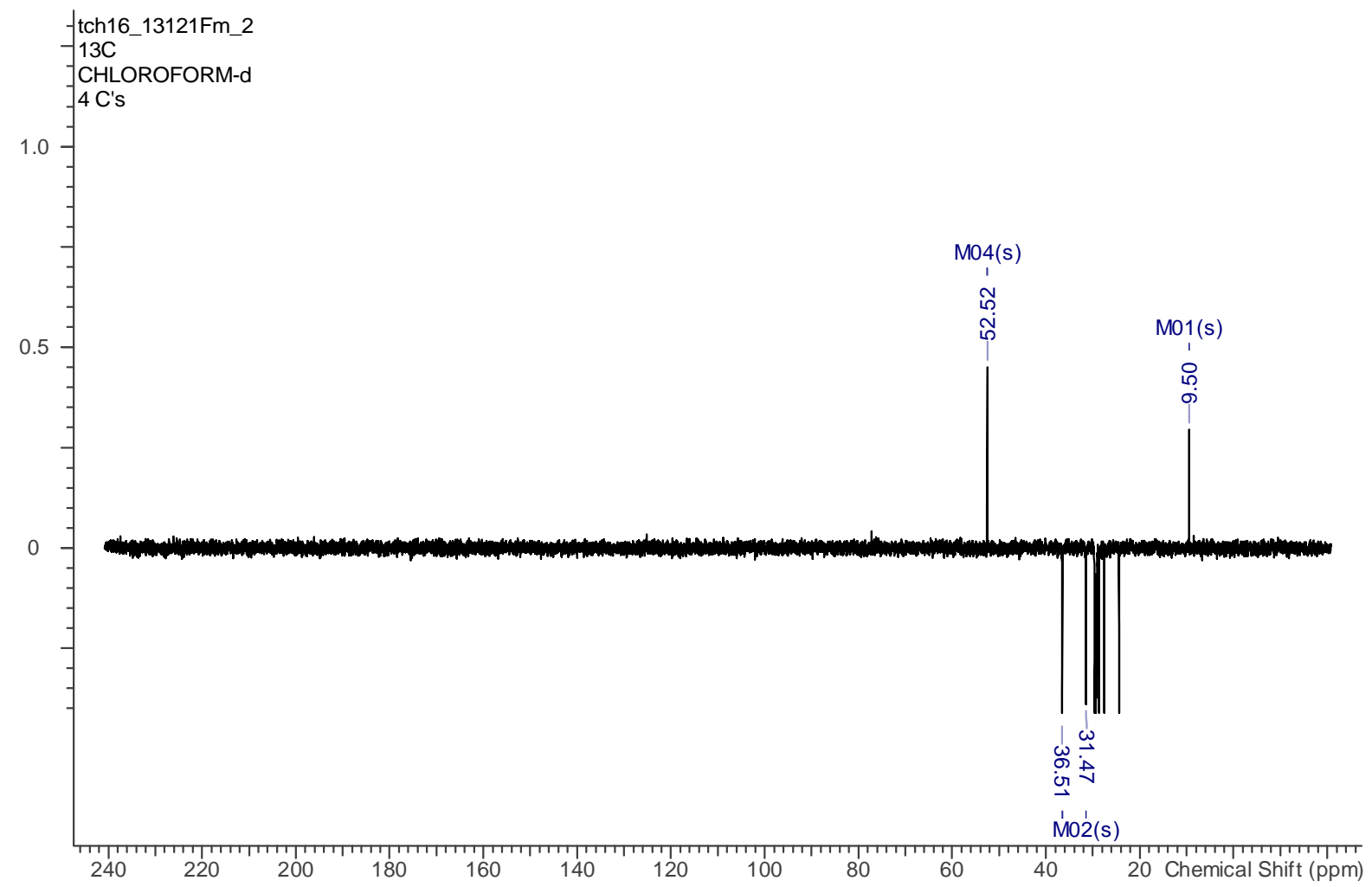


Figure S79: ${ }^{1} \mathrm{H},{ }^{13} \mathrm{C}$ HSQC NMR spectrum of skeletocutin I (10) in $\mathrm{CDCl}_{3}(500 \mathrm{MHz}, 125$ $\mathrm{MHz})$

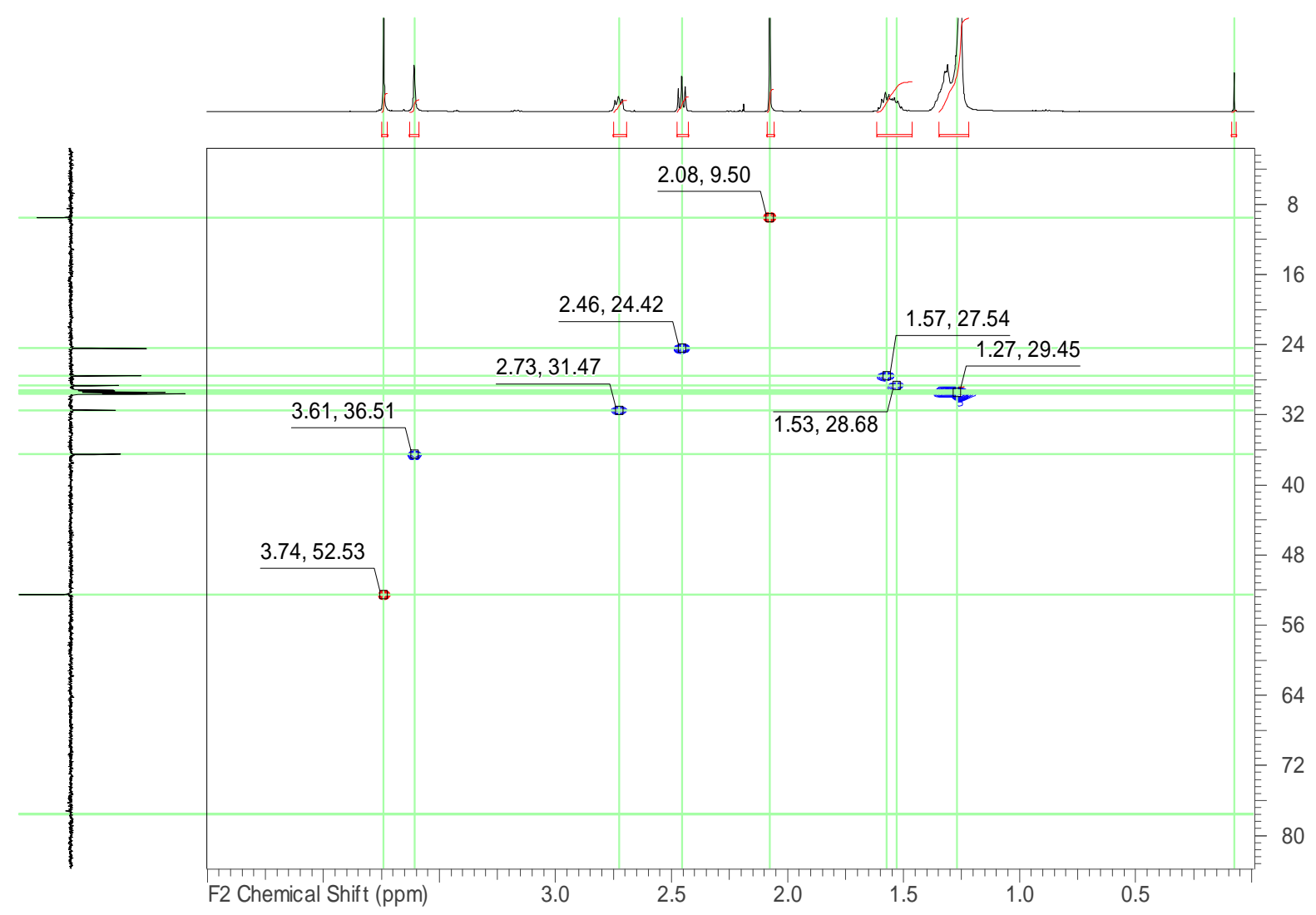

Figure S80: ${ }^{1} \mathrm{H},{ }^{13} \mathrm{C}$ HMBC NMR spectrum of skeletocutin I (10) in $\mathrm{CDCl}_{3}(500 \mathrm{MHz}, 125$ $\mathrm{MHz})$ 


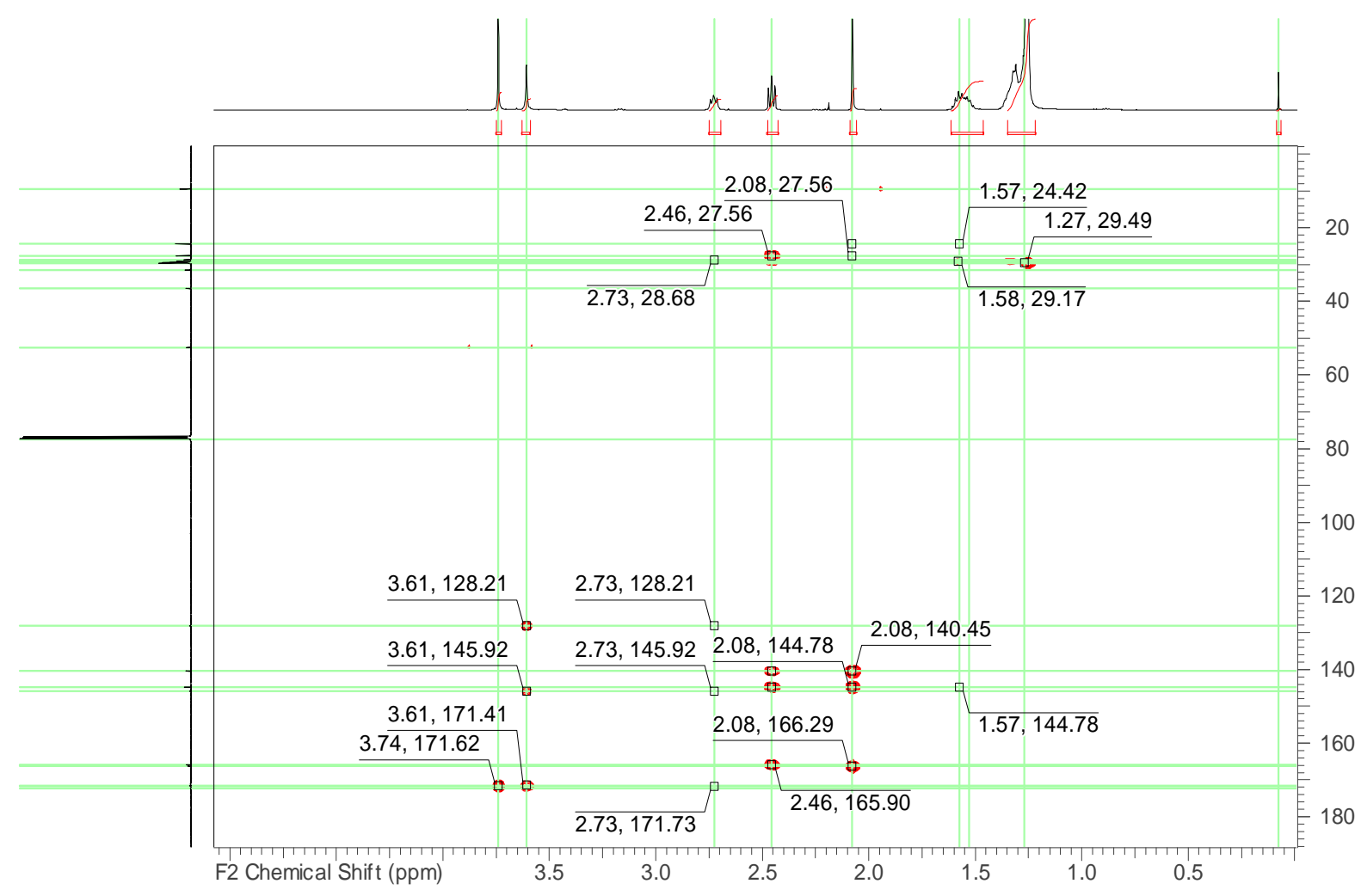

Figure S81: ${ }^{1} \mathrm{H},{ }^{1} \mathrm{H}$ COSY NMR spectrum of skeletocutin I (10) in $\mathrm{CDCl}_{3}(500 \mathrm{MHz})$

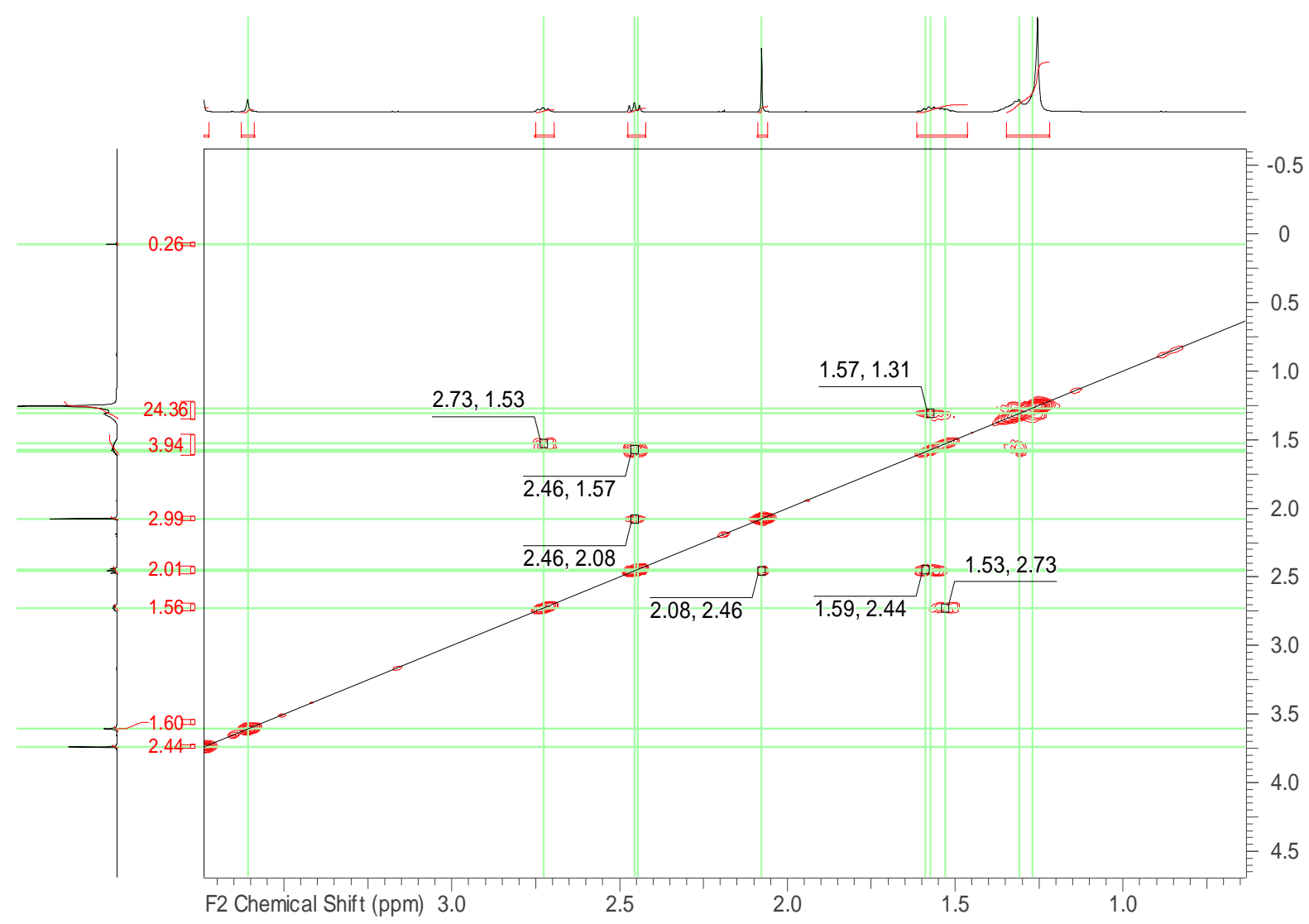


Figure S82: ${ }^{1} \mathrm{H},{ }^{1} \mathrm{H}$ ROESY NMR spectrum of skeletocutin I (10) in $\mathrm{CDCl}_{3}(500$ $\mathrm{MHz}$ )

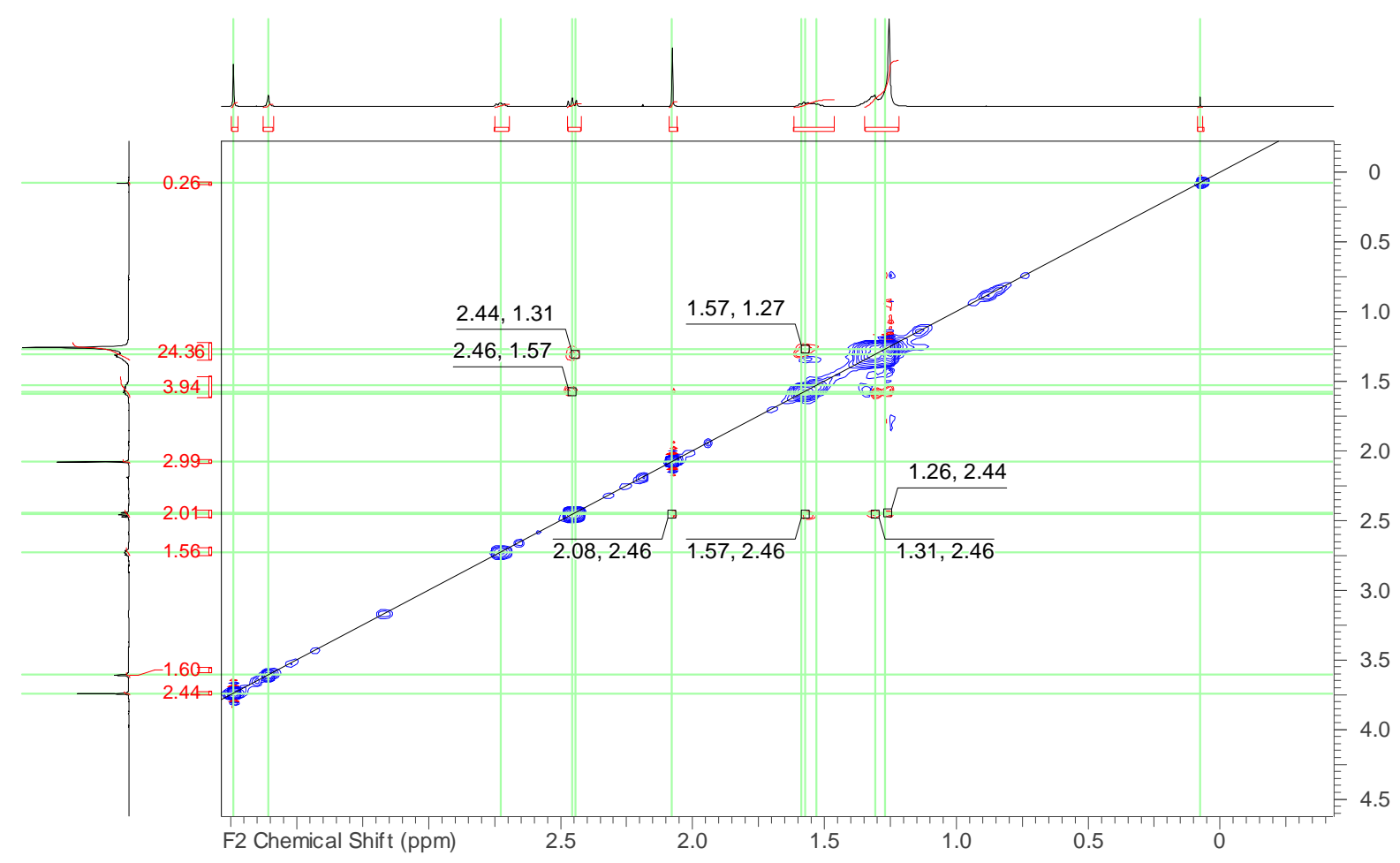

Figure S83: MS data of skeletocutin I (10)
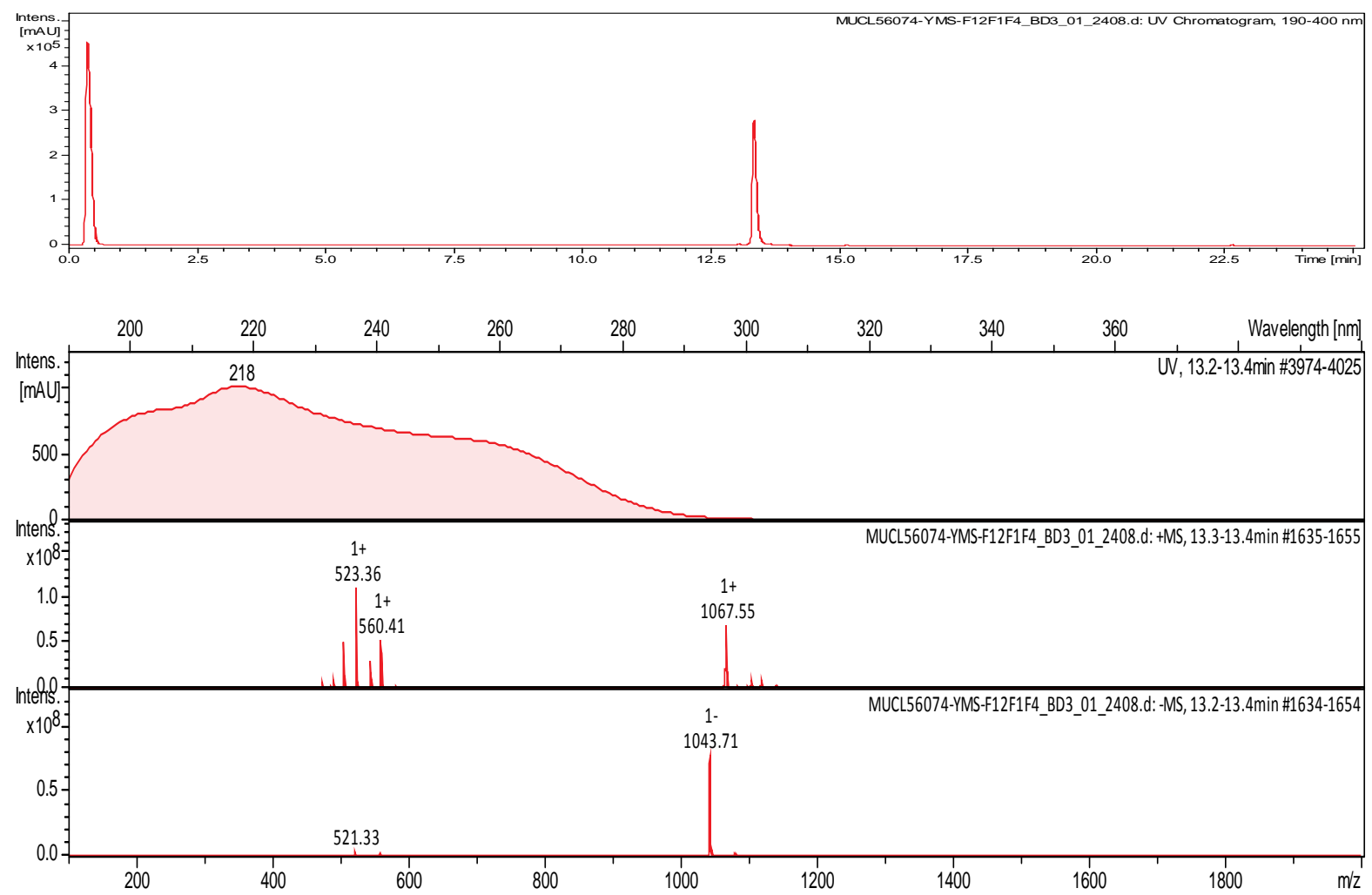
Figure S84: HRMS data of skeletocutin I (10)
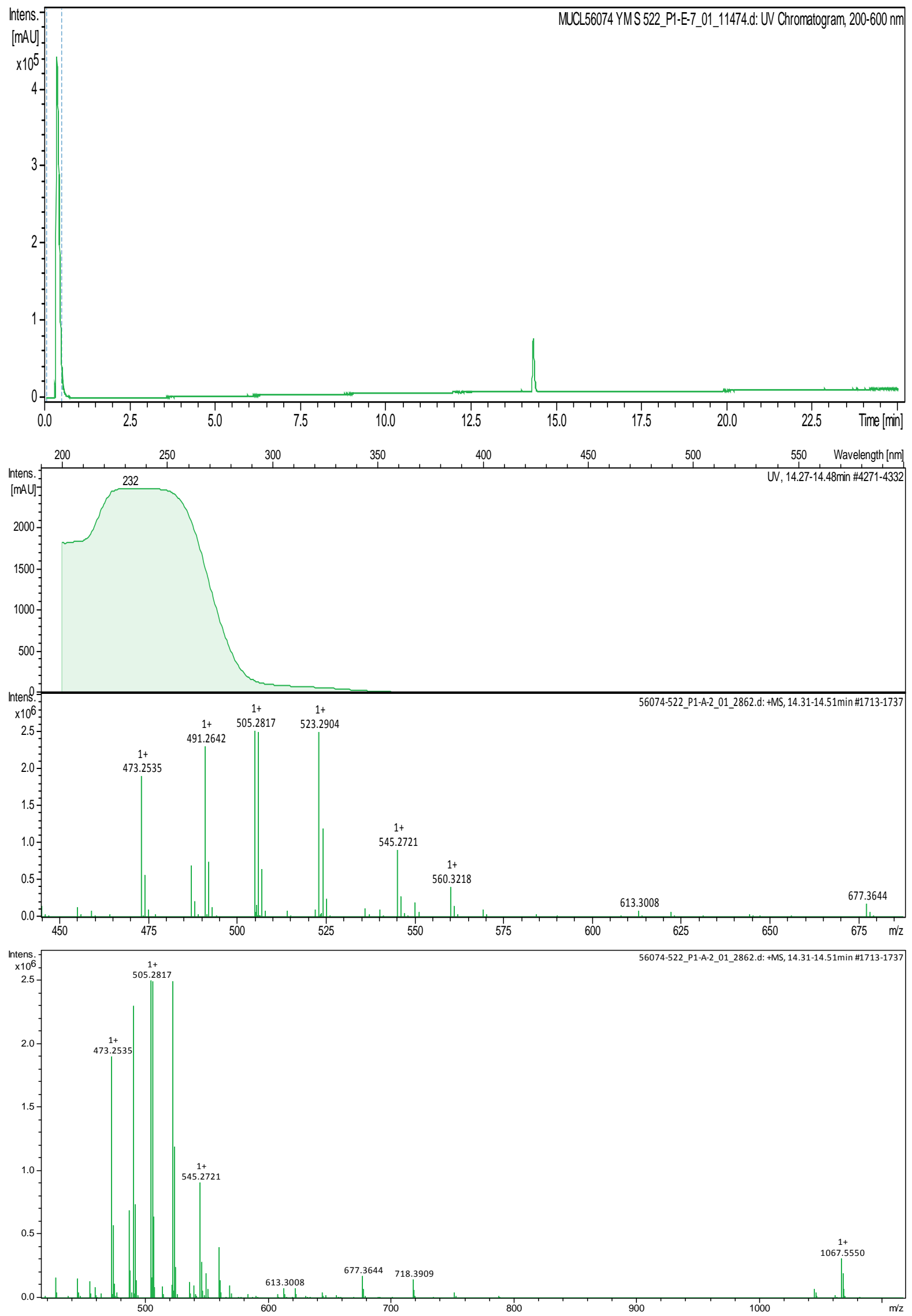


\section{1 and 2D NMR data for skeletocutin $J$ (11)}

Figure S85: ${ }^{1} \mathrm{H}$ NMR spectrum of skeletocutin $\mathrm{J}(\mathbf{1 1})$ in $\mathrm{CDCl}_{3}(500 \mathrm{MHz})$

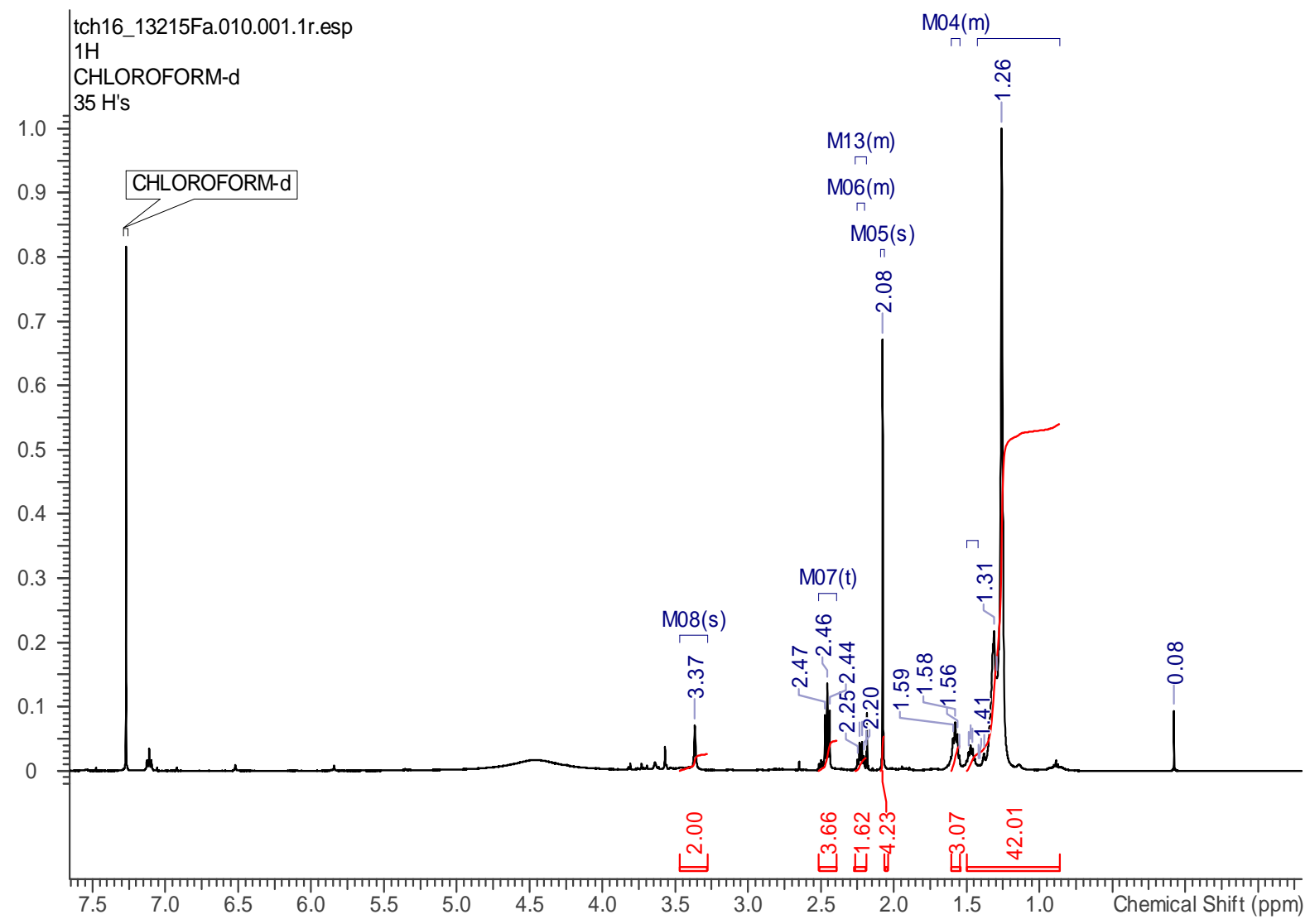

Figure S86: ${ }^{13} \mathrm{C}$ NMR spectrum of skeletocutin $\mathrm{J}(\mathbf{1 1})$ in $\mathrm{CDCl}_{3}(500 \mathrm{MHz})$

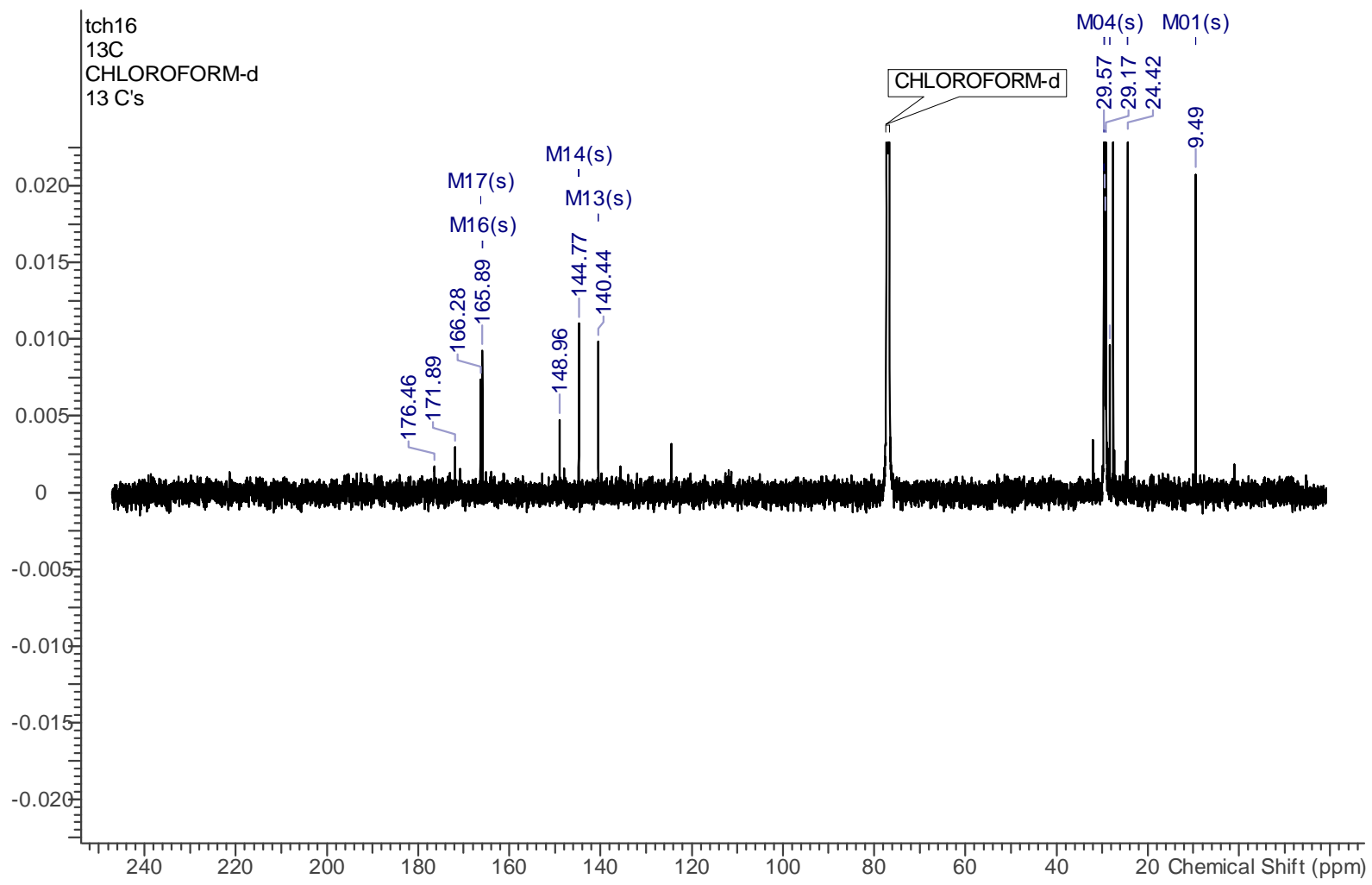


Figure S87: DEPT NMR spectrum of skeletocutin $\mathrm{J}(\mathbf{1 1})$ in $\mathrm{CDCl}_{3}(500 \mathrm{MHz})$

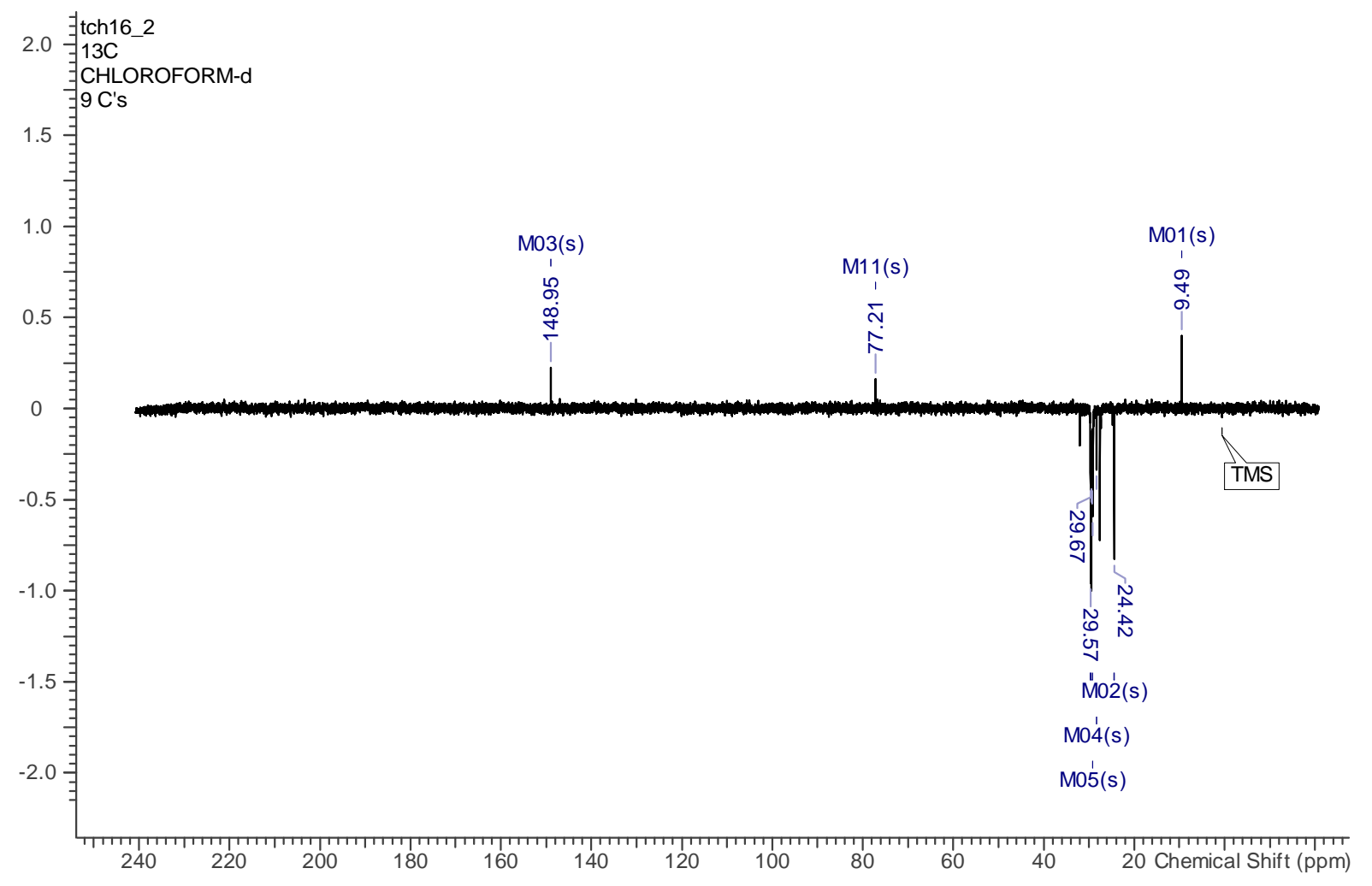

Figure S88: ${ }^{1} \mathrm{H},{ }^{13} \mathrm{C}$ HSQC NMR spectrum of skeletocutin $\mathrm{J}(\mathbf{1 1})$ in $\mathrm{CDCl}_{3}(500 \mathrm{MHz}, 125$ $\mathrm{MHz}$ ) 


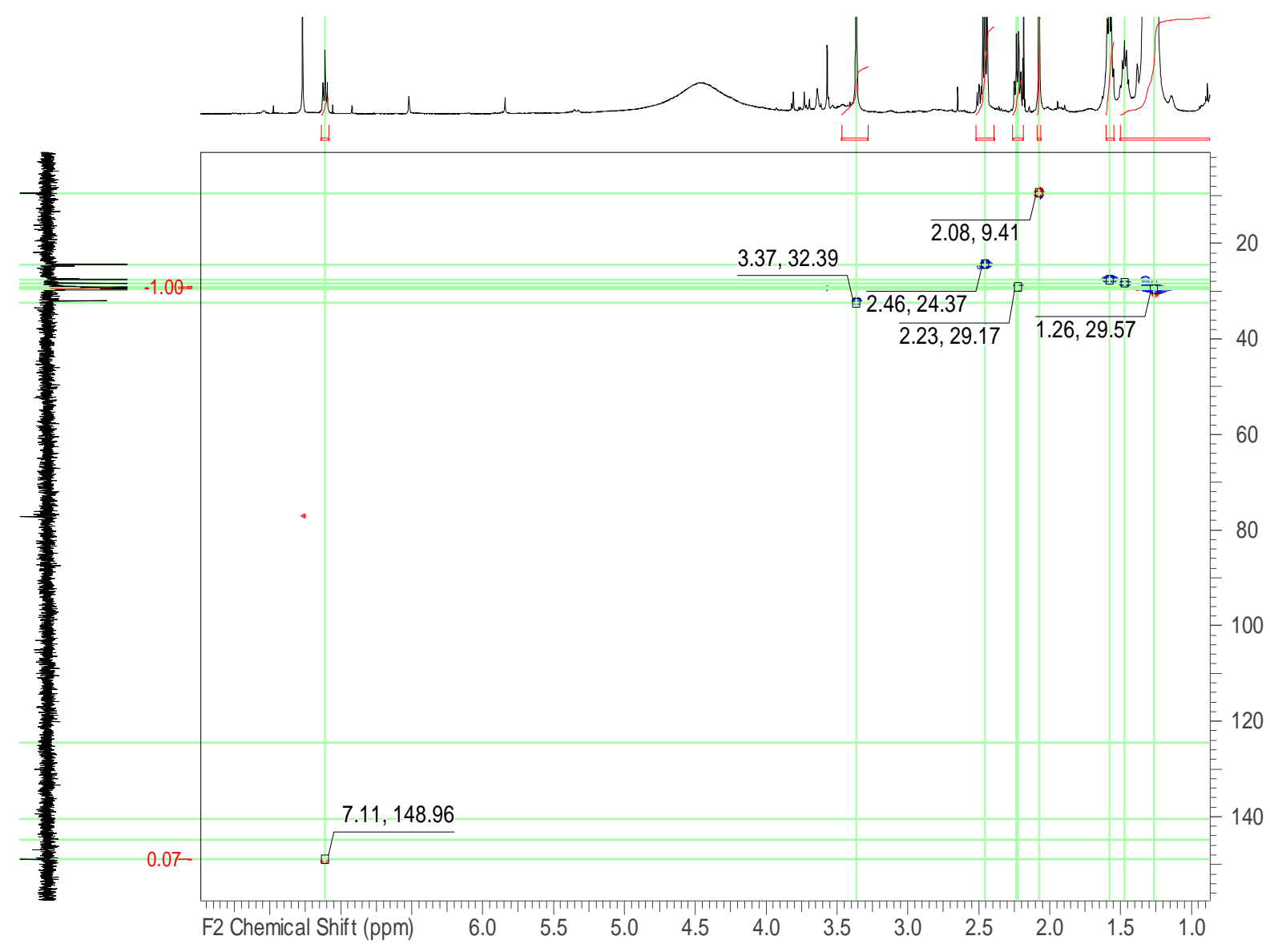

Figure S89: ${ }^{1} \mathrm{H},{ }^{13} \mathrm{C}$ HMBC NMR spectrum of skeletocutin $\mathrm{J}(11)$ in $\mathrm{CDCl}_{3}(500 \mathrm{MHz}, 125$ $\mathrm{MHz}$ ) 


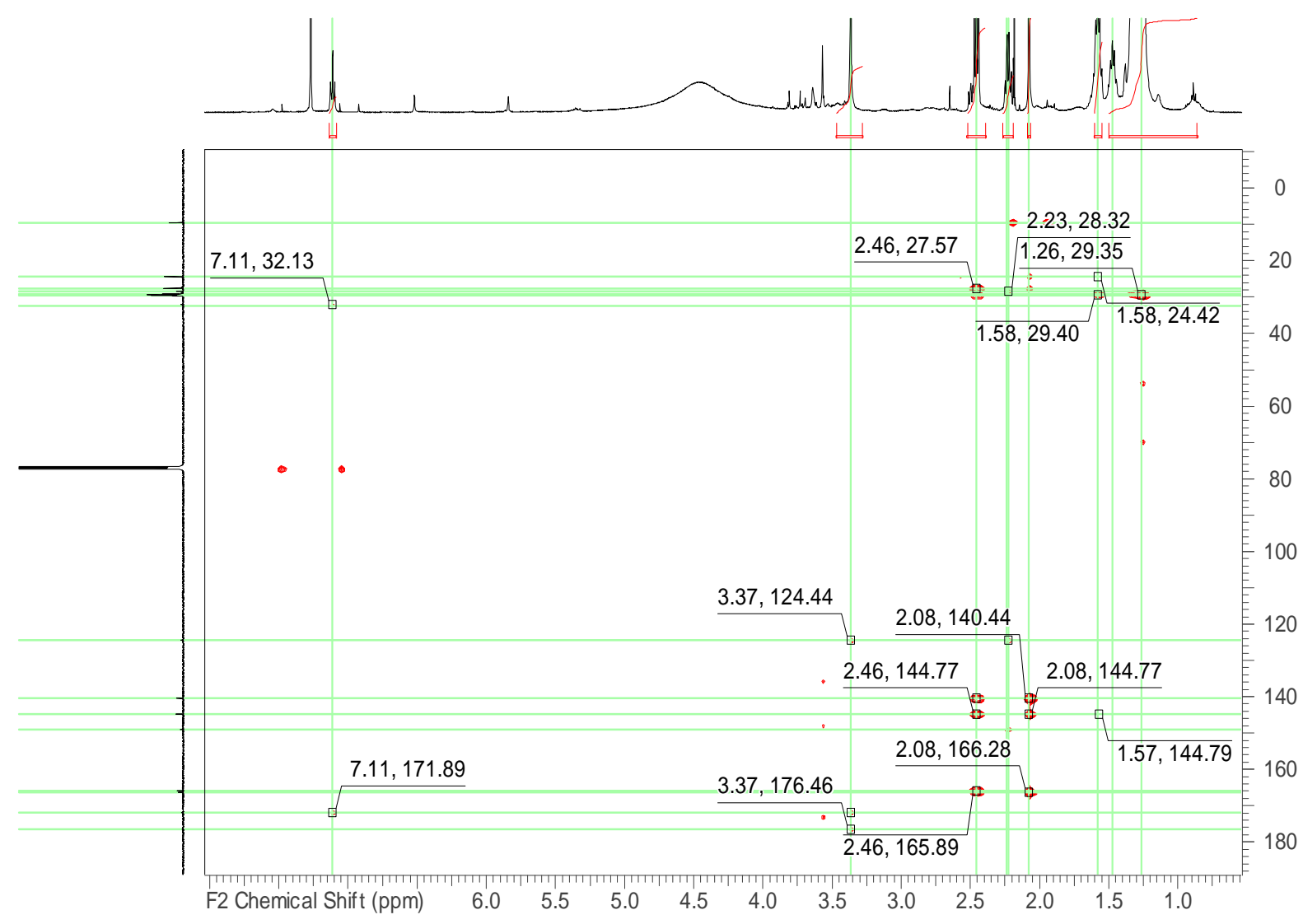

Figure S90: ${ }^{1} \mathrm{H},{ }^{1} \mathrm{H}$ COSY NMR spectrum of skeletocutin $\mathrm{J}(\mathbf{1 1})$ in $\mathrm{CDCl}_{3}(500 \mathrm{MHz})$

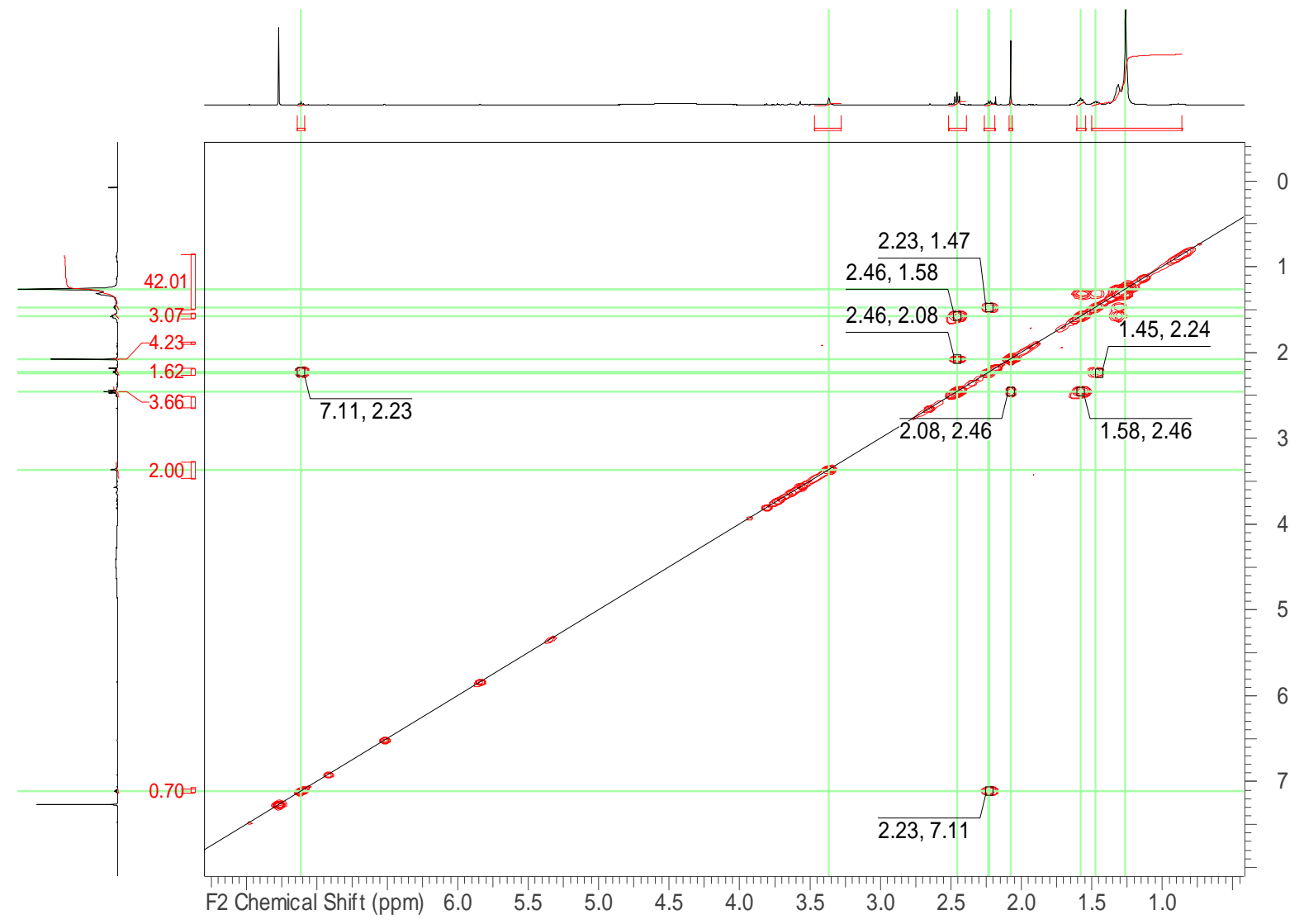


Figure S91: MS data of skeletocutin J (11)

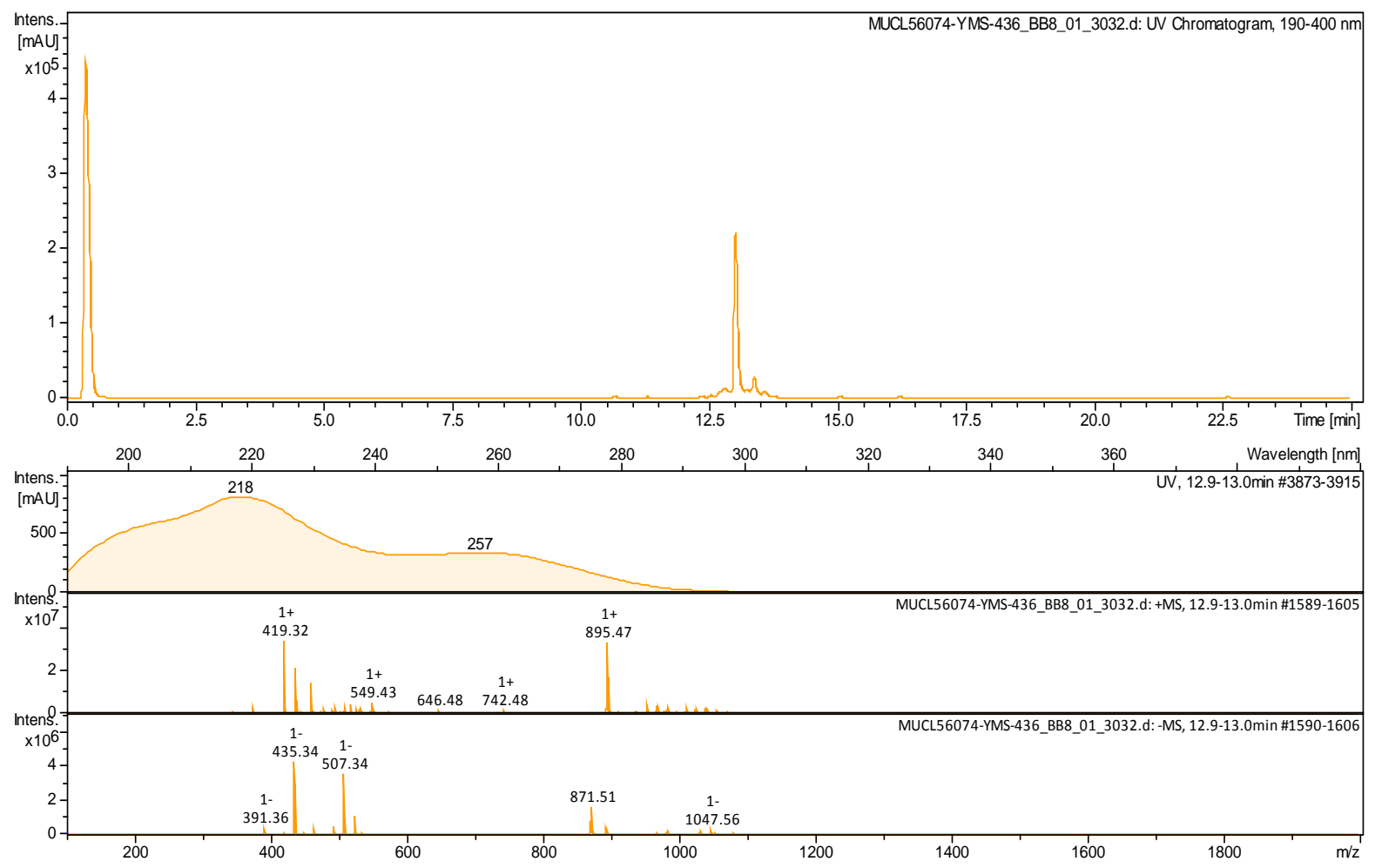

Figure S92: HRMS data of skeletocutin J (11)
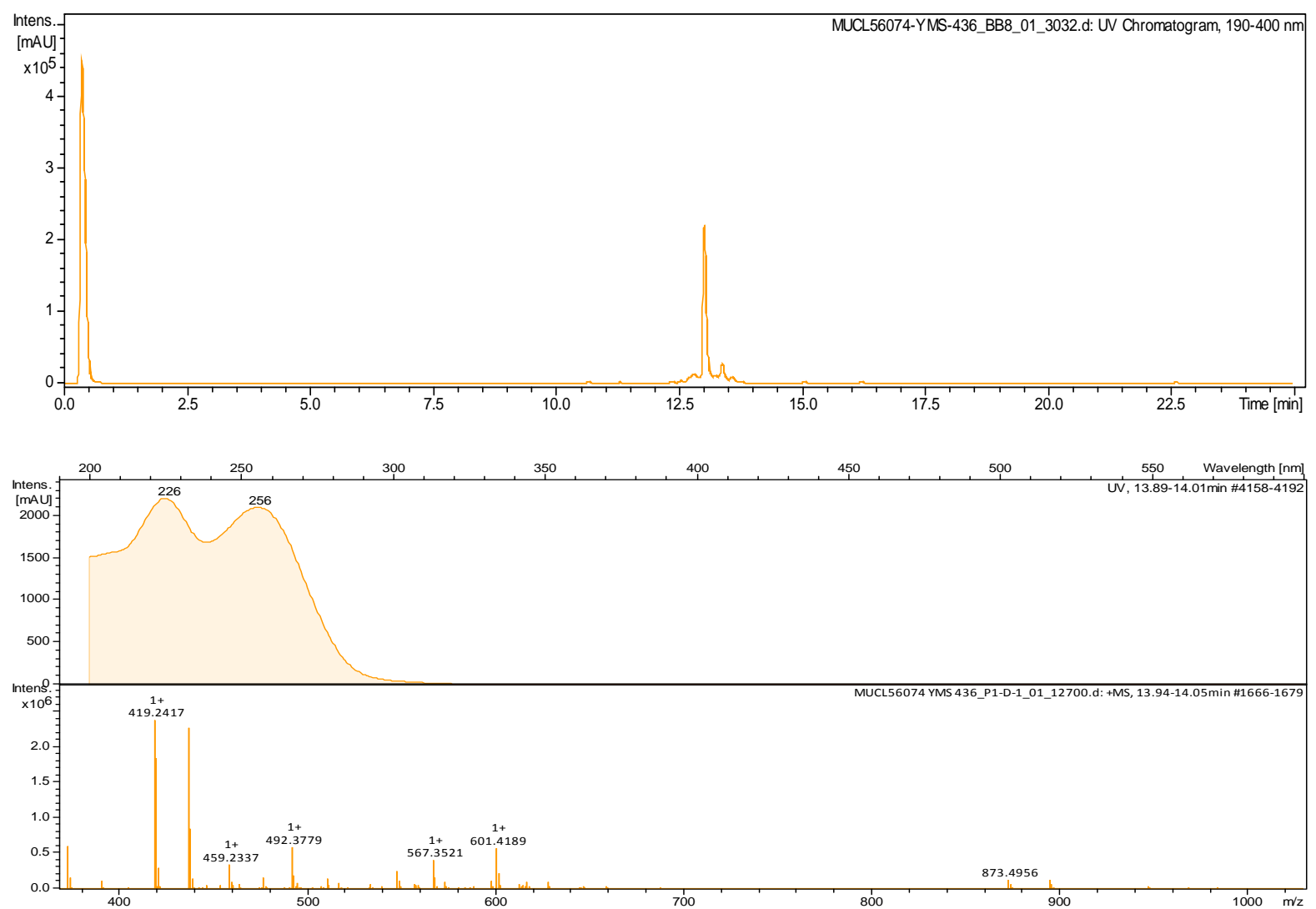


\section{1 and 2D NMR data for skeletocutin K (12)}

Figure S93: ${ }^{1} \mathrm{H}$ NMR spectrum of skeletocutin $\mathrm{K}(\mathbf{1 2})$ in $\mathrm{CDCl}_{3}(500 \mathrm{MHz})$

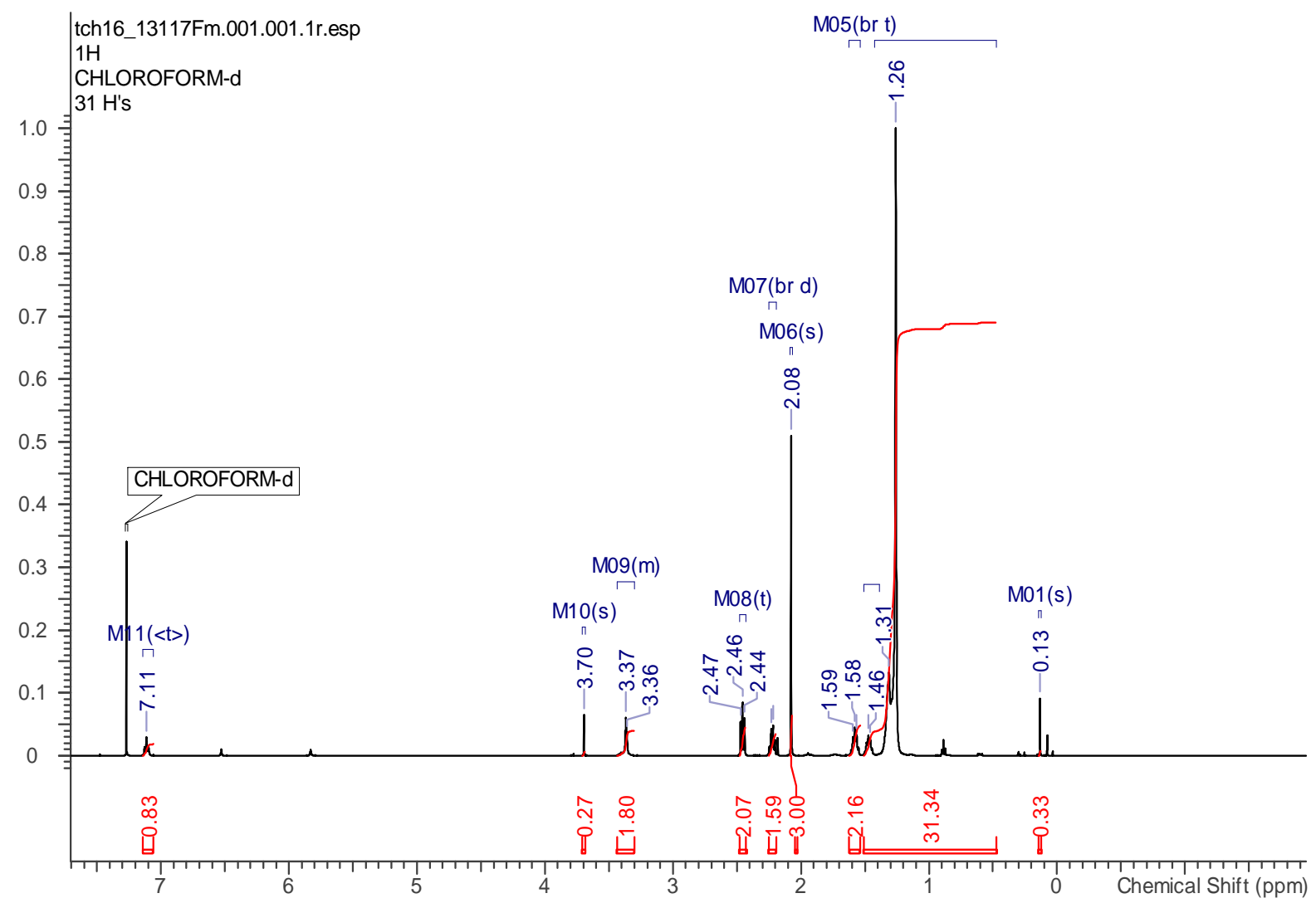

Figure S94: ${ }^{13} \mathrm{C}$ NMR spectrum of skeletocutin $\mathrm{K}(\mathbf{1 2})$ in $\mathrm{CDCl}_{3}(500 \mathrm{MHz})$

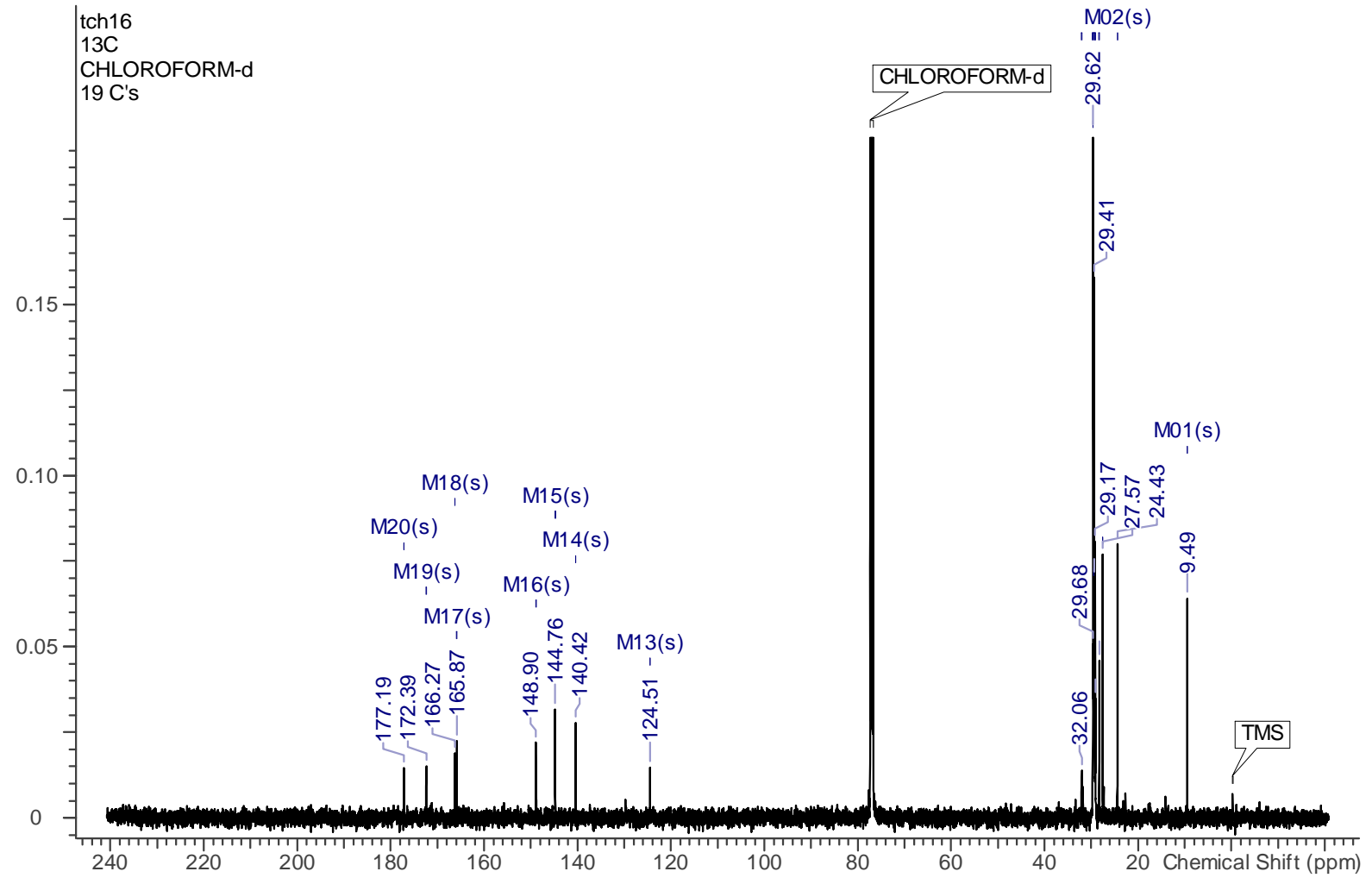


Figure S95: ${ }^{1} \mathrm{H},{ }^{13} \mathrm{C}$ HSQC NMR spectrum of skeletocutin $\mathrm{K}(12)$ in $\mathrm{CDCl}_{3}(500 \mathrm{MHz}, 125$ $\mathrm{MHz}$ )

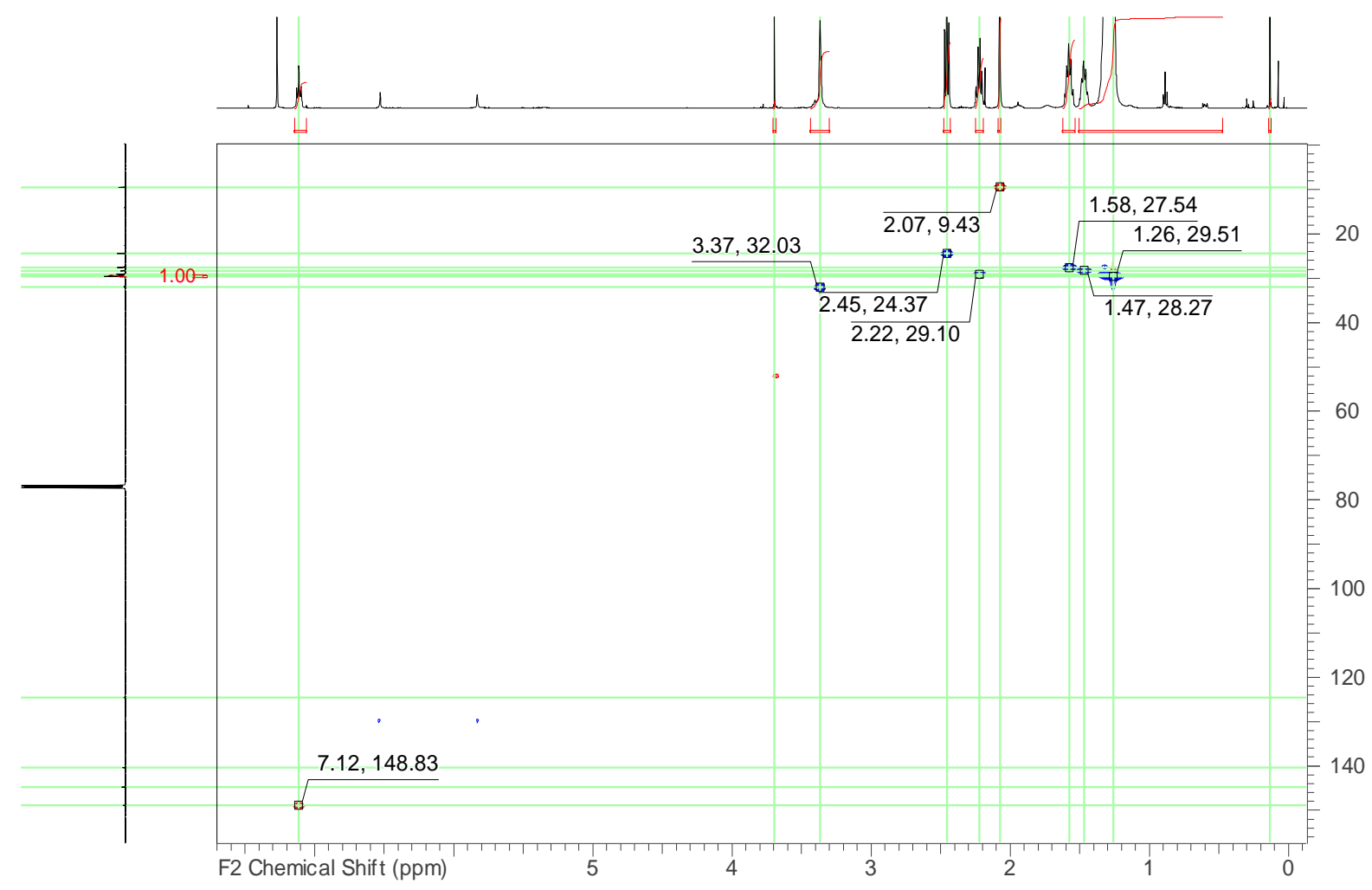

Figure S96: ${ }^{1} \mathrm{H},{ }^{13} \mathrm{C}$ HMBC NMR spectrum of skeletocutin $\mathrm{K}(12)$ in $\mathrm{CDCl}_{3}(500 \mathrm{MHz}, 125$ $\mathrm{MHz})$ 


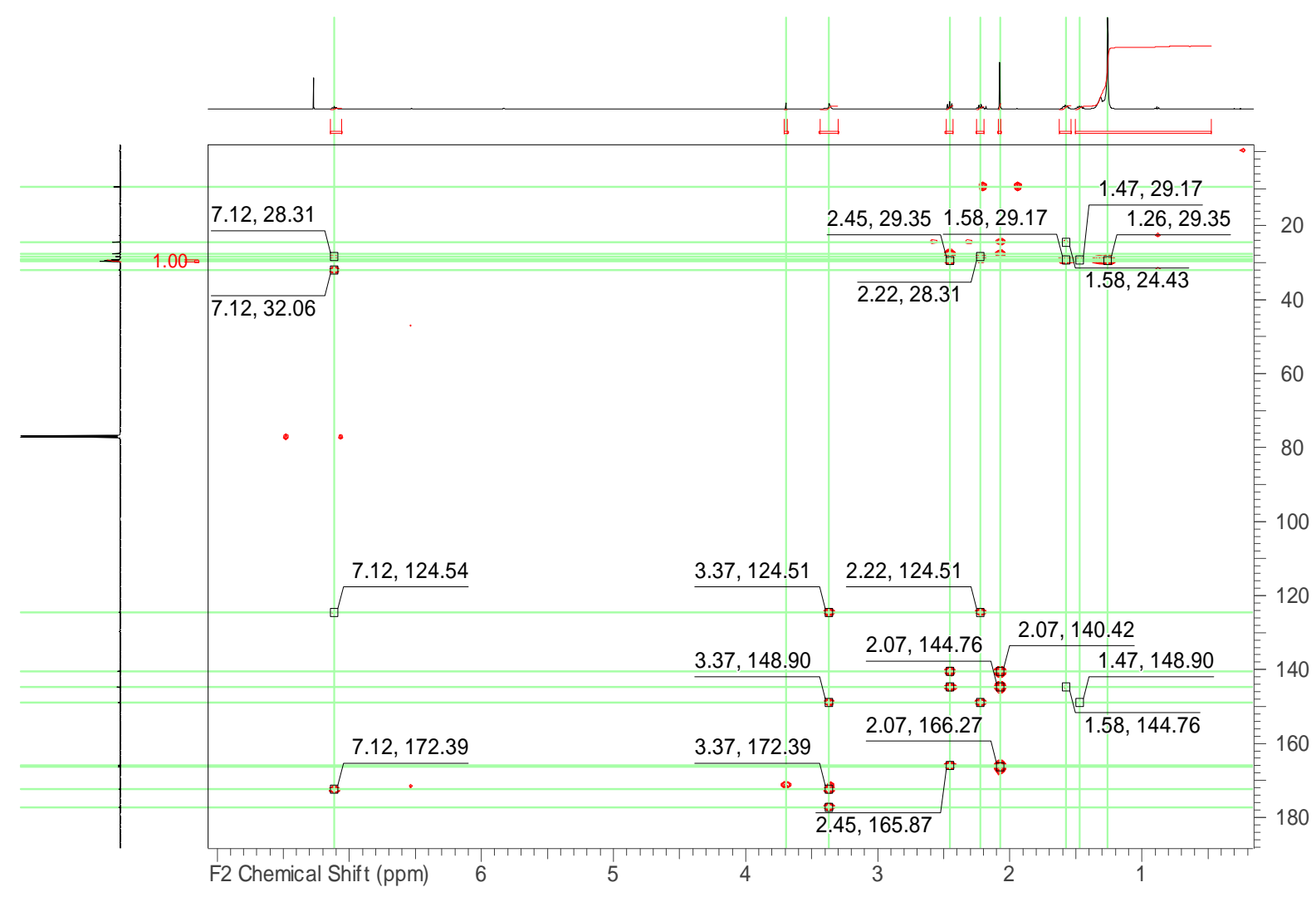

Figure S97: ${ }^{1} \mathrm{H},{ }^{1} \mathrm{H}$ COSY NMR spectrum of skeletocutin $\mathrm{K}(12)$ in $\mathrm{CDCl}_{3}(500 \mathrm{MHz})$

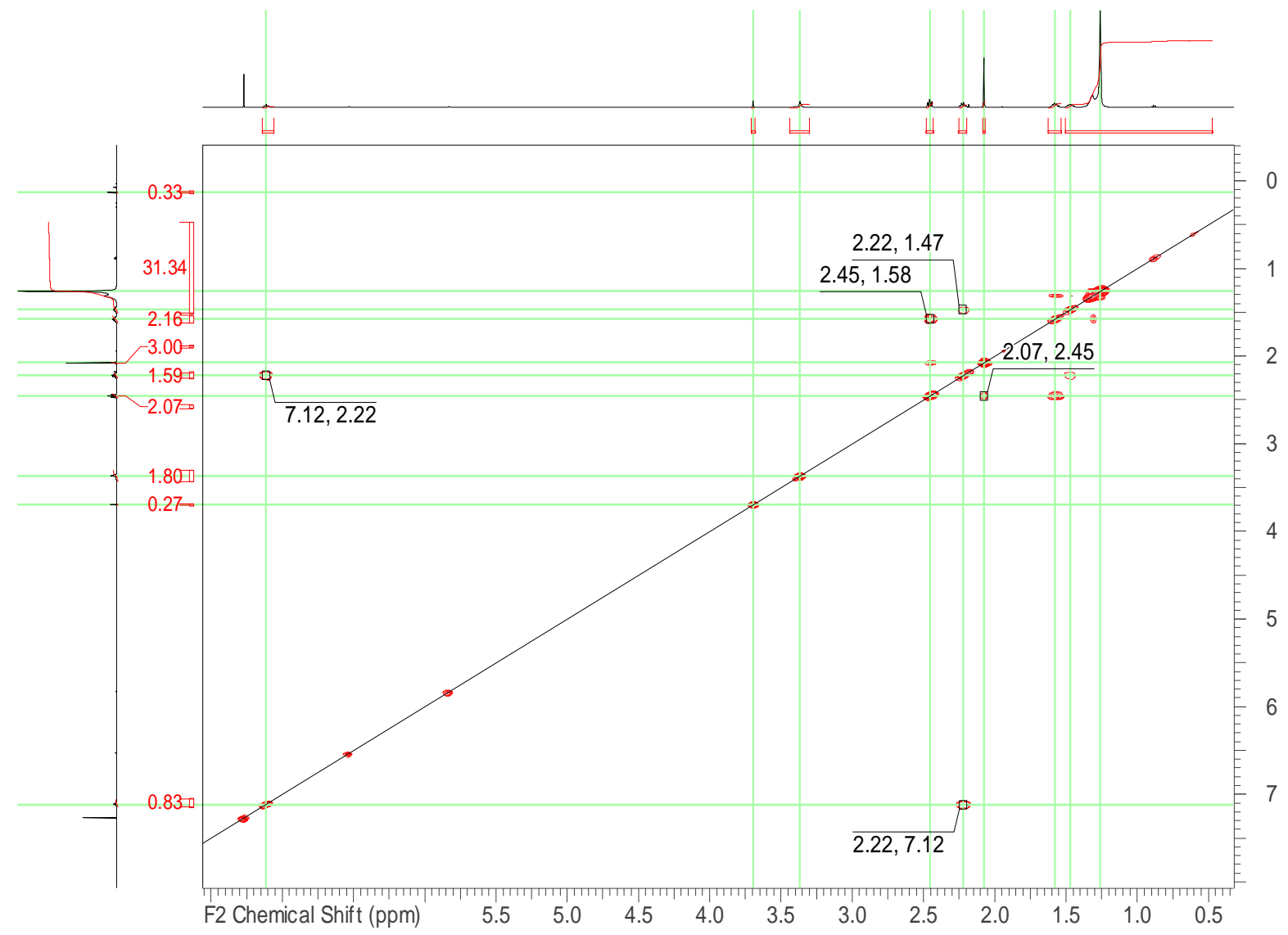


Figure S98: MS data of skeletocutin K (12)

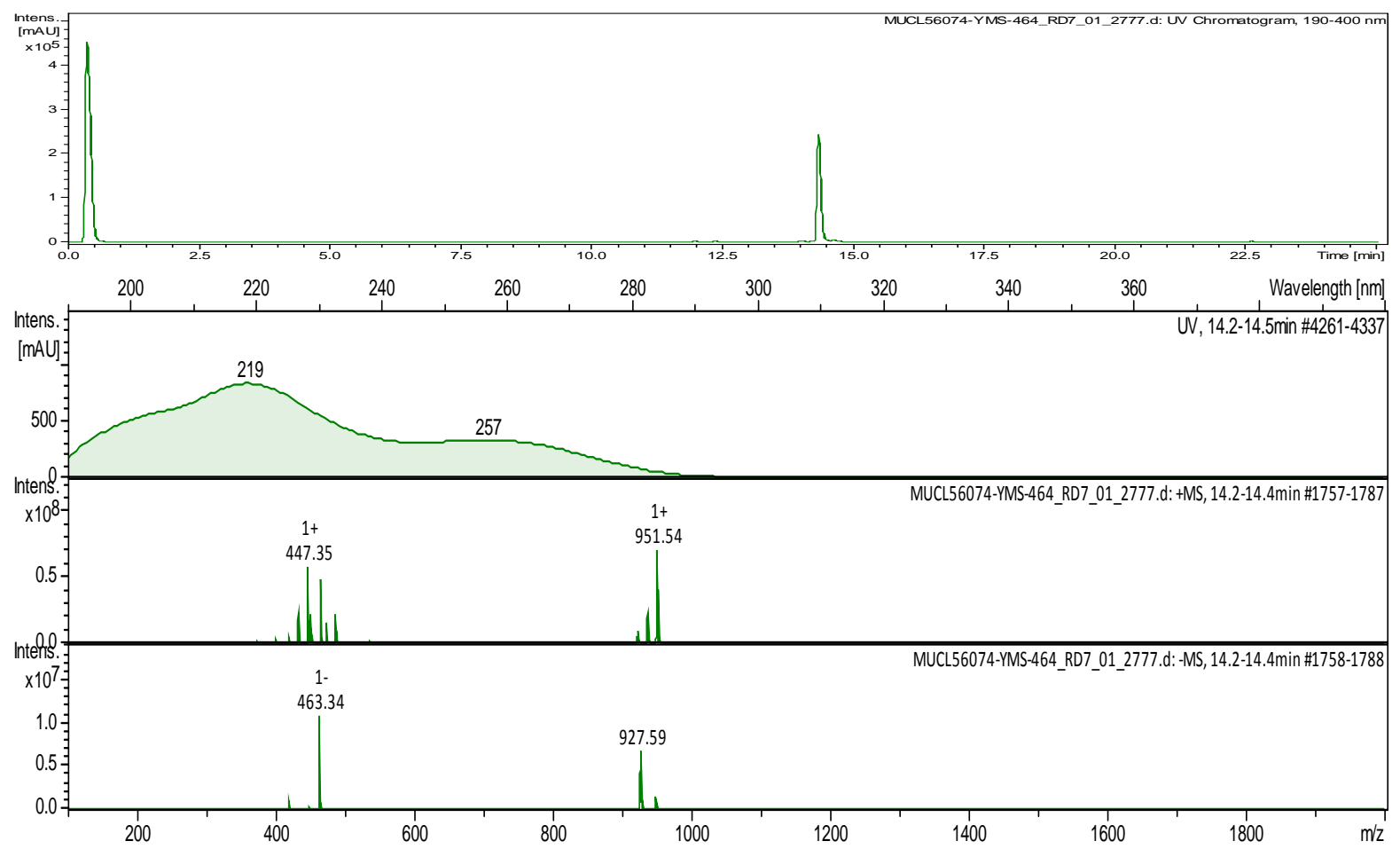

Figure S99: HRMS data of skeletocutin K (12)
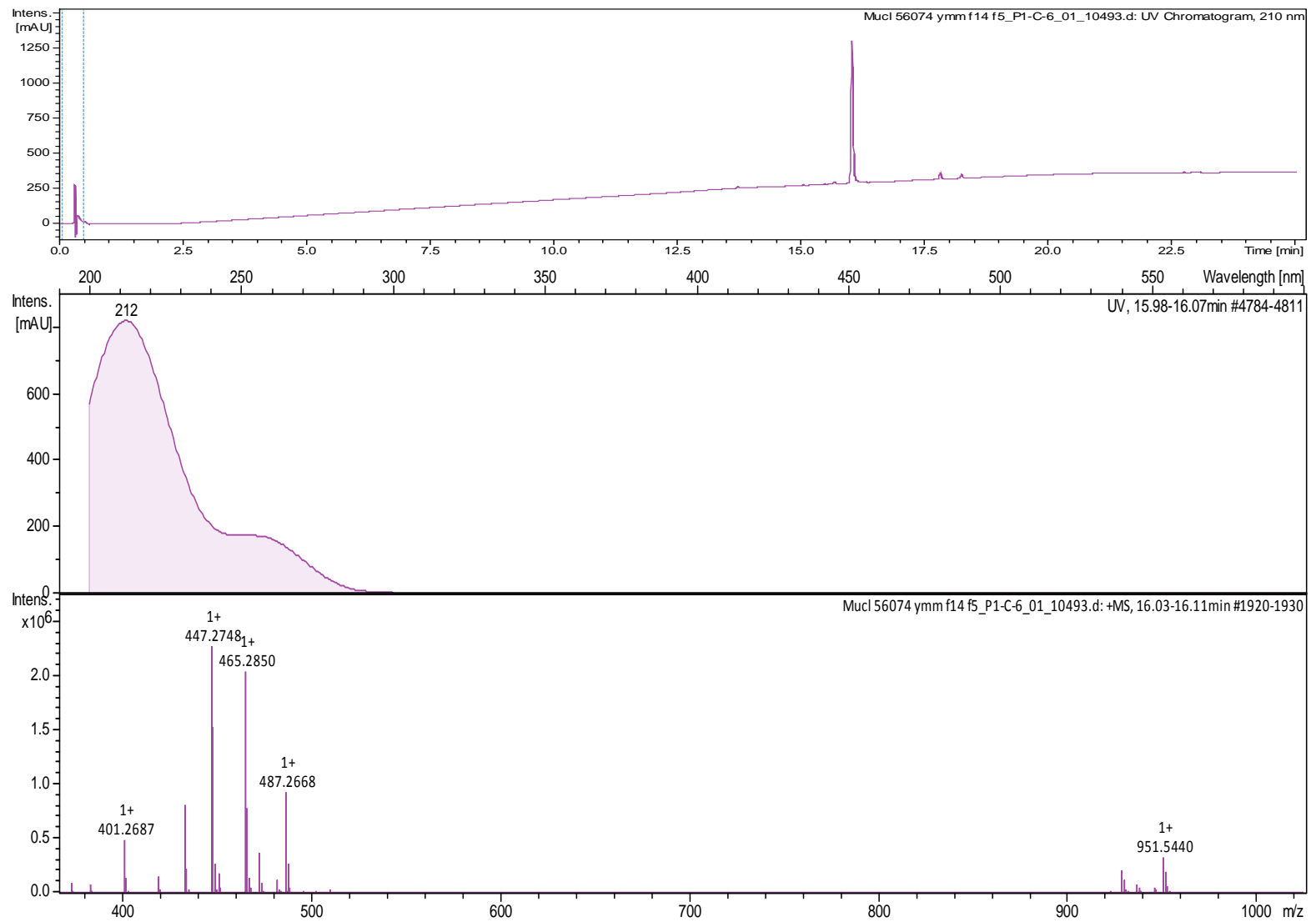


\section{1 and 2D NMR data for skeletocutin $L$ (13)}

Figure S100: ${ }^{1} \mathrm{H}$ NMR spectrum of skeletocutin $\mathrm{L}(\mathbf{1 3})$ in $\mathrm{CDCl}_{3}(500 \mathrm{MHz})$

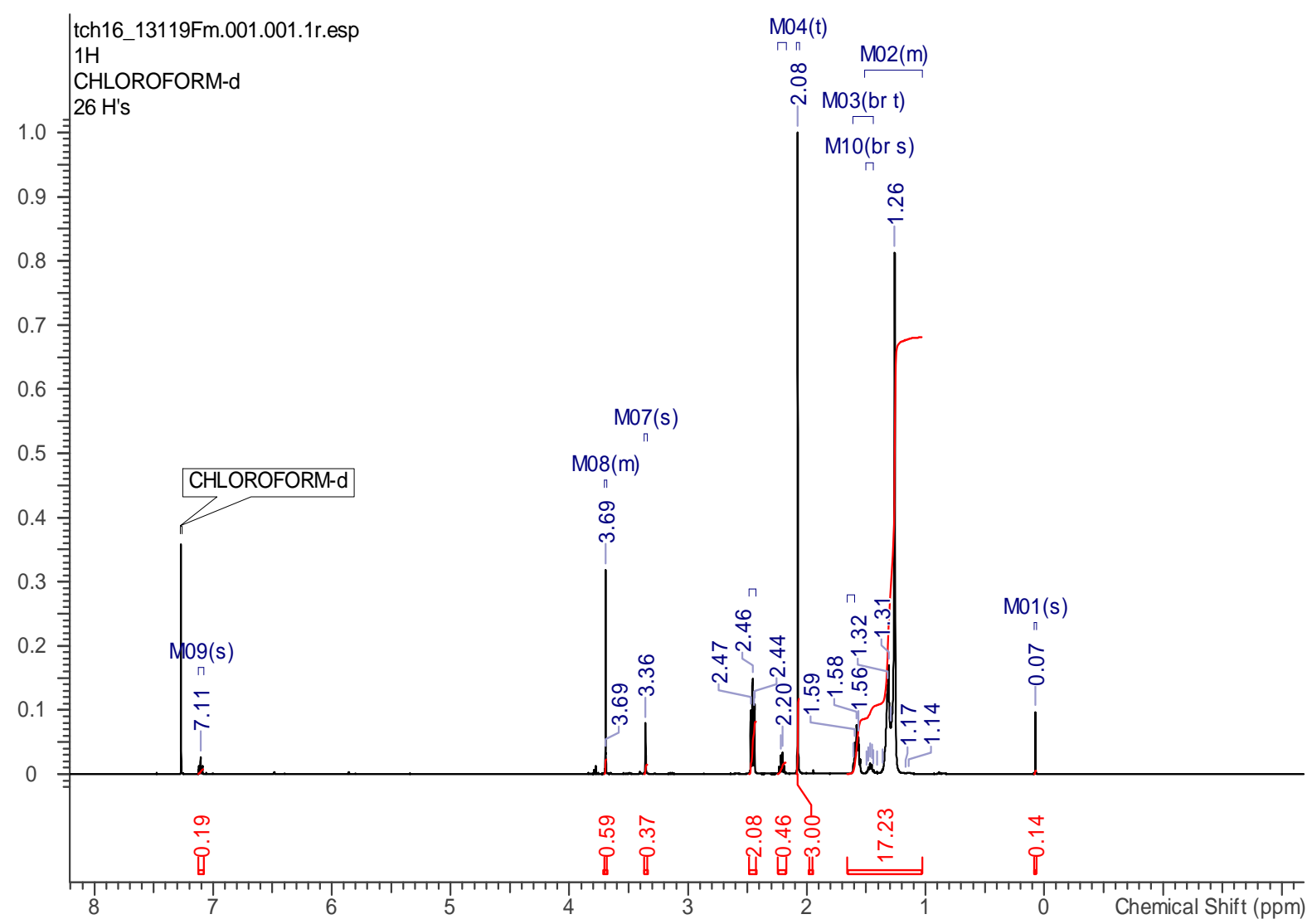

Figure S101: $13 \mathrm{C}$ NMR spectrum of skeletocutin $\mathrm{L}(13)$ in $\mathrm{CDCl}_{3}(125 \mathrm{MHz})$

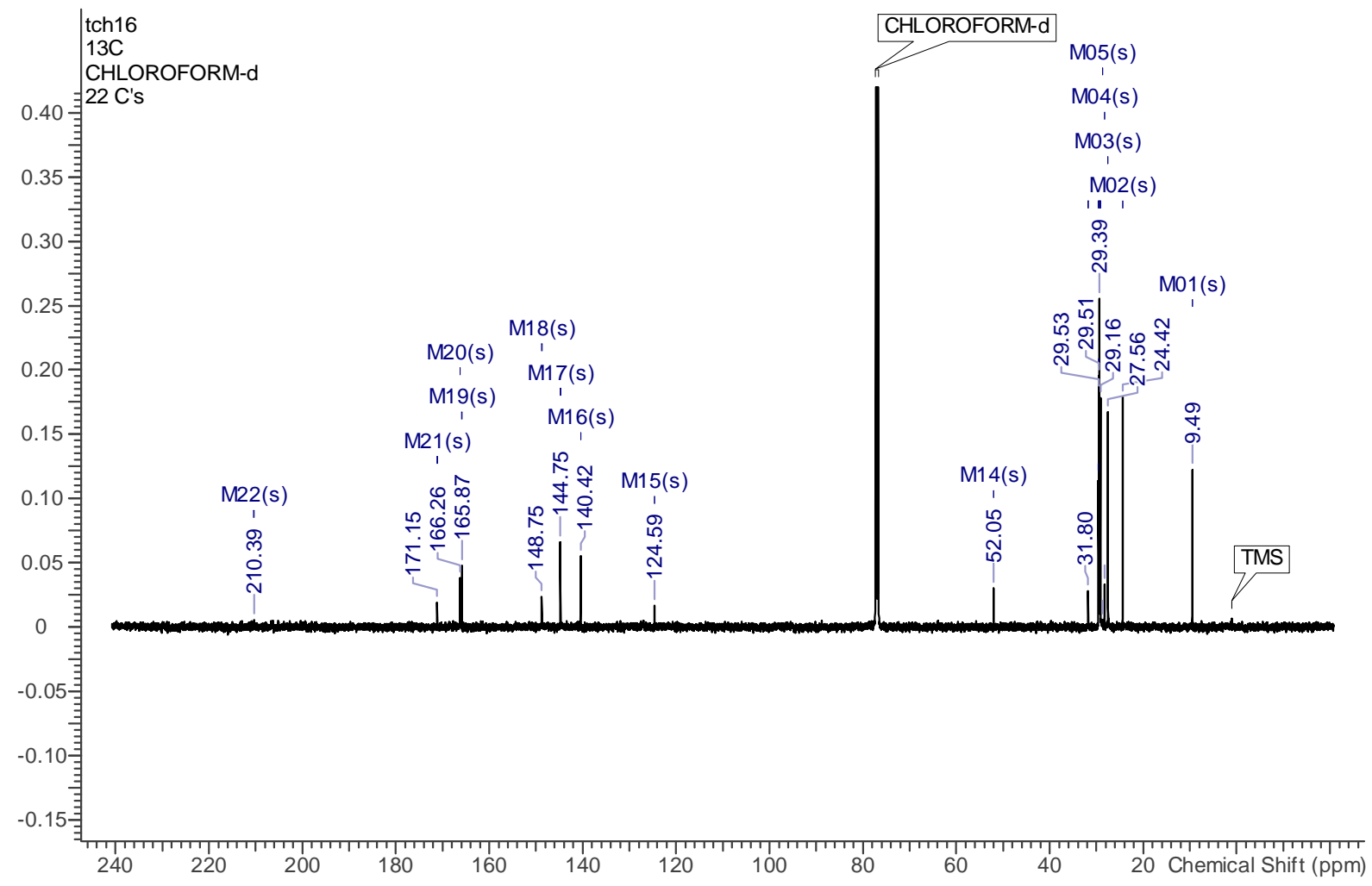


Figure S102: DEPT NMR spectrum of skeletocutin L (13) in $\mathrm{CDCl}_{3}(125 \mathrm{MHz})$

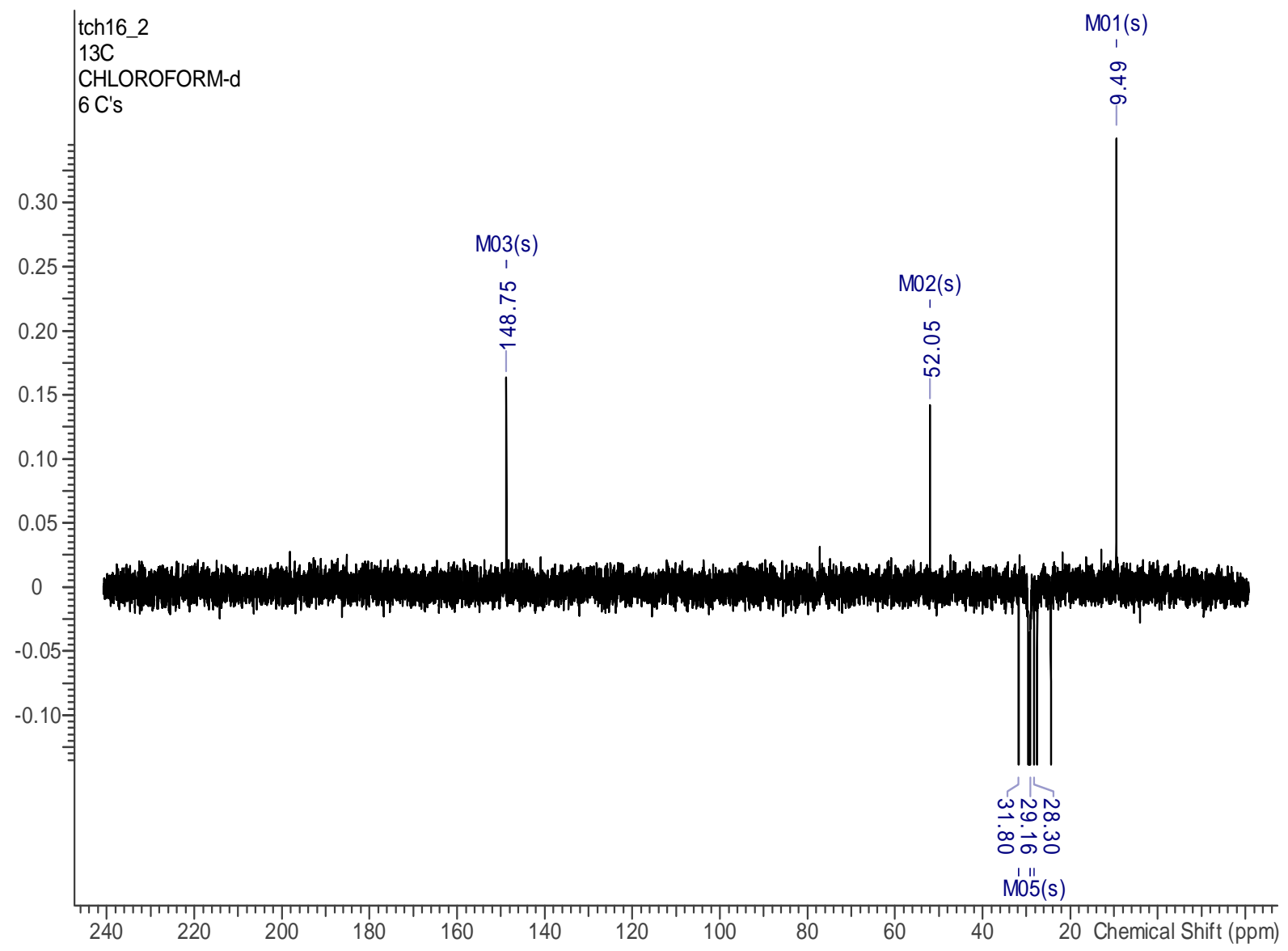

Figure S103: ${ }^{1} \mathrm{H},{ }^{13} \mathrm{C}$ HSQC NMR spectrum of skeletocutin $\mathrm{L}(\mathbf{1 3})$ in $\mathrm{CDCl}_{3}(500 \mathrm{MHz}, 125$ $\mathrm{MHz})$ 


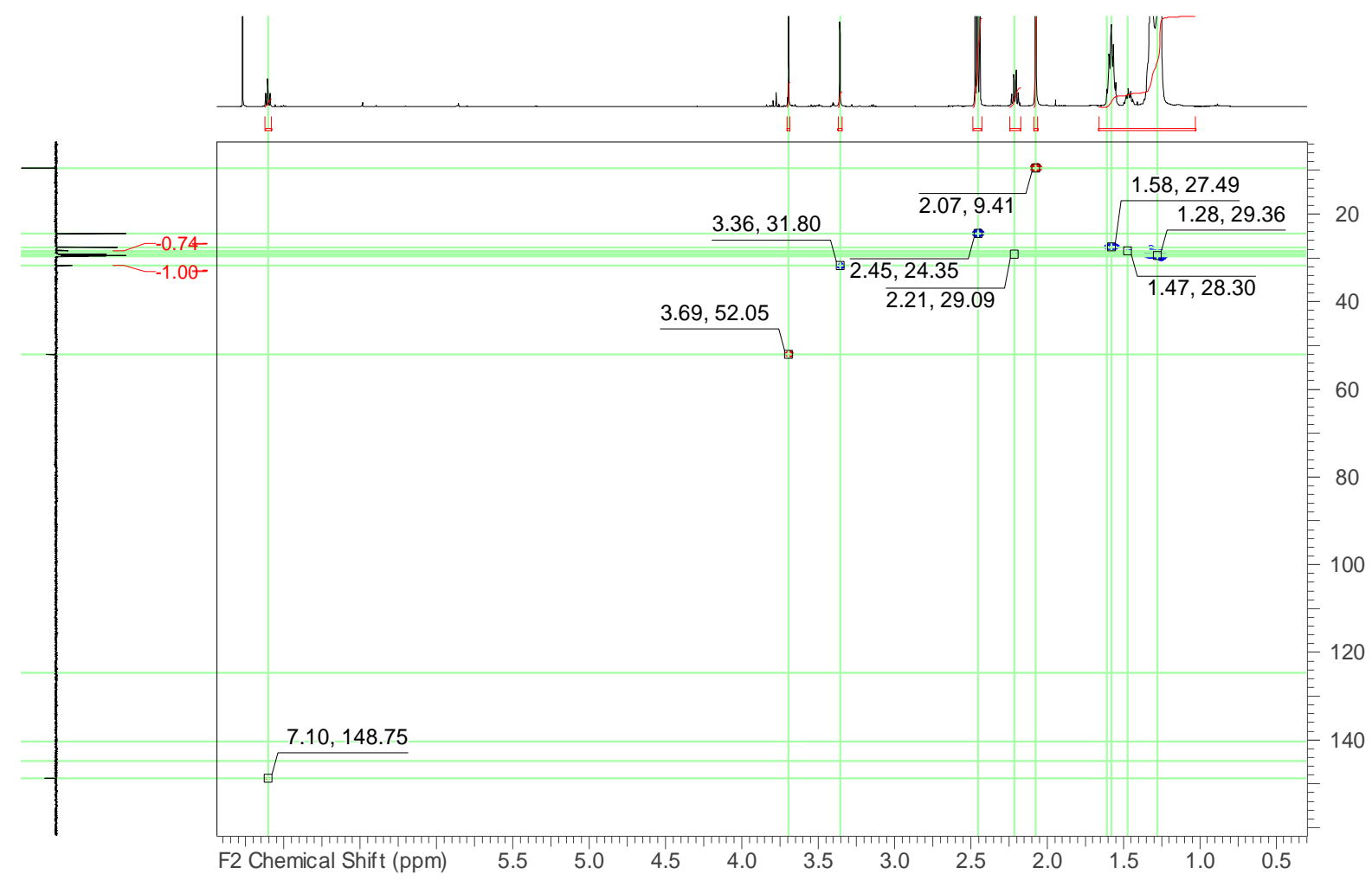

Figure S104: ${ }^{1} \mathrm{H},{ }^{13} \mathrm{C}$ HMBC NMR spectrum of skeletocutin $\mathrm{L}(\mathbf{1 3})$ in $\mathrm{CDCl}_{3}(500 \mathrm{MHz}, 125$ $\mathrm{MHz})$

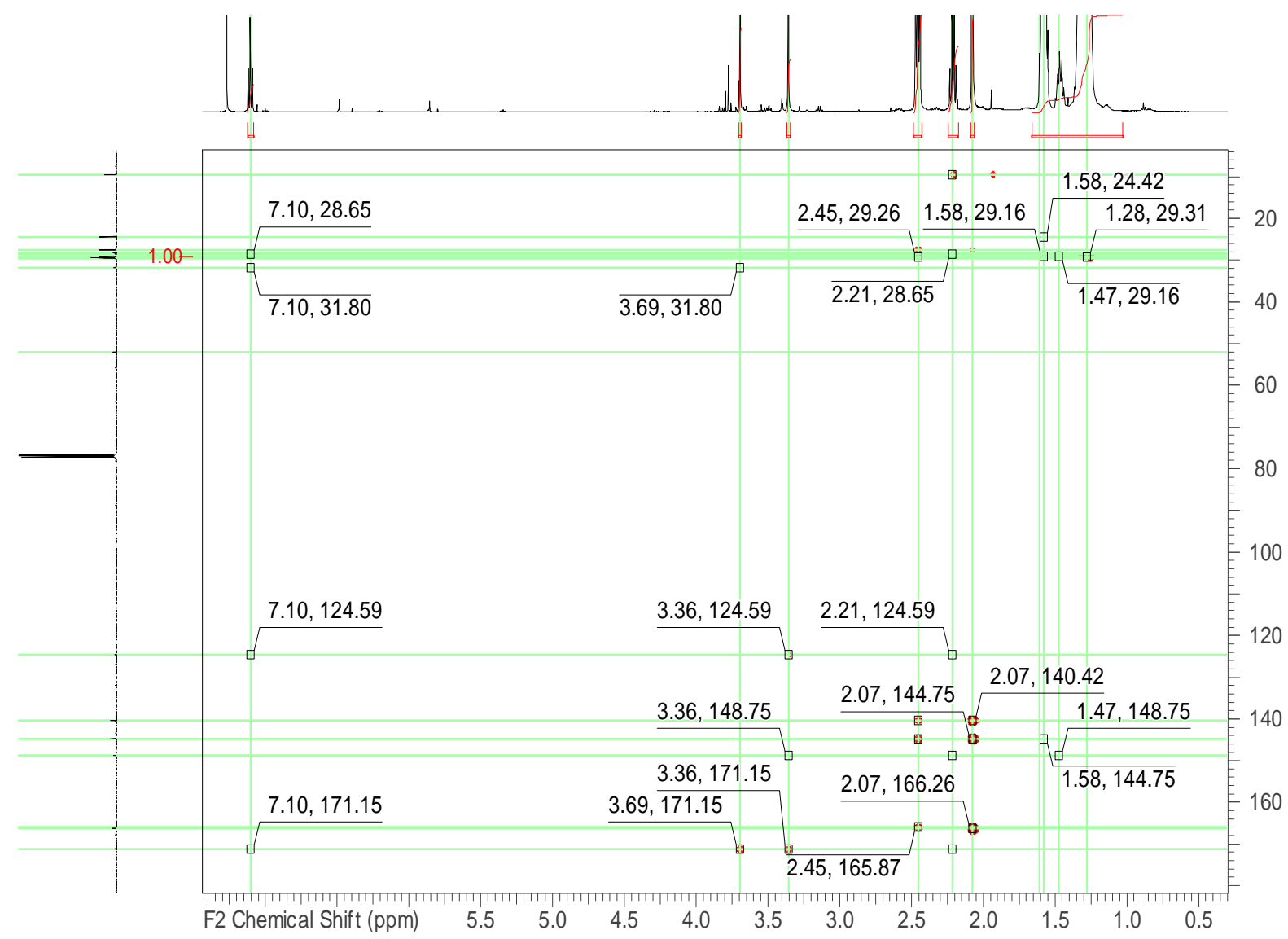


Figure S105: MS data of skeletocutin L (13)

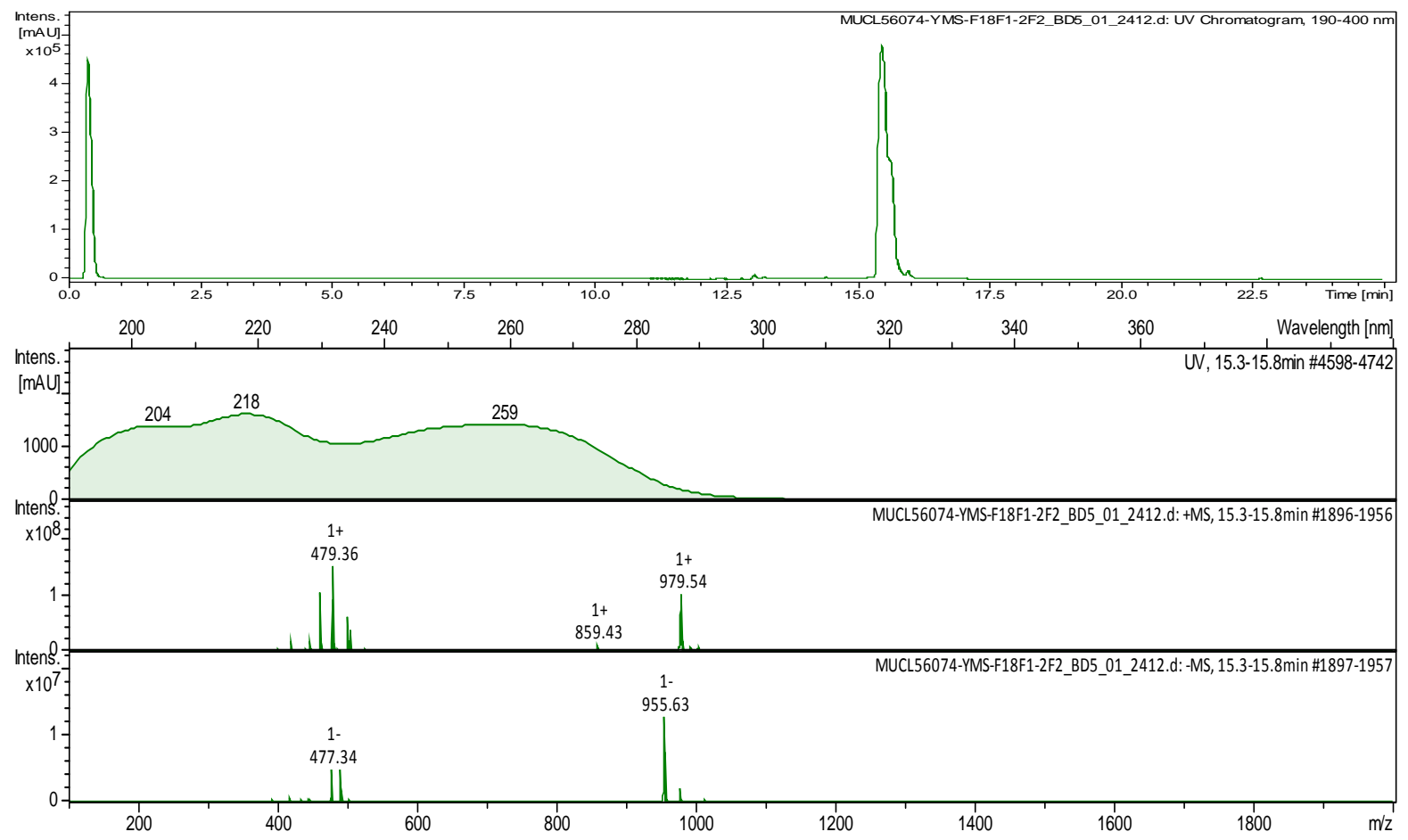

Figure S106: HRMS data of skeletocutin L (13)

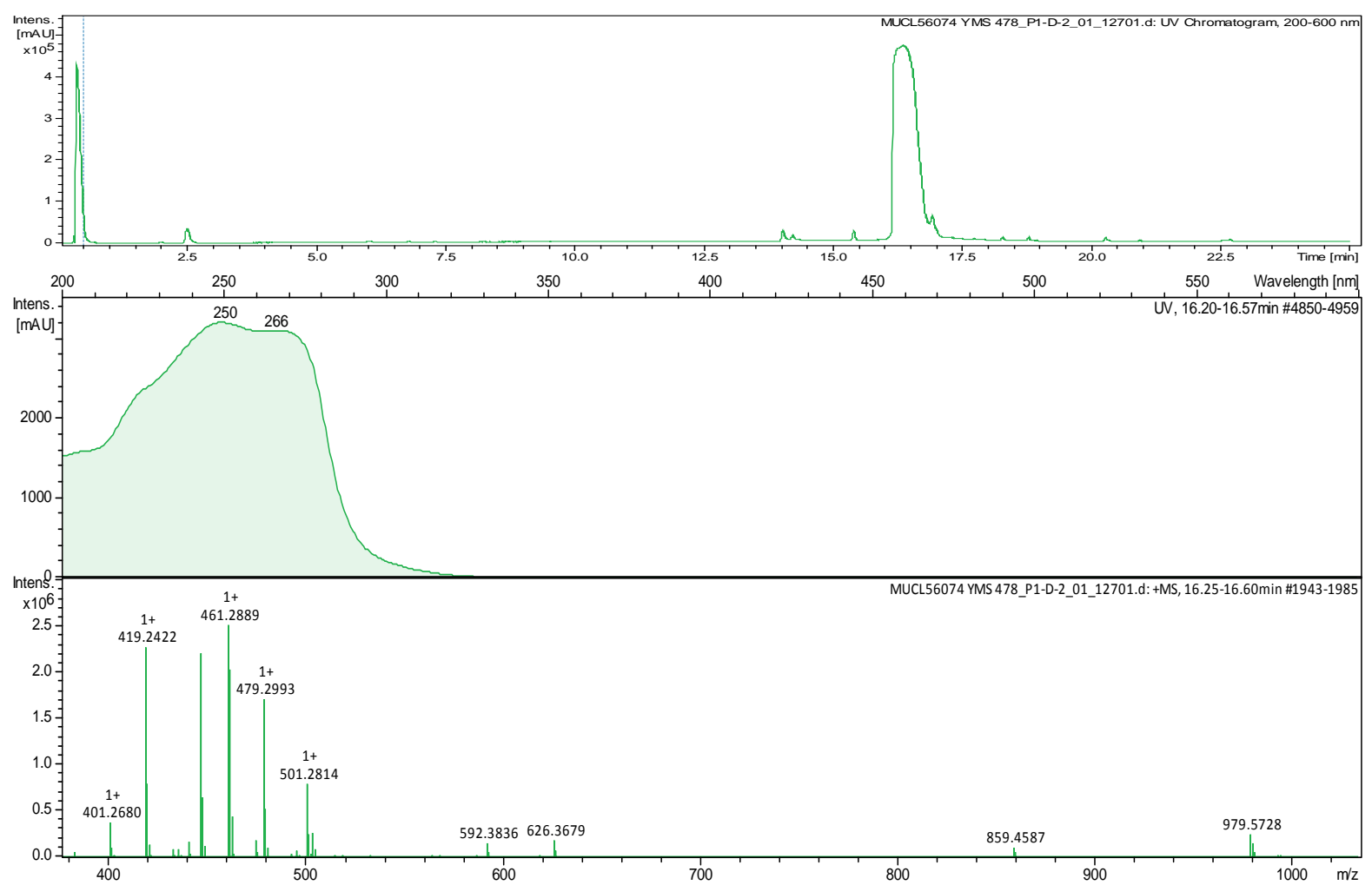




\section{Isolation of compound 1-13}

Purification of fraction F13 by reversed phase HPLC (solvent A/solvent B), elution gradient: $68 \%-80 \%$ solvent B for 30 min followed by gradient shift from $80 \%$ to $100 \%$ in 5 min and isocratic conditions at $100 \%$ for 5 min with a preparative HPLC column (Kromasil, MZ Analysentechnik, Mainz, Germany; 250 x $20 \mathrm{~mm}, 7 \mu \mathrm{m} \mathrm{C}-18$ ) as stationary phase and the flow rate was $15 \mathrm{~mL} / \mathrm{min}$, led to the isolation of compound 1 (40 mg). Unless stated otherwise, the same column was used to purify the other fractions. F12 was purified with the gradient: $65 \%-100 \%$ solvent B for 23 min followed by $100 \%$ solvent B for 7 min to give compound 2 (4 mg) and $10(25.5 \mathrm{mg})$. Compound $3(9.5 \mathrm{mg})$ was purified from F16 and F17 with gradient $75 \%-90 \%$ solvent B for $20 \mathrm{~min}$, then gradient shifted from $90 \%-100 \%$ solvent B in 2 min and finally isocratic condition at 100\% solvent B for $5 \mathrm{~min}$. Compound 4 (31.2 $\mathrm{mg})$ and 6 (191.1 mg) were purified from F19 with gradient $86 \%-100 \%$ solvent B for 23 min, followed by 7 min isocratic condition at $100 \%$. F18 was purified with the gradient $80 \%-100 \%$ solvent B for $23 \mathrm{~min}$, followed by isocratic gradient at $100 \%$ solvent B for 7 min to yield compounds 5 (17.9 mg) and $13(62.6 \mathrm{mg})$. Purification of fraction F5 with elution gradient: $50 \%-60 \%$ solvent B for $30 \mathrm{~min}$ followed by gradient shift from $60 \%$ to $100 \%$ in $5 \mathrm{~min}$ and isocratic conditions at $100 \%$ for $5 \mathrm{~min}$ led to the isolation of compound 7 (5.9 mg). Compound 8 (4.5 $\mathrm{mg})$ and $\mathbf{1 1}(19.5 \mathrm{mg})$ were purified from F9, F10 and F11 by applying the gradient: 65\%-100\% solvent B for $23 \mathrm{~min}$ followed isocratic condition at $100 \%$ solvent B for $7 \mathrm{~min}$. Using the modified elution gradient: $55 \%-65 \%$ solvent B for 30 min followed by isocratic condition at $100 \%$ for $5 \mathrm{~min}, \mathrm{~F} 6$ and F7 were purified to yield compound 9 (15.2 mg). F14 and F15 were purified with the elution gradient $72 \%-80 \%$ solvent B for $25 \mathrm{~min}$, followed by isocratic condition at 100\% solvent B for 5 min yielded compound $12(17.1 \mathrm{mg})$.

\section{Inhibitory Effects on HCV Infectivity}


Huh-7.5 cells were inoculated with RLuc Jc1 reporter viruses in the presence of di erent compounds. Monolayers were washed three times with PBS 4h later and overlaid with fresh medium without inhibitors. Infected cells were lysed 3 days later, and reporter virus infection was determined by Renilla luciferase activity. The cell viability was measured by determination of Firefly luciferase. Huh-7.5 cells stably expressing Firefly luciferase (Huh-7.5 Fluc) were cultured in Dulbecco's modified minimum essential medium (DMEM, Life Technologies Manchester UK) (containing 2mM/L glutamine, $1 \times$ minimum essential medium nonessential amino acids (MEM NEAA, Life Technologies), $100 \mu \mathrm{g} / \mathrm{mL}$ streptomycin, 100IU/mL penicillin (Life Technologies), $5 \mu \mathrm{g} / \mathrm{mL}$ blasticidin and $10 \%$ fetal bovine serum). Cells were incubated at $37^{\circ} \mathrm{C}$ with $5 \% \mathrm{CO} 2$ supply. Infected cells were lysed and then frozen at $-80^{\circ} \mathrm{C}$ for $1 \mathrm{~h}$ following measurements of Renilla and Firefly luciferase activities on a Berthold Technologies Centro XS3 Microplate Luminometer as indicators of viral genome replication and cell viability, respectively.${ }^{1,2}$

\section{Media}

YM 6.3:10 g/L malt extract, $4 \mathrm{~g} / \mathrm{L}$ yeast extract, $4 \mathrm{~g} / \mathrm{L}$ D-glucose and $\mathrm{PH}=6.3$;

Q6 $_{1 / 2}: 10 \mathrm{~g} / \mathrm{L}$ glycerol, $2.5 \mathrm{~g} / \mathrm{L}$ D-glucose, $5 \mathrm{~g} / \mathrm{L}$ cotton seed flour and PH=7.2;

ZM $_{1 / 2}: 5 \mathrm{~g} / \mathrm{L}$ molasses, $5 \mathrm{~g} / \mathrm{L}$ oatmeal, $1.5 \mathrm{~g} / \mathrm{L}$ D-glucose, $4 \mathrm{~g} / \mathrm{L}$ sucrose, $4 \mathrm{~g} / \mathrm{L}$ mannitol, 0.5 $\mathrm{g} / \mathrm{L}$ edamine; ammonium sulphate $0.5 \mathrm{~g} / \mathrm{L}, 1.5 \mathrm{~g} / \mathrm{L}$ calcium carbonate and $\mathrm{PH}=7.2$;

MHB: beef infusion solids, $2.0 \mathrm{~g} / \mathrm{L}$; casein hydrolysate, $17.5 \mathrm{~g} / \mathrm{L}$; starch, $1.5 \mathrm{~g} / \mathrm{L}$.

\section{ITS sequence}

>MUCL56074 
ATATGCTTAAGTTCAGCGGGTAGTCCTACCCGATTTGAGGTGCAGAT GTCAAAAGATTATTACAATCTGTCTTAAAAGACAACTAGAAGCGGAATTC CATACATGTGCTTAGACAGCTACAGCGTAGACAATTATCACACTGAAGCT AGACCTGAGCAAAGATTTCCAGCTAATATATTCAAGAGGAGCAGATTTAT TACTAAACCTGCAAAGAGACCTCCAAATCCAAAGCACCAACATCATCAAA AAATGAAGAGGGCTTTGAGAATACCATGACACTCAAACGGGCATGCCCTT CGGAATACCAAAGGGCGCAAGTTGCGTTCAAAGATTCGATGATTCACTGA ATTCTGCAATTCACATTACTTATCGCATTTCGCTGCGTTCTTCATCGATGCG AGAGCCAAGAGATCCGTTGCTAAAAGTTATATATAATGCGTTATTTAAGCG CAAGAGACATTCATGATACAGCGTGTGTGAATGAAACATAGGAAGGCGTC AACAACTAGAGAGGAACCTAAGTTCTTCTCCTGTATCAACCATCCTACAAT ATGTGCACAGGTGTTAAAGATGAGTTGGATTTGAGCGAAGCGTGCACATG CCCCGAAAGGCCAGCTACAACTTCTTTCAAAGACTCGATAATGATCCTTCC GCAGGTTCACCTACGGAAACCTTGTTACGACTTTTACTTCC

Figure S107: Phylogeny tree of Skeletocutis sp. and closely related species

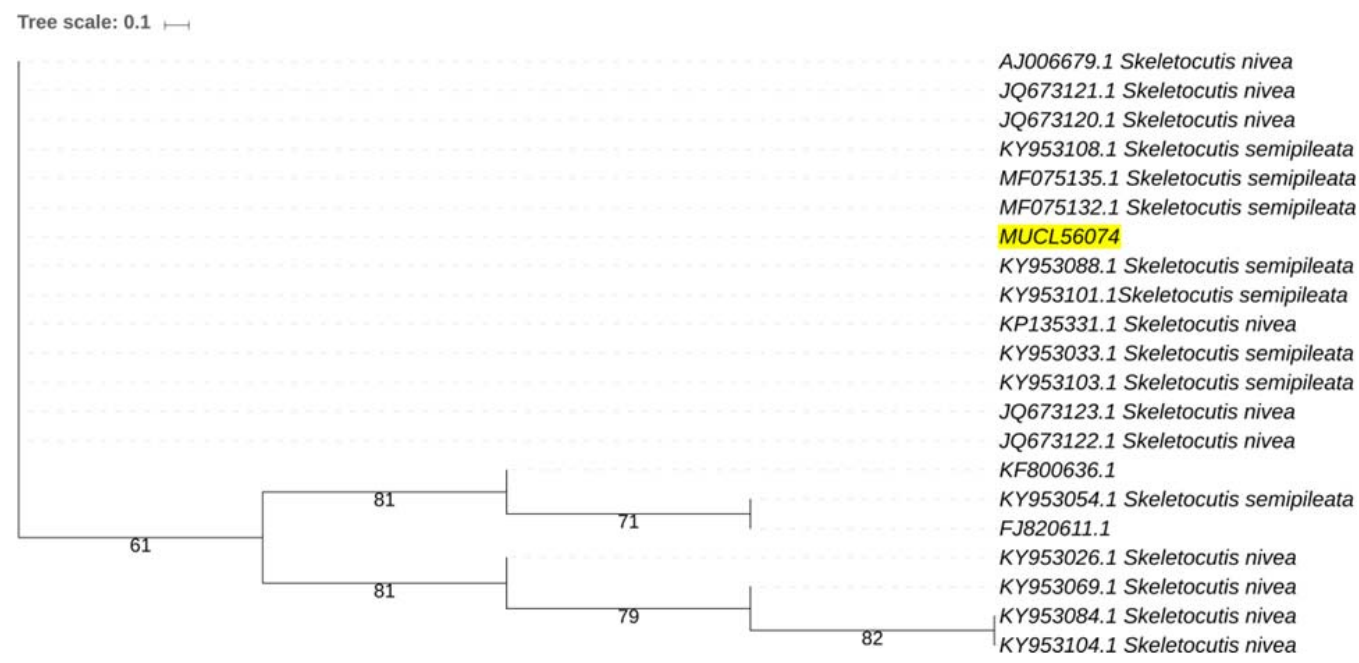


(1) Sandargo, B.; Michehl, M.; Praditya, D.; Steinmann, E.; Stadler, M.; Surup F. Antiviral meroterpenoid rhodatin and sesquiterpenoids rhodocoranes A-E from the wrinkled peach mushroom, Rhodotus palmatus. Org. Lett. 2019, 21, 3286-3289.

(2) Ciesek, S.; von Hahn, T.; Colpitts, C.C.; Schang, L.M.; Friesland, M.; Steinmann, J.; Manns, M.P.; Ott, M.; Wedemeyer, H.; Meuleman, P.; Pietschmann, T. The green tea polyphenol, epigallocatechin-3-gallate, inhibits hepatitis C virus entry. Hepatology 2011, 54, 1947-1955. 